\title{
Deworming drugs for soil-transmitted intestinal worms in children: effects on nutritional indicators, haemoglobin and school performance (Review)
}

Taylor-Robinson DC, Maayan N, Soares-Weiser K, Donegan S, Garner P

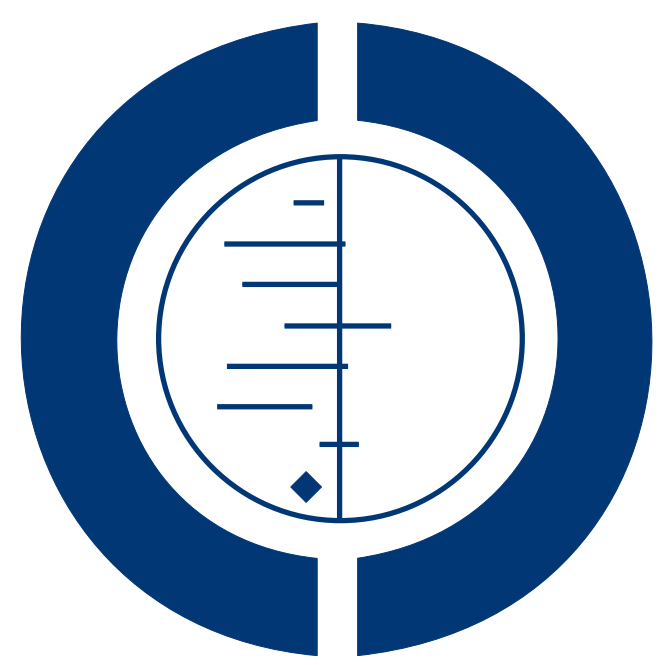

THE COCHRANE
COLLABORATION

This is a reprint of a Cochrane review, prepared and maintained by The Cochrane Collaboration and published in The Cochrane Library 2012, Issue 11

http://www.thecochranelibrary.com

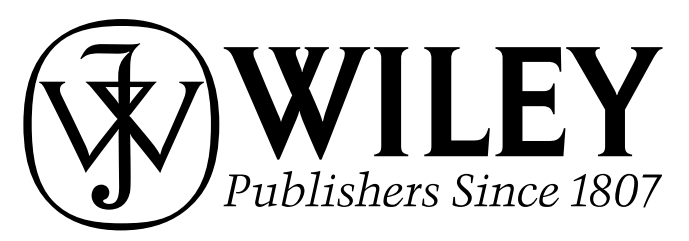

Deworming drugs for soil-transmitted intestinal worms in children: effects on nutritional indicators, haemoglobin and school performance (Review)

Copyright $\odot 2012$ The Cochrane Collaboration. Published by John Wiley \& Sons, Ltd. 
TABLE OF CONTENTS

HEADER . . . . . . . . . . . . . . . . . . . . . . . . . . . . . . . . . . . . . . . 1

ABSTRACT . . . . . . . . . . . . . . . . . . . . . . . . . . . . . . . . . . . . . . . . . . . . . . . . . . .

PLAIN LANGUAGE SUMMARY . . . . . . . . . . . . . . . . . . . . . . . . . . . . . . . . . . . . . . . 2

SUMMARY OF FINDINGS FOR THE MAIN COMPARISON $\quad . \quad$. . . . . . . . . . . . . . . . . . . . . . . . . . . .

BACKGROUND . . . . . . . . . . . . . . . . . . . . . . . . . . . . . . . . . . . . . . . . . . .

Figure 1. . . . . . . . . . . . . . . . . . . . . . . . . . . . . . . . . . . . . . 9

OBJECTIVES . . . . . . . . . . . . . . . . . . . . . . . . . . . . . . . . . . . . . . . . . . . .

METHODS . . . . . . . . . . . . . . . . . . . . . . . . . . . . . . . . . . . . . . 10

RESULTS . . . . . . . . . . . . . . . . . . . . . . . . . . . . . . . . . . . . . . . . . . . . . . .

Figure 2. . . . . . . . . . . . . . . . . . . . . . . . . . . . . . . . . . . . . . 16

Figure 3. . . . . . . . . . . . . . . . . . . . . . . . . . . . . . . . . . . . . . . . .

DISCUSSION . . . . . . . . . . . . . . . . . . . . . . . . . . . . . . . . . . . . . . . . . 21

AUTHORS' CONCLUSIONS . . . . . . . . . . . . . . . . . . . . . . . . . . . . . . . . . . . . .

ACKNOWLEDGEMENTS . . . . . . . . . . . . . . . . . . . . . . . . . . . . . . . . . . . . . . . . . .

REFERENCES . . . . . . . . . . . . . . . . . . . . . . . . . . . . . . . . . . . . . . . . . . . . .

CHARACTERISTICS OF STUDIES . . . . . . . . . . . . . . . . . . . . . . . . . . . . . . . . . . . .

DATA AND ANALYSES . . . . . . . . . . . . . . . . . . . . . . . . . . . . . . . . . . . . . . . . . . 93

Analysis 1.1. Comparison 1 Screened for infection - Single dose, Outcome 1 Weight $(\mathrm{kg})$. . . . . . . . . . . . . 96

Analysis 1.2. Comparison 1 Screened for infection - Single dose, Outcome 2 Height $(\mathrm{cm})$. . . . . . . . . . . . . . 97

Analysis 1.3. Comparison 1 Screened for infection - Single dose, Outcome 3 Mid-upper arm circumference $(\mathrm{cm}) . \quad$. 97

Analysis 1.4. Comparison 1 Screened for infection - Single dose, Outcome 4 Triceps skin fold thickness (mm). $\quad . \quad 98$

Analysis 1.5. Comparison 1 Screened for infection - Single dose, Outcome 5 Subscapular skin fold thickness (mm). . 99

Analysis 1.6. Comparison 1 Screened for infection - Single dose, Outcome 6 Body mass index. . . . . . . . . . . 99

Analysis 1.7. Comparison 1 Screened for infection - Single dose, Outcome 7 Haemoglobin $(\mathrm{g} / \mathrm{dL}) . \quad$. . . . . . . . 100

Analysis 2.1. Comparison 2 Screened for infection - Multiple dose, outcomes in the first year, Outcome 1 Body mass index. . . . . . . . . . . . . . . . . . . . . . . . . . . . . . . . . . . . . 100

Analysis 2.2. Comparison 2 Screened for infection - Multiple dose, outcomes in the first year, Outcome 2 School attendance (days present at school). . . . . . . . . . . . . . . . . . . . . . . . . . . . . . . . . . . . . . . . . . 101

Analysis 3.1. Comparison 3 Target population treated - Single dose, Outcome 1 Weight (kg). . . . . . . . . . . . 102

Analysis 3.2. Comparison 3 Target population treated - Single dose, Outcome 2 Height $(\mathrm{cm})$. . . . . . . . . . $\quad$. $\quad 103$

Analysis 3.3. Comparison 3 Target population treated - Single dose, Outcome 3 Mid-upper arm circumference $(\mathrm{cm}) . \quad 104$

Analysis 3.4. Comparison 3 Target population treated - Single dose, Outcome 4 Triceps skin fold thickness (mm). $\quad 105$

Analysis 3.5. Comparison 3 Target population treated - Single dose, Outcome 5 Subscapular skin fold thickness (mm). 106

Analysis 3.6. Comparison 3 Target population treated - Single dose, Outcome 6 Haemoglobin (g/dL). . . . . . . $\quad 107$

Analysis 3.7. Comparison 3 Target population treated - Single dose, Outcome 7 Harvard Step Test (measure of physical well being).

Analysis 4.1. Comparison 4 Target population treated - Multiple dose, outcomes in the first year, Outcome 1 Weight $(\mathrm{kg})$.

Analysis 4.2. Comparison 4 Target population treated - Multiple dose, outcomes in the first year, Outcome 2 Height (cm).

Analysis 4.3. Comparison 4 Target population treated - Multiple dose, outcomes in the first year, Outcome 3 Mid-upper arm circumference $(\mathrm{cm})$.

Analysis 4.4. Comparison 4 Target population treated - Multiple dose, outcomes in the first year, Outcome 4 Triceps skin fold thickness (mm).

Analysis 4.5. Comparison 4 Target population treated - Multiple dose, outcomes in the first year, Outcome 5 Subscapular skin fold thickness $(\mathrm{mm})$. .

Analysis 4.6. Comparison 4 Target population treated - Multiple dose, outcomes in the first year, Outcome 6 Haemoglobin $(\mathrm{g} / \mathrm{dL})$.

Analysis 4.7. Comparison 4 Target population treated - Multiple dose, outcomes in the first year, Outcome 7 School attendance (days present at school).

Deworming drugs for soil-transmitted intestinal worms in children: effects on nutritional indicators, haemoglobin and school 
Analysis 5.1. Comparison 5 Target population treated - Multiple dose, outcomes after the first year, Outcome 1 Weight $(\mathrm{kg})$.

Analysis 5.2. Comparison 5 Target population treated - Multiple dose, outcomes after the first year, Outcome 2 Height $(\mathrm{cm})$.

Analysis 5.3. Comparison 5 Target population treated - Multiple dose, outcomes after the first year, Outcome 3 Haemoglobin $(\mathrm{g} / \mathrm{dL}) .$. . . . . . . . . . . . . . . . . . . . . . . . . . . . . .

Analysis 5.4. Comparison 5 Target population treated - Multiple dose, outcomes after the first year, Outcome 4 School attendance (days present at school).

Analysis 6.1. Comparison 6 Target population treated - Single dose (low risk of bias for allocation concealment), Outcome 1 Weight $(\mathrm{kg})$.

Analysis 6.2. Comparison 6 Target population treated - Single dose (low risk of bias for allocation concealment), Outcome 2 Height $(\mathrm{cm})$.

Analysis 6.3. Comparison 6 Target population treated - Single dose (low risk of bias for allocation concealment), Outcome 3 Mid-upper arm circumference $(\mathrm{cm}) . \quad$. . . . . . . . . . . . . . . . . . . . . . . . . . . . . . . .

Analysis 6.4. Comparison 6 Target population treated - Single dose (low risk of bias for allocation concealment), Outcome 4 Haemoglobin $(\mathrm{g} / \mathrm{dL})$.

Analysis 7.1. Comparison 7 Target population treated - Multiple dose, outcomes in the first year (low risk of bias for

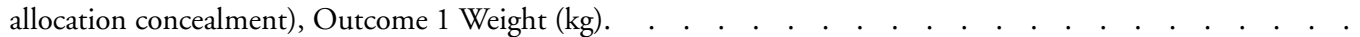

Analysis 7.2. Comparison 7 Target population treated - Multiple dose, outcomes in the first year (low risk of bias for allocation concealment), Outcome 2 Haemoglobin $(\mathrm{g} / \mathrm{dL}) . \quad$. . . . . . . . . . . . . . . . . . . . . .

Analysis 8.1. Comparison 8 Target population treated - Multiple dose, outcomes after the first year (low risk of bias for allocation concealment), Outcome 1 Weight $(\mathrm{kg})$.

Analysis 8.2. Comparison 8 Target population treated - Multiple dose, outcomes after the first year (low risk of bias for allocation concealment), Outcome 2 Height $(\mathrm{cm}) . \quad$. . . . . . . . . . . . . . . . . . . . .

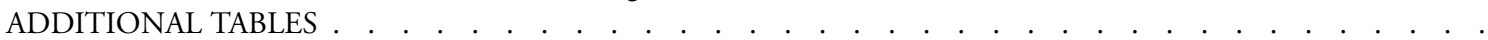

APPENDICES . . . . . . . . . . . . . . . . . . . . . . . . . . . . . . . . . . . .

WHAT'S NEW . . . . . . . . . . . . . . . . . . . . . . . . . . . . . . . . . . . . .

HISTORY . . . . . . . . . . . . . . . . . . . . . . . . . . . . . . . . . . . . . . . 140

CONTRIBUTIONS OF AUTHORS . . . . . . . . . . . . . . . . . . . . . . . . . . . . . . . . . . . 141

DECLARATIONS OF INTEREST . . . . . . . . . . . . . . . . . . . . . . . . . . . . . . . . . . . . 142

SOURCES OF SUPPORT . . . . . . . . . . . . . . . . . . . . . . . . . . . . . . . . . . . . . . . . . . . 142

DIFFERENCES BETWEEN PROTOCOL AND REVIEW . . . . . . . . . . . . . . . . . . . . . . . . . . 142

NOTES . . . . . . . . . . . . . . . . . . . . . . . . . . . . . . . . . . . . . . . 142

INDEX TERMS . . . . . . . . . . . . . . . . . . . . . . . . . . . . . . . . . . . . . . . . . . 142

Deworming drugs for soil-transmitted intestinal worms in children: effects on nutritional indicators, haemoglobin and school 


\title{
[Intervention Review]
}

\section{Deworming drugs for soil-transmitted intestinal worms in children: effects on nutritional indicators, haemoglobin and school performance}

\author{
David C Taylor-Robinson ${ }^{1}$, Nicola Maayan ${ }^{2}$, Karla Soares-Weiser ${ }^{2}$, Sarah Donegan ${ }^{1}$, Paul Garner ${ }^{1}$ \\ ${ }^{1}$ International Health Group, Liverpool School of Tropical Medicine, Liverpool, UK. ${ }^{2}$ Enhance Reviews Ltd, Wantage, UK \\ Contact address: David C Taylor-Robinson, International Health Group, Liverpool School of Tropical Medicine, Pembroke Place, \\ Liverpool, Merseyside, L3 5QA, UK. David.Taylor-Robinson@liverpool.ac.uk.
}

Editorial group: Cochrane Infectious Diseases Group.

Publication status and date: New search for studies and content updated (no change to conclusions), published in Issue 11, 2012.

Review content assessed as up-to-date: 31 May 2012.

Citation: Taylor-Robinson DC, Maayan N, Soares-Weiser K, Donegan S, Garner P. Deworming drugs for soil-transmitted intestinal worms in children: effects on nutritional indicators, haemoglobin and school performance. Cochrane Database of Systematic Reviews 2012, Issue 11. Art. No.: CD000371. DOI: 10.1002/14651858.CD000371.pub5.

Copyright (C) 2012 The Cochrane Collaboration. Published by John Wiley \& Sons, Ltd.

\begin{abstract}
A B S T R A C T
Background

The World Health Organization (WHO) recommends treating all school children at regular intervals with deworming drugs in areas where helminth infection is common. The WHO state this will improve nutritional status, haemoglobin, and cognition and thus will improve health, intellect, and school attendance. Consequently, it is claimed that school performance will improve, child mortality will decline, and economic productivity will increase. Given the important health and societal benefits attributed to this intervention, we sought to determine whether they are based on reliable evidence.
\end{abstract}

Objectives

To summarize the effects of giving deworming drugs to children to treat soil-transmitted intestinal worms (nematode geohelminths) on weight, haemoglobin, and cognition; and the evidence of impact on physical well being, school attendance, school performance, and mortality.

\section{Search methods}

In February 2012, we searched the Cochrane Infectious Diseases Group Specialized Register, MEDLINE, EMBASE, LILACS, $m$ RCT, and reference lists, and registers of ongoing and completed trials.

\section{Selection criteria}

We selected randomized controlled trials (RCTs) and quasi-RCTs comparing deworming drugs for geohelminth worms with placebo or no treatment in children aged 16 years or less, reporting on weight, haemoglobin, and formal test of intellectual development. In cluster-RCTs treating communities or schools, we also sought data on school attendance, school performance, and mortality. We included trials that included health education with deworming.

\section{Data collection and analysis}

At least two authors independently assessed the trials, evaluated risk of bias, and extracted data. Continuous data were analysed using the mean difference (MD) with 95\% confidence intervals (CI). Where data were missing, we contacted trial authors. We used GRADE

Deworming drugs for soil-transmitted intestinal worms in children: effects on nutritional indicators, haemoglobin and school performance (Review)

Copyright $\odot 2012$ The Cochrane Collaboration. Published by John Wiley \& Sons, Ltd. 
to assess evidence quality, and this is reflected in the wording we used: high quality ("deworming improves...."); moderate quality (“deworming probably improves...”); low quality (“deworming may improve...."); and very low quality (“we don't know if deworming improves....”).

\section{Main results}

We identified 42 trials, including eight cluster trials, that met the inclusion criteria. Excluding one trial where data are awaited, the 41 trials include 65,168 participants.

Screening then treating

For children known to be infected with worms (by screening), a single dose of deworming drugs may increase weight $(0.58 \mathrm{~kg}, 95 \%$ CI 0.40 to 0.76 , three trials, 139 participants; low quality evidence) and may increase haemoglobin $(0.37 \mathrm{~g} / \mathrm{dL}, 95 \% \mathrm{CI} 0.1$ to 0.64 , two trials, 108 participants; low quality evidence), but we do not know if there is an effect on cognitive functioning (two trials, very low quality evidence).

Single dose deworming for all children

In trials treating all children, a single dose of deworming drugs gave mixed effects on weight, with no effects evident in seven trials, but large effects in two (nine trials, 3058 participants, very low quality evidence). The two trials with a positive effect were from the same very high prevalence setting and may not be easily generalised elsewhere. Single dose deworming probably made little or no effect on haemoglobin (mean difference (MD) $0.06 \mathrm{~g} / \mathrm{dL}, 95 \% \mathrm{CI}-0.06$ to 0.17 , three trials, 1005 participants; moderate evidence), and may have little or no effect on cognition (two trials, low quality evidence).

Mulitple dose deworming for all children

Over the first year of follow up, multiple doses of deworming drugs given to all children may have little or no effect on weight (MD $0.06 \mathrm{~kg}$, 95\% CI -0.17 to 0.30; seven trials, 2460 participants; low quality evidence); haemoglobin, (mean $0.01 \mathrm{~g} / \mathrm{dL}$ lower; $95 \% \mathrm{CI}$ 0.14 lower to 0.13 higher; four trials, 807 participants; low quality evidence); cognition (three trials, 30,571 participants, low quality evidence); or school attendance (4\% higher attendance; $95 \%$ CI -6 to 14; two trials, 30,243 participants; low quality evidence);

For time periods beyond a year, there were five trials with weight measures. One cluster-RCT of 3712 children in a low prevalence area showed a large effect (average gain of $0.98 \mathrm{~kg}$ ), whilst the other four trials did not show an effect, including a cluster-RCT of 27,995 children in a moderate prevalence area (five trials, 37,306 participants; low quality evidence). For height, we are uncertain whether there is an effect of deworming $(-0.26 \mathrm{~cm}$; $95 \%$ CI -0.84 to 0.31 , three trials, 6652 participants; very low quality evidence). Deworming may have little or no effect on haemoglobin $(0.00 \mathrm{~g} / \mathrm{dL}, 95 \% \mathrm{CI}-0.08$ to 0.08 , two trials, 1365 participants, low quality evidence); cognition (two trials, 3720 participants; moderate quality evidence). For school attendance, we are uncertain if there is an effect (mean attendance 5\% higher, $95 \%$ CI -0.5 to 10.5 , approximately 20,000 participants, very low quality evidence).

Stratified analysis to seek subgroup effects into low, medium and high helminth endemicity areas did not demonstrate any pattern of effect. In a sensitivity analysis that only included trials with adequate allocation concealment, we detected no significant effects for any primary outcomes.

One million children were randomized in a deworming trial from India with mortality as the primary outcome. This was completed in 2005 but the authors have not published the results.

\section{Authors' conclusions}

Screening children for intestinal helminths and then treating infected children appears promising, but the evidence base is small. Routine deworming drugs given to school children has been more extensively investigated, and has not shown benefit on weight in most studies, except for substantial weight changes in three trials conducted 15 years ago or more. Two of these trials were carried out in the same high prevalence setting. For haemoglobin and cognition, community deworming seems to have little or no effect, and the evidence in relation to school attendance, and school performance is generally poor, with no obvious or consistent effect. Our interpretation of this data is that it is probably misleading to justify contemporary deworming programmes based on evidence of consistent benefit on nutrition, haemoglobin, school attendance or school performance as there is simply insufficient reliable information to know whether this is so.

\section{PLAIN LANGUAGE SUMMARY}

Deworming drugs for soil-transmitted intestinal worms in children: effects on nutritional indicators, haemoglobin and school 


\section{Deworming drugs for treating soil-transmitted intestinal worms in children: effects on nutrition and school performance}

The main soil-transmitted worms are roundworms, hookworms, and whipworms. Infections are common in tropical and subtropical areas, particularly in children from low-income areas where there is inadequate sanitation, overcrowding, low levels of education, and lack of access to health care. These infections sometimes cause malnutrition, poor growth, and anaemia in children, and some experts believe they cause poor performance at school. While improved sanitation and hygiene are likely to be helpful, drugs can also be used. In one approach, individuals found to be infected on screening are treated. Evidence from these trials suggests this probably improves weight and may improve haemoglobin values, but the evidence base is small. In another approach, currently recommended by the WHO, and much more extensively investigated, all school children are treated. In trials that follow up children after a single dose of deworming, and after multiple doses with follow up for over a year, we do not know if these programmes have an effect on weight, height, school attendance, or school performance; they may have little or no effect on haemoglobin or cognition.

One trial of a million children examined death and was completed in 2005 but the authors have not yet published the results. 


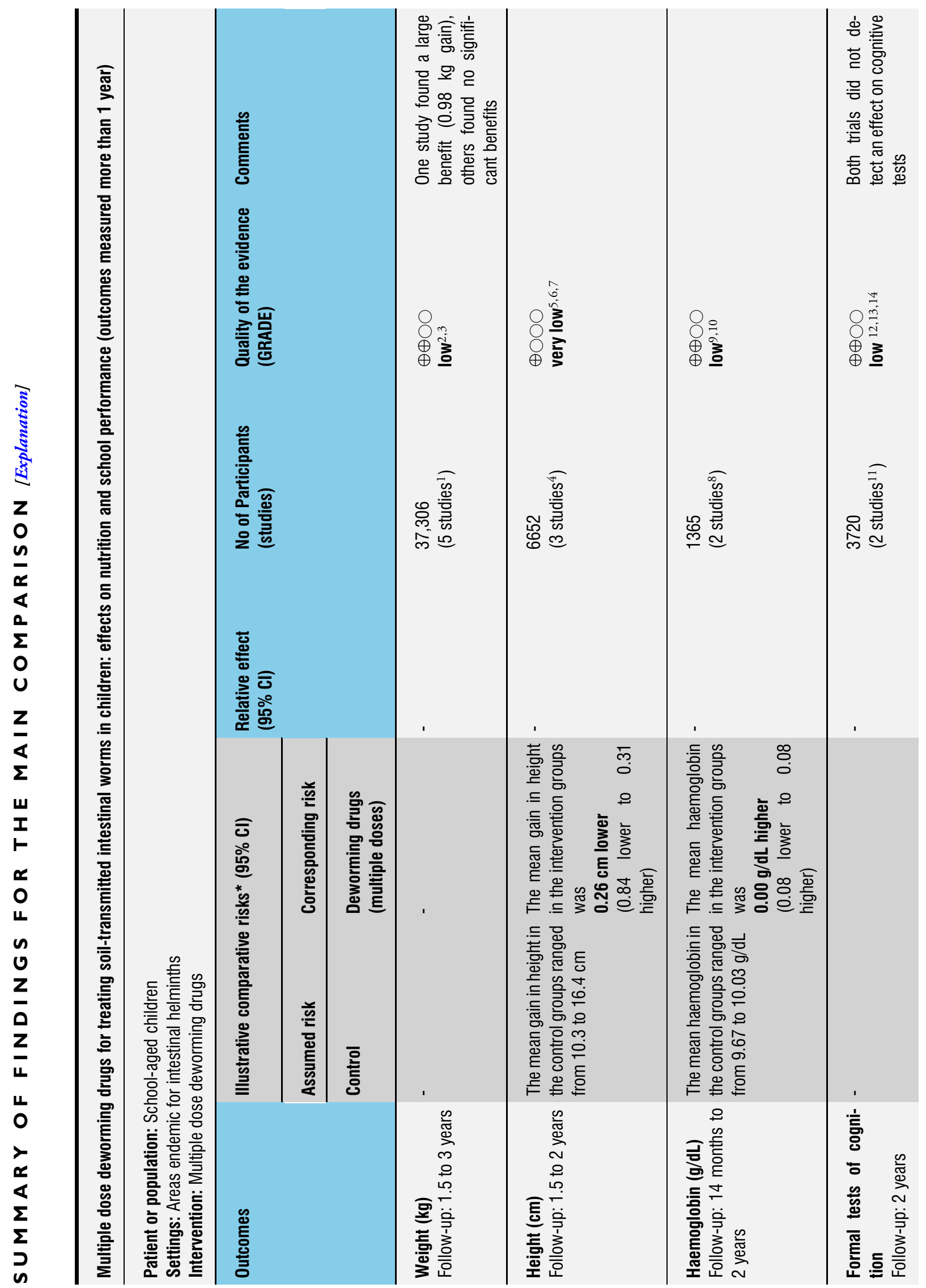

Deworming drugs for soil-transmitted intestinal worms in children: effects on nutritional indicators, haemoglobin and school performance (Review)

Copyright $\odot 2012$ The Cochrane Collaboration. Published by John Wiley \& Sons, Ltd. 


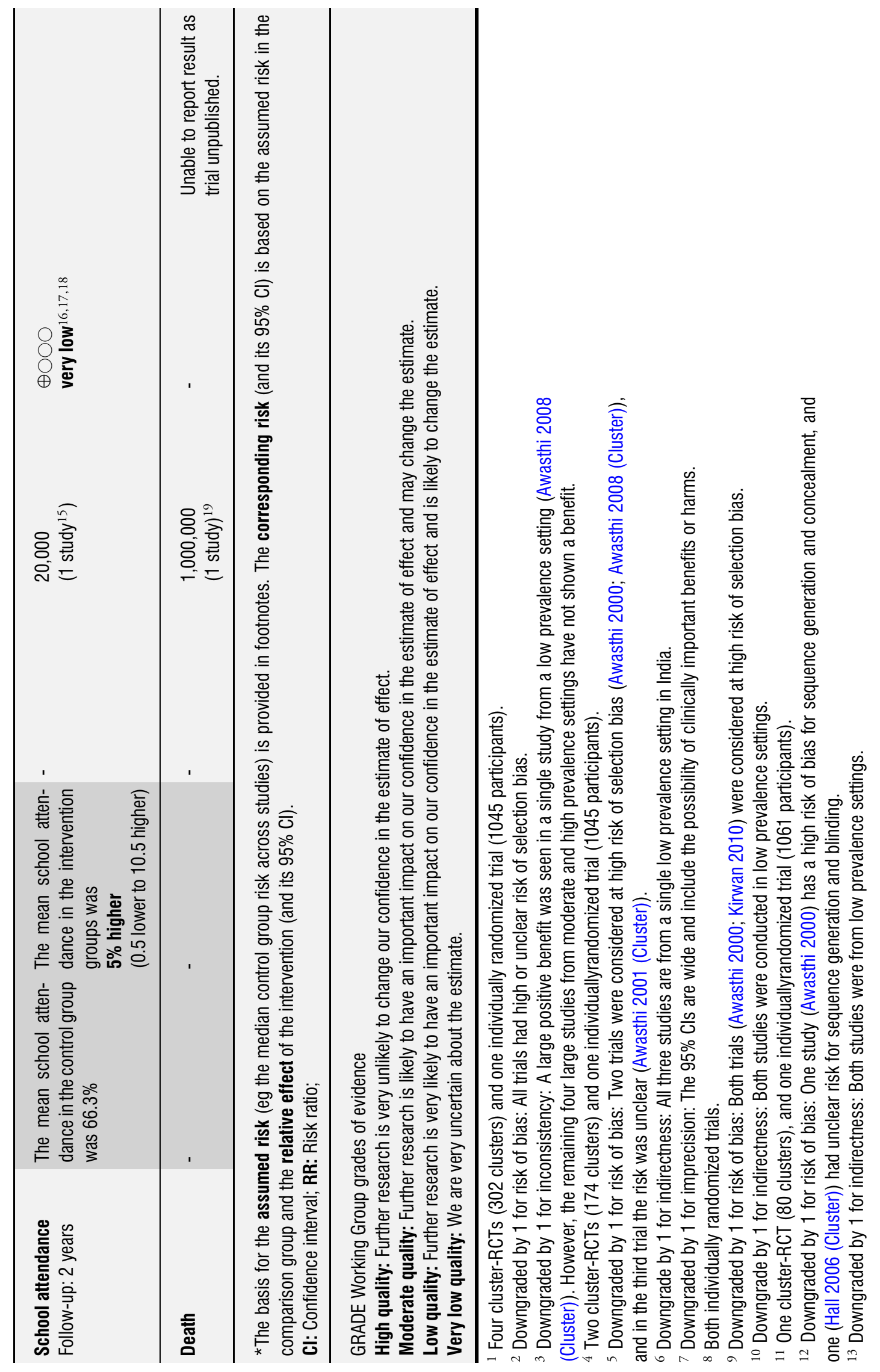

Deworming drugs for soil-transmitted intestinal worms in children: effects on nutritional indicators, haemoglobin and school 


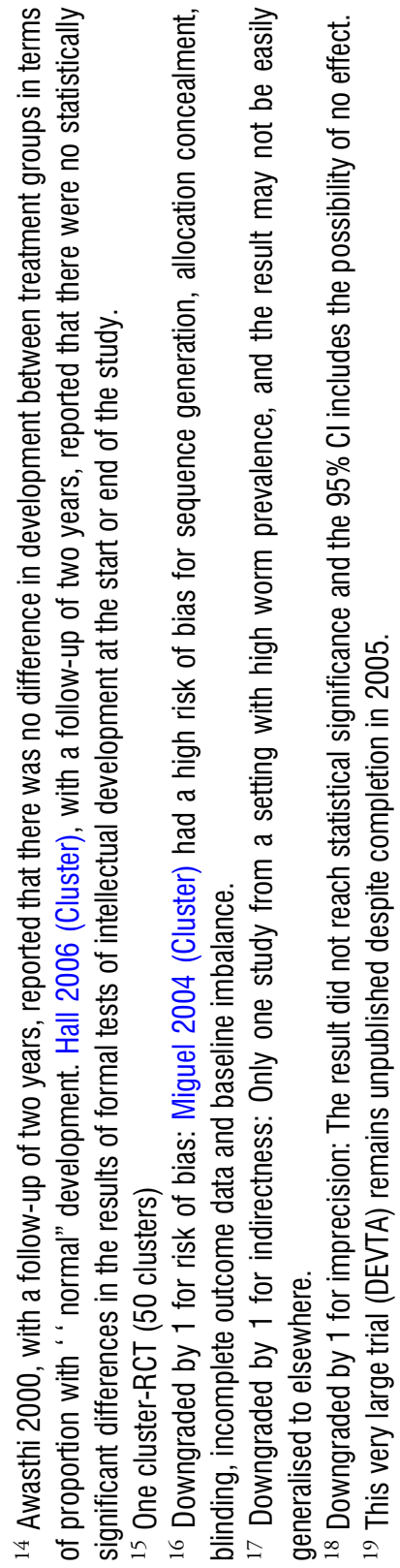

Deworming drugs for soil-transmitted intestinal worms in children: effects on nutritional indicators, haemoglobin and school

Copyright (? 2012 The Cochrane Collaboration. Published by John Wiley \& Sons, Ltd. 


\section{B A C K G R O U N D}

\section{Description of the condition}

The three soil-transmitted helminth (STH) infections, ascariasis (roundworm), trichuriasis (whipworm), and hookworm, are the main intestinal helminth infections in humans (Bethony 2006; de Silva 2003b). Specialists estimate that each type of infection causes between 600-800 million cases worldwide each year (Hotez 2009, de Silva 2003b), with more than a quarter of the world's population infected with one or more of the soil-transmitted intestinal worms (Chan 1997). Estimates from 2003 suggest that global prevalence of STH infections is declining, with marked improvement in the Americas and Asia, but a static picture in sub-Saharan Africa (de Silva 2003b). STH infections particularly affect children living in poverty, where inadequate sanitation, overcrowding, low levels of education, and lack of access to health care make them particularly susceptible (Bethony 2006, de Silva 2003b). In 1993, the World Bank ranked STH infection as a greater cause of ill health in children aged 5 to 15 years than any other infection (World Bank 1993), but there has been considerable variation in the quoted estimates of global burden (de Silva 2003b), which are currently being updated.

Policy makers are concerned that the long-term effects of worm infestation impair childhood nutritional status, school performance, and long-term cognitive development (Bethony 2006). It is thought that iron status may mediate these effects, since hookworm and whipworm disease are associated with iron-deficiency anaemia (Crompton 2000; de Silva 2003a), and a fall in blood haemoglobin levels is associated with increasing intensity of infection (Crompton 2003). Furthermore, hookworm-induced irondeficiency anaemia has been associated with decreased physical activity and worker productivity (Crompton 2003).

Worms are associated with malnutrition, impaired growth, and poor school performance. Roundworms obtain their nutrition from gastrointestinal contents. The association with malnutrition is possibly mediated through impaired fat digestion, reduced vitamin absorption (particularly vitamin A), and temporary lactose intolerance (WHO 2002). Whipworm infection has been associated with malnutrition, although the precise mechanism for this is unclear (Cappello 2004). Some suggest that the effects on nutrition are through appetite suppression, increased nutrient loss, and decreased nutrient absorption and utilization (Stephenson 2000; de Silva 2003a).

Roundworm, hookworm, and whipworm disease have all been associated with impaired growth in school children (de Silva 2003a). Observational studies have reported an association between worm infection and lower scores on tests of school performance (Sakti 1999; Kvalsvig 2003). In a multiple-regression model based on cross-sectional data, Sakti 1999 found that hookworm infection was associated with worse scores in six out of 14 cognitive tests in Indonesian school children. Severe whipworm (Trichuris dysentery syndrome) was associated with low IQ, school achievement, and cognitive function after a four-year follow up of a specific group of Jamaican children with severe infection (Callender 1998).

While these associations would suggest potential benefits of deworming, the associations could equally be caused by the confounding factor of poverty. Even with adjustment for known confounding factors, residual confounding could be a problem. Furthermore, the causal link between chronic infection and impaired childhood development is extrapolated from the recorded improvement in these features after deworming (Bethony 2006). Hence, reliable randomized controlled trials are required to assess whether policies are effective. These can examine the effectiveness of treating worm infection in an individual, as evidence of efficacy, and treatment in schools or communities, as evidence of the effectiveness of programmes. The latter studies are ideally clusterRCTs, and thus able to detect any externalities (benefits to other children) accruing as a result of reduced transmission.

\section{Description of the intervention}

Public health interventions to tackle worm infection include those that improve sanitation and hygiene, or those that administer drug therapy to populations or targeted groups in the community, often coupled with health education. The work of the Rockefeller Sanitary Commission in the early 1900s led to the recognition that sanitary reform was needed alongside chemotherapeutic approaches to have an effect on worm prevalence (Horton 2003). In Japan, worms virtually disappeared over a 20-year period after the Second World War; this has been credited to an integrated programme of sanitary reform combined with screening and treatment of positive cases (Savioli 2002; Horton 2003). A similar experience occurred in Korea (Savioli 2002). The current global decline in worm prevalence has been credited to economic development and deworming programmes (de Silva 2003b). The impact of the chemotherapeutic element is difficult to assess. In countries where an improvement in sanitation and hygiene has occurred as a component of economic growth, a parallel decline in the prevalence of geohelminths has occurred: for example, in Italy between 1965 and 1980, the trichuriasis prevalence dropped from 65\% to less than 5\% without control activity (Savioli 2002).

The World Health Organization (WHO) policy outlines three categories of public health drug treatment policies (WHO 2002):

- Selective: individual deworming based on a diagnosis of infection.

- Targeted: group deworming where a (risk) group is treated without prior diagnosis.

- Universal: population deworming in which the whole community is treated irrespective of infection status.

The WHO and others promote targeted treatment. They do not recommend individual screening since the cost is four to 10 times that of the treatment itself. The policy's aim appears to be to control morbidity by reducing the intensity of infection in the most 
vulnerable populations. The strategy is to target drug treatment at groups: pre-school-age children (between one and five years); school-age children (between six and 15 years); and women of childbearing age. The strategy requires a population survey for prevalence and intensity of infection to determine the population worm burden. This determines the recommended frequency of treatment, updated in a WHO field manual in 2006: once per year for low-risk communities with 20 to $50 \%$ prevalence, or twice per year for high-risk communities with $>50 \%$ prevalence (WHO 2006b).

The policy promotes the use of schools, maternal and child health clinics, and vaccination campaigns to reach at-risk groups. The WHO advocate school-based programmes in particular, as it is easy to deliver medicines through teaching staff, with estimated costs varying from US $\$ 0.05$ to 0.65 per child per year for annual dosing (Savioli 2002; WHO 2002). In areas with a high prevalence, the current policy recommends treatment three times per year (WHO 2006b), based on modelling and reinfection prevalence studies. Following drug treatment worm populations tend to return rapidly to pretreatment levels; in less than a year for roundworm and whipworm (Anderson 1991). Anderson 1991 suggests that to control morbidity in areas of endemic infection, targeted treatment should be repeated every three to four months for roundworm and whipworm, with longer intervals acceptable for longerlived species such as hookworm. The WHO recommends moni- toring with a range of impact indicators, including prevalence and intensity, incidence, morbidity and mortality (WHO 2010). The control programme is intended to reduce the worm burden in the $10 \%$ to $15 \%$ of children who are most heavily infected in a particular population and to keep it low through repeated treatments. It is also argued that treating individuals in communities reduces transmission in the community as a whole (Anderson 1991), and that this can lead to health and schooling benefits for the whole population, including those who have not received deworming treatment (Bundy 2009). These 'spill over' effects, or externalities, are not captured in individually randomized controlled trials, since any benefit in the control group reduces the overall treatment effect. A cluster design is therefore required to identify these additional putative effects.

\section{How the intervention might work}

It is argued that deworming programmes improve nutrition, haemoglobin, and cognition. As a result of these benefits, children are thought to have increased physical well being, with improved intellect, and are better able to attend school. As a result, performance at school is enhanced, and mortality is reduced; over the long-term this benefits society as a whole, and reduces poverty (Figure 1) (WHO 2005). 
Figure I.

\section{Logic model for the effects of community deworming}

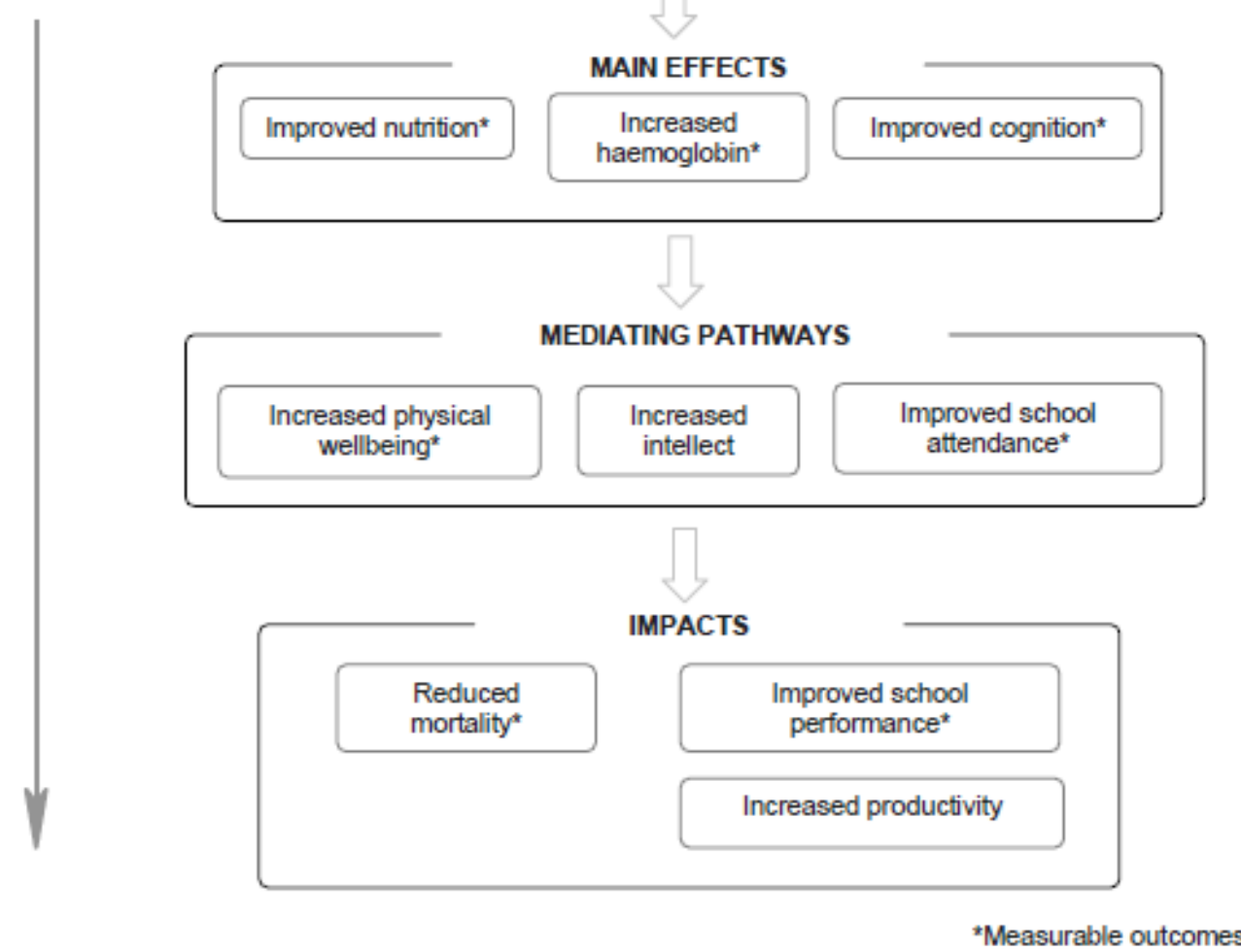

In this review, the primary outcomes sought are the main effects (increased haemoglobin, nutrition, and improved cognition); measurable aspects of the mediating pathways (school attendance and physical well being); and measurable aspects of impact (mortality and school performance; Figure 1 ).

Clinical observation of treating children heavily infected with worms indicated weight gain was sometimes marked, and so in this review we include community studies that measure effects after a single dose of deworming drugs ('efficacy' measures in the individual), as well as studies of multiple doses with follow-up under a year (showing early benefits) and studies with follow-up beyond a year. The latter studies are likely to detect externalities and potential long term benefits.

\section{Why it is important to do this review}

The intended impacts of deworming programmes - to reduce mortality, and increase children's long term economic productivity - are clearly worthwhile goals and are heavily promoted by advocates in the field such as the WHO (Montresor 2002; WHO 2002; WHO 2006b), and the World Bank (World 2011). Furthermore, deworming with albendazole was recently endorsed in the 2012 Copenhagen consensus statement, as the 4th highest ranking solution to address 'big issues facing the planet' in terms of cost and benefit (Copenhagen Consensus Center 2012). The widely-cited cost-effectiveness estimates from the Disease Control Priorities in Developing Countries (DCP2) report (Jamison 2006) state that deworming for STH infections was one of the most cost-effective interventions for global health. The reliability of these estimates, however, has been questioned recently by the organization GiveWell, which suggests they have been overstated by a factor of about 100 (GiveWell 2011).

Advocates point to the favourable cost-effectiveness estimates for deworming programmes, with a focus on the putative effect on 
schooling outcomes, and productivity (Deworm the World 2012). The evidential basis for this draws on a range of study designs, including historical econometric studies such as Bleakely 2004, which analysed the Rockefeller Sanitary Commission's campaign to eradicate hookworm in the American South. This showed an association between areas with higher levels of hookworm infection prior to the campaign and greater increases in school attendance and literacy after the intervention, and an association with income gains in the longer-term. Another influential study is Miguel 2004 (Cluster), which is included in this review.

Current policies have become even more challenging to assess, as global specialists conflate the evidence on different helminths. Some advocates describe the benefits of treating all helminths, including schistosomiasis, filariasis, and STH infections. For example, the WHO states that deworming treatment against schistosomes and STH infections helps (1) eradicate extreme poverty and hunger; (2) achieve universal primary education; (3) promote gender equality and empower women; (4) reduce child mortality and improve maternal health; and (5) combat HIV/AIDS, malaria, and other diseases (WHO 2005). The evidence for the benefit of treating populations with schistosomiasis is fairly clear (Danso-Appiah 2008), as the infection has a very substantive effect on health. However, this does not mean that a different drug treating a different helminth species is equally effective.

Despite the lack of rigour in considering the evidence for separate components of these policies, they are moving forward globally with large scale purchases of drugs. The current Neglected Tropical Disease (NTD) policy focus has been on addressing 'polyparasitism' by treating the parasites that cause ascariasis, trichuriasis, hookworm, lymphatic filariasis, onchocerciasis, schistosomiasis, and trachoma with ivermectin, albendazole, azithromycin, and praziquantel (Hotez 2009). These four drugs are donated by pharmaceutical companies, and the 'overlapping specificity' would mean multiple pathogens would be targeted (Hotez 2006b). Thus, mass drug administration for NTDs is promoted as "one of the lowest cost and cost-efficient mechanisms for both improving maternal child health and lifting the bottom billion out of poverty" (Hotez 2011b). Significant resources are being invested in this agenda, with the UK Department for International Development committing $£ 50$ million in 2008 , and the US government (USG) committing US\$65 million in 2010 as part of the US Global Health Initiative (GHI) (Hotez 2011a).

Given the amount of investment of public money in these programmes, it is important to be clear whether mass or targeted drug administration is able to contribute to health and development in such a substantive way - not least because if it does then major investment is justified. Indeed, international donors and developed country governments and tax payers are contributing to the efforts to tackle STH infections in the belief that they will improve the health of children in the way that the WHO claim (WHO 2005). Thus this review of reliable evidence from controlled trials will help delineate whether there is an impact of these drugs in populations with STH infections (ascariasis, trichuriasis, and hookworm).

\section{History of this review}

In 2007, we systematically reviewed the reliable evidence from controlled trials about the effects of anthelminth drugs for STH infection on child growth and cognition (Taylor-Robinson 2007). This systematic review demonstrated uncertainty around the assumed benefit and concluded that deworming may be effective in relation to weight gain in the short-term in some areas, but not in others; the potential long-term impact on weight was unclear. For school performance, data were very limited, and no convincing treatment effect was demonstrated.

New trials have been recently published, and other unpublished studies have been made available to us. In this review update, we have reapplied the inclusion criteria, repeated data extraction, added new trials, added haemoglobin as a primary outcome, restructured the analysis, and used GRADE to assess the quality of the evidence. We were also able to:

- combine trials with nutritional outcomes as change and end values in the same meta-analysis, as this has been shown to be valid.

- stratify the analysis by endemicity of worms, as the policy question is whether deworming should be given in all areas, or only high prevalence areas.

In addition, following correspondence with the authors of a large study that measured schooling as an outcome, we have included this in the current edition (Miguel 2004 (Cluster)).

Unfortunately, we have been unable to include a trial of over a million children completed in 2005 (DEVTA (unpublished). This is despite our best efforts in trying to elicit public disclosure of the results.

This Cochrane Review does not cover deworming and pregnancy, which is covered elsewhere (Haider 2009).

\section{O B J E C T I VES}

In deworming programmes for soil-transmitted intestinal worms (nematode geohelminths) in children, to summarise the effects on nutritional indicators, haemoglobin, cognition, school attendance; and the impacts on school performance and mortality.

\section{METHODS}

\section{Criteria for considering studies for this review}

\section{Types of studies}


Randomized and quasi-randomized controlled trials (RCTs). We included cluster-RCTs, provided more than two clusters were allocated to each treatment arm.

\section{Types of participants}

Children aged 16 years or less in community studies. We excluded trials of sick children or children being treated for malnutrition.

\section{Types of interventions}

\begin{abstract}
Intervention
Deworming drugs for geohelminth worms, administered at any location (including health facilities, schools, and communities). We included studies examining effects after a single dose, and after multiple doses.

The deworming drugs we included are those included in the WHO Model List of Essential Medicines for deworming drugs of geohelminths (WHO 2006a). This includes albendazole, levamisole, mebendazole, pyrantel, and ivermectin. Other drugs used are nitazoxanide, piperazine, tetrachlorethylene, and thiabendazole.

We included studies that provided health education to the intervention arm alone. Studies that provided other additional interventions (eg growth monitoring, micronutrient supplementation, malaria chemoprevention, or other drugs) were included when the additional intervention was given to both the control and intervention arm.
\end{abstract}

\section{Control}

Placebo or no treatment.

\section{Types of outcome measures}

\author{
Primary \\ - Weight. \\ - Haemoglobin. \\ - Psychometric tests of cognition.
}

\section{Secondary}

- Other nutritional indicators:

$\circ$ Height.

- Mid-upper arm circumference.

- Skin fold thickness (eg tricep and subscapular skin fold).

- Body mass index.

- Measures of physical well being (eg Harvard Step Test).

- School attendance:
- Days present at school.

- Number of children dropping out.

- School performance (measured by examination results).

- Death.

\section{Adverse events}

- Serious adverse events (death, life-threatening events, or events leading to hospitalisation).

- Other adverse events.

\section{Search methods for identification of studies}

The authors along with the Cochrane Infectious Diseases Group Information Specialist attempted to identify all relevant trials regardless of language or publication status (published, unpublished, in press, and in progress).

The Information Specialist searched the following databases using the search terms and strategy described in Table 1: Cochrane Infectious Diseases Group Specialized Register (15 February 2012); Cochrane Central Register of Controlled Trials (CENTRAL), published in The Cochrane Library (2011, Issue 4); MEDLINE (2000 to 15 February 2012); EMBASE (2000 to 15 February 2012); and LILACS (2000 to 15 February 2012). The metaRegister of Controlled Trials ( $m$ RCT) was also searched using 'helminth* OR anthelminth'' (15 February 2012).

We also searched the same databases for the effect of administration of deworming drugs on haemoglobin, using the search terms listed in Table 2. This additional search was conducted in February 2012. In addition, we drew on existing reviews of the topic and we checked the citations of all the trials identified by the above methods. We also re-appraised the studies identified in the previous versions of this review (Dickson 2000a; Taylor-Robinson 2007).

\section{Data collection and analysis}

\section{Selection of studies}

David Taylor-Robinson (DTR) checked the results of the search for potentially relevant trials and retrieved full articles as required. DTR and Paul Garner (PG) independently assessed the trial eligibility using an eligibility form based on the inclusion criteria; where there was uncertainty, all five authors participated in the decision about inclusion. We checked that trials with multiple publications were managed as one study. We recorded reasons for the exclusion of studies and we contacted authors of unpublished studies for information on when they intended to publish their results. 


\section{Data extraction and management}

DTR, Nicola Maayan (NM), Sarah Donegan (SD), and Karla Soares-Weiser (KSW) independently extracted data using data extraction forms. PG extracted and cross-checked the data from a selection of papers. We resolved any differences in opinion by discussion. Where methods, data, or analyses were unclear or missing, we contacted authors for further details.

For each treatment group of each trial, we extracted the number of patients randomized. For each outcome of interest, we extracted the number of participants analysed in each treatment group of each trial.

\section{RCTs that randomize individuals}

For dichotomous outcomes, we planned to extract the number of patients with the event. For continuous outcomes, we aimed to extract means and standard deviations. Where these data were not reported, we extracted medians and ranges or any other summary statistics. Where change from baseline results were presented alongside results purely based on the end value, we only extracted the change from baseline results.

\section{RCTs that randomize clusters}

For each cluster-RCT, we extracted the cluster unit, the number of clusters in the trial, the average size of clusters, and the unit of randomization (eg household or institution). Where possible, we extracted the statistical methods used to analyse the trial along with details describing whether these methods adjusted for clustering or other covariates. When reported, estimates of the intra-cluster correlation coefficient (ICC) for each outcome were extracted. Where a cluster-RCT adjusted for clustering in their analysis, we extracted the cluster adjusted results. When the trial did not account for clustering in their analysis, we extracted the same data as for trials that randomize individuals.

\section{Assessment of risk of bias in included studies}

DTR, PG, NM, SD, and KSW independently assessed the risk of bias (Higgins 2011b). Differences were resolved by discussion. On occasion, we corresponded with trial investigators when methods were unclear.

For RCTs that randomized individuals we addressed six components: sequence generation; allocation concealment; blinding; incomplete outcome data; selective outcome reporting; and other biases. For RCTS randomized by cluster, we addressed additional components: recruitment bias; baseline imbalance; loss of clusters; incorrect analysis; compatibility with RCTs randomized by individual. For each component, we placed judgments of low, high, or unclear/unknown risk of bias as described in Appendix 1. We displayed the results in risk of bias tables, a risk of bias summary, and a risk of bias graph.

\section{Measures of treatment effect}

Continuous data (means and standard deviations) were summarised using the mean differences. We planned to use the risk ratio to compare the treatment and control groups for dichotomous outcomes. All treatment effects were presented with $95 \%$ Confidence Intervals (CIs).

\section{Unit of analysis issues}

For a particular cluster-RCT when the analyses had not been adjusted for clustering, we attempted to adjust the results for clustering by estimating the design effect calculated as $1+(\mathrm{m}-1) * \mathrm{ICC}$ where $\mathrm{m}$ is the average cluster size and ICC is the intra-cluster correlation coefficient. To make the adjustment, we estimated a treatment effect that did not adjust for clustering and then multiplied the standard errors of the estimate by the square root of the design effect. When the true ICC was unknown, we estimated it from other included cluster-RCTs.

\section{Dealing with missing data}

We aimed to conduct a complete-case analysis in this review, such that all patients with a recorded outcome were included in the analysis.

\section{Assessment of heterogeneity}

We inspected the forest plots to detect overlapping CIs, applied the $\mathrm{Chi}^{2}$ test with a $\mathrm{P}$ value of 0.10 used to indicate statistical significance, and also implemented the $\mathrm{I}^{2}$ statistic with values of 30 to $60 \%, 59$ to $90 \%$, and 75 to $100 \%$ used to denote moderate, substantial, and considerable levels of heterogeneity, respectively.

\section{Assessment of reporting biases}

We decided not to construct funnel plots to look for evidence of publication bias because there were a limited number of trials in each analysis.

\section{Data synthesis}

KSW, NM, DTR, and SD analysed data with Review Manager 5. The analysis was structured into five sections:

Screened for infection: included trials that only included children who were identified as infected

- after a single dose;

- after multiple doses (outcomes measured in the first year).

Target population treated: included trials that included screened and unscreened children

- after a single dose;

- after multiple doses (outcomes measured in the first year);

- after multiple doses (outcomes measured after the first year). 
In the analyses of the target population, we stratified the analysis into three categories based on prevalence and intensity: High prevalence or high intensity areas (referred to as 'high prevalence'); moderate prevalence and low intensity (referred to as 'moderate prevalence'); and low prevalence with low intensity (referred to as 'low prevalence'). We used the WHO technical guidelines classification (WHO 2002; Table 3), rather than the simplified prevalence based field guide categories that are now used to determine treatment frequency (WHO 2006b; Table 3). In trials where information on intensity was not provided, we estimated the community category on the basis of quoted prevalence; it is possible that the community category has been underestimated in these trials (as per Table 3).

Cluster-RCTs that adjusted for clustering and RCTs that randomized individuals were combined using meta-analysis. We presented results of cluster-RCTs that were not adjusted for clustering in an additional table. We used a fixed-effect meta-analysis when the assessments of heterogeneity did not reveal heterogeneity. In the presence of heterogeneity, random-effects meta-analysis was used. For continuous data, we combined change from baseline results with end value results providing they were from distinct trials (Cochrane Collaboration 2002; Higgins 2011a). Labels on the meta-analyses indicate when end values were used.

We presented data that could not be meta-analysed in additional tables and reported on in these each section, under a heading, 'other data'.

\section{Subgroup analysis and investigation of heterogeneity}

In the presence of statistically significant heterogeneity, we planned to explore the following potential sources using subgroup analyses: age group ( $<$ five years versus $\geq$ five years); manufacturer; treatment setting (community, school, health post, hospital). We did not carry out these analyses because there were too few studies in the analyses.

\section{Sensitivity analysis}

We carried out sensitivity analyses including only those trials with a low risk of bias regarding allocation concealment.

\section{Summary of findings table}

We interpreted results using a summary of findings (SOF) table, which provides key information about the quality of evidence for the included studies in the comparison, the magnitude of effect of the interventions examined, and the sum of available data on the main outcomes. Data were imported from Review Manager 5 using the GRADE profiler (GRADE 2004). We selected the primary outcomes for the review in the SOF, and added height, school attendance, and death for multiple dose comparisons. Thus, our SOF table included:

- Weight $(\mathrm{kg})$
- Height $(\mathrm{cm})$ (for Comparison 4: Multiple dose, outcomes measured $>1$ year only)

- Haemoglobin $(\mathrm{g} / \mathrm{dL})$

- Psychometric tests of cognition

- School attendance (for Comparison 4: Multiple dose, outcomes measured < 1 year only; and Comparison 5: Multiple dose, outcomes measured $>1$ year only)

- Death (for Comparison 5: Multiple dose, outcomes measured > 1 year only): awaiting publication (DEVTA (unpublished).

In addition, physical fitness was measured in two studies after one dose of deworming medicine, and this measure was also included in the SOF table for this comparison only.

\section{RE S U L T S}

\section{Description of studies}

See: Characteristics of included studies; Characteristics of excluded studies; Characteristics of ongoing studies.

We identified 42 trials reported in 53 articles that met the inclusion criteria (see Characteristics of included studies); this includes one study of one million children, completed in 2005 , for which we are unable to report outcomes because it has not yet been published (DEVTA (unpublished)). A second study, completed in 2006, has never been published, but we were able to use the data from the manuscript supplied by the authors (Hall 2006 (Cluster)).

For Alderman 2006 (Cluster), the authors did not adjust the CIs to take into account clustering for the primary outcome. For this review, we used the corrected values supplied by the author.

Thirty-eight trials were excluded (see Characteristics of excluded studies), and two trials are ongoing (see Characteristics of ongoing studies).

\section{Location}

The included trials were undertaken in 23 different countries: Bangladesh (four trials); Ethiopia (two trials); Haiti (two trials); India (five trials); Indonesia (two trials); Jamaica (two trials); Kenya (five trials); South Africa (two trials); Vietnam (three trials); Zanzibar (two trials); Benin, Botswana, Cameroon, Guatemala, Java, Malaysia, Nigeria, Philippines, Sierra Leone, Tanzania, Uganda, Zaire (one trial in each); China, Philippines and Kenya (one multicentre trial).

\section{Population}

Children were recruited from school populations in 20 trials, communities in 16 trials, and in health facilities or by health workers 
in six trials. One of these recruited children on discharge from hospital (Donnen 1998). Olds 1999 also included adolescents 17 to 19 years, but the participants were predominantly under 16 years old.

Thirty-five trials were based on mass targeted treatment of an unscreened population. Fourteen trials were conducted in populations where worms were of high prevalence or intensity (community category 1), 10 in populations with moderate prevalence and low intensity (category 2), and 11 in populations with low prevalence and low intensity (category 3 ). Seven trials studied children that were screened and selected on the basis of their having high worm loads (Freij 1979a; Freij 1979a; Kvalsvig 1991a; Nokes 1992; Adams 1994; Simeon 1995; Sarkar 2002), and the purpose of three of these trials was to measure cognitive outcomes (Kvalsvig 1991a; Nokes 1992; Simeon 1995). Stephenson 1993 also studied an infected subgroup of the larger unscreened study population for cognitive and haemoglobin outcomes.

\section{Interventions}

\section{Albendazole studies}

- Twenty-four trials had albendazole only in one treatment arm (Adams 1994; Alderman 2006 (Cluster); Awasthi 2000; Awasthi 2001 (Cluster); Awasthi 2008 (Cluster); DEVTA (unpublished); Beach 1999; Dossa 2001; Fox 2005; Hadju 1997; Hall 2006 (Cluster); Kirwan 2010; Koroma 1996; Kruger 1996; Nga 2009; Nokes 1992; Olds 1999; Palupi 1997; Simeon 1995; Solon 2003; Stephenson 1989; Stephenson 1993; Sur 2005; Watkins 1996).

- In addition, some of these trials had arms with combinations with albendazole (with praziquantel (Olds 1999); ivermectin (Beach 1999)); but these interventions were also included in the control arms.

- One trial included antigiardial treatment in both intervention and control arms (Goto 2009).

- One trial was a deworming programme that included deworming drugs for STHs, praziquantel to treat schistosomiasis in schools with $>30 \%$ prevalence, and health promotion interventions (Miguel 2004 (Cluster).

\section{Other anthelminths}

- Mebendazole: eight trials (Donnen 1998; Garg 2002; Kloetzel 1982; Kvalsvig 1991a; Le Huong 2007; Rousham 1994 (Cluster); Stoltzfus 1997 (Cluster); Stoltzfus 2001); and in combination with pyrantel, two trials (Lai 1995; Rousham 1994 (Cluster)).

- Other deworming drugs used included pyrantel pamoate (Hadju 1996; Hadju 1997; Sarkar 2002), piperazine (Freij 1979a; Freij 1979b), piperazine citrate (Greenberg 1981), tetrachloroethylene (Michaelsen 1985), and levamisole (Willett 1979).

\section{Control groups}

Placebo or no treatment was used as a control in the majority of studies (see Characteristics of included studies). Others used vitamin A (Donnen 1998), vitamin C (Beach 1999; Fox 2005), or calcium powder (Awasthi 2000).

There were 13 trials where both the treatment and control group received nutritional supplementation: multi-nutrient (Kruger 1996, Nga 2009, Solon 2003); vitamin B (Sur 2005); iron (Dossa 2001, Le Huong 2007, Palupi 1997, Stoltzfus 2001); vitamin A (Awasthi 2001 (Cluster); Awasthi 2008 (Cluster); Hall 2006 (Cluster); DEVTA (unpublished)); or child health package (Alderman 2006 (Cluster)).

\section{Study design}

Eight trials were cluster randomized (Alderman 2006 (Cluster); Awasthi 2008 (Cluster); Awasthi 2001 (Cluster); DEVTA (unpublished); Hall 2006 (Cluster); Rousham 1994 (Cluster); Stoltzfus 1997 (Cluster)), one was a study with quasi-random allocation of the 75 clusters (Miguel 2004 (Cluster)). The rest used the individual as the unit of randomization.

Five out of the eight cluster-RCTs used an appropriate method to take clustering into account. Awasthi 2001 (Cluster) and Awasthi 2008 (Cluster) used urban slums as the unit of randomization (50 and 124 respectively), and DEVTA (unpublished) used 72 rural administrative blocks. These three trials were analysed at the cluster level (mean of cluster mean values and associated standard deviations). Stoltzfus 1997 (Cluster) randomized 12 schools and adjusted for within-school correlations using generalized estimating equations. Miguel 2004 (Cluster) adjust for clustering in their regression estimates, and present robust standard errors.

We encountered problems with the adjustment in the three remaining cluster-RCTs:

- Alderman 2006 (Cluster) had not adjusted the primary outcome for clustering in this study of 48 parishes containing 27,955 children in total. The authors upon request sent us the adjusted values which we have used in the analysis.

- Hall 2006 (Cluster) had 80 units of randomization (schools) containing 2659 children in total, and had not adjusted for clustering. We used the ICC calculated from the Alderman data to adjust the primary weight outcome for inclusion in metaanalysis. As the average cluster size for Hall 2006 (Cluster) (ie 33 children) differed somewhat from that of Alderman 2006 (Cluster) (ie 582 children), the true ICC for Hall 2006 (Cluster) may be different to that of Alderman 2006 (Cluster), therefore the adjusted result for weight is merely an approximation.

- Rousham 1994 (Cluster) had 13 units of randomization (villages) containing 1476 children in total and had also not 
adjusted for clustering, but no outcomes from this study were suitable for meta-analysis.

Four trials had a factorial design. DEVTA (unpublished) randomized clusters to usual care, six-monthly vitamin A, six-monthly 400 mg albendazole, and both vitamin A and albendazole. Kruger 1996 randomized individual participants to albendazole or placebo, and, also, three of the five schools in the trial received soup fortified with vitamins and iron, and two received unfortified soup. Le Huong 2007 randomized individual participants to iron-fortified noodles and mebendazole, noodles without iron fortification and mebendazole, iron-fortified noodles and placebo, noodles without iron fortification and placebo, and iron supplementation and mebendazole. Stoltzfus 2001 randomized households to iron, with random allocation of mebendazole by child, stratified by iron allocation and age grouped households; disaggregated data for each treatment allocation group was not provided for each outcome.

Follow-up periods for the trials that used a single dose ranged from one to 11 months, while the follow-up periods for trials that used multiple doses ranged from six months to 5 years.

Miguel 2004 (Cluster) included 75 schools with a total of 30,000 pupils enrolled. The intervention was a deworming package that was phased over time. The package included public health lectures, wall charts, teacher education, and health education in handwashing. In addition, a number of schools in the study were also mass treated for schistosomiasis. We previously excluded this study on the basis of confounding by schistosomiasis treatment. We received clarification from the authors that allowed inclusion of the study in this review update. The authors kindly provided data excluding 17 of the 75 schools that were mass treated for schistosomiasis. Overall, this analysis showed very similar results so we have included the data from the published paper.

In Miguel 2004 (Cluster), there were two potential quasi-randomized comparisons, one in 1998 and one in 1999. Included schools were stratified by zone, their involvement with other NGO programmes, and then listed alphabetically and every third school assigned to start the programme in 1998 , to start it in 1999 , or to be a control. The schools were thus divided into three groups: Group 1 schools were in the treatment group throughout; Group 2 schools were in the control group for the 1998 comparison, but in the treatment group in the 1999 comparison; Group 3 schools were in the control group throughout. Two comparisons were thus identified: Group 1 schools versus Group 2 and 3 schools in 1998; and Group 1 and 2 schools versus Group 3 schools in 1999.

The authors clarified that there were no health outcome data for Group 3 schools for 1999. This left one quasi-randomized comparison with contemporary health information in both treatment and control, which was 1998, Group 1 versus Group 2 and 3. However, results for health outcomes were presented for the 1998 comparison of Group 1 ( 25 schools) versus Group 2 ( 25 schools). Details of the outcomes we extracted and present are:

- Haemoglobin. This was measured in $4 \%$ of the randomized population $(778 / 20,000)$. It was unclear how the sample were selected.

- Weight and height. This was measured in an unknown sample of the 20,000 children. No sampling method was given.

- School attendance with up to a year follow-up was calculated as the weighted average school participation rate among all pupils enrolled, comparing Group 1 to Groups 2 and 3 (1998), and Group 2 versus Group 3 (1999), with approximately 20,000 children per group. Pupils present on the day of an unannounced NGO visit were considered participants. Pupils had 3.8 observations on average per year. School attendance with follow up over one year was also reported in 1999, comparing Group 1 and Group 3. However, the authors did not give any baseline values for attendance, so it was not possible to know whether differences detected are the results of the intervention or random differences in average attendance between groups.

- Exam performance was measured, but the authors did not provide the results by the quasi-randomized comparisons eligible for this review, and it was unclear how many children contributed to this outcome (1998 Group 1 versus Group 2 and 3; 1999 Group 1 and 2 versus Group 3).

Cognitive tests results were collected in 2000 for all three groups, but the authors did not report these results.

\section{Outcome measures}

\section{Nutritional outcomes}

Nutritional indicators were measured in 42 trials. Some trials reported absolute values, or changes in absolute values of weight and height (or other anthropometric measures). Many trials presented anthropometric data in terms of $\mathrm{z}$-scores or percentiles of weightfor-age, weight-for-height, and height-for-age, and compared the trial results to an external reference. Sometimes these values were dichotomised and presented as the prevalence of underweight, stunting or wasting (defined as -2SD z-scores). The external standard was usually quoted as the National Centre for Health Statistics (NCHS) standard, but a variety of references was quoted (eg anthropometric computer packages or country standards). These data have not been used in the meta-analyses as the results were already incorporated in the values for weight and height. Furthermore, in some trials, outcome data were not reported or were incomplete and could not be used in meta-analysis. A number did not report summary outcome data for each trial arm, and the results were reported in terms of regression modelling outcomes or subgroup analyses. The results of these trials are described in Table 4.

\section{Haemoglobin}

Seventeen trials measured haemoglobin. Of these, two trials did not report the measured haemoglobin results (Olds 1999; Solon 
2003), two trials only measured this outcome in a subset of the participants (DEVTA (unpublished), Miguel 2004 (Cluster)) and one trial did not report results by randomized comparisons (Stephenson 1993).

\section{Psychometric tests of cognition}

Ten trials measured intellectual development using formal tests (Table 5).

\section{Measures of physical well being}

Two studies (Stephenson 1989; Stephenson 1993) measured physical well being using the Harvard Step Test.

\section{School attendance}

Three trials measured school attendance (Table 6).

\section{School performance}

Exam performance was measured by Miguel 2004 (Cluster).

\section{Death}

DEVTA (unpublished) provided data on mortality although these data are not yet in the public domain so we are unable to report them.

\section{Adverse events}

Two trials provided information on adverse events (Michaelsen 1985; Fox 2005).

\section{Risk of bias in included studies}

See Figure 2 and Figure 3 for Summaries of the risk of bias and 'Characteristics of included studies' for details of the risk of bias and methods used in each trial.

Figure 2. Risk of bias graph: review authors' judgements about each risk of bias item presented as percentages across all included studies.

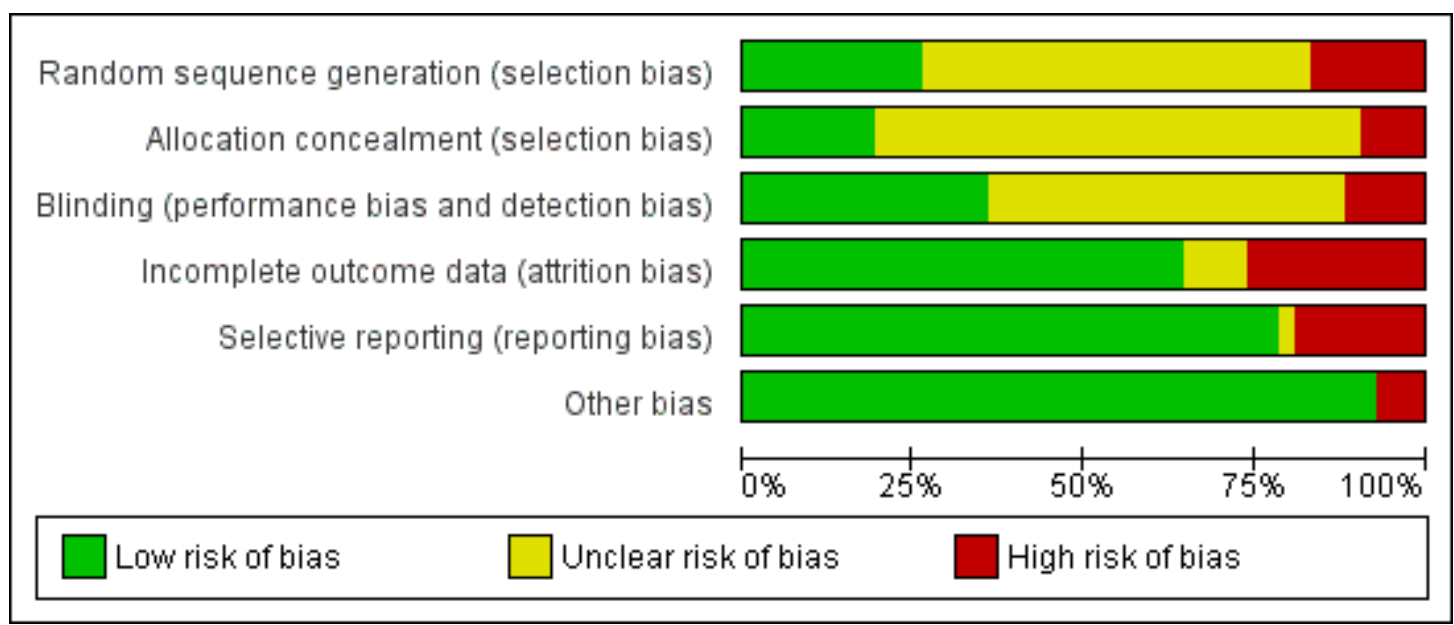

Deworming drugs for soil-transmitted intestinal worms in children: effects on nutritional indicators, haemoglobin and school 
Figure 3. Risk of bias summary: review authors' judgements about each risk of bias item for each included study.

\begin{tabular}{|c|c|c|c|c|c|c|}
\hline & 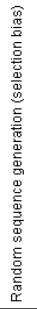 & 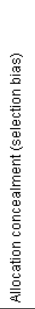 & 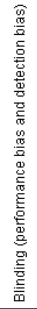 & 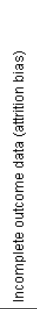 & 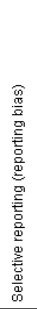 & 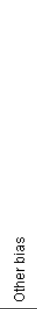 \\
\hline Adams 1994 & $?$ & $?$ & $?$ & $\odot$ & ๑) & † \\
\hline Alderman 2006 (Cluster) & ๑) & ? & - & - & (†) & $\odot$ \\
\hline Awasthi 2000 & - & ○ & $?$ & ๑) & ๑) & $\odot$ \\
\hline Awasthi 2001 (Cluster) & $?$ & $?$ & $?$ & $\odot$ & $\odot$ & $\odot$ \\
\hline Awasthi 2008 (Cluster) & - & $\odot$ & $\odot$ & $\odot$ & $\odot$ & $\odot$ \\
\hline Beach 1999 & $\odot$ & $?$ & $\odot$ & $\odot$ & - & $\odot$ \\
\hline DEVTA (unpublished) & $?$ & $?$ & $?$ & (†) & - & $\odot$ \\
\hline Donnen 1998 & $?$ & $?$ & $?$ & † & - & $\odot$ \\
\hline Dossa 2001 & $?$ & $?$ & $?$ & - & • & ○ \\
\hline Fox 2005 & $\odot$ & $\odot$ & $\odot$ & $\odot$ & + & + \\
\hline Freil 1979a & ○ & $?$ & $?$ & $?$ & $\odot$ & $\odot$ \\
\hline Freij 1979b & $\odot$ & $?$ & $?$ & $\odot$ & $\odot$ & $\odot$ \\
\hline Garg 2002 & - & ๑) & ○ & $\odot$ & ๑) & $\odot$ \\
\hline Goto 2009 & (†) & $?$ & (- & † & (†) & (†) \\
\hline Greenberg 1981 & $?$ & $?$ & $?$ & + & ○ & $\odot$ \\
\hline Hadju 1996 & $?$ & $?$ & $?$ & $\odot$ & - & + \\
\hline Hadju 1997 & $?$ & $?$ & $?$ & ○ & (†) & $\odot$ \\
\hline Hall 2006 (Cluster) & $?$ & $\odot$ & $?$ & $?$ & ๑) & $\odot$ \\
\hline Kirwan 2010 & - & - & + & ? & అ & (†) \\
\hline Kloetzel 1982 & $?$ & $?$ & $?$ & $?$ & $\odot$ & $\odot$ \\
\hline Koroma 1996 & $?$ & $?$ & $?$ & ○ & (†) & $\odot$ \\
\hline Kruger 1996 & $?$ & $?$ & $?$ & ○ & (†) & (†) \\
\hline Kvalsvig 1991a & $?$ & $?$ & $?$ & $?$ & $\odot$ & + \\
\hline Lai 1995 & ○ & $?$ & $\odot$ & † & - & (†) \\
\hline Le Huong 2007 & $?$ & $\odot$ & + & $\odot$ & - & $\odot$ \\
\hline Michaelsen 1985 & $?$ & $?$ & $?$ & ○ & - & $\odot$ \\
\hline Miguel 2004 (Cluster) & ○ & ○ & $\ominus$ & ○ & $\odot$ & ○ \\
\hline Nga 2009 & $\odot$ & $\odot$ & $\odot$ & $\odot$ & $\theta$ & (†) \\
\hline Nokes 1992 & $?$ & $?$ & $?$ & ? & $?$ & (†) \\
\hline Olds 1999 & (†) & $\odot$ & (†) & (†) & ○ & (†) \\
\hline Palupi 1997 & $?$ & $?$ & $?$ & $\odot$ & ( & (†) \\
\hline Rousham 1994 (Cluster) & $?$ & $?$ & † & $\odot$ & $\odot$ & ๑ \\
\hline Sarkar 2002 & (†) & $?$ & + & + & + & + \\
\hline Simeon 1995 & $\odot$ & $?$ & $?$ & $\odot$ & - & $\odot$ \\
\hline Solon 2003 & $?$ & $?$ & † & + & 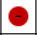 & (†) \\
\hline Stephenson 1989 & $?$ & $?$ & $\odot$ & + & ๑) & (†) \\
\hline Stephenson 1993 & $?$ & $?$ & $\odot$ & (†) & - & + \\
\hline Stoltzus 1997 (Cluster) & $?$ & $?$ & $?$ & $\odot$ & $\theta$ & (†) \\
\hline Stoltzfus 2001 & $?$ & $\odot$ & $?$ & ○ & 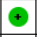 & ? \\
\hline Sur 2005 & $\odot$ & + & $\odot$ & $\odot$ & ○ & $\odot$ \\
\hline Watkins 1996 & $?$ & $?$ & $\odot$ & $\odot$ & $\odot$ & $\odot$ \\
\hline Willett 1979 & $\odot$ & $?$ & $\odot$ & - & - & + \\
\hline
\end{tabular}




\section{Generation of sequence}

In the 35 individually randomized trials, the risk of bias was low in 10 trials (see Figure 2 and Figure 3), high in five, and unclear in the other trials. For the eight cluster-RCTs, the risk of bias was low in one trial (Alderman 2006 (Cluster)), high in two trials (Awasthi 2008 (Cluster); Miguel 2004 (Cluster) ) and unclear in five trials.

\section{Allocation concealment}

For the 35 individually randomized trials, the risk of bias was low in seven trials (Fox 2005; Garg 2002; Le Huong 2007; Nga 2009; Olds 1999; Stoltzfus 2001; Sur 2005), high in two trials (Awasthi 2000; Kirwan 2010), and unclear in the other trials.

The risk of bias was low in one of the eight cluster-RCTs (Hall 2006 (Cluster)), high in two trials (Awasthi 2008 (Cluster); Miguel 2004 (Cluster)), and unclear in the remaining five trials.

\section{Blinding}

Fifteen trials were double blinded (Beach 1999; Fox 2005; Goto 2009; Kirwan 2010; Le Huong 2007; Nga 2009; Olds 1999; Rousham 1994 (Cluster); Sarkar 2002; Solon 2003; Stephenson 1989; Stephenson 1993; Sur 2005; Watkins 1996; Willett 1979) and judged to be at a low risk of bias. Five trials were at high risk of bias as they did not use blinding (Alderman 2006 (Cluster); Awasthi 2008 (Cluster); Garg 2002; Lai 1995; Miguel 2004 (Cluster)). Details of blinding were unclear in the remaining 22 trials.

\section{Incomplete outcome data}

Twenty-four trials had a low risk of bias for incomplete outcome data (Adams 1994; Awasthi 2000; Awasthi 2001 (Cluster); Awasthi 2008 (Cluster); Beach 1999; Donnen 1998; Fox 2005; Freij 1979b; Garg 2002; Goto 2009; Greenberg 1981; Hadju 1996; Le Huong 2007; Lai 1995; Nga 2009; Palupi 1997; ; Rousham 1994 (Cluster); Sarkar 2002; Simeon 1995; Stephenson 1989; Stephenson 1993; Stoltzfus 1997 (Cluster); Sur 2005; Watkins 1996), in seven trials the risk of bias was unclear (DEVTA (unpublished); Freij 1979a; Hall 2006 (Cluster); Kloetzel 1982; Kvalsvig 1991a; Olds 1999; Solon 2003), and in the remaining trials there was a high risk of bias.

Overall, the percentage of randomized participants that were evaluable ranged from $4 \%$ to $100 \%$, with 18 trials including $90 \%$ or more of the randomized participants (low risk cut-off). The percentage was particularly low in two of the trials measuring school performance and cognitive outcomes: $73 \%$ in Nokes 1992; and $52 \%$ in Stoltzfus 2001, and in one trial measuring haemoglobin: 26\% in Kirwan 2010. In Miguel 2004 (Cluster), for haemoglobin approximately $4 \%(778 / 20,000)$ of eligible participants were assessed, but it is unclear how these were selected, and for nutritional outcomes the number assessed was unclear.

\section{Selective outcome reporting}

Thirteen trials had evidence of selective reporting and were judged to be at high risk of bias (Goto 2009; Greenberg 1981; Kirwan 2010; Koroma 1996; Nga 2009; Nokes 1992; Olds 1999; Simeon 1995; Solon 2003; Stoltzfus 1997 (Cluster); Stoltzfus 2001; Sur 2005; Willett 1979). The remaining trials did not show evidence of selective reporting.

\section{Other biases}

Quality of the design of the eight cluster-RCTs was judged as low risk for recruitment bias (five trials), baseline imbalance (eight trials), loss of clusters (eight trials), compatibility with RCTs that randomized individuals (one trial) and incorrect analysis (seven trials). Alderman 2006 (Cluster) did not adjust for clustering in the published trial, but gave us the adjusted data (see study design above), and we used this to adjust the analysis in Hall 2006 (Cluster).

\section{Effects of interventions}

See: Summary of findings for the main comparison Multiple dose deworming drugs for treating soil-transmitted intestinal worms in children: effects on nutrition and school performance (outcomes measured at more than 1 year)

The effects were grouped into:

- trials where children were screened for infection (comparisons 1 and 2);

- trials treating whole populations (comparisons 3 to 5). Comparison 3 is after a single dose of deworming drug, comparison 4 after multiple doses with follow up for up to a year, and comparison 5 after multiple doses with follow up of one year or more.

In the trials treating whole populations, we stratified the results by community worm prevalence. Prevalence strata are detailed in Table 3 (high prevalence or high intensity areas (referred to as 'high prevalence'); moderate prevalence and low intensity referred to as ('moderate prevalence'); and low prevalence with low intensity referred to as 'low prevalence'). Within each section, we present the results of the meta-analysis, and then report any other data from trials that we could not include in the meta-analysis. 


\section{Only infected children included}

These trials screened for infection, and then only included children with proven infection. None of these trials provided data for the outcomes school attendance (number of children dropping out), school performance, mortality or adverse events.

\section{Single dose (comparison I)}

For nutritional measures, trials measured weight $(\mathrm{n}=3)$, height $(\mathrm{n}=2)$, MUAC $(\mathrm{n}=3)$, triceps $(\mathrm{n}=2)$, subscapular $(\mathrm{n}=1)$ skinfold and BMI $(\mathrm{n}=1)$. The trials demonstrated weight gain $(0.58 \mathrm{~kg}$, $95 \%$ CI 0.40 to $0.76 ; 149$ participants, three trials; Analysis 1.1 ); and gains in MUAC, triceps and subscapular skinfold values ( Analysis 1.3; Analysis 1.4; Analysis 1.5). No difference in height or body mass index was detected after a single dose (Analysis 1.2; Analysis 1.6). Nokes 1992 did not provide data for nutritional outcomes as nine weeks was cited as too short a follow-up period to demonstrate a change (Table 4).

For haemoglobin, the mean value was slightly higher at the end of the study with deworming (mean difference $0.37 \mathrm{~g} / \mathrm{dL}, 95 \%$ CI 0.10 to $0.64 ; 108$ participants, two trials; Analysis 1.7).

For psychometric tests of cognition, two trials reported on formal tests (Table 5). Kvalsvig 1991a did not clearly report change in cognitive scores; Nokes 1992 did not report unadjusted data, but results of multiple regression suggest an improvement in treated children in three of the 10 tests carried out (fluency, digit span forwards, digit span backwards).

\section{Multiple doses (comparison 2)}

Simeon 1995 gave screened children albendazole at 0,3 and 6 months and then carried out measurements two weeks after the last dose.

For nutritional measures, the authors reported end values of body mass index, and did not demonstrate a difference (mean difference $-0.20 \mathrm{~cm}, 95 \%$ CI -0.46 to 0.06 ; 407 participants, one trial, Analysis 2.1). They also reported height for age $\mathrm{z}$-score and did not detect a difference.

For psychometric tests of cognition, the authors measured intellectual development using a wide range achievement test in the main study, and digit spans and verbal fluency tests in subgroups. The authors reported that deworming had no effect on intellectual development scores, but did not report the data (Table 5).

For school attendance (days present at school), deworming had no demonstrable effect on school attendance rates of children actively attending school (mean difference -2.00 , 95\% CI -5.49 to 1.49; 407 participants, one trial; Analysis 2.2).

\section{Whole population treated}

Single dose (comparison 3)
No trials provided data for the outcomes school attendance, adverse events and mortality.

For nutritional measures, trials were in high $(\mathrm{n}=4)$, moderate ( $\mathrm{n}$ $=2)$ and low $(\mathrm{n}=3)$ prevalence areas. Across prevalence categories for weight, height, MUAC, and skinfold (triceps and subscapular) no effect was evident in seven trials; but a substantive effect was seen in two trials (Stephenson 1989 and 1993) for weight, MUAC, and skinfold (both triceps and subscapular) (Analysis 3.1; Analysis 3.3; Analysis 3.4; Analysis 3.5), with an average weight gain of over one kilogram in both studies. These trials were in a high prevalence area of Kenya. Stephenson 1989 also showed the gain in height was higher in the albendazole group by $6 \mathrm{~mm}$ over six months, but Stephenson 1993 did not detect a difference (Analysis 3.2). The high level of heterogeneity precludes meta-analysis in the high prevalence groups, but in moderate and low prevalence areas the meta-analysis suggests no marked effect, although the CIs do not exclude a clinically important effect (3058 participants, nine trials; Analysis 3.1).

For haemoglobin, two studies were in moderate prevalence areas, and one in low prevalence areas. No effect was demonstrable in individual studies or on meta analysis (mean difference $0.06 \mathrm{~g} /$ dL, 95\% CI - 0.05 to 0.17; 1005 participants, three trials; Analysis 3.6).

For psychometric tests of cognition, Solon 2003 measured cognitive ability using a standardized written mental-abilities test, and reported that deworming had either no effect or a negative effect on mental ability scores, but did not report the data. Nga 2009 reported no effects on any cognitive tests measured (Table 5).

For measures of physical well being, two trials in the same high prevalence area of Kenya measured performance on the Harvard Step Test (Stephenson 1989; Stephenson 1993). This indicated benefit (Analysis 3.7; mean difference 6.00, 95\% CI 4.31 to 7.69; 86 participants, two trials).

For adverse events, Fox 2005 reported none in 46 patients given albendazole. Michaelsen 1985 reported a number of adverse events with tetra-chloroethylene, a drug no longer used (Table 4).

\section{Other data}

Six trials did not provide data in a form that we could use in meta-analysis. We have collated these data in Table 4, and this information is summarized below:

- Beach 1999 did not detect a nutritional benefit of treatment after four months for the entire study population (no figures provided).

- Fox 2005 only reported on subgroups infected with worms.

- Greenberg 1981 stated there was no significant difference for all measured anthropometric variables for the total group and for subgroups defined by severity of infection (no figures provided).

- Kloetzel 1982 reported the proportion of treatment or control group that improved, deteriorated, or experienced no 
change, but it is not known what anthropological measures were used.

- Koroma 1996 found significant increases in weight-forheight, weight-for-age, and height-for-age z-scores recorded in rural and urban treatment groups at six months.

- Michaelsen 1985 found no significant difference in change in mean for haemoglobin or weight for height at five months.

\section{Sensitivity analysis}

In the sensitivity analysis including only trials where the risk of bias for allocation concealment was low, no significant difference between treatment and control groups in weight, height, midupper arm circumference, or haemoglobin was evident (Analysis 6.1; Analysis 6.2; Analysis 6.3; Analysis 6.4).

\section{Multiple doses, less than a year of follow up (comparison 4).}

No trials provided data for the outcomes adverse events, school attendance (number of children dropping out) and mortality.

For nutritional outcomes, studies were carried out in high ( $\mathrm{n}=$ $2)$, moderate $(\mathrm{n}=2)$ and low $(\mathrm{n}=3)$ prevalence areas. For weight, overall there was no evidence of an effect (Analysis 4.1), although one trial (Stephenson 1993) showed a large weight gain in the treatment group $(900 \mathrm{~g})$; notably this effect had been detected after a single dose (see 'single dose' section above). Overall, the metaanalysis did not demonstrate a difference in weight gain between intervention and control (mean difference $0.06 \mathrm{~kg}, 95 \%$ CI -0.17 to $0.30 ; 2460$ participants, seven trials), but the heterogeneity was high $\left(\mathrm{I}^{2}=80 \%\right)$. When the trials were stratified by community category, heterogeneity was not explained. On the other hand, no significant effect was apparent in any subgroup. For MUAC, and triceps skinfold, no effects were evident in the studies measuring this (Dossa 2001, Watkins 1996, Donnen 1998), apart from Stephenson 1993, who reported large effects for MUAC, triceps and subscapular skinfold thickness (Analysis 4.3; Analysis 4.4; Analysis 4.5). No effect in height was demonstrated in any of the six trials measuring this (Analysis 4.2).

For haemoglobin, four trials reported this, with no difference between intervention and control apparent (Analysis 4.6).

For psychometric tests of cognition, three trials measured this (Table 5). Watkins 1996 measured reading and vocabulary, and Stoltzfus 2001 measured motor and language development, and reported that no effect was demonstrated. Miguel 2004 (Cluster) measured a range of cognitive tests. The results were not reported, but the authors state that no deworming effect was demonstrated. For school attendance (days present at school), two trials report this (Watkins 1996; Miguel 2004 (Cluster); Table 6 Analysis 4.7). Watkins reports attendance rates of children actively attending school, at baseline and after treatment, and no effect was demonstrated. Miguel 2004 (Cluster) reports on end value differences in attendance for girls under 13 and all boys. In 1998, between Group
1 versus Group 2 and 3: there was a difference of 9.3\% in schooling attendance detected, and in 1999, Group 2 versus Group 3, a difference of $5.5 \%$ was detected. No comparable baseline values of attendance were given so it was unclear whether these reflect differences in baseline or true effects. As the two comparisons in the Miguel 2004 (Cluster) trial were not independent (the control children in 1998 become the intervention children in 1999), they could not be meta-analysed together, so we carried out two separate meta-analyses (Analysis 4.7), the first with Miguel (1998 comparison) + Watkins; and the second with Miguel (1999 comparison) + Watkins. Neither meta-analysis demonstrated a significant effect on school attendance (using 1998 data: mean difference $4 \%, 95 \%$ CI -6 to 14 ; using 1999 data, mean difference $2 \%$, $95 \%$ CI -4 to $8 \%$ ).

For school performance, Miguel 2004 (Cluster) measured exam score performance (English, Mathematics and Science-Agriculture exams in pupils in grades 3 to 8 ), but did not report results by the quasi-randomized comparisons.

\section{Other data}

Six trials did not provide data in a form that we could use in meta-analysis. We have collated these data in Table 4, and this information is summarized below:

- Goto 2009 reported no significant differences in mean zscores or prevalence of stunting, underweight or wasting between the intervention groups, and the changes between intervals (eg between weeks 0 to 12,0 to 24,0 to 36,12 to 24 , etc) did not differ significantly between groups.

- Hadju 1997 reported no significant differences detected between treatment groups on basis of multivariate analyses.

- Le Huong 2007 reported no obvious trend in nutritional variable.

- Miguel 2004 (Cluster) demonstrated no significant effect on weight-for-age z score, height-for-age z score, and haemoglobin (only $4 \%$ of quasi-randomized participants followed up for haemoglobin outcome; the proportion followed up for nutritional outcomes is unclear).

- Stoltzfus 2001 reported that mebendazole significantly reduced the prevalence of mild wasting malnutrition in a subgroup of children aged $<30$ months.

- Stoltzfus 1997 (Cluster) reported that in a subgroup of under 10 year olds, the twice-yearly treated group experienced significantly greater weight gain $(\mathrm{kg})$ compared to control $(2.38$ (SE 0.08) versus 2.11 (SE 0.08), $\mathrm{P}<0.05$ ).

- Willett 1979 reported no statistical difference in growth rates in terms of height and weight between the two groups.

\section{Sensitivity analysis}

Including only trials with low risk of bias for allocation of concealment: no significant difference between treatment and con- 
trol groups was detected in weight or haemoglobin (Analysis 7.1; Analysis 7.2).

\section{Multiple doses, follow up of one year or more (comparison}

5).

No trials provided data for adverse events and school attendance (number of children dropping out).

For nutritional indicators, one study (Awasthi 2008 (Cluster)) showed a very large effect of $0.98 \mathrm{~kg}$ average difference in weight gain - with all the others showing small average non-significant differences of less than $0.2 \mathrm{~kg}$ (Analysis 5.1; 37,306 participants: 302 clusters and 1045 individually randomized participants, five trials). The high level of heterogeneity in the low prevalence group precludes meta-analysis. Of the five trials, all but one reported change in weight, and one reported end values only. For height, gain was similar in the deworming and control groups (mean difference $-0.26 \mathrm{~cm}, 95 \%$ CI -0.84 to $0.31 ; 6652$ participants: 174 clusters and 1045 individually randomized participants, three trials; Analysis 5.2).

For haemoglobin, deworming drugs did not increase haemoglobin compared with control (mean difference $0.00 \mathrm{~g} / \mathrm{dL}, 95 \% \mathrm{CI}$ -0.08 to 0.08 ; 1365 participants, two trials; Analysis 5.3).

For psychometric tests of cognition, Awasthi 2000 measured developmental status using the Denver Questionnaire, and Hall 2006 (Cluster) measured mathematics and Vietnamese test scores (Table 5). Both trials reported that they did not demonstrate an effect of deworming (3720 participants: 80 clusters and 1061 individually randomised participants).

For school attendance (days present at school), (Miguel 2004 (Cluster) Table 6; Analysis 5.4) reported on end values for attendance rates of children (1999, Group 1 versus Group 3), and found no significant effect (mean difference 5\%, 95\% CI -0.5 to 10.5 ; around 20,000 participants in 50 clusters). No baseline values were given so there is potential for any random differences between the groups to confound the end values.

For death, data from the DEVTA trial are awaited (DEVTA (unpublished)).

\section{Other data}

Four trials reported narratively on results, collated in Table 4. In summary:

- Awasthi 2008 (Cluster) reported 23 deaths during the study, 13 of which were in the usual care arm, and 10 were in the treatment arm.

- Lai 1995 found no difference in height or weight between treatment and control group at the end of two-year follow up.

- Hall 2006 (Cluster) reported no difference in final and change in height.

- Rousham 1994 (Cluster) ANOVAS of the change in zscores revealed no significant improvement with treatment.

\section{Sensitivity analysis}

Only one study had low risk of bias for allocation of concealment. In Hall 2006 (Cluster), no significant difference between treatment and control groups was detected in weight or height (Analysis 8.1; Analysis 8.2)

\section{I SCUSSION}

\section{Summary of main results}

\section{Selective deworming}

What is the effect of a dose of deworming drug given to children infected with worms in populations screened for intestinal helminths?

\section{It may increase weight gain}

In three trials, the meta-analysis shows a mean difference of 0.58 $\mathrm{kg}, 95 \%$ CI 0.40 to 0.76 ; 149 participants; low quality evidence; Analysis 1.1 .

\section{It may increase haemoglobin levels}

In two trials, the meta-analysis shows a mean difference of $0.37 \mathrm{~g} /$ $\mathrm{dL}, 95 \%$ CI 0.10 to 0.64 ; 108 participants, low quality evidence; Analysis 1.7.

\section{We do not know whether there is an effect on cognition}

Two trials reported on formal tests of intellectual development, using different outcomes. One trial did not report the outcome, and one trial reported and improvement in 3/10 tests of cognitive function in treated children: very low quality evidence; Table 5 . See Summary of findings (A), Table 7.

\section{Targeted deworming (one dose)}

\section{What is the effect of one dose of deworming drug given to all children living in an endemic area?}

\section{We do not know the effect on weight gain}

Deworming increased weight gain in two early trials, both carried out in the same location, but had no effect in seven trials 
conducted subsequently (3058 participants, nine trials; very low quality evidence; Analysis 3.1).

\section{It probably has no effect on haemoglobin levels}

In three trials, meta-analysis of haemoglobin difference was not significant (mean difference $0.06 \mathrm{~g} / \mathrm{dL}, 95 \% \mathrm{CI}-0.05$ to 0.17 ; 1005 participants, three trials moderate quality evidence; Analysis 3.6).

\section{It may have no effect on cognition}

One trial reported that deworming had either no effect or a negative effect on mental ability scores, but did not report the data, and one trial reported no effect (1361 participants, two trials, low quality evidence; Table 5 .

\section{It may have an effect on physical well being}

Two trials in the same high prevalence area of Kenya indicated benefit (Harvard Step Test mean difference 6.00, 95\% CI 4.31 to $7.69 ; 86$ participants, two trials, low quality evidence; Analysis 3.7)

See Summary of findings (B), Table 8.

\section{Targeted deworming (multiple doses)}

Eight of the 42 trials in this systematic review were cluster-RCTs and assessed multiple doses of deworming, and thus will potentially capture any population effects as a result of interrupting transmission.

What is the effect of multiple doses of deworming drugs to all children (follow up for up to a year)?

\section{It may have little or no effect on weight gain}

Deworming increased weight gain in one trial in a high prevalence location, decreased weight in one trial in a low prevalence area, but had no effect elsewhere (mean difference $0.06 \mathrm{~kg}$, 95\% CI 0.17 to $0.30 ; 2460$ participants, seven trials, low quality evidence; Analysis 4.1 )

\section{It may have little or no effect on haemoglobin levels.}

In four trials, the the meta-analysis shows a mean difference of $0.01 \mathrm{~g} / \mathrm{dL}, 95 \%$ CI -0.14 to 0.13 ; 807 participants, low quality evidence; Analysis 4.6.

\section{It may have no effect on cognition}

Three trials measured formal tests of intellectual development using different outcomes. All three trials reported no effect of deworming (30,571 participants; 75 clusters and 571 individually randomized participants low quality evidence: Table 5 .)

\section{It may have no effect on school attendance}

In two trials (30,243 participants, 75 clusters and 243 individually randomized participants), the mean difference was $4 \%$ higher attendance; 95\% CI -6 to 14, low quality evidence; Table 6 . See Summary of findings (C), Table 9.

What is the effect of multiple doses of deworming drugs to all children (follow up for over a year)?

This outcome will capture both deworming effects and any effects as a result of a potential reduction in transmission.

\section{It may have no effect on weight gain}

Deworming increased weight gain in one early trial in a low prevalence location, but had no effect in two subsequent trials in the same location, or in higher prevalence locations. Four out of five trials in this analysis were cluster-RCTs so capturing both the individual effect and any additional population level effect as a result of interrupting transmission (37,306 participants; 302 clusters and 1045 individually randomized participants, five trials, low quality evidence; Analysis 5.1)

\section{We do not know the effect on height gain}

In three trials, 6652 participants (174 clusters and 1045 individually randomized participants), the meta-analysis shows a mean difference of $-0.26 \mathrm{~cm}, 95 \% \mathrm{CI}-0.84$ to 0.31 , very low quality evidence; Analysis 5.2 .

\section{It may have no effect on haemoglobin levels}

In two trials, no difference was detected (mean $0.00 \mathrm{~g} / \mathrm{dL}, 95 \% \mathrm{CI}$ -0.08 to $0.08 ; 1365$ participants, two trials; low quality evidence; Analysis 5.3).

\section{It may have no effect on cognition}

Two trials reported on formal tests of intellectual development using different outcomes. Both trials reported no effect of deworming (3720 participants; 80 clusters and 1061 individually randomized participants; low quality evidence; Table 5 . 


\section{We do not know the effect on school attendance}

In one trial the mean difference in school attendance was 5\%, 95\% CI -0.5 to 10.5 (approximately 20,000 participants in 50 clusters, very low quality evidence; Table 6. .)

\section{For mortality}

A large trial of around one million children carried out in Lucknow was completed in 2005, but the results have not been published (DEVTA (unpublished).

See Summary of findings for the main comparison.

\section{Secondary outcomes}

For anthropometry, results were broadly consistent with the primary outcomes.

\section{Key messages}

Selective deworming may increase weight and haemoglobin in children confirmed to have worms on the basis of screening. Targeted deworming:

- has sometimes demonstrated a substantive early impact on weight gain (three trials), but in the majority of studies no effect has been shown on nutritional indicators;

- does not appear to have an effect on haemoglobin;

- may have an effect on physical well being;

- may have little or no effect on cognition;

- has not been shown to have a convincing effect on school attendance.

Mortality has been evaluated in a large trial completed in 2005 but this has not been published.

\section{Overall completeness and applicability of evidence}

Review question: The review indicates that screening and treating children infected with worms is promising, but the evidence base is small. However, when the intervention is used in the way the WHO currently recommends - targeted treatment to high risk populations - the effect is not so clear. An effect on weight was only seen in the two Stephenson trials assessing single-dose deworming in the same high prevalence school (Stephenson 1989; Stephenson 1993), where more than $90 \%$ of the children were infected with both hookworm and Trichuris, with heavy worm loads; and a cluster-RCT assessing long-term multiple dosing in a low-burden community undertaken in 1995 in India (Awasthi 2008 (Cluster)). What is also interesting in the two Stephenson studies in Kenya is that effects were seen after a single dose only, and the effects in the results of 'multiple-doses, outcomes less than one year of followup' can be mainly attributed to the effect seen after one dose of the deworming drug. Trials conducted subsequently, some of them large cluster-RCTs, have not demonstrated significant effects.

Ten trials measured intellectual development using formal tests. Only one of these trials demonstrated an effect on cognitive outcomes in 3/10 of the outcomes measured (Nokes 1992, Table 5, Table 6). The trials used a range of cognitive tests, which seems to reflect the difficulty inherent in choosing appropriate cognitive performance tests since there is no accepted test battery that can be applied across cultures and settings, and, as Miguel 2004 (Cluster) points out, the mechanisms for any putative effects are unknown. For school attendance, one quasi-randomized trial (Miguel 2004 (Cluster) reported an effect, which was apparent in only one of the two comparisons in up to a year of follow up, and not apparent in the one comparison after one year. Miguel 2004 (Cluster) measured attendance outcomes directly, unlike the other two trials (Simeon 1995; Watkins 1996) which measured attendance using school registers, which may be inaccurate in some settings. However, in Miguel 2004 (Cluster), the values for school attendance were end values and not corrected for baseline. Thus random differences in baseline attendance between the two groups could have confounded any result.

Completeness of the analysis: Critics of a previous version of this review (Dickson 2000a) stated that the impact must be considered stratified by the intensity of the infection (Cooper 2000; Savioli 2000). We have done this comprehensively in this edition and no clear pattern of effect has emerged. Other criticisms were that studies of short-term treatment cannot assess the long-term benefits of regular treatment (Bundy 2000). However, this analysis clearly examines long-term outcomes from trials conducted over the last 10 years.

Extrapolating evidence on selective deworming to targeted deworming: It could be argued that evidence of benefit seen in selective deworming provides an evidential base for targeted deworming, because the latter reduces costs due to diagnostic screening. However, the data on targeted deworming is limited (three small trials, $\mathrm{n}=149$ ); the quality of the evidence is 'low' for weight and haemoglobin; and the intervention itself is different. For example, having been screened, and then told they have worms, children are more likely to comply with treatment, and alter their behaviour. Choking: The WHO has raised concerns about the prevalence of choking in young children (aged between 1 to 3 years), with several pages of recommendations about how to administer albendazole in tablet form without children choking (http://www.who.int/ wormcontrol/newsletter/PPC8 eng.pdf) WHO 2007. Although common sense might suggest this is a rare occurrence, nevertheless some might argue there is a lack of evidence on the safety of administering deworming drugs to young children in tablet form in a community setting.

Polyparasitism: Individuals and communities are often infected with more than one helminth infection (Molyneux 2005) and the 
WHO is currently promoting the large-scale use of 'preventive chemotherapy'. This involves use of multiple anthelminthic drugs to treat a range of diseases, including STHs, schistosomiasis, and filariasis. Engels 2009 comment on the need for a comprehensive assessment of the impact of deworming. In the absence of such evidence, there is a need to demonstrate that a drug is effective against a particular parasite and to quantify its effects on humans before combining all the drugs into a basket treatment for all helminth infections, and assuming that all components are effective.

Secular trends in worm burden: Evidence of benefit of deworming on nutrition appear to depend on three studies, all conducted more than 15 years ago, with two from the same area of Kenya where nearly all children were infected with worms and worm burdens were high. Later and much larger studies have failed to demonstrate the same effects. It may be that over time the intensity of infection has declined, and that the results from these few trials are simply not applicable to contemporary populations with lighter worm burdens.

\section{Quality of the evidence}

Conducting field trials to test this intervention is complex and challenging, and researchers have worked hard to generate this body of research evidence. There is now a reasonable amount of evidence from studies in a range of settings, including high, moderate, and low burden areas. There have also been five studies (Analysis 5.1) that have assessed the long-term effects of multiple doses of deworming, four of which were cluster-RCTs. These are particularly important, because they can detect the 'real life' community level effects of treatment that include possible effects from a reduction in worm transmission (Bundy 2009).

We formally assessed the quality of the evidence using the standard GRADE methods. The quality of evidence was downgraded due to 'risk of bias', 'consistency' and 'indirectness'. For 'Risk of bias' the study designs were often wanting: only one trial out of 42 provided complete information to assure good methodological quality (Fox 2005). Allocation concealment was adequate in only eight trials (20\%), and 18 trials (42\%) included $90 \%$ of the randomized participants in the analysis. 'Consistency' relates to variation (unexplained heterogeneity) between the studies, which leads to uncertainty about the pooled estimates. There was marked heterogeneity (above $80 \%$ ) in the analyses of weight gain in unscreened populations, which was not explained by stratification of the results by worm prevalence. We had concerns about 'indirectness' in the context of the two Stephenson studies, which were carried out in the same school (Stephenson 1989; Stephenson 1993). Evidence from this very high worm burden population may not be applicable to other populations.

\section{Potential biases in the review process}

Publication bias: We are uncertain about the number of unpublished trials in this area. We know of two unpublished trials.

1. Hall 2006 (Cluster) is a large trial from Vietnam, with two years follow-up and did not demonstrate a significant difference in weight gain. Clustering was not taken into account in the analysis, which artificially narrows the CIs. In this update we included the results of this trial in meta-analysis by imputing an intra-cluster correlation coefficient, calculated from the adjusted data from Alderman 2006 (Cluster).

2. (DEVTA (unpublished); the world's largest ever RCT, which includes over a million children randomized in a cluster design with mortality as the primary outcome, remains unpublished six years after completion. We have corresponded with the senior author on several occasions. We also wrote a letter to the Lancet in June 2011, asking for publication of this important study. When this letter was accepted, the authors submitted the manuscript to the Lancet within a week, and we withdrew our letter. However, at the time of writing (October 2012) the paper remains unpublished.

Statistical errors in analysis: Of the eight cluster-RCTs, three did not take adequate account of cluster randomization (Alderman 2006 (Cluster), Hall 2006 (Cluster), Rousham 1994 (Cluster). This has a substantive impact on the interpretation of the trials. For example, the significant difference between intervention and control quoted on the cover of the BMJ for Alderman 2006 (Cluster), assumed 27,995 children had been individually randomized. When we clarified this with the authors, they provided the $B M J$ with a correction, which showed that no significant difference was detected in weight gain between intervention and control groups; this corrected result has been used in the meta-analysis in this study.

Nutritional outcomes: The included trials reported a range of nutritional status outcomes. For meta-analysis, we did not use nutritional data expressed as z-scores or percentile scores calculated on the basis of reference standards, or dichotomised $\mathrm{z}$ - or percentile scores (eg proportion stunted with height-for-age $\mathrm{z}$-score $<-2$ ). As these data were derived from the absolute values, we used these values for evidence of benefit. We knew the nutritional data would be captured in the absolute values and wanted to reduce selective reporting through collection of multiple variables from papers that are all derived from the same basic outcomes measured in the trial. We noted that in some trials there was a discrepancy between what was measured and what was reported; for example, Nokes 1992 recorded but did not report anthropometric data. This is a concern as it may indicate selective reporting. However, we have systematically reported all relevant outcomes not included in metaanalysis in Table 4.

Subgroup analyses: Some trials presented data from subgroups, selected on the basis of factors such as infection status (Beach 1999, Fox 2005, Greenberg 1981), location (Koroma 1996), age ( Stoltzfus 2001), frequency of treatment (Stoltzfus 1997 (Cluster)), and sex (Lai 1995). These comparisons were not randomized and have not been included in meta-analysis. Two trials, one of which 
one was a cluster-RCT, demonstrated improvements in nutritional outcomes in subgroup analyses (Stoltzfus 1997 (Cluster); Stoltzfus 2001). These data are reported in Table 4.

\section{Agreements and disagreements with other studies or reviews}

A review and meta-analysis by Hall et al (Hall 2008), funded by the World Bank, presents evidence in favour of an effect of deworming on weight gain (mean difference $0.21 \mathrm{~kg} 95 \% \mathrm{CI}$ 0.17 to $0.26,11$ studies). This analysis differs from our analyses of weight gain in a number of respects: it was not a protocol driven systematic review; the review excluded studies in lower prevalence areas $(<50 \%)$; pooled results were presented without exploration of significant heterogeneity; it combined trials that included both screened and unscreened children; it included trials excluded from our study on the basis of methodological quality; it included data from subgroup analyses; and included data unadjusted for cluster randomization.

The narrative review (Albonico 2008) explored the evidence for the impact of deworming on pre-school age children, and concluded that deworming has been shown to improve growth. Their analysis differed from our analyses in a number of ways: a different population was considered, although our review considers data from this subgroup; it was not a protocol driven systematic review; it included trials excluded from our review; it was a narrative summary rather than meta-analysis of data; it reported results from subgroup analyses; it reported point estimates without taking into account statistical significance; and it included data unadjusted for cluster randomization. The authors state: "A few studies have failed to show any impact of deworming on growth". This is at odds with our interpretation of the reliable randomized comparisons of nutritional outcomes in this review, which suggests that the majority of studies have failed to show an effect on nutrition. Gulani and colleagues undertook a systematic review of the effects of deworming on haemoglobin, and reported a marginal increase in mean values that could translate into small reduction $(5 \%$ to $10 \%$ ) in anaemia in a population with a high prevalence of intestinal helminths (Gulani 2007). This systematic review differs from our analysis of haemoglobin in a number of respects: it included studies in adults and pregnant women; included studies excluded from our study on the basis of methodological quality.

Other advocates of deworming, such as Bundy 2009, have argued that many of the underlying trials of deworming suffer from three critical methodological problems: treatment externalities in dynamic infection systems, inadequate measurement of cognitive outcomes and school attendance, and sample attrition. We agree with these points. However, externalities will be detected by large cluster-RCTs with a year or more follow up, and there are now five trials such as this included in this review.

\section{A U THORS'CONCLUSIONS}

\section{Implications for practice}

In examining the logic model in relation to targeted treatment (Figure 1), the evidence for the main effects is weak.

An effect on nutrition has only been demonstrated in the studies mentioned above; haemoglobin does not seem to improve; and cognition may not improve. Evidence for the mediating pathways is more sparse: there are no data on intellect, the data on physical well being are encouraging but from same studies showing substantive weight gain after a single dose of deworming drug (Stephenson 1989; Stephenson 1993); and the data on school attendance are insufficient to demonstrate an effect. Evidence of impact, in terms of school performance, is unknown; it was measured in one study but not reported by the comparison, and in terms of mortality, the data have been collected in one study, but not yet published.

In conclusion:

- Selective deworming - screening school children for intestinal helminths, and then treating those infected - may have some value in relation to weight and haemoglobin but the evidence base is small. The frequency of the screening and the effectiveness of subsequent doses is not known.

- There is insufficient evidence to recommend deworming drugs in targeted community programmes. The research has not shown an effect in most studies, although clearly there was an impact on weight gain reported in some older studies. Exactly what makes the intervention effective in these and not more recent studies is not clear. There is no direct evidence from trials to show that this depends on background helminth prevalence or intensity.

- It is probably misleading to justify deworming on the basis of effects on school performance or attendance. There is simply insufficient reliable information to know whether this is so.

- The evidence of deworming externalities - in terms of impacts on nutrition, haemoglobin and cognitive function in groups of people treated over a longer period of time - has not been clearly demonstrated in the studies included, although one study in India did show a large effect on weight.

- The WHO should review its guidelines and policies in this area, using currently recommended methods for guideline development, drawing on summaries such as this review and GRADE assessment in transparent decision making processes.

- Guideline developers and policy makers at global, national, and local levels should be allowed to consider the evidence carefully before committing to investing existing resources in delivering these programmes. Governments funding deworming programmes should consider current evidence before 
committing public funds to programmes where the evidence base from RCTs is so limited.

\section{Implications for research}

- Our view is that the tools exist to answer the research questions investigated in this review, particularly through clusterRCTs. Further research will be needed, however, if policymakers want to predict when it is worthwhile to implement deworming in a community, and to determine if and when treating all schoolchildren is effective.

- Further research is required before policymakers can be clear whether the intervention is of benefit or not on children's long-term nutrition and school performance.

- Further research is needed to determine the impact of deworming packages that include multiple interventions. These studies are important, but the results are more difficult to generalise to other settings since it is often not clear which component of an intervention is effective.

- Trial authors are encouraged to present trial data in line with CONSORT guidelines (Moher 2001).
- Authors of cluster-RCTs should report their data adjusting for design effects. We recommend trials that use current standards of design and are planned together to allow an individual patient data meta-analysis to correct for clustering and to help explore subgroup effects.

- Authors of trials, whether they are small or large, should publish the results of the trials irrespective of the findings, in line with the basic principles of research integrity.

\section{ACKNOWLEDGEMENTS}

The authors wish to thank all of those people who gave of their time and expertise to comment on this review. Thanks to the authors of the previous version of this Cochrane Review (Dickson 2000a; Taylor-Robinson 2007). We are grateful to Dr David Sinclair for his advice and assistance in preparing Summary of Findings tables.

This document is an output from a project funded by the UK Department for International Development (DFID) for the benefit of developing countries. The views expressed are not necessarily those of DFID.

\section{R E F E R E N C E S}

\section{References to studies included in this review}

\section{Adams 1994 \{published data only\}}

Adams EJ, Stephenson LS, Latham MC, Kinoti SN. Physical activity and growth of Kenyan school children with hookworm, Trichuris trichiura and Ascaris lumbricoides infections are improved after treatment with albendazole. Journal of Nutrition 1994;124(8):1199-206.

Alderman 2006 (Cluster) \{published data only\} Alderman H, Konde-Lule J, Sebuliba I, Bundy D, Hall A. Effect on weight gain of routinely giving albendazole to preschool children during child health days in Uganda: cluster randomised controlled trial. BMJ 2006;333(7559): 122.

Awasthi 2000 \{published and unpublished data\} Awasthi S, Pande VK, Fletcher RS. Effectiveness and costeffectiveness of albendazole in improving nutritional status of pre-school children in urban slums. Indian Pediatrics 2000;37(1):19-29.

Awasthi 2001 (Cluster) \{published data only\} Awasthi S, Pande VK. Six-monthly de-worming in infants to study effects on growth. Indian Journal of Pediatrics 2001;68(9):823-7.

Awasthi 2008 (Cluster) \{published data only\} Awasthi S, Peto R, Fletcher R, Glick H. Controlling parasitic infection in children under five years of age: giving albendazole in conjunction with an Indian government
Vitamin A supplement program. Treating parasitic infestations in children [Monograph No. 3]. Philadelphia: International Clinical Epidemiology Network (INCLEN), 1995.

* Awasthi S, Peto R, Pande VK, Fletcher RH, Read S, Bundy DA. Effects of deworming on malnourished preschool children in India: an open-labelled, cluster-randomized trial. PLoS Neglected Tropical Diseases 2008;2(4):e223.

Beach 1999 \{published data only\} Beach MJ, Streit TG, Addiss DG, Prospere R, Roberts JM, Lammie PJ. Assessment of combined ivermectin and albendazole for treatment of intestinal helminth and Wuchereria bancrofti infections in Haitian schoolchildren. American Journal of Tropical Medicine and Hygiene 1999;60 (3):479-86.

DEVTA (unpublished) \{unpublished data only\} Awasthi S, Peto R, Read S, Richards S, Pande V, Bundy DA and the DEVTA team. Population de-worming with 6-monthly albendazole: DEVTA, a cluster-randomised trial among 1 million preschool children in North India. [unpublished manuscript].

* University of Oxford and the United States Agency for International Development (USAID). Deworming and Enhanced Vitamin A Supplementation DEVTA Project (The DEVTA Trial). Registered September 13, 2005; Completed October 27, 2005; Clinical Trials Register Number NCT00222547:Information obtained from 
ClinicalTrials.gov on February 23, 2012.

Donnen 1998 \{published data only\}

Donnen P, Brasseur D, Dramaix M, Vertongen F, Zihindula M, Muhamiriza M, et al.Vitamin A Supplemenation but not deworming improves growth of malnourished preschool children in eastern Zaire. Journal of Nutrition 1998;128(8): $1320-7$.

\section{Dossa 2001 \{published data only\}}

Dossa RA, Ategbo EA, de Koning FL, van Raaij JM, Hautvast JG. Impact of iron supplementation and deworming on growth performance in preschool Beninese children. European Journal of Clinical Nutrition 2001;55(4): 223-8.

Fox 2005 \{published data only\} Fox LM, Furness BW, Haser JK, Desire D, Brissau JM, Milord MD, et al.Tolerance and efficacy of combined diethylcarbamazine and albendazole for treatment of Wuchereria bancrofti and intestinal helminth infections in Haitian children. American Journal of Tropical Medicine and Hygiene 2005;73(1):115-21.

Freij 1979a \{published data only\}

Freij L, Meeuwisse GW, Berg NO, Wall S, Gebre-Medhin M. Ascariasis and malnutrition. A study in urban Ethiopian children. American Journal of Clinical Nutrition 1979;32 (7):1545-53.

Freij 1979b \{published data only\}

Freij L, Meeuwisse GW, Berg NO, Wall S, Gebre-Medhin M. Ascariasis and malnutrition. A study in urban Ethiopian children. American Journal of Clinical Nutrition 1979;32 (7):1545-53.

Garg 2002 \{published data only\}

Garg R, Lee LA, Beach MJ, Wamae CN, Ramakrishnan U, Deming MS. Evaluation of the Integrated Management of Childhood Illness guidelines for treatment of intestinal helminth infections among sick children aged 2-4 years in western Kenya. Transactions of the Royal Society of Tropical Medicine and Hygiene 2002;96(5):543-8.

Goto 2009 \{published data only\}

Goto R, Mascie-Taylor CG, Lunn PG. Impact of antiGiardia and anthelminthic treatment on infant growth and intestinal permeability in rural Bangladesh: a randomised double-blind controlled study. Transactions of the Royal Society of Tropical Medicine and Hygiene 2009;103:520-9.

Greenberg 1981 \{published data only\}

Greenberg BL, Gilman RH, Shapiro H, Gilman JB, Mondal G, Maksud M, et al.Single dose piperazine therapy for Ascaris lumbricoides: an unsuccessful method of promoting growth. American Journal of Clinical Nutrition 1981;34 (11):2508-16.

Hadju 1996 \{published data only\}

Hadju V, Stephenson LS, Abadi K, Mohammed HO, Bowman DD, Parker RS. Improvements in appetite and growth in helminth-infected schoolboys three and seven weeks after a single dose of pyrantel pamoate. Parasitology 1996;113(Pt 5):497-504.
Hadju 1997 \{published data only\}

Hadju V, Satriono, Abadi K, Stephenson LS. Relationship between soil-transmitted helminthiases and growth in urban slum school children in Ujung Pandang, Indonesia. International Journal of Food Sciences and Nutrition 1997;48 (2):85-93.

Hall 2006 (Cluster) \{unpublished data only\} Hall A, Nguyen Bao Khanh L, Bundy D, Quan Dung N, Hong Son T, Lansdown R. A randomized trial of six monthly deworming on the growth and educational achievements of Vietnamese school children. Unpublished manuscript.

Kirwan 2010 \{published data only\}

Kirwan P, Asaolu SO, Molloy SF, Abiona TC, Jackson AL, Holland CV. Patterns of soil-transmitted helminth infection and impact of four monthly albendazole treatments in preschool children from semi-urban communities in Nigeria: a double-blind placebo-controlled randomised trial. BMC Infectious Diseases 2009;9:20.

* Kirwan P, Jackson AL, Asaolu SO, Molloy SF, Abiona TC, Bruce MC, et al.Impact of repeated four-monthly anthelmintic treatment on Plasmodium infection in preschool children: a double-blind placebo-controlled randomized trial. BMC Infectious Diseases 2010;10:277.

Kloetzel 1982 \{published data only\}

Kloetzel K, Merluzzi Filho TJ, Kloetzel D. Ascaris and malnutrition in a group of Brazilian children - a follow-up study. Journal of Tropical Pediatrics 1982;28(1):41-3.

Koroma 1996 \{published data only\} Koroma MM, Williams RA, de la Haye RR, Hodges M. Effects of albendazole on growth of primary school children and the prevalence and intensity of soil-transmitted helminths in Sierra Leone. Journal of Tropical Pediatrics 1996;42(6):371-2.

\section{Kruger 1996 \{published data only\}}

Kruger M, Badenhorst CJ, Mansvelt EPG, Laubscher JA, Benade AJS. The effect of iron fortification in a school feeding scheme and anthelminthic therapy on the iron status and growth of 6-8 year old school children. Food and Nutrition Bulletin 1996;17(1):11-21.

Kvalsvig 1991a \{published data only\} Kvalsvig JD, Cooppan RM, Connolly KJ. The effects of parasite infections on cognitive processes in children. Annals of Tropical Medicine and Parasitology 1991;85(5):551-68.

Lai 1995 \{published data only\}

Lai KP, Kaur H, Mathias RG, Ow-Yang CK. Ascaris and Trichuris do not contribute to growth retardation in primary school children. Southeast Asian Journal of Tropical Medicine and Public Health 1995;26(2):322-8.

Le Huong 2007 \{published data only\}

* Le Huong T, Brouwer ID, Nguyen KC, Burema J, Kok FJ. The effect of iron fortification and de-worming on anaemia and iron status of Vietnamese schoolchildren. British Journal of Nutrition 2007;97(5):955-62. 
Michaelsen 1985 \{published data only\}

Michaelsen KF. Hookworm infection in Kweneng District, Botswana. A prevalence survey and a controlled treatment trial. Transactions of the Royal Society of Tropical Medicine and Hygiene 1985;79(6):848-51.

Miguel 2004 (Cluster) \{published data only\} Miguel E, Kremer M. Worms: Identifying impacts on education and health in the presence of treatment externalities. Econometrica 2004;72(1):159-217.

Nga 2009 \{published data only\}

* Nga TT, Winichagoon P, Dijkhuizen MA, Khan NC, Wasantwisut E, Furr H, et al.Multi-micronutrient-fortified biscuits decreased prevalence of anemia and improved micronutrient status and effectiveness of deworming in rural Vietnamese school children. Journal of Nutrition 2009;139 (5):1013-21.

Nga TT, Winichagoon P, Dijkhuizen MA, Khan NC, Wasantwisut E, Wieringa FT. Decreased parasite load and improved cognitive outcomes caused by deworming and consumption of multi-micronutrient fortified biscuits in rural Vietnamese schoolchildren. American Journal of Tropical Medicine and Hygiene 2011;85(2):333-40.

Nokes 1992 \{published data only\}

Nokes C, Grantham-McGregor SM, Sawyer AW, Cooper ES, Bundy DA. Parasitic helminth infection and cognitive function in school children. Proceedings of The Royal Society of London. Series B: Biological sciences 1992;247(1319): 77-81.

* Nokes C, Grantham-McGregor SM, Sawyer AW, Cooper ES, Robinson BA, Bundy DA. Moderate to heavy infections of Trichuris trichiura affect cognitive function in Jamaican school children. Parasitology 1992;104(Pt 3):539-47.

Olds 1999 \{published data only\} Olds GR, King C, Hewlett J, Olveda R, Wu G, Ouma J, et al.Double-blind placebo-controlled study of concurrent administration of albendazole and praziquantel in school children with schistosomiasis and geohelminths. The Journal of Infectious Diseases 1999;179(4):996-1003.

Palupi 1997 \{published data only\}

Palupi L, Schultink W, Achadi E, Gross R. Effective community intervention to improve hemoglobin status in preschoolers receiving once-weekly iron supplementation. American Journal of Clinical Nutrition 1997;65(4):1057-61.

Rousham 1994 (Cluster) \{published data only\}

Northrop-Clewes CA, Rousham EK, Mascie-Taylor CN, Lunn PG. Anthelmintic treatment of rural Bangladeshi children: effect on host physiology, growth, and biochemical status. American Journal of Clinical Nutrition 2001;73(1): 53-60.

* Rousham EK, Mascie-Taylor CG. An 18-month study of the effect of periodic anthelminthic treatment on the growth and nutritional status of pre-school children in Bangladesh. Annals of Human Biology 1994;21(4):315-24.

Sarkar 2002 \{published data only\}

Sarkar NR, Anwar KS, Biswas KB, Mannan MA. Effect of deworming on nutritional status of ascaris infested slum children of Dhaka, Bangladesh. Indian Pediatrics 2002;39

(11):1021-6.

Simeon 1995 \{published data only\}

Gardner JM, Grantham-McGregor S, Baddeley A. Trichuris trichiura infection and cognitive function in Jamaican school children. Annals of Tropical Medicine and Parasitology 1996;90(1):55-63.

* Simeon DT, Grantham-McGregor SM, Callender JE, Wong MS. Treatment of Trichuris trichiura infections improves growth, spelling scores and school attendance in some children. Journal of Nutrition 1995;125(7):1875-83. Simeon DT, Grantham-McGregor SM, Wong MS. Trichuris trichiura infection and cognition in children: results of a randomized clinical trial. Parasitology 1995;110(Pt 4): 457-64.

Solon 2003 \{published data only\} Solon FS, Sarol JN, Bernardo ABI, Solon JA, Mehansho $\mathrm{H}$, Sanchez-Fermin LE, et al.Effect of a multiplemicronutrient-fortified fruit powder beverage on the nutrition status, physical fitness, and cognitive performance of schoolchildren in the Philippines. Food and Nutrition Bulletin 2003;24(4):S129-40.

Stephenson 1989 \{published data only\} Stephenson LS, Latham MC, Kinoti SN, Kurz KM, Brigham H. Improvements in physical fitness of Kenyan school boys infected with hookworm, Trichuris trichiura, and Ascaris lumbricoides following a single dose of albendazole. Transactions of the Royal Society of Tropical Medicine and Hygiene 1990;84(2):277-82.

* Stephenson LS, Latham MC, Kurz KM, Kinoti SN, Brigham $\mathrm{H}$. Treatment with a single dose of albendazole improves growth of Kenyan schoolchildren with hookworm, Trichuris trichiura, and Ascaris lumbricoides infections. American Journal of Tropical Medicine and Hygiene 1989;41 (1):78-87.

Stephenson 1993 \{published data only\}

Stephenson LS, Latham MC, Adams EJ, Kinoti SN, Pertet A. Physical fitness, growth and appetite of Kenyan school boys with hookworm, Trichuris trichiura and Ascaris lumbricoides infections are improved four months after a single dose of albendazole. Journal of Nutrition 1993;123 (6): 1036-46.

* Stephenson LS, Latham MC, Adams EJ, Kinoti SN, Pertet A. Weight gain of Kenyan school children infected with hookworm, Trichuris trichiura and Ascaris lumbricoides is improved following once- or twice-yearly treatment with albendazole. Journal of Nutrition 1993;123(4):656-65.

Stoltzfus 1997 (Cluster) \{published and unpublished data\} Stoltzfus RJ, Albonico M, Chwaya HM, Tielsch JM, Schulze KJ, Savioli L. Effects of the Zanzibar school-based deworming program on iron status of children. American Journal of Clinical Nutrition 1998;68(1):179-86.

* Stoltzfus RJ, Albonico M, Tielsch JM, Chwaya HM, Savioli L. School-based deworming program yields small improvement in growth of Zanzibari school children after one year. Journal of Nutrition 1997;127(11):2187-93. 
Stoltzfus 2001 \{published data only\}

Stoltzfus RJ, Chway HM, Montresor A, Tielsch JM, Jape

JK, Albonico M, et al.Low dose daily iron supplementation improves iron status and appetite but not anemia, whereas quarterly anthelminthic treatment improves growth, appetite and anemia in Zanzibari preschool children. Journal of Nutrition 2004;134(2):348-56.

* Stoltzfus RJ, Kvalsvig JD, Chwaya HM, Montresor A, Albonico M, Tielsch JM, et al.Effects of iron supplementation and anthelmintic treatment on motor and language development of preschool children in Zanzibar: double blind, placebo controlled study. BMJ 2001;323 (7326):1389-93.

Sur 2005 \{published data only\} Sur D, Saha DR, Manna B, Rajendran K, Bhattacharya SK. Periodic deworming with albendazole and its impact on growth status and diarrhoeal incidence among children in an urban slum of India. Transactions of the Royal Society of Tropical Medicine and Hygiene 2005;99(4):261-7.

Watkins 1996 \{published data only\}

Watkins WE, Cruz JR, Pollitt E. The effects of deworming on indicators of school performance in Guatemala. Transactions of the Royal Society of Tropical Medicine and Hygiene 1996;90(2):156-61.

* Watkins WE, Pollitt E. Effect of removing Ascaris on the growth of Guatemalan schoolchildren. Pediatrics 1996;97(6 Pt 1):871-6.

Willett 1979 \{published data only\}

Willett WC, Kilama WL, Kihamia CM. Ascaris and growth rates: a randomized trial of treatment. American Journal of Public Health 1979;69(10):987-91.

\section{References to studies excluded from this review}

\section{Araujo 1987 \{published data only\}}

Araujo RL, Araujo MB, Machado RD, Braga AA, Leite BV, Oliveira JR. Evaluation of a program to overcome vitamin $\mathrm{A}$ and iron deficiencies in areas of poverty in Minas Gerais, Brazil. Archivos Latinoamericanos de Nutricion 1987;37(1): 9-22.

Beasley 1999 \{published data only\} Beasley NM, Tomkins AM, Hall A, Kihamia CM, Lorri W, Nduma B, et al.The impact of population level deworming on the haemoglobin levels of schoolchildren in Tanga, Tanzania. Tropical Medicine and International Health 1999; 4(11):744-50.

Bhargava 2003 \{published data only\}

Bhargava A, Jukes M, Lambo J, Kihamia CM, Lorri W, Nokes C, et al.Anthelmintic treatment improves the hemoglobin and serum ferritin concentrations of Tanzanian schoolchildren. Food and Nutrition Bulletin 2003;24(4): 332-42.

Bhutta 2009 \{published data only\} Bhutta Z, Klemm R, Shahid F, Rizvi A, Rah JH, Christian P. Treatment response to iron and folic acid alone is the same as with multivitamins and/or anthelminthics in severely anemic 6- to 24-month-old children. The Journal of Nutrition 2009;139(8):1568-74.

Boivin 1993 \{published data only\}

Boivin MJ, Giordani B. Improvements in cognitive performance for schoolchildren in Zaire, Africa, following an iron supplement and treatment for intestinal parasites. Journal of Pediatric Psychology 1993;18(2):249-64.

Cooper 2006 \{published data only\} Cooper PJ, Chico ME, Vaca MG, Moncayo AL, Bland JM, Mafla E, et al.Effect of albendazole treatments on the prevalence of atopy in children living in communities endemic for geohelminth parasites: a cluster-randomised trial. Lancet 2006;367(9522):1598-603.

Cowden 2000 \{published data only\}

Cowden J, Hotez P. Mebendazole and albendazole treatment of geohelminth infections in children and pregnant women. Pediatric Infectious Disease Journal 2000;19(7):659-60.

Diouf 2002 \{published data only\} Diouf S, Diagne I, Moreira C, Signate SY, Faye O, Ndiaye $\mathrm{O}$, et al.Integrated treatment of iron deficiency, vitamin A deficiency and intestinal parasitic diseases: impact on Senegalese children's growth [Traitement integre de la carence en fer, de l'avitaminose A et des parasitoses intestinales: impact sur la croissance des enfants senegalais]. Archives de Pédiatrie 2002;9(1):102-3.

Evans 1986 \{unpublished data only\}

Evans J, Martin J, Mascie-Taylor CGN. The effect of periodic deworming with pyrantel pamoate on the growth and nutritional status of pre-school children in northern Bangladesh [Monograph No. 3]. London: Save the Children Fund, 1986.

Fernando 1983 \{published and unpublished data\} Fernando MA, Balasuriya, Somaratne. Effect of Ascaris lumbricoides infestation on growth of children. Indian Pediatrics 1983;20(10):721-31.

Forrester 1998 \{published data only\} Forrester JE, Bailar JC 3rd, Esrey SA, Jose MV, Castillejos BT, Ocampo G. Randomised trial of albendazole and pyrantel in symptomless trichuriasis in children. Lancet 1998;352(9134):1103-8.

\section{Friis 2003 \{published data only\}}

Friis H, Mwaniki D, Omondi B, Muniu E, Thiong'o F, Ouma J, et al.Effects on haemoglobin of multimicronutrient supplementation and multi-helminth chemotherapy: a randomized, controlled trial in Kenyan school children. European Journal of Clinical Nutrition 2003;57(4):573-9.

Gilgen 2001 \{published data only\}

Gilgen D, Mascie-Taylor CG. The effect of anthelmintic treatment on helminth infection and anaemia. Parasitology 2001;122(Pt 1):105-10.

Gilgen DD, Mascie-Taylor CG, Rosetta L. Intestinal helminth infections, anaemia and labour productivity of female tea pluckers in Bangladesh. Tropical Medicine and International Health 2001;6(6):449-57. 
Gupta 1982 \{published data only\}

Gupta MC, Urrutia JJ. Effect of periodic antascaris and antigiardia treatment on nutritional status of preschool children. American Journal of Clinical Nutrition 1982;36 (1):79-86.

Hadidjaja 1998 \{published data only\}

Hadidjaja P, Bonang E, Suyardi MA, Abidin SA, Ismid IS, Margono SS. The effect of intervention methods on nutritional status and cognitive function of primary school children infected with Ascaris lumbricoides. American Journal of Tropical Medicine and Hygiene 1998;59(5):791-5.

Hathirat 1992 \{published data only\}

Hathirat P, Valyasevi A, Kotchabhakdi NJ, Rojroongwasinkul N, Pollitt E. Effects of an iron supplementation trial on the Fe status of Thai schoolchildren. The British Journal of Nutrition 1992;68(1):245-52.

Jalal 1998 \{published data only\}

Jalal F, Nesheim MC, Agus Z, Sanjur D, Habicht JP. Serum retinol concentrations in children are affected by food sources of beta-carotene, fat intake, and anthelmintic drug treatment. American Journal of Clinical Nutrition 1998;68 (3):623-9.

Jinabhai 2001a \{published data only\} Jinabhai CC, Taylor M, Coutsoudis A, Coovadia HM, Tomkins AM, Sullivan KR. Epidemiology of helminth infections: implications for parasite control programmes, a South African perspective. Public Health Nutrition 2001;4 (6):1211-9.

Jinabhai 2001b \{published data only\} Jinabhai CC, Taylor M, Coutsoudis A, Coovadia HM, Tomkins AM, Sullivan KR. A randomized controlled trial of the effect of antihelminthic treatment and micronutrient fortification on health status and school performance of rural primary school children. Annals of Tropical Paediatrics 2001;21(4):319-33.

Karyadi 1996 \{published data only\}

Karyadi E, Gross R, Sastroamidjojo S, Dillon D, Richards AL, Sutanto I. Anthelminithic treatment raises plasma iron levels but dose not decrease the acute-phase response in Jakarta School children. Southeast Asian Journal of Tropical Medicine and Public Health 1996;27(4):742-53.

Krubwa 1974 \{published data only\}

Krubwa F, Gatti F, Lontie M, Nguete M, Vandepitte J, Thiepont D. Quarterly administration of mebendazole to suburban school children [Administration trimestrielle de mebendazole en milieu scolaire suburbain]. Medecine Tropicale 1974;34(5):679-87.

Kvalsvig 1991b \{published data only\} Kvalsvig JD, Cooppan RM, Connolly KJ. The effects of parasite infections on cognitive processes in children. Annals of Tropical Medicine and Parasitology 1991;85(5):551-68.

Latham 1990 \{published data only\}

Latham MC, Stephenson LS, Kurz KM, Kinoti SN. Metrifonate or praziquantel treatment improves physical fitness and appetite of Kenyan schoolboys with Schistosoma haematobium and hookworm infections. American Journal of Tropical Medicine and Hygiene 1990;43(2):170-9.

Marinho 1991 \{published data only\}

Marinho HA, Shrimpton R, Giugliano R, Burini RC. Influence of enteral parasites on the blood vitamin A levels in preschool children orally supplemented with retinol and/ or zinc. European Journal of Clinical Nutrition 1991;45(11): 539-44.

Mwaniki 2002 \{published data only\}

Mwaniki D, Omondi B, Muniu E, Thiong'o F, Ouma J, Magnussen P, et al.Effects on serum retinol of multimicronutrient supplementation and multi-helminth chemotherapy: a randomised, controlled trial in Kenyan school children. European Journal of Clinial Nutrition 2002; 56(7):666-73.

Pollitt 1991 \{published data only\}

Pollitt E, Wayne W, Perez-Escamilla R, Latham M, Stephenson LS. Double blind clinical trial on the effects of helminth infection on cognition. FASEB Journal 1991;5: A1081.

Rohner 2010 \{published data only\}

Rohner F, Zimmermann MB, Amon RJ, Vounatsou P, Tschannen AB, N'Goran EK, et al.In a randomized controlled trial of iron fortification, anthelmintic treatment and intermittent preventive treatment of malaria for anemia control in Ivorian children, only anthelmintic treatment shows modest benefit. Journal of Nutrition 2010;140(3): 635-41.

\section{Steinmann 2008 \{published data only\}}

Steinmann P, Zhou XN, Du ZW, Jiang JY, Xiao SH, Wu $\mathrm{ZX}$, et al.Tribendimidine and albendazole for treating soiltransmitted helminths, Strongyloides stercoralis and Taenia spp.: open-label randomized trial. PLoS Neglected Tropical Diseases 2008;2(10):e322.

Stephenson 1980 \{published data only\}

Stephenson LS, Crompton DW, Latham MC, Schulpen TW, Nesheim MC, Jansen AA. Relationships between Ascaris infection and growth of malnourished preschool children in Kenya. American Journal of Clinical Nutrition 1980;33(5):1165-72.

Stephenson 1985 \{published data only\} Stephenson LS, Latham MC, Kurz KM, Kinoti SN, Oduori ML, Crompton DW. Relationships of Schistosoma hematobium, hookworm and malarial infections and metrifonate treatment to hemoglobin level in Kenyan school children. American Journal of Tropical Medicine and Hygiene 1985;34(3):519-28.

Tanumihardjo 1996 \{published data only\} Tanumihardjo SA, Permaesih D, Muherdiyantiningsih, Rustan E, Rusmil K, Fatah AC, et al.Vitamin A status of Indonesian children infected with Ascaris lumbricoides after dosing with vitamin A supplements and albendazole. Journal of Nutrition 1996;126(2):451-7.

Tanumihardjo 2004 \{published data only\}

Tanumihardjo SA, Permaesih D, Muhilal. Vitamin A status and hemoglobin concentrations are improved in Indonesian 
children with vitamin A and deworming interventions.

European Journal of Clinical Nutrition 2004;58(9):1223-30.

Taylor 2001 \{published data only\}

Taylor M, Jinabhai CC, Couper I, Kleinschmidt I, Jogessar VB. The effect of different anthelmintic treatment regimens combined with iron supplementation on the nutritional status of schoolchildren in KwaZulu-Natal, South Africa: a randomized controlled trial. Transactions of the Royal Society of Tropical Medicine and Hygiene 2001;95(2):211-6.

Thein-Hlaing 1991 \{published data only\}

Thein-Hlaing, Thane-Toe, Than-Saw, Myat-Lay-Kyin, Myint-Lwin. A controlled chemotherapeutic intervention trial on the relationship between Ascaris lumbricoides infection and malnutrition in children. Transactions of the Royal Society of Tropical Medicine and Hygiene 1991;85(4): 523-8.

Uscátegui 2009 \{published data only\}

Uscátegui RM, Correa AM, Carmona-Fonseca J. Changes in retinol, hemoglobin and ferritin concentrations in Colombian children with malaria. Biomédica: revista del Instituto Nacional de Salud 2009;29(2):270-81.

Wright 2009 \{published data only\}

Wright VJ, Ame SM, Haji HS, Weir RE, Goodman D, Pritchard DI, et al.Early exposure of infants to GI nematodes induces $\mathrm{Th} 2$ dominant immune responses which are unaffected by periodic anthelminthic treatment. PLoS Neglected Tropical Diseases 2009;3(5):e433.

Yang 2003 \{published data only\}

Yang WP, Shao JO, Chen YJ. Effect of chemotherapeutic regimens on soil-transmitted nematode infections in areas with low endemicity. Zhongguo Ji Sheng Chong Xue Yu Ji Sheng Chong Bing Za Zhi 2003;21(2):128.

\section{References to ongoing studies}

\section{Alam 2006 \{unpublished data only\}}

Alam MM, Principal Investigator, ICDDR, B: Centre for Health and Population Research. Relative efficacy of two regimens of ante-helminthic treatment. ClinicalTrials.gov identifier: NCT00367627.

Elliot 2007 \{published data only\}

Elliott AM, Kizza M, Quigley MA, Ndibazza J, Nampijja M, Muhangi L, et al.The impact of helminths on the response to immunization and on the incidence of infection and disease in childhood in Uganda: design of a randomized, doubleblind, placebo-controlled, factorial trial of deworming interventions delivered in pregnancy and early childhood [ISRCTN32849447]. Clinical Trials (London, England). 2007; 4(1):42-57; ISSN: CN-00587053.

\section{Additional references}

\section{Albonico 2008}

Albonico M, Allen H, Chitsulo L, Engels D, Gabrielli AF, Savioli L. Controlling soil-transmitted helminthiasis in pre-school-age children through preventive chemotherapy. PLoS Neglected Tropical Diseases 2008;2(3):e126.

\section{Anderson 1991}

Anderson RM, May RM. Infectious diseases of humans: dynamics and control. Oxford: Oxford University Press, 1991.

Bethony 2006

Bethony J, Brooker S, Albonico M, Geiger SM, Loukas A, Diemert D, et al.Soil-transmitted helminth infections: ascariasis, trichuriasis, and hookworm. Lancet 2006;367 (9521):1521-32.

Bleakely 2004

Bleakley H. Disease and Development: Evidence from Hookworm Eradication in the American South. The Quarterly Journal of Economics 2007;122(1):73-117.

Bundy 2000 Bundy D, Peto R. Treatment for intestinal helminth infection. Studies of short term treatment cannot assess long term benefits of regular treatment. BMJ (Clinical research ed.) 2000;321(7270):1225.

Bundy 2009

Bundy DA, Kremer M, Bleakley H, Jukes MC, Miguel E. Deworming and development: asking the right questions, asking the questions right. PLoS Neglected Tropical Diseases 2009;3(1):e362.

\section{Callender 1998}

Callender JE, Walker SP, Grantham-McGregor SM, Cooper ES. Growth and development four years after treatment for the Trichuris dysentery syndrome. Acta Paediatrica 1998;87 (12):1247-9.

\section{Cappello 2004}

Cappello M. Global health impact of soil-transmitted nematodes. Pediatric Infectious Disease Journal 2004;23(7): 663-4.

\section{Chan 1997}

Chan, MS. The global burden of intestinal nematode infections - fifty years on. Parasitology Today 1997;13(11): 438-43.

Cochrane Collaboration 2002

Alderson P, Green S (editors). Meta-analysis of continuous data: Deciding on a change (from baseline). The Cochrane Collaboration: Open learning material for reviewers (Available at http://www.cochrane-net.org/openlearning/html/modA16.htm). 2002.

\section{Cooper 2000}

Cooper E. Treatment for intestinal helminth infection. Message does not follow from systematic review's findings. BMJ 2000;321(7270):1225-6.

Copenhagen Consensus Center 2012 Copenhagen Consensus Center. Copenhagen Consensus 2012. http://www.copenhagenconsensus.com/ Default.aspx?ID=1626 (accessed 22nd May 2012).

\section{Crompton 2000} Crompton DW. The public health importance of hookworm disease. Parasitology 2000;121 Suppl:S39-50.

Crompton 2003 Crompton DWT, Torlesse H, Hodges ME. Hookworm infection and iron status. In: Crompton DWT, Montresor 
A, Nesheim MC, Savioli L editor(s). Controlling disease due to helminth infections. Geneva: World Health Organization, 2003:23-32.

\section{Danso-Appiah 2008}

Danso-Appiah A, Utzinger J, Liu J, Olliaro P. Drugs for treating urinary schistosomiasis. Cochrane Database of Systematic Reviews 2008, Issue 3. [DOI: 10.1002/ 14651858.CD000053.pub2]

\section{de Silva 2003a}

de Silva NR. Impact of mass chemotherapy on the morbidity due to soil-transmitted nematodes. Acta Tropica 2003;86(2-3):197-214.

\section{de Silva 2003b}

de Silva NR, Brooker S, Hotez PJ, Montresor A, Engels D, Savioli L. Soil-transmitted helminth infections: updating the global picture. Trends in Parasitology 2003;19(12): 547-51.

\section{Deworm the World 2012}

Deworm the World. [The Evidence For School-Based Deworming]. http://www.dewormtheworld.org/?q=node/ 105 (accessed 22nd May 2012).

\section{Engels 2009}

Engels D, Savioli L. Evidence-based policy on deworming. PLoS Neglected Tropical Diseases 2009;3(1):e359.

\section{GiveWell 2011}

GiveWell 2011. Errors in DCP2 cost-effectiveness estimate for deworming. http://blog.givewell.org/2011/09/29/ errors-in-dcp2-cost-effectiveness-estimate-for-deworming/ (accessed 22nd May 2012).

\section{GRADE 2004}

Jan Brozek, Andrew Oxman, Holger Schunemann. GRADEpro. Version 3.2 for Windows. Jan Brozek, Andrew Oxman, Holger Schunemann, 2008.

\section{Gulani 2007}

Gulani A, Nagpal J, Osmond C, Sachdev HP. Effect of administration of intestinal anthelmintic drugs on haemoglobin: systematic review of randomised controlled trials. BMJ 2007;334(7603):1095.

\section{Haider 2009}

Haider BA, Humayun Q, Bhutta ZA. Effect of administration of antihelminthics for soil transmitted helminths during pregnancy. Cochrane Database of Systematic Reviews 2009, Issue 2. [DOI: 10.1002/ 14651858.CD005547.pub2]

\section{Hall 2008}

Hall A, Hewitt G, Tuffrey V, de Silva N. A review and metaanalysis of the impact of intestinal worms on child growth and nutrition. Maternal and Child Nutrition 2008;4(Suppl 1):118-236.

\section{Higgins 2011a}

Higgins JPT, Green S (editors). Cochrane Handbook for Systematic Reviews of Interventions. Version 5.1.0 [updated March 2011]. The Cochrane Collaboration, 2011. Available from www.cochrane-handbook.org.

\section{Higgins 2011b}

Higgins JP, Altman DG, Gotzsche PC, Juni P, Moher D, Oxman $\mathrm{AD}$, et al.The Cochrane Collaboration's tool for assessing risk of bias in randomised trials. BMJ 2011; Vol. 343:d5928.

\section{Horton 2003}

Horton J. Global anthelmintic chemotherapy programs: learning from history. Trends in Parasitology 2003;19(9): 405-9.

\section{Hotez 2006b}

Hotez P, Bundy D, Beegle K, Brooker S, Drake L, se Silva $\mathrm{N}$, et al.Helminth infections: Soil-transmitted helminth infections and schistosomiasis. Disease control priorities in developing countries. 2nd Edition. New York: Oxford University Press, 2006:467-82.

\section{Hotez 2009}

Hotez PJ, Fenwick A, Savioli L, Molyneux DH. Rescuing the bottom billion through control of neglected tropical diseases. Lancet 2009;373(9674):1570-5.

\section{Hotez 2011a}

Hotez PJ. New antipoverty drugs, vaccines, and diagnostics: a research agenda for the US President's Global Health Initiative (GHI). PLoS Neglected Tropical Diseases 2011;5 (5):e1133.

\section{Hotez 2011b}

Hotez PJ. Unleashing "Civilian Power": A new American diplomacy through neglected tropical disease control, elimination, research, and development. PLoS Neglected Tropical Diseases 2011;5(6):e1134.

\section{Jamison 2006}

Jamison DT, Breman JG, Measham AR, Alleyne G, Claeson M. Evans DB, et al (editors). Disease Control Priorities in Developing Countries. 2nd Edition. New York: Oxford University Press and the World Bank, 2006.

\section{Kvalsvig 2003}

Kvalsvig JD. Parasites, nutrition, child development and public policy. In: Crompton DWT, Montresor A, Nesheim MC, Savioli L editor(s). Controlling disease due to helminth infections. Geneva: World Health Organization, 2003: $55-65$.

Lefebvre 2011

Lefebvre C, Manheimer E, Glanville J. Chapter 6: Searching for studies. In: Higgins JPT, Green S editor(s). Cochrane Handbook for Systematic Reviews of Interventions Version 5.0.1 (updated March 2011). The Cochrane Collaboration, 2011.

\section{Moher 2001}

Moher D, Schulz KF, Altman DG for the CONSORT Group. The CONSORT statement: Revised recommendations for improving the quality of reports of parallel group randomized trials 2001. www.consortstatement.org/Statement/revisedstatement.htm (accessed 3 August 2005).

\section{Molyneux 2005} Molyneux DH, Hotez PJ, Fenwick A. "Rapid-impact interventions": How a policy of integrated control for 
Africa's neglected tropical diseases could benefit the poor. PLoS Medicine 2005;2(11):e336.

\section{Montresor 2002}

Montresor A, Crompton DWT, Gyorkos TW, Savioli L. Helminth control in school-age children: a guide for managers of control programmes. Geneva: World Health Organization, 2002.

Review Manager 5

The Nordic Cochrane Centre, The Cochrane Collaboration. Review Manager (RevMan). 5.1 for Windows. Copenhagen: The Nordic Cochrane Centre, The Cochrane Collaboration, 2011.

\section{Sakti 1999}

Sakti H, Nokes C, Hertanto WS, Hendratno S, Hall A, Bundy DA, et al.Evidence for an association between hookworm infection and cognitive function in Indonesian school children. Tropical Medicine \& International Health 1999;4(5):322-34.

\section{Savioli 2000}

Savioli L, Neira M, Albonico M, Beach MJ, Chwaya HM, Crompton DW, et al.Treatment for intestinal helminth infection. Review needed to take account of all relevant evidence, not only effects on growth and cognitive performance. BMJ 2000;321(7270):1226-7.

\section{Savioli 2002}

Savioli L, Montresor A, Albonico M. Control strategies. In: Holland CV, Kennedy MW editor(s). The geohelminths: Ascaris, Trichuris and Hookworm. Netherlands: Kluwer Academic Publishers, 2002:25-37.

\section{Stephenson 2000}

Stephenson LS, Latham MC, Ottesen EA. Malnutrition and parasitic helminth infections. Parasitology 2000;121 (Suppl):S23-38.

\section{Taylor-Robinson 2007}

Taylor-Robinson DC, Jones AP, Garner P. Deworming drugs for treating soil-transmitted intestinal worms in children: effects on growth and school performance. Cochrane Database of Systematic Reviews 2007, Issue 4. [DOI: 10.1002/14651858.CD000371.pub3]

\section{WHO 2002}

WHO Expert Committee on the Control of Schistosomiasis (2001: Geneva, Switzerland). Prevention and control of schistosomiasis and soil-transmitted helminthiasis: report of a WHO expert committee. WHO technical report series no. 912. Geneva: World Health Organization, 2002.

\section{WHO 2005}

World Health Organization. Strategy Development and Monitoring for Parasitic Diseases and Vector Control
Team. Deworming: The Millennium Development Goals. The evidence is in: deworming helps meet the Millennium Development Goals [WHO/CDS/CPE/PVC/2005.12]. Geneva: World Health Organization, 2005.

\section{WHO 2006a}

World Health Organization. WHO Essential Medicines Library. mednet3.who.int/emlib/ 2006 (accessed 13 June 2007).

\section{WHO 2006b}

WHO. Preventive chemotherapy in human helminthiasis: coordinated use of anthelminthic drugs in control interventions: a manual for health professionals and programme managers. Accessed at http://whqlibdoc.who.int/publications/2006/ 9241547103 eng.pdf. WHO, 2006.

\section{WHO 2007}

WHO. Action against worms. http://www.who.int/ wormcontrol/newsletter/PPC8 ${ }^{*}$ eng.pdf 2007.

\section{WHO 2010}

WHO. Monitoring drug coverage for preventive chemotherapy. http://whqlibdoc.who.int/publications/ 2010/9789241599993 eng.pdf 2010.

\section{World 2011}

World Bank. School Deworming http:// web.worldbank.org/WBSITE/EXTERNAL/TOPICS/ EXTHEALTHNUTRITIONANDPOPULATION/ EXTPHAAG/0,,contentMDK:20785786-menuPK: 1314819-pagePK:64229817-piPK:64229743-theSitePK: 672263,00.html(accessed 10th Jan 2012). 2011.

World Bank 1993

The World Bank. World Development Report 1993: Investing in health. Oxford: Oxford University Press, 1993.

\section{References to other published versions of this review}

\section{Dickson 2000a}

Dickson R, Awasthi S, Demellweek C, Williamson P. Anthelmintic drugs for treating worms in children: effects on growth and cognitive performance. Cochrane Database of Systematic Reviews 2000, Issue 2. [DOI: 10.1002/ 14651858.CD000371]

\section{Dickson 2000b}

Dickson R, Awasthi S, Williamson P, Demellweek C, Garner P. Effects of treatment for intestinal helminth infection on growth and cognitive performance in children: systematic review of randomised trials. BMJ 2000;320 (7251):1697-701.

* Indicates the major publication for the study 


\section{CHARACTERISTICS OF STUDIES}

\section{Characteristics of included studies [ordered by study ID]}

\section{Adams 1994}

Methods

Randomized controlled trial

Length of follow up: 2.25 months (9 weeks)

\begin{tabular}{|c|c|}
\hline Participants & $\begin{array}{l}\text { Number analysed for primary outcome: } 55 \\
\text { Inclusion criteria: children in nursery and standard } 1 \text { classes of Mvindeni Primary School } \\
\text { in Kwale, Kenya; }>500 \text { eggs/g hookworm or }>1000 \text { eggs/g Trichuris or Ascaris; pre- } \\
\text { pubertal; }>5 \text { years old } \\
\text { Exclusion criteria: severe anaemia (haemoglobin }<75 \mathrm{~g} / \mathrm{L} \text { ) }\end{array}$ \\
\hline Interventions & $\begin{array}{l}\text { Single dose versus placebo } \\
\text { 1. Albendazole: } 3 \text { x } 400 \mathrm{mg} \text { doses on } 3 \text { consecutive days } \\
\text { 2. Identical placebo } \\
\text { Treatment strategy: screened children then randomized and treated infected children }\end{array}$ \\
\hline Outcomes & $\begin{array}{l}\text { 1. Mean weight post-treatment } \\
\text { 2. Mean change in weight post-treatment } \\
\text { 3. Mean height post-treatment } \\
\text { 4. Mean change in height post-treatment } \\
\text { 5. Mean mid-upper arm circumference } \\
\text { 6. Mean change in mid-upper arm circumference } \\
\text { 7. Mean triceps skinfold thickness } \\
\text { 8. Mean change in triceps skinfold thickness } \\
\text { 9. Mean subscapular skinfold thickness } \\
\text { 10. Mean change in subscapular skinfold thickness } \\
\text { 11. Mean haemoglobin post-treatment } \\
\text { 12. Activity levels (a measure of gross motor activity of legs) } \\
\text { 13. Self rating of appetite } \\
\text { Not included in review: helminth prevalence and intensity (arithmetic and geometric } \\
\text { mean eggs/g); baseline and post-intervention values for arm muscle area and arm fat area; } \\
\text { z-scores for weight, height, weight-for-height, mid-upper-arm circumference, triceps } \\
\text { skinfold, subscapular, arm muscle, and arm fat area }\end{array}$ \\
\hline Notes & $\begin{array}{l}\text { Location: Kenya } \\
\text { Community category: } 1 \\
\text { Source of funding not stated }\end{array}$ \\
\hline
\end{tabular}

Risk of bias

\begin{tabular}{|c|c|c|}
\hline Bias & Authors' judgement & Support for judgement \\
\hline $\begin{array}{l}\text { Random sequence generation (selection } \\
\text { bias) }\end{array}$ & Unclear risk & $\begin{array}{l}\text { "Subjects were grouped according to sex } \\
\text { and paired according to hookworm inten- } \\
\text { sity,- one of each pair was allocated at ran- } \\
\text { dom to the albendazole-treated group or }\end{array}$ \\
\hline
\end{tabular}

Deworming drugs for soil-transmitted intestinal worms in children: effects on nutritional indicators, haemoglobin and school 
Adams 1994 (Continued)

the placebo group.” Method not reported

\begin{tabular}{l|ll}
\hline Allocation concealment (selection bias) & Unclear risk & No details reported. \\
\hline $\begin{array}{l}\text { Blinding (performance bias and detection } \\
\text { bias) }\end{array}$ & Unclear risk & No details reported. \\
All outcomes & & \\
\hline
\end{tabular}

Incomplete outcome data (attrition bias) Low risk All outcomes
One participant lost to follow-up in the placebo group, data for this subject were omitted from analyses. No details of reason for drop out. Inclusion of all randomized participants (number evaluable/number randomized): $98 \%(55 / 56)$

All stated outcomes reported.

No other obvious source of bias.

\section{Alderman 2006 (Cluster)}

Methods Cluster-randomized controlled trial

Method to adjust for clustering: multivariate regression models in Stata for table 3.

Primary outcome of weight gain not adjusted for clustering in BMJ paper

Cluster unit: parish

Average cluster size: 560

ICCs: not reported but calculated from adjusted ands unadjusted figures to be 0.01

Length of follow up: 3 years

Participants

Number analysed for primary outcome: 27,995 in 48 clusters

Age range: 1 to 7 years

Inclusion criteria: children aged 1 to 7 in 50 parishes in Uganda selected by the government on the basis that around $60 \%$ of children aged 5 to 10 years in these parishes were infected with intestinal nematodes

Exclusion criteria: sick children

Interventions

Multiple dose versus no treatment

1. Albendazole: $400 \mathrm{mg}$ tablet (Zentel, GSK) every 6 months, although in the event a year elapsed between the first and second treatment round; given in conjunction with a child health package including vaccinations, vitamin $\mathrm{A}$, and health promotion

2. Child health package including vaccinations, vitamin $A$, and health promotion

Treatment strategy: randomized and treated all children

Outcomes

1. Mean change in weight post-treatment

Notes

Location: Uganda

Community category: 2

Weight gain data taking into account the effects of cluster randomization provided by

Deworming drugs for soil-transmitted intestinal worms in children: effects on nutritional indicators, haemoglobin and school 
Alderman 2006 (Cluster) (Continued)

the author

Source of funding: the nutrition and early child development project, government of Uganda, the Institute of Public Health and the research committee of the World Bank

\section{Risk of bias}

\begin{tabular}{|c|c|c|}
\hline Bias & Authors' judgement & Support for judgement \\
\hline $\begin{array}{l}\text { Random sequence generation (selection } \\
\text { bias) }\end{array}$ & Low risk & $\begin{array}{l}\text { Coin toss "The randomization was done } \\
\text { by a member of the research team (HA) } \\
\text { by assigning numbers to all of the parishes } \\
\text { and converting these to base two and then } \\
\text { determining which of the parishes were to } \\
\text { be in the treatment by coin flips" }\end{array}$ \\
\hline Allocation concealment (selection bias) & Unclear risk & No details reported \\
\hline $\begin{array}{l}\text { Blinding (performance bias and detection } \\
\text { bias) } \\
\text { All outcomes }\end{array}$ & High risk & $\begin{array}{l}\text { None. "It was not possible for us to carry } \\
\text { out a double blind trial because of the scale } \\
\text { of the programme and because we aimed } \\
\text { to assess the effectiveness of giving albenda- } \\
\text { zole [...] during standard child health days } \\
\text { without any study specific inputs" }\end{array}$ \\
\hline $\begin{array}{l}\text { Incomplete outcome data (attrition bias) } \\
\text { All outcomes }\end{array}$ & High risk & $\begin{array}{l}75 \%(27,995 / 37,165) \text { of randomized par- } \\
\text { ticipants were evaluated }\end{array}$ \\
\hline Selective reporting (reporting bias) & Low risk & All stated outcomes reported. \\
\hline Other bias & Low risk & $\begin{array}{l}\text { Recruitment bias: low risk } \\
\text { Baseline imbalance: Characteristics similar } \\
\text { (low risk) } \\
\text { Loss of clusters: nil (low risk) } \\
\text { Incorrect analysis:primary outcome in pa- } \\
\text { per not adjusted for clustering, but was sub- } \\
\text { sequently corrected (low risk) } \\
\text { Comparability with RCTs randomizing in- } \\
\text { dividuals: unclear }\end{array}$ \\
\hline
\end{tabular}

\section{Awasthi 2000}

\begin{tabular}{ll}
\hline Methods & $\begin{array}{l}\text { Quasi-randomized controlled trial } \\
\text { Length of follow up: } 2 \text { years }\end{array}$ \\
\hline Participants & $\begin{array}{l}\text { Number analysed for primary outcome: } 1045 \\
\text { Age range: } 1.5 \text { to } 3.5 \text { years } \\
\text { Inclusion criteria: children living in } 32 \text { randomly selected urban slums; registered with } \\
\text { an Anganwadi worker (health worker); between } 1.5 \text { to } 3.5 \text { years of age }\end{array}$ \\
\hline
\end{tabular}

Deworming drugs for soil-transmitted intestinal worms in children: effects on nutritional indicators, haemoglobin and school 
Awasthi 2000 (Continued)

Exclusion criteria: none stated

\begin{tabular}{|c|c|}
\hline Interventions & $\begin{array}{l}\text { Multiple doses versus placebo } \\
\text { 1. Albendazole powder: } 600 \mathrm{mg} \text { every } 6 \text { months for } 2 \text { years } \\
\text { 2. Placebo: calcium powder } \\
\text { Treatment strategy: randomized and treated all children }\end{array}$ \\
\hline Outcomes & $\begin{array}{l}\text { 1. Mean weight post-treatment } \\
\text { 2. Mean change in weight post-treatment } \\
\text { 3. Mean height post-treatment } \\
\text { 4. Mean change in height post-treatment } \\
\text { 5. Developmental status (Denver Questionnaire): reported as proportion with normal } \\
\text { development } \\
\text { 6. Haemoglobin } \\
\text { Not included in review: prevalence of underweight and stunting over } 2 \text { years as defined by } \\
\text { z-scores, haemoglobin (visual colour estimation), stool examination (non-concentration } \\
\text { method), incidence of illness, and death }\end{array}$ \\
\hline Notes & $\begin{array}{l}\text { Location: Lucknow, India } \\
\text { Community category: } 3 \\
\text { Source of funding: International Clinical Epidemiology Network (INCLEN), Philadel- } \\
\text { phia, USA grant \#2002-94-623 under the Clinical Economics Small Grants Program }\end{array}$ \\
\hline
\end{tabular}

Risk of bias

\begin{tabular}{l|l|l}
\hline Bias & Authors' judgement & Support for judgement \\
\hline $\begin{array}{l}\text { Random sequence generation (selection } \\
\text { bias) }\end{array}$ & High risk & $\begin{array}{l}32 \text { Anganwadi centres randomly selected, } \\
\text { and then children allocated to a serial num- } \\
\text { ber; those with odd or non-zero ending } \\
\text { numbers were assigned to placebo }\end{array}$ \\
\hline $\begin{array}{l}\text { Allocation concealment (selection bias) } \\
\begin{array}{l}\text { Blinding (performance bias and detection } \\
\text { bias) } \\
\text { All outcomes }\end{array}\end{array}$ & High risk & Not concealed \\
\hline
\end{tabular}

Incomplete outcome data (attrition bias) Low risk All outcomes
9/610 children in the albendazole group and $7 / 451$ in the placebo group were lost to follow-up

Inclusion of all randomized participants (number evaluable/number randomized): 98\% (1045/1061)

\begin{tabular}{lll}
\hline Selective reporting (reporting bias) & Low risk & All stated outcomes reported \\
\hline Other bias & Low risk & No other obvious source of bias \\
\hline
\end{tabular}

Deworming drugs for soil-transmitted intestinal worms in children: effects on nutritional indicators, haemoglobin and school 


Cluster-randomized controlled trial
Method to adjust for clustering: cluster used as unit of analysis
Cluster unit: urban slums
Average cluster size: 13.5
ICCs: not reported.
Length of follow up: 1.5 years

Participants

Number analysed for primary outcome: 124 slums randomized containing 1672 children Inclusion criteria: clusters selected if they have functional community workers in slum areas of Lucknow; within each cluster, children recruited if aged between 0.5 and 1 year, on basis of survey register held by each worker of their particular area

Exclusion criteria: none stated

Interventions

Multiple doses versus placebo

1. Albendazole plus placebo: albendazole suspension (concentration not stated) (Zentel, SZB) every 6 months and 100,000 units of vitamin A every 6 months

2. Placebo: 100,000 units of vitamin A every 6 months

Treatment strategy: randomized and treated all children

Outcomes

1. Mean weight post-treatment

2. Mean change in weight post-treatment

3. Mean height post-treatment

4. Mean change in height post-treatment (not used due to question over quoted standard error)

Not included in review: stool smear for Ascaris prevalence on a subsample of the group; death rates

Notes

Location: Lucknow, India

Community category: 3

Means of cluster means used in analysis. The results (weight gain) in the abstract differ from the text

Source of funding: International Clinical Epidemiological Network (INCLEN) Inc, USA and Clinical Trials Unit (CTSU), Oxford, UK

Risk of bias

\begin{tabular}{l|ll}
\hline Bias & Authors' judgement & Support for judgement \\
\hline $\begin{array}{l}\text { Random sequence generation (selection } \\
\text { bias) }\end{array}$ & Unclear risk & Cluster-randomized trial, no further details \\
\hline $\begin{array}{l}\text { Allocation concealment (selection bias) } \\
\begin{array}{l}\text { Blinding (performance bias and detection } \\
\text { bias) } \\
\text { All outcomes }\end{array}\end{array}$ & Unclear risk & No details reported \\
\hline
\end{tabular}

Incomplete outcome data (attrition bias) Low risk All outcomes
Intention to treat analysis; $13.9 \%$ lost to follow-up in albendazole group and $16.2 \%$ 
Awasthi 2001 (Cluster) (Continued)

in the placebo group. Inclusion of all randomized participants (number evaluable/ number randomized): 83\% (1672/2010)

\begin{tabular}{|c|c|c|}
\hline Selective reporting (reporting bias) & Low risk & All stated outcomes reported \\
\hline Other bias & Low risk & $\begin{array}{l}\text { Recruitment bias: Unclear (Not known if } \\
\text { children shift clinics in the light of the in- } \\
\text { tervention) } \\
\text { Baseline imbalance: Characteristics similar } \\
\text { (low risk) } \\
\text { Loss of clusters: No loss reported (low risk) } \\
\text { Incorrect analysis: Cluster adjusted (low } \\
\text { risk) } \\
\text { Comparability with RCTs randomising in- } \\
\text { dividuals: low (Analysis } 5.1 \text { and Analysis } \\
5.2 \text { ) }\end{array}$ \\
\hline
\end{tabular}

\section{Awasthi 2008 (Cluster)}

\begin{tabular}{|c|c|}
\hline Methods & $\begin{array}{l}\text { Cluster-quasi-randomized controlled trial } \\
\text { Method to adjust for clustering: cluster used as unit of analysis } \\
\text { Cluster unit: urban slum } \\
\text { Average cluster size: } 74 \\
\text { ICCs: not reported. } \\
\text { Length of follow up: } 2 \text { years }\end{array}$ \\
\hline Participants & $\begin{array}{l}\text { Number analysed for primary outcome: } 3712 \\
\text { Age range: } 1 \text { to } 4 \text { years } \\
\text { Inclusion criteria: children aged } 1 \text { to } 4 \text { from } 50 \text { urban slums in Lucknow selected on the } \\
\text { basis of geographic convenience } \\
\text { Exclusion criteria: none stated }\end{array}$ \\
\hline Interventions & $\begin{array}{l}\text { Multiple doses versus placebo } \\
\text { 1. Albendazole plus placebo: } 400 \mathrm{mg} \text { albendazole plus } 2 \mathrm{~mL} \text { vitamin A every } 6 \text { months } \\
\text { 2. Placebo: } 2 \mathrm{~mL} \text { vitamin A every } 6 \text { months } \\
\text { Treatment strategy: randomized and treated all children }\end{array}$ \\
\hline Outcomes & $\begin{array}{l}\text { 1. Mean change in weight post-treatment } \\
\text { 2. Mean change in height post-treatment }\end{array}$ \\
\hline Notes & $\begin{array}{l}\text { Location: Lucknow, India } \\
\text { Community category: } 3 \\
\text { Trail carried out in } 1995 \text { and published in } 2008 \text {. } \\
\text { Weight data taken from Awasthi } 2008 \text { published document. Height data from INCLEN } \\
1995 \text { monograph. Means of cluster means used in analysis; details of correspondence } \\
\text { from previous review suggest that trial was ongoing; data for 3-year follow up are provided } \\
\text { from R Dickson's correspondence with the author for the Dickson 2000a Cochrane }\end{array}$ \\
\hline
\end{tabular}

Deworming drugs for soil-transmitted intestinal worms in children: effects on nutritional indicators, haemoglobin and school 
Review, but the loss to follow up is very high: only $24 \%$ analysed

Source of funding: Clinical Trial Service Unit (CTSU), University of Oxford, United Kingdom, and co-funded by the International Clinical Epidemiology Network Inc. , Philadelphia, United States of America. Albendazole was donated by SmithKline Beecham (now GlaxoSmithKline)

\section{Risk of bias}

\begin{tabular}{|c|c|c|}
\hline Bias & Authors' judgement & Support for judgement \\
\hline $\begin{array}{l}\text { Random sequence generation (selection } \\
\text { bias) }\end{array}$ & High risk & $\begin{array}{l}\text { Quasi-randomized: "Random allocation } \\
\text { was done by SA, listing the anganwadi cen- } \\
\text { ters of each slum area serially in alphabetical } \\
\text { order, numbering them from } 1 \text { to } 50 \text {, and } \\
\text { then generating a single random number } \\
\text { by computer that allocated either all odd or } \\
\text { all even numbers to a specific intervention } \\
\text { type." }\end{array}$ \\
\hline Allocation concealment (selection bias) & High risk & Not concealed \\
\hline $\begin{array}{l}\text { Blinding (performance bias and detection } \\
\text { bias) } \\
\text { All outcomes }\end{array}$ & High risk & $\begin{array}{l}\text { Cluster RCT with health staff and partic- } \\
\text { ipants knowing which group they were al- } \\
\text { located to }\end{array}$ \\
\hline $\begin{array}{l}\text { Incomplete outcome data (attrition bias) } \\
\text { All outcomes }\end{array}$ & Low risk & $\begin{array}{l}1852 / 1968 \text { children in the treatment group } \\
\text { completed all follow-up visits; } 1860 / 1967 \\
\text { children in the usual care group completed } \\
\text { all follow-up visits. Inclusion of all random- } \\
\text { ized participants (number evaluable/num- } \\
\text { ber randomized): } 94 \%(3712 / 3935)\end{array}$ \\
\hline Selective reporting (reporting bias) & Low risk & All stated outcomes reported \\
\hline Other bias & Low risk & $\begin{array}{l}\text { Recruitment bias: Unclear (Not known if } \\
\text { children shift clinics in the light of the in- } \\
\text { tervention) } \\
\text { Baseline imbalance: Unclear } \\
\text { Loss of clusters: Low (none reported) } \\
\text { Incorrect analysis: Cluster adjusted (low } \\
\text { risk) } \\
\text { Comparability with RCTs randomising } \\
\text { individuals: unclear (Analysis } 5.1 \text { and } \\
\text { Analysis 5.2) }\end{array}$ \\
\hline
\end{tabular}




\begin{tabular}{|c|c|}
\hline Methods & $\begin{array}{l}\text { Randomized controlled trial } \\
\text { Length of follow up: } 4 \text { months }\end{array}$ \\
\hline Participants & $\begin{array}{l}\text { Number analysed for primary outcome: } 853 \\
\text { Inclusion criteria: all children attending } 5 \text { schools (grades } 1 \text { to } 4 \text { ) } \\
\text { Exclusion criteria: haematocrit }<22 \%\end{array}$ \\
\hline Interventions & $\begin{array}{l}\text { Single dose versus placebo } \\
\text { 1. Albendazole: } 400 \mathrm{mg} \text { (SmithKlineBeecham, Philadelphia or generic BeltaPharm, Mi- } \\
\text { lan) } \\
\text { 2. Ivermectin: } 200 \text { to } 400 \mu \mathrm{g} / \mathrm{kg} \text { (mean } 282.7 \mu \mathrm{g} / \mathrm{kg} \text { ) (Merck, West Point, PA) } \\
\text { 3. Albendazole plus ivermectin } \\
\text { 4. Placebo: } 250 \mathrm{mg} \text { vitamin C } \\
\text { Treatment strategy: randomized and treated all children }\end{array}$ \\
\hline Outcomes & $\begin{array}{l}\text { 1. Height } \\
\text { 2. Weight } \\
\text { 3. Stool examination for helminth prevalence and intensity (geometric mean) } \\
\text { 4. Haematocrit }\end{array}$ \\
\hline Notes & $\begin{array}{l}\text { Location: Haiti } \\
\text { Community category: } 3 \\
\text { Results presented in a stratified analysis as per individual infection: disaggregated results } \\
\text { not presented; measures of error not given in tables } \\
\text { Source of funding: USAID. } \\
\text { Invermectin provided by Philippe Gaxotte (Merck, Inc.) and albendazole by John Horton } \\
\text { (SmithKline Beecham) }\end{array}$ \\
\hline
\end{tabular}

\section{Risk of bias}

\begin{tabular}{|c|c|c|}
\hline Bias & Authors' judgement & Support for judgement \\
\hline $\begin{array}{l}\text { Random sequence generation (selection } \\
\text { bias) }\end{array}$ & Low risk & Random number table \\
\hline Allocation concealment (selection bias) & Unclear risk & No details reported \\
\hline $\begin{array}{l}\text { Blinding (performance bias and detection } \\
\text { bias) } \\
\text { All outcomes }\end{array}$ & Low risk & $\begin{array}{l}\text { Participants, provider, and assessors were } \\
\text { blind }\end{array}$ \\
\hline $\begin{array}{l}\text { Incomplete outcome data (attrition bias) } \\
\text { All outcomes }\end{array}$ & Low risk & $\begin{array}{l}29 / 229 \text { were lost to follow-up in the } \\
\text { placebo group and } 25 / 244 \text { were lost to fol- } \\
\text { low-up in the albendazole group. Inclu- } \\
\text { sion of all randomized participants (num- } \\
\text { ber evaluable/number randomized): } 88.4 \% \\
(853 / 965)\end{array}$ \\
\hline
\end{tabular}

\begin{tabular}{l|l|l}
\hline Selective reporting (reporting bias) & Low risk & All stated outcomes reported
\end{tabular}


Beach 1999 (Continued)

\begin{tabular}{l|l} 
Other bias $\quad$ Low risk $\quad$ No other obvious source of bias
\end{tabular}

DEVTA (unpublished)

\begin{tabular}{|c|c|}
\hline Methods & $\begin{array}{l}\text { Cluster-randomized controlled trial } \\
\text { Method to adjust for clustering: cluster used as unit of analysis ('means of block-specific } \\
\text { numbers of deaths per AWC') } \\
\text { Cluster unit: a block of 10,000-20,000 children } \\
\text { Average cluster size: } 9259 \text { approximately (under-5 population } 1 \text { million/108 clusters) } \\
\text { ICCs: not reported. } \\
\text { Length of follow up: } 5 \text { years }\end{array}$ \\
\hline Participants & $\begin{array}{l}\text { Number analysed for primary outcome: } 8338 \text { ICDS-staffed preschool centres in } 72 \\
\text { administrative blocks (under-5 population } 1 \text { million) } \\
\text { Inclusion criteria: All preschool children then aged } 1-6 \cdot 0 \text { in } 72 \text { participating blocks near } \\
\text { Lucknow that were considered to have a well-functioning ICDS system with willing } \\
\text { district and block directors and with paid workers in most of the block's anganwadi } \\
\text { centres } \\
\text { Exclusion criteria: severe anaemia (haemoglobin }<75 \mathrm{~g} / \mathrm{L} \text { ) }\end{array}$ \\
\hline Interventions & $\begin{array}{l}\text { Multiple doses versus placebo } \\
\text { Factorial design in four arms: } \\
\text { 1. Usual care - no placebo; } \\
\text { 2. 6-monthly vitamin A [for } 5 \text { years]; } \\
\text { 3. 6-monthly } 400 \mathrm{mg} \text { albendazole; } \\
\text { 4. Both 6-monthly vitamin A and 6-monthly } 400 \mathrm{mg} \text { albendazole }\end{array}$ \\
\hline Outcomes & 1. Mortality \\
\hline Notes & $\begin{array}{l}\text { Location: Lucknow, India } \\
\text { Community category: } 3 \\
\text { Annually about } 30 \text { non-randomly selected preschool children were surveyed for growth, } \\
\text { nutritional and morbidity outcomes from one randomly selected AWC per block (10, } \\
000 \text { to } 20,000 \text { children in about } 120 \text { AWCs per block) } \\
\text { Source of funding: UK Medical Research Council, USAID OMNI project, World Bank. } \\
\text { Albendazole (Zentel) was donated by SmithKlineBeecham }\end{array}$ \\
\hline
\end{tabular}

Risk of bias

\begin{tabular}{lll}
\hline Bias & Authors' judgement & Support for judgement \\
\hline $\begin{array}{l}\text { Random sequence generation (selection } \\
\text { bias) }\end{array}$ & Unclear risk & $\begin{array}{l}\text { "randomly allocated"; "Randomisation (in } \\
\text { Oxford) was stratified in groups of } 4 \text { neigh- } \\
\text { bouring blocks, where possible in the same } \\
\text { district." }\end{array}$ \\
\hline Allocation concealment (selection bias) & Unclear risk & See above
\end{tabular}

Deworming drugs for soil-transmitted intestinal worms in children: effects on nutritional indicators, haemoglobin and school 
DEVTA (unpublished) (Continued)

\begin{tabular}{|c|c|c|}
\hline $\begin{array}{l}\text { Blinding (performance bias and detection } \\
\text { bias) } \\
\text { All outcomes }\end{array}$ & Unclear risk & All cause mortality is the outcome \\
\hline $\begin{array}{l}\text { Incomplete outcome data (attrition bias) } \\
\text { All outcomes }\end{array}$ & Low risk & $\begin{array}{l}89 \text { AWCs }(2 \%) \text { in the albendazole block } \\
\text { lost to follow-up, } 86 \text { AWCs ( } 2 \% \text { ) in the } \\
\text { placebo block lost to follow-up. "Loss to } \\
\text { follow-up is defined by having only } 1-6 \\
\text { follow-up visits (mean only } 3 \text {, as against } \\
12 \text { in the included AWCs), and was gener- } \\
\text { ally because the AWC had ceased to func- } \\
\text { tion." Inclusion of all randomized partici- } \\
\text { pants (number evaluable/number random- } \\
\text { ized): Denominator for mortality was all } \\
\text { children. A subset of } 5165 \text { children were } \\
\text { assessed for other outcomes }\end{array}$ \\
\hline Selective reporting (reporting bias) & Low risk & Mortality is the single outcome for this trial \\
\hline Other bias & Low risk & $\begin{array}{l}\text { Recruitment bias: unclear. } \\
\text { Baseline imbalance: unclear. } \\
\text { Loss of clusters: unclear. } \\
\text { Incorrect analysis: Cluster adjusted (low } \\
\text { risk). } \\
\text { Comparability with RCTs randomising in- } \\
\text { dividuals: unclear. }\end{array}$ \\
\hline
\end{tabular}

Donnen 1998

\begin{tabular}{ll}
\hline Methods & $\begin{array}{l}\text { Randomized controlled trial } \\
\text { Length of follow up: } 1 \text { year }\end{array}$ \\
\hline Participants & $\begin{array}{l}\text { Number analysed for primary outcome: } 222 \\
\text { Inclusion criteria: children aged } 0 \text { to } 72 \text { months eligible on discharge from hospital where } \\
\text { primary cause for admission is malnutrition } \\
\text { Exclusion criteria: none stated }\end{array}$ \\
\hline
\end{tabular}

Interventions

Multiple doses versus placebo and no treatment

1. Mebendazole: $500 \mathrm{mg}$ at start and every 3 months

2. Placebo: $60 \mathrm{mg}$ vitamin $\mathrm{A}$ at start and 3 months

3. No treatment

Treatment strategy: randomized and treated all children

Outcomes

1. Mean weight post-treatment

2. Mean change in weight post-treatment

3. Mean height post-treatment

4. Mean change in height post-treatment

5. Mean mid-upper arm circumference

Deworming drugs for soil-transmitted intestinal worms in children: effects on nutritional indicators, haemoglobin and school 
6. Mean change in mid-upper arm circumference

Not included in review: vitamin A levels; z-scores for height-for-age, weight-for-age, weight-for-height (NCHS reference); egg counts (eggs/g: Kato Katz method)

\begin{tabular}{ll} 
Notes & Location: Zaire \\
Community category: 3 \\
Unadjusted data not provided in original paper; results of multiple-regression models \\
presented on basis of stratifications into vitamin A status and sex; results in meta-anal- \\
ysis from R Dickson's correspondence with author when preparing the Dickson $2000 \mathrm{a}$ \\
Cochrane Review. \\
$\begin{array}{l}\text { Source of funding: Fonds de la Recherche Scientifique et Medicale (FRSM), contract 3. } \\
4505.94 \text { and the David and Alice Van Buuren Foundation }\end{array}$ \\
\hline
\end{tabular}

\section{Risk of bias}

\begin{tabular}{l|ll}
\hline Bias & Authors' judgement & Support for judgement \\
\hline $\begin{array}{l}\text { Random sequence generation (selection } \\
\text { bias) }\end{array}$ & Unclear risk & “randomized”, no further details reported. \\
\hline $\begin{array}{l}\text { Allocation concealment (selection bias) } \\
\begin{array}{l}\text { Blinding (performance bias and detection } \\
\text { bias) } \\
\text { All outcomes }\end{array}\end{array}$ & Unclear risk & No details reported. \\
\hline
\end{tabular}

Incomplete outcome data (attrition bias) Low risk All outcomes
Overall, $6 \%$ of children were lost to followup, with approximately equal proportions from each group. During the follow- up period, 25 children died. The final sample included 311 children Inclusion of all randomized participants (number evaluable/ number randomized): $86 \%(311 / 358)$

All stated outcomes reported.

Selective reporting (reporting bias)

Low risk

No other obvious source of bias.

\section{Dossa 2001}

Methods
Randomized controlled trial

Length of follow up: 10 months

Number analysed for primary outcome: 65

Inclusion criteria: children aged 3 to 5 years; not acutely unwell

Exclusion criteria: none stated 
Dossa 2001 (Continued)

\begin{tabular}{|c|c|}
\hline Interventions & $\begin{array}{l}\text { Multiple doses versus placebo } \\
\text { 1. Albendazole plus iron: } 200 \mathrm{mg} \text { albendazole per day for } 3 \text { consecutive days repeated } 1 \\
\text { month later plus iron } \\
\text { 2. Placebo plus iron } \\
\text { 3. Albendazole: } 200 \mathrm{mg} \text { per day for } 3 \text { consecutive days repeated } 1 \text { month later plus iron } \\
\text { placebo } \\
\text { 4. Placebo plus placebo } \\
\text { Treatment strategy: randomized and treated all children }\end{array}$ \\
\hline Outcomes & $\begin{array}{l}\text { 1. Mean change in weight post-treatment } \\
\text { 2. Mean change in height post-treatment } \\
\text { 3. Mean change in mid-upper arm circumference } \\
\text { 4. Mean change in triceps skinfold thickness } \\
\text { 5. Mean haemoglobin post-treatment } \\
\text { Not included in review: weight-for-height z-score and height-for-age z-score at } 3 \text { and } 10 \\
\text { months (both after } 2 \text { doses) } \\
\text { Measured but not reported: z-scores for weight-for-height, height for age using NCHS } \\
\text { reference data; egg count (arithmetic and geometric mean); prevalence, intensity; food } \\
\text { intake over } 3 \text { days in subset at end of trial (not at baseline) }\end{array}$ \\
\hline Notes & $\begin{array}{l}\text { Location: Benin } \\
\text { Community category: } 2 \\
\text { Source of funding: The Nestle Foundation (Lausanne, Switzerland). Smithkline Beecham } \\
\text { provided the deworming and placebo tablets }\end{array}$ \\
\hline
\end{tabular}

Risk of bias

\begin{tabular}{|c|c|c|}
\hline Bias & Authors' judgement & Support for judgement \\
\hline $\begin{array}{l}\text { Random sequence generation (selection } \\
\text { bias) }\end{array}$ & Unclear risk & $\begin{array}{l}\text { "Randomly assigned", no further details } \\
\text { provided }\end{array}$ \\
\hline Allocation concealment (selection bias) & Unclear risk & No details reported \\
\hline $\begin{array}{l}\text { Blinding (performance bias and detection } \\
\text { bias) } \\
\text { All outcomes }\end{array}$ & Unclear risk & $\begin{array}{l}\text { "Double-blind", no further details pro- } \\
\text { vided }\end{array}$ \\
\hline
\end{tabular}

Incomplete outcome data (attrition bias) High risk All outcomes

$175 / 177$ children finished the study, but 140 were included in the final analysis: "One child was treated for severe worm infection and 34 children received other pills during the study period (iron, vitamins/minerals or deworming pills that were not provided by our research team)." Inclusion of all randomized participants (number evaluable/number randomized): $79 \%$ $(140 / 177)$ 
Dossa 2001 (Continued)

\begin{tabular}{l|ll}
\hline Selective reporting (reporting bias) & Low risk & All stated outcomes reported \\
\hline Other bias & High risk & No obvious other source of bias \\
\hline
\end{tabular}

\section{Fox 2005}

Methods $\quad$ Randomized controlled trial

Length of follow up: 6 months

\begin{tabular}{|c|c|}
\hline Participants & $\begin{array}{l}\text { Number analysed for primary outcome: } 626 \\
\text { Inclusion criteria: children aged } 5 \text { to } 11 \text { years attending any of } 12 \text { primary schools in } \\
\text { Haiti where no other deworming activity was taking place } \\
\text { Exclusion criteria: none stated }\end{array}$ \\
\hline Interventions & $\begin{array}{l}\text { Single dose versus placebo: } \\
\text { 1. Albendazole } 400 \mathrm{mg} \text { plus placebo }(250 \mathrm{mg} \text { vitamin } \mathrm{C} \text { tablet) } \\
\text { 2. } 6 \mathrm{mg} / \mathrm{kg} \text { diethylcarbamazine (DEC) plus placebo ( } 250 \mathrm{mg} \text { vitamin } \mathrm{C} \text { tablet) } \\
\text { 3. Albendazole } 400 \mathrm{mg} \text { plus single dose of } 6 \mathrm{mg} / \mathrm{kg} \text { diethylcarbamazine (DEC) } \\
\text { 4. Placebo plus placebo }(2 \times 250 \mathrm{mg} \text { vitamin } \mathrm{C} \text { tablets) } \\
\text { Treatment strategy: randomized and treated all children }\end{array}$ \\
\hline Outcomes & $\begin{array}{l}\text { 1. Weight: final and change in weight } \\
\text { 2. Height: final and change in height } \\
\text { 3. Adverse effects } \\
\text { Not included in review: worm intensity and prevalence; microfilarial density }\end{array}$ \\
\hline Notes & $\begin{array}{l}\text { Location: Haiti } \\
\text { Community category: } 2 \\
\text { Weight and height outcomes are only presented for a subgroup of children infected with } \\
\text { Trichuris } \\
\text { Source of funding: Emerging Infections Program of the Centers for Disease Control and } \\
\text { Prevention and an Institutional Strengthening Grant from the World Health Organiza- } \\
\text { tion to the Hopital Sainte Croix }\end{array}$ \\
\hline
\end{tabular}

Risk of bias

\begin{tabular}{l|ll}
\hline Bias & Authors' judgement & Support for judgement \\
\hline $\begin{array}{l}\text { Random sequence generation (selection } \\
\text { bias) }\end{array}$ & Low risk & Random-number table \\
\hline $\begin{array}{l}\text { Allocation concealment (selection bias) } \\
\text { Llinding (performance bias and detection }\end{array}$ & Low risk & Low risk \\
All outcomes & & $\begin{array}{l}\text { Centrally-coded allocation system broken } \\
\text { after baseline measures taken }\end{array}$ \\
\hline
\end{tabular}

Deworming drugs for soil-transmitted intestinal worms in children: effects on nutritional indicators, haemoglobin and school 
Fox 2005 (Continued)

blinded

Incomplete outcome data (attrition bias) Low risk

$626 / 646$ participants analysed for the priAll outcomes

mary outcome. Reasons for loss to followup unclear

Inclusion of all randomized participants (number evaluable/number randomized): $97 \%(626 / 646)$

\begin{tabular}{lll}
\hline Selective reporting (reporting bias) & Low risk & All stated outcomes reported \\
\hline Other bias & Low risk & No obvious other source of bias \\
\hline
\end{tabular}

Freij 1979a

Methods

Quasi-randomized controlled trial

Length of follow up: 28 days

Participants

Number analysed for primary outcome: 13

Inclusion criteria: boys attending mother and child clinic with Ascaris on stool smear; aged 1.5 to 5 years with no history of diarrhoea for preceding 2 weeks; no fever; no respiratory symptoms; no signs of severe disease

Exclusion criteria: children diagnosed with other parasites; excluded girls to eliminate the contamination of samples with urine

Interventions

Single dose versus placebo

1. Piperazine: 3 g single dose

2. Placebo syrup: single dose

Treatment strategy: screened children then randomized and treated infected children

\begin{tabular}{ll} 
Outcomes & 1. Weight \\
2. Mid-upper arm circumference & 3. Triceps skinfold thickness \\
& Not included in review: Ascaris worm count \\
\hline Notes & Location: Ethiopia \\
& Community category: unclear \\
& The authors mention that boys were matched in pairs so that if there were drop outs they \\
could be replaced. They do not indicate if there were any drop outs. Standard deviations & calculated from individual data \\
Freij 1979 a and Freij 1979 ai were reported in the same article. \\
Source of funding: Semper Nutrition Fund, Stockholm; Swedish Medical Research \\
Council
\end{tabular}

Risk of bias

Bias

Authors' judgement

Support for judgement

Deworming drugs for soil-transmitted intestinal worms in children: effects on nutritional indicators, haemoglobin and school 
Freij 1979a (Continued)

\begin{tabular}{|c|c|c|}
\hline $\begin{array}{l}\text { Random sequence generation (selection } \\
\text { bias) }\end{array}$ & High risk & $\begin{array}{l}\text { Quasi-randomized controlled trial: boys } \\
\text { matched into pairs of equal age and nutri- } \\
\text { tional status }\end{array}$ \\
\hline Allocation concealment (selection bias) & Unclear risk & No details reported \\
\hline $\begin{array}{l}\text { Blinding (performance bias and detection } \\
\text { bias) } \\
\text { All outcomes }\end{array}$ & Unclear risk & $\begin{array}{l}\text { Described as double blind, no further de- } \\
\text { tails reported }\end{array}$ \\
\hline $\begin{array}{l}\text { Incomplete outcome data (attrition bias) } \\
\text { All outcomes }\end{array}$ & Unclear risk & $\begin{array}{l}100 \%(13 / 13) \text { of enrolled participants were } \\
\text { evaluated. The authors mention that boys } \\
\text { were matched in pairs so that if there were } \\
\text { drop outs they could be replaced. They do } \\
\text { not indicate if there were any drop outs. } \\
\text { Inclusion of all randomized participants } \\
\text { (number evaluable/number randomized): } \\
100 \%(13 / 13)\end{array}$ \\
\hline Selective reporting (reporting bias) & Low risk & $\begin{array}{l}\text { Authors had intended to measure bicep and } \\
\text { tricep skinfolds, but staff were unable to } \\
\text { take these measurements }\end{array}$ \\
\hline Other bias & Low risk & No obvious other source of bias \\
\hline
\end{tabular}

\section{Freij 1979b}

Methods

Quasi-randomized controlled trial

Length of follow up: 34 days

Participants

Number analysed for primary outcome: 44

Inclusion criteria: 92 children 1 to 5 years from a community morbidity study

Interventions $\quad$ Single dose versus placebo

1. Piperazine: $3 \mathrm{~g} /$ day for 2 days

2. Placebo: for 2 days

Treatment strategy: screened children then randomized and treated infected children

Outcomes

1. Mid-upper arm circumference

2. Morbidity

Not included in review: weight in \% of Harvard standard; authors had intended to measure bicep and tricep skinfolds, but staff were unable to take these measurements

Notes

Location: Ethiopia

Community category: 3

Freij 1979a and Freij 1979ai were reported in the same article.

Source of funding: Semper Nutrition Fund, Stockholm; Swedish Medical Research Council 
Freij 1979b (Continued)

\section{Risk of bias}

\begin{tabular}{|c|c|c|}
\hline Bias & Authors' judgement & Support for judgement \\
\hline $\begin{array}{l}\text { Random sequence generation (selection } \\
\text { bias) }\end{array}$ & High risk & $\begin{array}{l}\text { Quasi-randomized controlled trial: chil- } \\
\text { dren matched into pairs of equal age and } \\
\text { nutritional status }\end{array}$ \\
\hline Allocation concealment (selection bias) & Unclear risk & No details reported \\
\hline $\begin{array}{l}\text { Blinding (performance bias and detection } \\
\text { bias) } \\
\text { All outcomes }\end{array}$ & Unclear risk & $\begin{array}{l}\text { Described as double blind, no further de- } \\
\text { tails reported }\end{array}$ \\
\hline $\begin{array}{l}\text { Incomplete outcome data (attrition bias) } \\
\text { All outcomes }\end{array}$ & Low risk & $\begin{array}{l}100 \% \text { (44/44) of enrolled participants were } \\
\text { evaluated. Inclusion of all randomized par- } \\
\text { ticipants (number evaluable/number ran- } \\
\text { domized): } 100 \%(44 / 44)\end{array}$ \\
\hline Selective reporting (reporting bias) & Low risk & $\begin{array}{l}\text { Authors had intended to measure bicep and } \\
\text { tricep skinfolds, but staff were unable to } \\
\text { take these measurements }\end{array}$ \\
\hline Other bias & Low risk & No obvious other source of bias \\
\hline
\end{tabular}

\section{Garg 2002}

\begin{tabular}{ll}
\hline Methods & $\begin{array}{l}\text { Randomized controlled trial } \\
\text { Length of follow up: } 6 \text { months }\end{array}$ \\
\hline Participants & $\begin{array}{l}\text { Number analysed for primary outcome: } 347 \\
\text { Inclusion criteria: sick children } 2 \text { to } 4 \text { years old presenting to } 3 \text { government health centres } \\
\text { in Bungamo district, without palmar pallor } \\
\text { Exclusion criteria: children with palmar pallor }\end{array}$ \\
\hline Interventions & $\begin{array}{l}\text { Single dose versus placebo } \\
\text { 1. Mebendazole: } 500 \text { mg (Vermox, Janssen, Belgium) }\end{array}$ \\
\hline $\begin{array}{l}\text { 2. Placebo: sucrose starch capsule } \\
\text { Treatment strategy: randomized and treated all children }\end{array}$ \\
\hline Outcomes & $\begin{array}{l}\text { 1. Mean weight post-treatment } \\
\text { 2. Mean change in weight post-treatment } \\
\text { 3. Mean height post-treatment } \\
\text { 4. Mean change in height post-treatment } \\
\text { 5. Mean haemoglobin post-treatment } \\
\text { 6. Mean change in haemoglobin post-treatment } \\
\text { Not included in review: z-scores for weight-for-age, height-for-age, and weight-for- } \\
\text { height; egg count (formol-ethyl acetate concentration method) in categories of intensity }\end{array}$ \\
\hline
\end{tabular}

Deworming drugs for soil-transmitted intestinal worms in children: effects on nutritional indicators, haemoglobin and school 
Garg 2002 (Continued)

\begin{tabular}{|c|c|c|}
\hline Notes & \multicolumn{2}{|c|}{$\begin{array}{l}\text { Location: Kenya } \\
\text { Community category: } 3 \\
\text { Source of funding: the Centers for Disease Control and Prevention, Atlanta, USA }\end{array}$} \\
\hline \multicolumn{3}{|l|}{ Risk of bias } \\
\hline Bias & Authors' judgement & Support for judgement \\
\hline $\begin{array}{l}\text { Random sequence generation (selection } \\
\text { bias) }\end{array}$ & Low risk & $\begin{array}{l}\text { Computer-generated list of random num- } \\
\text { bers }\end{array}$ \\
\hline Allocation concealment (selection bias) & Low risk & $\begin{array}{l}\text { Drugs kept in envelope until after baseline } \\
\text { assessment }\end{array}$ \\
\hline $\begin{array}{l}\text { Blinding (performance bias and detection } \\
\text { bias) } \\
\text { All outcomes }\end{array}$ & High risk & $\begin{array}{l}\text { "the trial was not double-blinded" Asses- } \\
\text { sors were blinded; participants unclear; } \\
\text { provider not blinded }\end{array}$ \\
\hline $\begin{array}{l}\text { Incomplete outcome data (attrition bias) } \\
\text { All outcomes }\end{array}$ & Low risk & $\begin{array}{l}93 \%(347 / 370) \text { of randomized participants } \\
\text { were evaluated, loss to follow-up balanced } \\
\text { across groups. Inclusion of all random- } \\
\text { ized participants (number evaluable/num- } \\
\text { ber randomized): } 93 \%(347 / 370)\end{array}$ \\
\hline Selective reporting (reporting bias) & Low risk & All stated outcomes included \\
\hline Other bias & Low risk & No obvious other source of bias \\
\hline
\end{tabular}

Goto 2009

\begin{tabular}{|c|c|}
\hline Methods & $\begin{array}{l}\text { Randomized controlled trial } \\
\text { Length of follow up: } 36 \text { weeks }\end{array}$ \\
\hline Participants & $\begin{array}{l}\text { Number analysed for primary outcome: } 410 \\
\text { Inclusion criteria: infants under } 11 \text { months of age in the local area } \\
\text { Exclusion criteria: Not stated. }\end{array}$ \\
\hline Interventions & $\begin{array}{l}\text { Multiple doses versus placebo } \\
\text { 1. anti-Giardia (secnidazole every } 4 \text { weeks) and anthelminthic (albendazole every } 12 \\
\text { weeks) } \\
\text { 2. anti-Giardia treatment only (secnidazole every } 4 \text { weeks) and placebo. } \\
\text { 3. Placebo and placebo } \\
\text { Treatment strategy: } \\
\text { Secnidazole: a } 70 \mathrm{mg} / \mathrm{mL} \text { suspension with about } 0.5 \mathrm{~g} \text { of sweetener was made up, and } \\
0.5 \mathrm{~mL} \text { per kg body weight was given by spoon. If the infant was sick immediately, } \\
\text { secnidazole was re-administrated } \\
\text { Albendazole: A } 200 \mathrm{mg}(5 \mathrm{~mL} \text { ) suspension given by spoon. }\end{array}$ \\
\hline
\end{tabular}

Deworming drugs for soil-transmitted intestinal worms in children: effects on nutritional indicators, haemoglobin and school 


\begin{tabular}{|c|c|}
\hline Outcomes & $\begin{array}{l}\text { 1. Hb (g/L) (endpoint week 36) } \\
\text { Not included in review: } \\
\text { 2. Height-for-age z-score (endpoint week 36) } \\
\text { 3. Weight-for-age z-score (endpoint week 36) } \\
\text { 4. Weight-for-height z-score (endpoint week 36) } \\
\text { 5. Plasma albumin (g/L) (endpoint week 36) } \\
\text { 6. IgG (g/L) (endpoint week 36) } \\
\text { 7. Alpha-1-acid glycoprotein (g/L) (endpoint week 36) } \\
\text { 8. Giardia-specific IgM titre (endpoint week 36) } \\
\text { 9. Lactulose/mannitol ratio (endpoint week 36) } \\
\text { 10. Prevalence of Giardia-specific IgM titre, \% (week 0,12,24,36) } \\
\text { 11. Prevalence of Giardia cysts, \% (week } 0,12,24,36 \text { ) } \\
\text { 12. Prevalence of Ascaris/Trichuris, \% (week 0,12,24,36) } \\
\text { 13. Prevalence of Intestinal mucosal damage, \% (week } 0,12,24,36 \text { ) } \\
\text { 14. Prevalence of Anaemia, \% (week } 0,12,24,36 \text { ) }\end{array}$ \\
\hline Notes & $\begin{array}{l}\text { Location: Dhamrai Upazila, located } 40 \mathrm{~km} \text { northwest of Dhaka, Bangladesh } \\
\text { Community category: } 3 \text {. "Prevalences and intensities of geohelminths were consistently } \\
\text { low throughout the intervention" } \\
\text { Drug source: Dhaka, Bangladesh (Essential Drugs Company Ltd for secnidazole; Square } \\
\text { Pharmaceuticals Ltd for the secnidazole placebo; Opsonin Chemical Industries Ltd for } \\
\text { albendazole; and UniMed and UniHealthManufacturing Ltd for albendazole placebo) }\end{array}$ \\
\hline
\end{tabular}

Risk of bias

\begin{tabular}{|c|c|c|}
\hline Bias & Authors' judgement & Support for judgement \\
\hline $\begin{array}{l}\text { Random sequence generation (selection } \\
\text { bias) }\end{array}$ & Low risk & $\begin{array}{l}\text { Computer generated } \\
\text { Randomized on the basis of their age, sex, } \\
\text { height-for-age, weight-for-age and weight- } \\
\text { for-height z-scores, socio-demographic and } \\
\text { economic data and presence of any parasitic } \\
\text { infection }\end{array}$ \\
\hline Allocation concealment (selection bias) & Unclear risk & $\begin{array}{l}\text { Unclear whether the allocation was con- } \\
\text { cealed since patients were randomized by } \\
\text { their characteristics }\end{array}$ \\
\hline $\begin{array}{l}\text { Blinding (performance bias and detection } \\
\text { bias) } \\
\text { All outcomes }\end{array}$ & Low risk & $\begin{array}{l}\text { Double-blind } \\
\text { "Bottles containing the two medications } \\
\text { and placebo suspensions were labelled with } \\
\text { different colours corresponding to the three } \\
\text { intervention groups, but the assistants did } \\
\text { not know the relationship between the } \\
\text { colour codings and the contents of the bot- } \\
\text { tles." }\end{array}$ \\
\hline
\end{tabular}


Incomplete outcome data (attrition bias) Low risk All outcomes

$394 / 410(96.10 \%)$ of randomized participants were evaluated.

"A total of 16 infants were excluded from the study, as they had either moved away from the study area $(n=12)$, or were absent during the study period $(n=2)$ or the parents subsequently refused to participate $(n=2)$. Of the infants who completed the study $(n=394)$, data on 96 infants was incomplete (ie they did not provide information for all the ten z-scores and four intestinal permeabilities, serological variables and prevalences of parasite infections), and severe anaemic infants were also omitted from the study" Inclusion of all randomized participants (number evaluable/number randomized): 96\% (394/410)

\begin{tabular}{lll}
\hline Selective reporting (reporting bias) & Low risk & All stated outcomes reported \\
\hline Other bias & Low risk & No obvious other source of bias \\
\hline
\end{tabular}

\section{Greenberg 1981}

Methods

Participants

Interventions

Single dose versus placebo

1. Piperazine citrate: $80 \mathrm{mg} / \mathrm{kg}$ added to flavoured syrup; 2 doses in 2-week period

2. Placebo: syrup only

Treatment strategy: randomized and treated all children

Outcomes

Randomized controlled trial

Length of follow up: 11 months

Number analysed for primary outcome: 152 aged 1.5 to 8 years measurements taken at first visit entered

Exclusion criteria: none stated

\section{Cure rates}

Inclusion criteria: children aged 1.5 to 8 years living in Nandipara, Bangladesh; $50 \%$ entered into study; only those who provided stool sample and had anthropometric

2. Reinfection rates

3. Weight-for-height

4. Height-for-age (NCHS reference)

5. Weight-for-age (graphically)

6. Other measured parameters not reported: weight; height; triceps skinfold thickness; mid-upper arm circumference; chest circumference; abdominal girth; egg counts (Dunn's method); prevalence; triceps skinfold for age; mid-upper arm circumference for age (Tanner reference charts) 


\section{Greenberg 1981 (Continued)}

\begin{tabular}{|c|c|c|}
\hline Notes & \multicolumn{2}{|c|}{$\begin{array}{l}\text { Location: Bangladesh } \\
\text { Community category: } 1 \\
\text { Groups stratified by intensity of Ascaris infection } \\
\text { Source of funding not reported. }\end{array}$} \\
\hline \multicolumn{3}{|l|}{ Risk of bias } \\
\hline Bias & Authors' judgement & Support for judgement \\
\hline $\begin{array}{l}\text { Random sequence generation (selection } \\
\text { bias) }\end{array}$ & Unclear risk & $\begin{array}{l}\text { "Randomly assigned", no further details } \\
\text { provided }\end{array}$ \\
\hline Allocation concealment (selection bias) & Unclear risk & No details reported \\
\hline $\begin{array}{l}\text { Blinding (performance bias and detection } \\
\text { bias) } \\
\text { All outcomes }\end{array}$ & Unclear risk & $\begin{array}{l}\text { "Double-blind". Participants blinded both } \\
\text { placebo and treatment given as a flavoured } \\
\text { syrup, no information about provider and } \\
\text { assessor blinding }\end{array}$ \\
\hline $\begin{array}{l}\text { Incomplete outcome data (attrition bias) } \\
\text { All outcomes }\end{array}$ & Low risk & $\begin{array}{l}82 \%(152 / 185) \text { of randomized partici- } \\
\text { pants were evaluated. Reasons for leav- } \\
\text { ing the study early not reported. Inclu- } \\
\text { sion of all randomized participants (num- } \\
\text { ber evaluable/number randomized): } 82 \% \\
(152 / 185)\end{array}$ \\
\hline Selective reporting (reporting bias) & High risk & Not all stated outcomes reported \\
\hline Other bias & Low risk & No obvious other source of bias \\
\hline
\end{tabular}

\section{Hadju 1996}

Methods

Quasi-randomized controlled trial

Length of follow up: 1.75 months (7 weeks)

Participants

Number analysed for primary outcome: 64

Inclusion criteria: boys aged 6 to 10 years attending second grade at 3 primary schools; completed assessment and provided a stool sample; randomized by descending hookworm count (all treated)

Exclusion criteria: none stated

Interventions

Single dose versus placebo

1. Pyrantel pamoate: $10 \mathrm{mg} / \mathrm{kg}$

2. Placebo

Treatment strategy: randomized and treated all children 


\section{Hadju 1996 (Continued)}

\begin{tabular}{ll}
\hline Outcomes & $\begin{array}{l}\text { 1. Mean weight post-treatment } \\
\text { 2. Appetite: consumption test (mL porridge) and self assessment } \\
\text { Not included in review: egg counts arithmetic and geometric means (Kato-Katz); weight- } \\
\text { for-age (NCHS reference) }\end{array}$ \\
\hline \multirow{2}{*}{ Notes } & $\begin{array}{l}\text { Location: Indonesia } \\
\text { Community category: } 1 \\
\text { Large drops in geometric mean egg counts in placebo noted } \\
\text { Source of funding not reported. }\end{array}$ \\
\hline
\end{tabular}

Risk of bias

\begin{tabular}{|c|c|c|}
\hline Bias & Authors' judgement & Support for judgement \\
\hline $\begin{array}{l}\text { Random sequence generation (selection } \\
\text { bias) }\end{array}$ & Unclear risk & $\begin{array}{l}\text { Randomized: "Randomly assigned" by de- } \\
\text { scending A. lubricoides egg count" }\end{array}$ \\
\hline Allocation concealment (selection bias) & Unclear risk & No details reported \\
\hline $\begin{array}{l}\text { Blinding (performance bias and detection } \\
\text { bias) } \\
\text { All outcomes }\end{array}$ & Unclear risk & $\begin{array}{l}\text { "Double-blind". Participants blinded both } \\
\text { placebo and treatment identical round } \\
\text { white tablets, no information about } \\
\text { provider and assessor blinding }\end{array}$ \\
\hline $\begin{array}{l}\text { Incomplete outcome data (attrition bias) } \\
\text { All outcomes }\end{array}$ & Low risk & $\begin{array}{l}85 \%(64 / 75) \text { of randomized participants } \\
\text { were evaluated. Reasons for loss to fol- } \\
\text { low-up included: moved away, refused to } \\
\text { be examined, did not return a stool sam- } \\
\text { ple, absent during examination. Not clear } \\
\text { how many lost from each treatment group. } \\
\text { Inclusion of all randomized participants } \\
\text { (number evaluable/number randomized): } \\
85 \%(64 / 75)\end{array}$ \\
\hline Selective reporting (reporting bias) & Low risk & All stated outcomes reported \\
\hline Other bias & Low risk & No obvious other source of bias. \\
\hline
\end{tabular}

\section{Hadju 1997}

Methods

Participants
Randomized controlled trial

Length of follow up: 12 months

Number analysed for primary outcome: 330 ; mean age 8.3 years

Inclusion criteria: all primary school children in grades 1, 2, and 3 in 2 schools in slum areas in Indonesia; randomized according to Ascaris egg count and age

Exclusion criteria: children $>11$; signs of puberty; signs of severe protein energy malnu- 
Hadju 1997 (Continued)

trition

\begin{tabular}{|c|c|}
\hline Interventions & $\begin{array}{l}\text { Multiple doses versus placebo } \\
\text { 1. Pyrantel pamoate: } 10 \mathrm{mg} / \mathrm{kg} \\
\text { 2. Pyrantel pamoate: } 10 \mathrm{mg} / \mathrm{kg} \text { repeated at } 6 \text { months } \\
\text { 3. Albendazole: } 400 \mathrm{mg} \\
\text { 4. Albendazole: } 400 \mathrm{mg} \text { repeated at } 6 \text { months } \\
\text { 5. Placebo } \\
\text { Treatment strategy: randomized and treated all children }\end{array}$ \\
\hline Outcomes & $\begin{array}{l}\text { 1. Stool (Kato-Katz) prevalence and intensity } \\
\text { 2. Weight } \\
\text { 3. Height } \\
\text { 4. Mid-upper arm circumference } \\
\text { 5. z-scores: weight-for-age, height for age, weight-for-height, and mid-upper arm cir- } \\
\text { cumference } \\
\text { Results of multivariate analysis using z-scores presented and could not be used in meta- } \\
\text { analysis; unadjusted results not reported }\end{array}$ \\
\hline Notes & $\begin{array}{l}\text { Location: Indonesia } \\
\text { Community category: } 1 \\
\text { Placebo group showed an unexplained drop in egg counts at the 3-month exam } \\
\text { Source of funding: Directorate of Higher Education, Department of Education and } \\
\text { Culture, Government of Indonesia through Hibah Bersaing Project I \& II. Albendazole } \\
\text { and placebo provided by Smithkline Beecham Pharmaceuticals Indonesia. }\end{array}$ \\
\hline
\end{tabular}

Risk of bias

\begin{tabular}{l|ll}
\hline Bias & Authors' judgement & Support for judgement \\
\hline $\begin{array}{l}\text { Random sequence generation (selection } \\
\text { bias) }\end{array}$ & Unclear risk & Randomly assigned "by sex and egg count" \\
\hline $\begin{array}{l}\text { Allocation concealment (selection bias) } \\
\begin{array}{l}\text { Blinding (performance bias and detection } \\
\text { bias) } \\
\text { All outcomes }\end{array}\end{array}$ & Unclear risk & No details reported \\
\hline
\end{tabular}

Incomplete outcome data (attrition bias) High risk All outcomes

$65 \%(330 / 507)$ of randomized participants were evaluated, number lost from each treatment group not reported. Inclusion of all randomized participants (number evaluable/number randomized): $65 \%$ $(330 / 507)$

\begin{tabular}{l|l|l} 
Selective reporting (reporting bias) $\quad$ Low risk & All stated outcomes reported
\end{tabular}

Deworming drugs for soil-transmitted intestinal worms in children: effects on nutritional indicators, haemoglobin and school 


\section{Hadju 1997 (Continued)}

\begin{tabular}{l|l} 
Other bias $\quad$ Low risk $\quad$ No obvious other source of bias
\end{tabular}

Hall 2006 (Cluster)

Cluster-randomized controlled trial
Methods
from Alderman 2006)
Cluster unit: school
Average cluster size: 33
ICCs: not reported.
Length of follow up: 2 years

Participants

Number analysed for primary outcome: 80 schools randomized containing 2659 children in class 3

Mean age: 104.5 months

Inclusion criteria: children from class 3 and born in 1990 of 80/81 schools in the Red

River delta of north Vietnam

Interventions

Multiple doses versus placebo

1. Albendazole (GlaxoSmithKline): $400 \mathrm{mg}$ every 6 months and 200,000 IU retinol after first 6 months only

2. Retinol: 200,000 IU after first 6 months followed by inert placebo every 6 months

Treatment strategy: randomized and treated all children

Outcomes

Measured:

1. Hookworm, Trichuris, and Ascaris prevalence

2. Eggs/g faeces

3. Weight and height

4. Mathematics test score, Vietnamese test score

Location: Vietnam
Community category: 1
It is unclear what is meant by "randomization was adjusted so that there were equal
numbers of schools in each district of the study group". It is also appears as if the analysis
has not taken into account the effects of cluster randomization
Source of funding not reported

Risk of bias

\begin{tabular}{|c|c|c|}
\hline Bias & Authors' judgement & Support for judgement \\
\hline $\begin{array}{l}\text { Random sequence generation (selection } \\
\text { bias) }\end{array}$ & Unclear risk & $\begin{array}{l}\text { "randomization was adjusted so that there } \\
\text { were equal numbers of schools in each dis- } \\
\text { trict of the study group" (unclear what this } \\
\text { means) }\end{array}$ \\
\hline Allocation concealment (selection bias) & Low risk & $\begin{array}{l}\text { Central allocation. "...using a list provided } \\
\text { by the Ministry of Education" }\end{array}$ \\
\hline
\end{tabular}

Deworming drugs for soil-transmitted intestinal worms in children: effects on nutritional indicators, haemoglobin and school 


\section{Hall 2006 (Cluster) (Continued)}

Blinding (performance bias and detection Unclear risk bias)

All outcomes

Incomplete outcome data (attrition bias) Unclear risk All outcomes
Placebo was used, blinding not reported

Insufficient reporting of attrition/exclusions. 80 schools containing 56,444 pupils randomized, and those from class 3 used in study. Inclusion of all randomized participants (number evaluable/number randomized): unclear; 80 schools containing 56,444 pupils randomized, and those from class 3 used in study

All stated outcomes reported

Although not adjusted for clustering, we used estimates to adjust in the review Recruitment bias: Low (schools)

Baseline imbalance: Low (characteristics similar)

Loss of clusters: Low (no loss reported)

Incorrect analysis: not cluster adjusted (high risk)

Comparability with RCTs randomising individuals: Unclear

Kirwan 2010

\section{Methods}

Participants

Interventions
Randomized controlled trial

Length of follow up: 14 months

Number analysed for primary outcome: 320

Inclusion criteria: Pre-school children aged 12 to 59 months, either sex Exclusion criteria: Severe anaemia less than $5 \mathrm{~g} / \mathrm{dL}$, severe malaria

Multiple doses versus placebo

1. Albendazole

2. Placebo

Treatment strategy: $200 \mathrm{mg}$ (one tablet) albendazole was given to children aged 1 year, $400 \mathrm{mg}$ (two tablets) albendazole was given to children aged 2, 3 and 4 years. Children who were in the placebo group were given one or two ( 1 year) placebo (2-4 years) tablets. Treatment or placebo was given at baseline, 4, 8 and 12 months and then followed up for the last time at 14 months. Children in the placebo group were treated with albendazole at 14 months

Outcomes

1. Haemoglobin, measured at baseline and 4, 8, 12 and 14 months Unable to use: Nutritional status and anthropometric measures, at baseline and 14 months, no data was reported for these outcomes 
Not included in review: Infection with soil-transmitted helminths, measured at baseline and 4, 8, 12 and 14 months (eggs or worms in stool sample). Incidence of malaria and malaria attacks, measured at baseline and 4, 8, 12 and 14 months. Adverse events not fully reported for albendazole treatment versus placebo

Location: 4 semi-urban villages, Osun State, Nigeria
Community category: 3
No adverse events reported in the Albendazole treatment group. Not reported for control
group
$\begin{aligned} & \text { Source of funding: Health Research Board (HRB) (Ireland). GlaxoSmithKline sponsored } \\ & \text { the drug albendazole which } \\ & \text { was used in the study. }\end{aligned}$

\section{Risk of bias}

\begin{tabular}{|c|c|c|}
\hline Bias & Authors' judgement & Support for judgement \\
\hline $\begin{array}{l}\text { Random sequence generation (selection } \\
\text { bias) }\end{array}$ & High risk & $\begin{array}{l}\text { Quasi-randomized, "During the first as- } \\
\text { sessment each alternate child was assigned } \\
\text { tablet B" }\end{array}$ \\
\hline
\end{tabular}

Allocation concealment (selection bias) High risk

Alternation, one of the investigators "placed the albendazole and placebo tablets in containers labelled either A or B" later "The treatment coordinator [...] oversaw the allocation of treatments to the children"

Blinding (performance bias and detection Low risk bias)

All outcomes
Participants and key personnel were blinded. "Experienced physicians [...] enrolled all participants, measured all study endpoints, and were kept masked to treatment allocation of children. Field workers involved in data collection and mothers of participating children were also masked to the treatment allocation."

"Albendazole and placebo tablets were identical"

320 children (out of $1228,26.1 \%$ ) complied with all the follow-up assessments and were included in the analyses. Inclusion of all randomized participants (number evaluable/number randomized): $26 \%$ $(320 / 1228)$

Nutritional status and anthropometric measures not reported. Main paper states these outcomes are reported in the companion paper; no data reported for these 
Kirwan 2010 (Continued)

outcomes in the companion paper

\begin{tabular}{lll}
\hline Other bias & Low risk & No obvious other source of bias \\
\hline
\end{tabular}

Kloetzel 1982

\begin{tabular}{|c|c|}
\hline Methods & $\begin{array}{l}\text { Randomized controlled trial } \\
\text { Length of follow up: } 10 \text { months }\end{array}$ \\
\hline Participants & $\begin{array}{l}\text { Number analysed for primary outcome: } 337 \text {; unclear how many randomized; aged } 1 \text { to } \\
8 \text { years old } \\
\text { Inclusion criteria: enlisted from } 9 \text { rural communities in Pariquera-Acu state of Sao Paulo } \\
\text { Exclusion criteria: none stated }\end{array}$ \\
\hline Interventions & $\begin{array}{l}\text { Single dose versus placebo } \\
\text { 1. Mebendazole: } 100 \mathrm{mg} \text { twice per day for } 3 \text { days } \\
\text { 2. Placebo } \\
\text { Treatment strategy: randomized and treated all children }\end{array}$ \\
\hline Outcomes & $\begin{array}{l}\text { 1. Weight } \\
\text { 2. Height } \\
\text { 3. Head, chest, and mid-arm circumference } \\
\text { 4. Triceps skinfold } \\
\text { 5. Stool egg counts (Kato-Katz) }\end{array}$ \\
\hline Notes & $\begin{array}{l}\text { Location: Cameroon } \\
\text { Community category: } 1 \\
\text { Results reported as changes in nutritional status grouped into } 3 \text { categories: improved, } \\
\text { deteriorated, no change (unclear on basis of which parameter), and proportions compared } \\
\text { Source of funding: Fundacao de Amparo a Pesquisa do Estado de Sao Paulo (FAPESP) }\end{array}$ \\
\hline
\end{tabular}

Risk of bias

\begin{tabular}{|c|c|c|}
\hline Bias & Authors' judgement & Support for judgement \\
\hline $\begin{array}{l}\text { Random sequence generation (selection } \\
\text { bias) }\end{array}$ & Unclear risk & "Randomized", no further details provided \\
\hline Allocation concealment (selection bias) & Unclear risk & No details reported \\
\hline $\begin{array}{l}\text { Blinding (performance bias and detection } \\
\text { bias) } \\
\text { All outcomes }\end{array}$ & Unclear risk & $\begin{array}{l}\text { Described as double blind, no details re- } \\
\text { ported }\end{array}$ \\
\hline $\begin{array}{l}\text { Incomplete outcome data (attrition bias) } \\
\text { All outcomes }\end{array}$ & Unclear risk & $\begin{array}{l}\text { No details about losses to follow-up re- } \\
\text { ported; "the present report only deals with } \\
\text { those } 337 \text { that could be followed through- } \\
\text { out the entire } 10 \text { months". Inclusion of }\end{array}$ \\
\hline
\end{tabular}

Deworming drugs for soil-transmitted intestinal worms in children: effects on nutritional indicators, haemoglobin and school 
Kloetzel 1982 (Continued)

all randomized participants (number evaluable/number randomized): unclear (337 analysed).

\begin{tabular}{|c|c|c|}
\hline Selective reporting (reporting bias) & Low risk & All stated outcomes reported \\
\hline Other bias & Low risk & No obvious other sources of bias \\
\hline
\end{tabular}

Koroma 1996

\begin{tabular}{ll} 
Methods & $\begin{array}{l}\text { Randomized controlled trial } \\
\text { Length of follow up: } 6 \text { months }\end{array}$ \\
\hline Participants & $\begin{array}{l}\text { Number analysed for primary outcome: } 187 \\
\text { Inclusion criteria: selected (unclear how) urban and rural school primary children aged } \\
6 \text { to } 10 \text { years } \\
\text { Exclusion criteria: not stated }\end{array}$ \\
\hline Interventions & $\begin{array}{l}\text { Single dose versus placebo } \\
1 . \text { Albendazole: } 400 \text { mg }\end{array}$ \\
$\begin{array}{l}2 . \text { Placebo } \\
\text { Treatment strategy: randomized and treated all children }\end{array}$ \\
\hline Outcomes & $\begin{array}{l}\text { 1. Prevalence and intensity (arithmetic mean eggs/g) } \\
2 . \text { z-scores (no reference category stated): weight-for-height, weight-for-age, and height- } \\
\text { for-age }\end{array}$ \\
\hline Notes & $\begin{array}{l}\text { Location: Sierra Leone } \\
\text { Community category: } 2 \\
\text { Source of funding: Fundacao de Amparo a Pesquisa do Estado de Sao Paulo (FAPESP) }\end{array}$ \\
\hline
\end{tabular}

\section{Risk of bias}

\begin{tabular}{l|l|l}
\hline Bias & Authors' judgement & Support for judgement \\
\hline $\begin{array}{l}\text { Random sequence generation (selection } \\
\text { bias) }\end{array}$ & Unclear risk & “Randomized”, no further details provided \\
\hline $\begin{array}{l}\text { Allocation concealment (selection bias) } \\
\text { Blinding (performance bias and detection } \\
\text { bias) } \\
\text { All outcomes }\end{array}$ & Unclear risk & No details reported \\
\hline $\begin{array}{l}\text { Incomplete outcome data (attrition bias) } \\
\text { All outcomes }\end{array}$ & High risk & No details reported \\
\hline
\end{tabular}


Koroma 1996 (Continued)

ber randomized): $76 \%(187 / 247)$

\begin{tabular}{lll}
\hline Selective reporting (reporting bias) & Low risk & All stated outcomes reported \\
\hline Other bias & Low risk & No obvious other sources of bias \\
\hline
\end{tabular}

Kruger 1996

\begin{tabular}{ll} 
Methods & $\begin{array}{l}\text { Randomized controlled trial } \\
\text { Length of follow up: } 11 \text { months }\end{array}$ \\
\hline Participants & $\begin{array}{l}\text { Number analysed for primary outcome: } 74 \text { aged } 6 \text { to } 8 \text { years } \\
\text { Inclusion criteria: } 65 \text { pupils in first year of school randomly selected from each of } 5 \\
\text { primary schools; schools included in a feeding scheme }\end{array}$ \\
\hline $\begin{array}{l}\text { Exclusion criteria: age }>9 \text { years; current use of iron supplements; inclusion in an iron } \\
\text { fortification trial; infection (raised white cell count) }\end{array}$ \\
\hline Multiple doses versus placebo \\
\hline $\begin{array}{l}\text { Interventions Albendazole: } 2 \mathrm{x} 200 \text { mg repeated at } 4 \text { months, daily unfortified soup } \\
\text { 2. Placebo: daily unfortified soup } \\
\text { Also: whole population } \\
\text { 3/5 schools also allocated soup fortified with } 20 \text { mg elemental iron per day, and } 100 \text { mg } \\
\text { vitamin C for } 6 \text { months; unclear whether this intervention was cluster randomized. All } \\
\text { schools taking part in feeding programme providing bread, soup, and peanut butter to } \\
\text { all pupils } \\
\text { Treatment strategy: randomized and treated all children }\end{array}$ \\
\hline
\end{tabular}

\begin{tabular}{ll} 
Outcomes & $\begin{array}{l}\text { 1. Mean change in weight post-treatment } \\
\text { 2. Mean change in height post-treatment } \\
\text { 3. Mean change in haemoglobin post-treatment } \\
\text { Not included in review: other iron indices; stool egg counts (Visser filter method); z- } \\
\text { scores for weight-for-age, height for age, and weight-for-height }\end{array}$ \\
\hline \multirow{2}{*}{ Notes } & $\begin{array}{l}\text { Location: South Africa } \\
\text { Community category: } 3\end{array}$ \\
\hline $\begin{array}{l}\text { In the Dickson } 2000 \text { C Cochrane Review, the data were combined irrespective of the pos- } \\
\text { sible confounding effects of iron allocation; data extracted for albendazole-iron placebo } \\
\text { versus placebo-placebo groups only for this review } \\
\text { Data stratified by baseline iron stores into } 2 \text { groups that were combined for meta-analysis } \\
\text { Source of funding: Fortified and unfortified soup provided by Funa Foods, Zentel and } \\
\text { placebo provided by SmithKline Beecham Pharmaceuticals (Pty) Ltd }\end{array}$
\end{tabular}

Risk of bias

\begin{tabular}{|c|c|c|}
\hline Bias & Authors' judgement & Support for judgement \\
\hline $\begin{array}{l}\text { Random sequence generation (selection } \\
\text { bias) }\end{array}$ & Unclear risk & $\begin{array}{l}\text { "Randomly assigned", no further details } \\
\text { provided }\end{array}$ \\
\hline
\end{tabular}

Deworming drugs for soil-transmitted intestinal worms in children: effects on nutritional indicators, haemoglobin and school 


\section{Kruger 1996 (Continued)}

\begin{tabular}{l|l|l}
\hline Allocation concealment (selection bias) & Unclear risk & No details reported \\
\hline $\begin{array}{l}\text { Blinding (performance bias and detection } \\
\text { bias) } \\
\text { All outcomes }\end{array}$ & Unclear risk & No details reported \\
\hline $\begin{array}{l}\text { Incomplete outcome data (attrition bias) } \\
\text { All outcomes }\end{array}$ & High risk & $\begin{array}{l}\text { 72\% (179/247) of randomized participants } \\
\text { were evaluated. Reasons for loss to follow- } \\
\text { up not reported. Inclusion of all random- } \\
\text { ized participants (number evaluable/num- } \\
\text { ber randomized): } 72 \% \text { (179/247) }\end{array}$ \\
\hline \begin{tabular}{l} 
Selective reporting (reporting bias) \\
\hline Other bias
\end{tabular} & Low risk & All stated outcomes reported \\
\hline
\end{tabular}

\section{Kvalsvig 1991a}

Methods

Participants

Interventions

Notes

Outcomes

Randomized controlled trial

Length of follow up: 1 month

Number analysed for primary outcome: unclear; age range unclear Inclusion criteria: most severely infected 100 children in a primary school Exclusion criteria: children with schistosomiasis

Single dose versus placebo

1. Mebendazole: $500 \mathrm{mg}$

2. Placebo

Treatment strategy: screened children then randomized and treated infected children

1. Cognition tests: card sorting task (coloured cards; cancellation task - striking out of letter 's' in text, number done in a period)

Not included in review: height; weight at baseline; standardized using NCHS standards; stool examination (intensity index designed for this trial); no nutritional outcomes reported that can be used in the review

Location: South Africa

Community category: 1

No data used in meta-analysis since standard deviations not provided

Source of funding: Janssen Pharmaceutica, South African Medical Research Council

\section{Risk of bias}

\begin{tabular}{|c|c|c|}
\hline Bias & Authors' judgement & Support for judgement \\
\hline $\begin{array}{l}\text { Random sequence generation (selection } \\
\text { bias) }\end{array}$ & Unclear risk & $\begin{array}{l}\text { "Assigned randomly", no further details } \\
\text { provided }\end{array}$ \\
\hline
\end{tabular}

Deworming drugs for soil-transmitted intestinal worms in children: effects on nutritional indicators, haemoglobin and school 


\section{Kvalsvig 1991a (Continued)}

\begin{tabular}{|c|c|c|}
\hline Allocation concealment (selection bias) & Unclear risk & No details reported \\
\hline $\begin{array}{l}\text { Blinding (performance bias and detection } \\
\text { bias) } \\
\text { All outcomes }\end{array}$ & Unclear risk & $\begin{array}{l}\text { "A 'blind' procedure was adopted; the re- } \\
\text { search assistant did not know whether } \\
\text { a particular child had received drug or } \\
\text { placebo", no further details provided }\end{array}$ \\
\hline $\begin{array}{l}\text { Incomplete outcome data (attrition bias) } \\
\text { All outcomes }\end{array}$ & Unclear risk & $\begin{array}{l}\text { No details reported. Inclusion of all ran- } \\
\text { domized participants (number evaluable/ } \\
\text { number randomized): unclear }\end{array}$ \\
\hline Selective reporting (reporting bias) & Low risk & All stated outcomes reported \\
\hline Other bias & Low risk & No obvious other source of bias \\
\hline
\end{tabular}

Lai 1995

Methods

Quasi-randomized controlled trial

Length of follow up: 2 years

Participants

Number analysed for primary outcome: 314

Inclusion criteria: school children aged 8 who provided a stool sample

Exclusion criteria: concurrent illness; anthelminth treatment in previous 3 months

Interventions $\quad$ Multiple doses versus placebo

1. Mebendazole plus pyrantel: $100 \mathrm{mg}$ mebendazole and $200 \mathrm{mg}$ pyrantel every 3 months for 2 years

2. Placebo: every 3 months for 2 years

Treatment strategy: randomized and treated all children

Outcomes

Measured:

1. Hookworm, Trichuris, and Ascaris prevalence

2. Eggs/g faeces

3. Weight and height

Notes Location: Malaysia

Community category: 1

No data used in meta-analysis since standard deviations not provided

Source of funding not reported.

\section{Risk of bias}

\begin{tabular}{|c|c|c|}
\hline Bias & Authors' judgement & Support for judgement \\
\hline $\begin{array}{l}\text { Random sequence generation (selection } \\
\text { bias) }\end{array}$ & High risk & $\begin{array}{l}\text { Quasi-randomized: block assignment de- } \\
\text { sign by school, then by sex, then by pres- } \\
\text { ence of worms as none, light, or moder- }\end{array}$ \\
\hline
\end{tabular}




\begin{tabular}{|c|c|c|}
\hline & & $\begin{array}{l}\text { ate/heavy, and then by rank order of body } \\
\text { weight in the group; used odd and even } \\
\text { numbers; in urban area the odd numbered } \\
\text { children were assigned to treatment; in the } \\
\text { peri-urban area the even numbered chil- } \\
\text { dren were assigned to the treatment group }\end{array}$ \\
\hline Allocation concealment (selection bias) & Unclear risk & No details reported \\
\hline $\begin{array}{l}\text { Blinding (performance bias and detection } \\
\text { bias) } \\
\text { All outcomes }\end{array}$ & High risk & $\begin{array}{l}\text { Participants were blinded; study staff new } \\
\text { which group they were in }\end{array}$ \\
\hline $\begin{array}{l}\text { Incomplete outcome data (attrition bias) } \\
\text { All outcomes }\end{array}$ & Low risk & $\begin{array}{l}89 \%(314 / 353) \text { of randomized participants } \\
\text { were evaluated } \\
\text { Inclusion of all randomized participants } \\
\text { (number evaluable/number randomized): } \\
89 \%(314 / 353)\end{array}$ \\
\hline Selective reporting (reporting bias) & Low risk & All stated outcomes reported \\
\hline Other bias & Low risk & No obvious other sources of bias \\
\hline
\end{tabular}

\section{Le Huong 2007}

\section{Methods}

Randomized controlled trial

Length of follow up: 6 months
Participants

I.

Number analysed for primary outcome: 510 randomized

Inclusion criteria: Children in Grades 1-3 with $\mathrm{Hb}$ less than $110 \mathrm{~g} / \mathrm{L}$ but not less than $70 \mathrm{~g} / \mathrm{L}$

Exclusion criteria: Haemoglobin $(\mathrm{Hb})$ concentrations $<70 \mathrm{~g} / \mathrm{L}$
Multiple dose versus placebo

Factorial design

Mebendazole $500 \mathrm{mg}$ at 0 and 3 months

1. iron-fortified noodles and mebendazole $500 \mathrm{mg}$;

2. noodles without iron fortificant and mebendazole $500 \mathrm{mg}$;

3. iron-fortified noodles and placebo;

4. noodles without iron fortificant and placebo; and

5. iron supplementation and mebendazole $500 \mathrm{mg}$.

Treatment strategy: children screened for anaemia then randomized and all children treated

\section{Outcomes}

1. Haemoglobin - change

2. Prevalence of underweight, stunting and wasting (defined as -2SD for weight-forheight, height-for-age and weight-for- age using WHO/NCHS reference data)

Not included in review: Ferritin; serum transferrin; worm prevalence; CRP 
Le Huong 2007 (Continued)

\begin{tabular}{|c|c|c|}
\hline Notes & \multicolumn{2}{|c|}{$\begin{array}{l}\text { Location:Vietnam } \\
\text { Community category: } 2 \\
\text { Source of funding: Neys-van Hoogstraten Foundation, Ellison Medical Foundation and } \\
\text { the Ministry of Education and Training, Vietnam }\end{array}$} \\
\hline \multicolumn{3}{|l|}{ Risk of bias } \\
\hline Bias & Authors' judgement & Support for judgement \\
\hline $\begin{array}{l}\text { Random sequence generation (selection } \\
\text { bias) }\end{array}$ & Unclear risk & Randomized, no further details \\
\hline Allocation concealment (selection bias) & Low risk & $\begin{array}{l}\text { Central allocation. "Randomization was } \\
\text { carried out by a researcher }[\ldots] \text { who did not } \\
\text { know the children and could not introduce } \\
\text { bias in the randomization." }\end{array}$ \\
\hline $\begin{array}{l}\text { Blinding (performance bias and detection } \\
\text { bias) } \\
\text { All outcomes }\end{array}$ & Low risk & $\begin{array}{l}\text { Participants and key personnel blinded. } \\
\text { "Children, teachers and researchers were } \\
\text { blinded to the treatment." } \\
\text { Placebo identical to intervention drug }\end{array}$ \\
\hline $\begin{array}{l}\text { Incomplete outcome data (attrition bias) } \\
\text { All outcomes }\end{array}$ & Low risk & $\begin{array}{l}409 / 425 \text { participants were evaluated. Rea- } \\
\text { son for drop-out: refusal }(\mathrm{n}=16 \text {, inter- } \\
\text { vention: } 4.7 \% \text {, placebo: } 2.3 \%) \text {. Inclu- } \\
\text { sion of all randomized participants (num- } \\
\text { ber evaluable/number randomized): } 96 \% \\
(409 / 425)\end{array}$ \\
\hline Selective reporting (reporting bias) & Low risk & Pre-specfied outcomes reported \\
\hline Other bias & Low risk & No obvious other sources of bias \\
\hline
\end{tabular}

Michaelsen 1985

\begin{tabular}{ll}
\hline Methods & $\begin{array}{l}\text { Randomized controlled trial } \\
\text { Length of follow up: } 5 \text { months }\end{array}$ \\
\hline Participants & $\begin{array}{l}\text { Number analysed for primary outcome: } 121 \text { for nutritional outcomes; age range } 5 \text { to } 14 \\
\text { years } \\
\text { Inclusion criteria: children from a school identified as having high prevalence of hook- } \\
\text { worm on the basis of a previous survey } \\
\text { Exclusion criteria: children with height above } 137 \mathrm{~cm} \text { girls and } 145 \mathrm{~cm} \text { for boys since } \\
\text { these were the upper limits in the reference ranges }\end{array}$ \\
\hline Interventions & $\begin{array}{l}\text { Single dose versus placebo } \\
\text { 1. Tetrachloroethylene: } 0.1 \mathrm{~mL} / \mathrm{kg}(\mathrm{max} 5 \mathrm{~mL} \text { dose) } \\
\text { 2. Placebo: children's cough medicine }\end{array}$
\end{tabular}

Deworming drugs for soil-transmitted intestinal worms in children: effects on nutritional indicators, haemoglobin and school 
Michaelsen 1985 (Continued)

Treatment strategy: randomized and treated all children

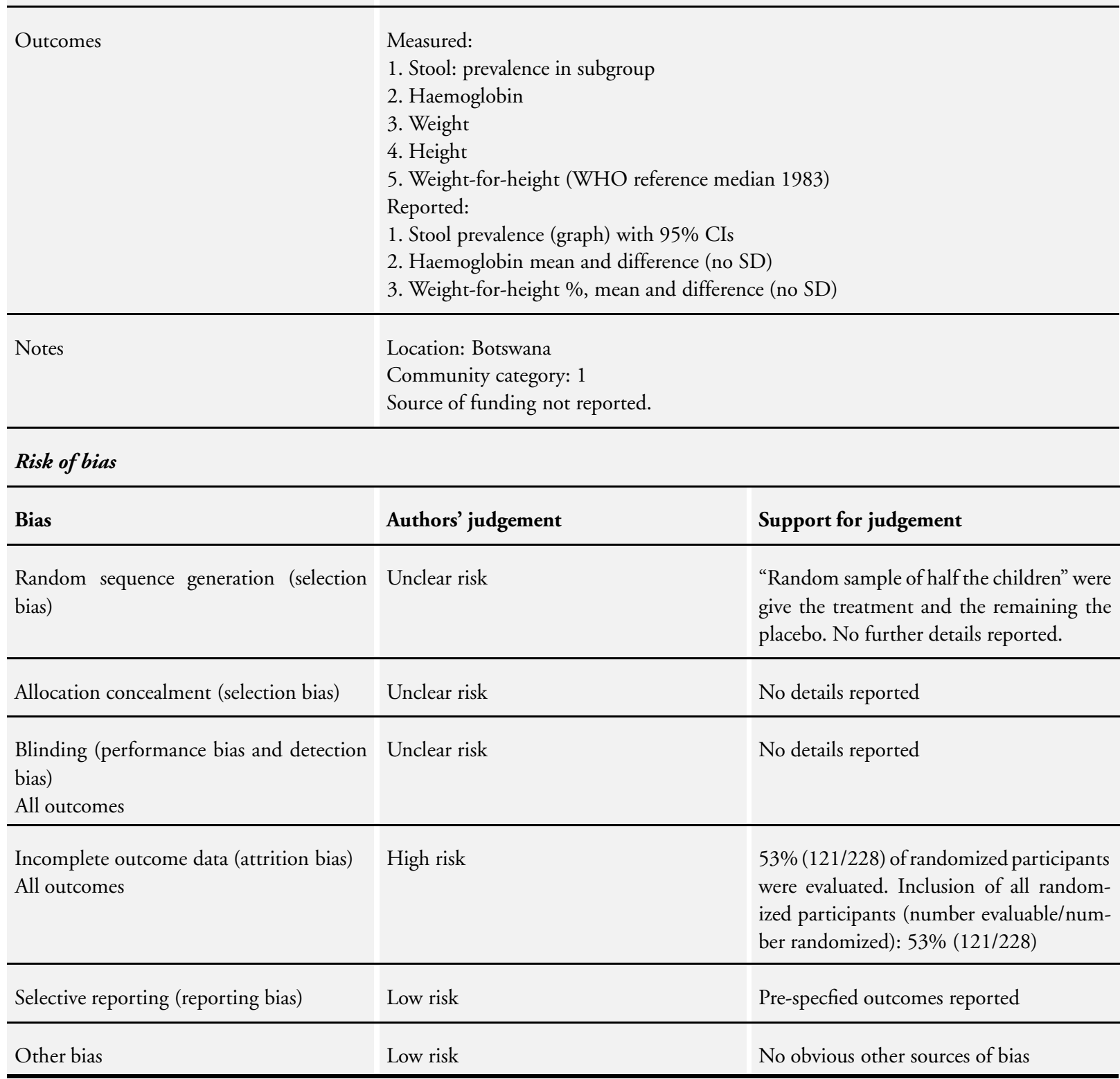



robust standard errors presented (confirmed in correspondence with authors).

Cluster unit: schools.

Average cluster size: 400

ICCs: not reported.

Length of follow up: one year for phased quasi-randomized comparisons for health outcomes. Two years for school attendance

Participants

Interventions
Number analysed for primary outcome: For haemoglobin approximately 4\% (778/20, 000) - unclear how these were selected. Unclear for nutritional outcomes. Unclear for exam performance and cognitive tests

Inclusion criteria: none explicitly stated. "Nearly all rural primary schools" in Busia district, Kenya, involved in a NGO deworming programme were studied, with a total enrolment of 30,000 pupils aged six to eighteen. Exclusion criteria: girls > 13 years old

Deworming package of interventions including multiple doses of anthelminth versus no treatment within phased intervention

1. Albendazole $600 \mathrm{mg}$ (Zentel, SZB) every 6 months in 1998 intervention, and albendazole 400mg (Zentel, SZB) in 1999. In addition:

- Worm prevention education (public health lectures, wall charts and teacher training in worm prevention. Health education on hand washing and wearing shoes to prevent worm infection.

- Schools with schistosomiasis prevalence over 30\% were mass treated with praziquantel (40mg/kg Bayer) annually. $6 / 25$ schools treated with praziquantel in 1998 , and $16 / 50$ treated with praziquantel in 1990.

2. No treatment

Outcomes

1. Weight-for-age $Z$ score difference in end value

2. Haemoglobin difference in end value

3. Exam score performance (ICS administered English, Mathematics and Science-Agriculture exams in pupils in grades 3 to 8 )

4. Cognitive tests including picture search, Raven matrix, verbal fluency, digit span, Spanish learning, and a dynamic test using syllogisms

5. Height-for-age $Z$ score difference in end value

6. School participation rate based on external NGO assessment at unannounced visit Not included in review: worm prevalence and intensity, self reported sickness, worm prevention behaviours: proportion "clean" as per health worker observation, proportion wearing shoes as per health worker observation, self-reported contact with fresh-water in past week, access to home latrine, malaria/fever

Notes

This was an econometric analysis of 75 schools with a total of 30,000 pupils enrolled. The intervention was phased over time, and there were two comparisons, one in 1998 and one in 1999 if the analysis is comparative within each individual year. Schools in a deworming project were stratified by zone, their involvement with other NGO programmes, and then listed alphabetically and every third school assigned to start the programme in 1998, to start it in 1999, or to be a control. The schools are divided into 3 groups: Group 1 schools are in the treatment group throughout. Group 2 schools are in the control group for the 1998 comparison, but in the treatment group in the 1999 
comparison. Group 3 schools are in the control group throughout.

In the description of the intervention two comparisons are thus identified: Group 1 schools versus Group 2 and 3 schools in 1998, and Group 1 and 2 schools versus Group 3 schools in 1999. However, in a personal correspondence the authors state that there is no health data for Group 3 schools for 1999. For nutritional and haemoglobin outcomes, this implies that there is one possible quasi-randomized comparison with contemporary information in both treatment and control, which is 1998, Group 1 versus Group $2 \&$ 3. However, results for health outcomes are presented for the 1998 comparison of Group 1 ( 25 schools) versus Group 2 ( 25 schools)

Number of children followed up for nutritional outcomes in 1998 comparison is unclear.

A sub-sample of the original quasi-randomized comparison appears to have been followed up for haemoglobin and nutritional outcomes, but it is not clear how this sample was selected (table $\mathrm{V}$ in the paper)

For school attendance, during the study, the authors carry out a rigorous assessment of participation rate. This was then calculated as a weighted average by school. For school attendance results are presented for Group 1 versus Group 2 \& 3 in 1998 (one year of treatment, multiple dose), and for Group 1 versus Group 3 in 1999 (two years of treatment, multiple dose), and for Group 2 versus Group 3 in 1999 (one year of treatment, multiple dose). Baseline data is presented for attendance at schools, recorded by school registers in a four week period prior to intervention, recording $97.3 \%$ in Group 1, and $96.3 \%$ in Group 2. However the authors state that this is not considered reliable. There are no comparable baseline values (ie measured in the same way as the outcome measurement of school attendance) to know whether baseline attendance happens to be different across groups

Group 1 schools have an overall prevalence of 38\% heavy/moderate worm infection in 1998 , compared to the initial survey in control schools in 1999, where it was $52 \%$

Academic performance measured by Internationaal Christelijk Steunfonds Africa (ICS) exam scores in a regression analysis that included school participation during the year of the exam, and also if it was a year 1 treatment school or a year 2 treatment school. The authors did not provide the results by the quasi-randomized comparison eligible for this review (1998 Group 1 versus Group 2 \& 3; 1999 Group 1 \& 2 versus group 3)

The cognitive tests were carried out in all three groups of schools during 2000. The authors do not formally report the result in the paper, other than to state that they were not significant.

27/75 schools were involved in other NGO projects which consisted of financial assistance for textbook purchase and classroom construction, and teacher performance incentives. The distribution of these other interventions is not clear, but the authors state that these schools were stratified according to involvement in these other programmes.

The authors state that health education had a minimal impact on behaviour, and that any programme effect is almost certainly due to the effect of deworming drugs, rather than health education.

School participation rate was computed among all pupils enrolled in 1998. Pupils present on the day of an unannounced NGO visit were considered participant. Pupils had 3.8 
Miguel 2004 (Cluster) (Continued)

observations on average per year

Location: Kenya

Community category: 1

Source of funding: Sponsored by the World Bank and the Partnership for Child Devel-

opment

\section{Risk of bias}

\begin{tabular}{l|l|l}
\hline Bias & Authors' judgement & Support for judgement \\
\hline $\begin{array}{l}\text { Random sequence generation (selection } \\
\text { bias) }\end{array}$ & High risk & $\begin{array}{l}\text { Schools in a deworming project were strat- } \\
\text { ified by zone, their involvement with other } \\
\text { NGO programmes, and then listed alpha- } \\
\text { betically and every third school assigned to } \\
\text { start the programme in 1998, to start it in } \\
1999, \text { or to be a control }\end{array}$ \\
\hline
\end{tabular}

Allocation concealment (selection bias) High risk

Not concealed (see above).

Blinding (performance bias and detection High risk bias)

All outcomes

Pragmatic cluster implementation study with no blinding.

Incomplete outcome data (attrition bias) High risk All outcomes
For haemoglobin, weight and height the outcomes appear to have been measured on a sub-sample of the quasi-randomized population. For haemoglobin this was approximately $4 \%(778 / 20,000)$ - it is unclear how these were selected. The number of participants or measurements on which nutritional outcomes are based is not stated. For exam performance only regression data are given

Outcome data not reported for cognitive tests, though authors state: Deworming treatment effects are not significantly different than zero for any component of the cognitive exam (results available on request)

Other bias

High risk
Recruitment bias: Low (no asymmetric migration between schools)

Baseline imbalance: High (Group 1 schools have an overall prevalence of $38 \%$ heavy/ moderate worm infection in 1998, compared to the initial survey in control schools in 1999 , where it was $52 \%$.)

Loss of clusters: Low (none reported) 
Miguel 2004 (Cluster) (Continued)

Incorrect analysis: Low (correctly adjusted for clustering).

Comparability with RCTs randomizing individuals: high (Analysis 4.7)

The intervention was a package including deworming drugs for soil transmitted helminths, praziquantel to treat schistosomiasis in schools with $>30 \%$ prevalence, and health promotion interventions. In addition $27 / 75$ schools were involved in other NGO projects which consisted of financial assistance for textbook purchase and classroom construction, and teacher performance incentives. The distribution of the latter interventions is not clear

These co-interventions confound the potential effects of deworming drugs to treat STHs. However, the authors kindly provided a re-analysis of their data, with the praziquantel treated schools removed from the analysis. This represents as subgroup analysis of the original quasi-randomized comparison

Nga 2009

Methods

Randomized controlled trial

Length of follow up: 4 months

Participants

Number analysed for primary outcome: 510 randomized

Inclusion criteria: School children aged 6-8 years and written informed consent from parents/caregivers

Exclusion criteria: Haemoglobin $(\mathrm{Hb})$ concentrations $<80 \mathrm{~g} / \mathrm{L}$, chronic illness, congenital abnormalities, mental or severe physical handicap, severe malnutrition ([z-scores for weight-for-height (WHZ) <-3.0 SD), obesity (BMI >=25 or z-scores for WHZ >+2 SD) , or receiving deworming within the previous 6 months

Interventions

Single dose versus placebo

1. Non-fortified biscuit plus placebo deworming-treatment (placebo);

2. Multi-micronutrient-fortified biscuit plus placebo deworming-treatment;

3. Non- fortified biscuit plus deworming treatment with albendazole $(400 \mathrm{mg})$;

4. Multi-micronutrient-fortified biscuits plus deworming treatment with Albendazole (400 mg)

Treatment strategy: randomized and treated all children

Outcomes

1. Haemoglobin

2. Mean mid-upper arm circumference

3. Cognitive function

Deworming drugs for soil-transmitted intestinal worms in children: effects on nutritional indicators, haemoglobin and school 
4. Change in weight-for-age (WAZ), height-for-age (HAZ), and WHZ, using the EpiInfo program (version 6.0, CDC) and the National Center for Health Statistics/WHO nutritional reference data

Not included in review: Changes in zinc, iodine, and ferritin concentration; worm prevalence

Measured but not reported:

Weight and height recorded at baseline and end point but only baseline data reported.

Skin fold thickness recorded at baseline and end point, but no data reported

$\begin{array}{ll}\text { Notes } & \text { Location:Vietnam } \\ \text { Community category: } 2 \\ \text { This study was supported by the Neys-van Hoogstraten Foundation, The Netherlands, } \\ \text { and the Ellison Medical Foundation }\end{array}$

Risk of bias

\begin{tabular}{|c|c|c|}
\hline Bias & Authors' judgement & Support for judgement \\
\hline $\begin{array}{l}\text { Random sequence generation (selection } \\
\text { bias) }\end{array}$ & Low risk & $\begin{array}{l}\text { Computer generated. "pupils were allo- } \\
\text { cated to } 1 \text { of the } 4 \text { intervention groups } \\
\text { based on a computer generated list, } \\
\text { matched on age ( } 12 \text {-mo age groups) and } \\
\text { sex, and using a block size of } 8 \text { by one of the } \\
\text { researchers not involved in the field work" }\end{array}$ \\
\hline Allocation concealment (selection bias) & Low risk & Central allocation. \\
\hline $\begin{array}{l}\text { Blinding (performance bias and detection } \\
\text { bias) } \\
\text { All outcomes }\end{array}$ & Low risk & $\begin{array}{l}\text { Participants and key personnel were } \\
\text { blinded. "All investigators, field assistants, } \\
\text { teachers, and children did not know the } \\
\text { codes of the study groups." } \\
\text { Placebo identical to treatment (orange } \\
\text { chewable tablet). }\end{array}$ \\
\hline $\begin{array}{l}\text { Incomplete outcome data (attrition bias) } \\
\text { All outcomes }\end{array}$ & Low risk & $\begin{array}{l}482 / 510 \text { randomized participants were } \\
\text { evaluated. Reasons for drop-out: moved= } \\
12 \text {, surgery }=2 \text {, refusal to participate ( } \mathrm{n}= \\
14) \text {, balanced across intervention groups. } \\
\text { Inclusion of all randomized participants } \\
\text { (number evaluable/number randomized): } \\
94.5 \%(482 / 510)\end{array}$ \\
\hline Selective reporting (reporting bias) & High risk & $\begin{array}{l}\text { Three outcomes (weight, height and skin } \\
\text { fold thickness) not reported adequately }\end{array}$ \\
\hline Other bias & Low risk & No obvious other source of bias. \\
\hline
\end{tabular}

Deworming drugs for soil-transmitted intestinal worms in children: effects on nutritional indicators, haemoglobin and school 
Nokes 1992

\begin{tabular}{|c|c|}
\hline Methods & $\begin{array}{l}\text { Randomized controlled trial } \\
\text { Length of follow up: } 2.25 \text { months ( } 9 \text { weeks) }\end{array}$ \\
\hline Participants & $\begin{array}{l}\text { Number analysed for primary outcome: 103; age range } 9 \text { to } 12 \text { years } \\
\text { Inclusion criteria: children from } 3 \text { schools in Mandeville; Trichuris egg counts > 1900, } \\
\text { but low hookworm counts on } 2 \text { occasions before the trial separated by } 3 \text { months } \\
\text { Exclusion criteria: twins; severe illness; physical handicaps; neurological disorders }\end{array}$ \\
\hline Interventions & $\begin{array}{l}\text { Single dose versus placebo } \\
\text { 1. Albendazole: } 400 \mathrm{mg} \text { daily for } 3 \text { days (SmithKlineBeecham) } \\
\text { 2. Placebo: identical } \\
\text { Treatment strategy: screened children then randomized and treated infected children }\end{array}$ \\
\hline Outcomes & $\begin{array}{l}\text { Cognitive tests: digit span forwards/backwards; arithmetic and coding from Wechsler } \\
\text { Intelligence Scale for Children; fluency and listening comprehension from the Clinical } \\
\text { Evaluation of Language functions; and matching familiar figures test } \\
\text { Not included in review: stool egg counts at baseline and } 10 \text { days (prevalence and arith- } \\
\text { metic mean); height and weight (expressed as \% NCHS standard) iron status; school } \\
\text { attendance; IQ; socioeconomic status; educational opportunity measures at baseline } \\
\text { Outcomes not reported: nutritional outcomes at } 9 \text { weeks cited as too short a follow-up } \\
\text { period to demonstrate a change. School attendance only measured at baseline }\end{array}$ \\
\hline Notes & $\begin{array}{l}\text { Location: Jamaica } \\
\text { Community category: } 1 \\
\text { There was an infected placebo group and an "uninfected control group" } \\
\text { Source of funding not reported. }\end{array}$ \\
\hline
\end{tabular}

Risk of bias

\begin{tabular}{l|l|l} 
Bias & Authors' judgement & Support for judgement \\
\hline $\begin{array}{l}\text { Random sequence generation (selection } \\
\text { bias) }\end{array}$ & Unclear risk & $\begin{array}{l}\text { "Randomly assigned”; no further details re- } \\
\text { ported }\end{array}$ \\
\hline $\begin{array}{l}\text { Allocation concealment (selection bias) } \\
\begin{array}{l}\text { Blinding (performance bias and detection } \\
\text { bias) } \\
\text { All outcomes }\end{array}\end{array}$ & Unclear risk & No details reported \\
\hline
\end{tabular}

Incomplete outcome data (attrition bias) High risk All outcomes

Selective reporting (reporting bias)
Unclear risk
$73 \%(103 / 140)$ of randomized participants were evaluated. Inclusion of all randomized participants (number evaluable/number randomized): $73 \%(103 / 140)$

Pyschometric tests reported; other outcomes such as nutrition not reported 


\section{Nokes 1992 (Continued)}

\begin{tabular}{lll}
\hline Other bias & Low risk & No obvious other source of bias \\
\hline
\end{tabular}

Olds 1999

\begin{tabular}{ll} 
Methods & $\begin{array}{l}\text { Randomized controlled trial } \\
\text { Length of follow up: } 6 \text { months for randomized comparison }\end{array}$ \\
\hline Participants & $\begin{array}{l}\text { Number analysed for primary outcome: } 1518 \text { randomized, } 90 \% \text { followed up at } 6 \text { months } \\
\text { Inclusion criteria: School age children }\end{array}$ \\
$\begin{array}{l}\text { Exclusion criteria: Failure to submit } 2 \text { stool specimens prior to the initial treatment, } \\
\text { known allergy to either drug, treatment with either drug within } 6 \text { months, lack of } \\
\text { consent, and marriage or possible pregnancy }\end{array}$
\end{tabular}

Interventions
$\begin{aligned} & \text { Albendazole }(400 \mathrm{mg}) \text { plus praziquantel }(40 \mathrm{mg} / \mathrm{kg}) \\ & \text { Praziquantel plus an albendazole placebo } \\ & \text { Albendazole plus a praziquantel placebo, } \\ & \text { Both placebos. }\end{aligned}$

Outcomes

No useable data.

Not included in review: Ultrasound, physical examination and history findings, duplicate stool and urine measurements of egg counts

Measured but not reported:

Weight, height, skinfold thickness (subscapular, triceps, and abdominal) and haemoglobin recorded at baseline and end point but only baseline data reported. Data for side effects not useable in review

Notes

Location: China, Philippines and Kenya

Community category: 1

randomized comparison up to 6 months at which point all infected children were treated as needed, and followed up until one year

There was no difference between the side effect rate from albendazole or the double placebo

Result text: "No statistically significant improvement was seen in haemoglobin after albendazole treatment. In the study population as a whole, no significant differences between treatment groups were seen in any of the growth and anthropometric measurements."

Source of funding: Tropical Disease Research of the World Health Organization

\section{Risk of bias}

Bias

Authors' judgement

Support for judgement

Random sequence generation (selection Low risk bias)

Computer generated. "Randomization lists were prepared by WHO/TDR using a randomized block design with a block size of 80 " 
Olds 1999

(Continued)

Blinding (performance bias and detection Low risk bias)

All outcomes

Incomplete outcome data (attrition bias) Low risk All outcomes

Selective reporting (reporting bias)

High risk

Randomized controlled trial

Length of follow up: 9 weeks (2.25 months)
Number analysed for primary outcome: 191

Inclusion criteria: children ages 2 to 5 years registered at village health centres

Exclusion criteria: none stated

Single dose versus placebo
$\begin{aligned} & \text { 1. Albendazole: } 400 \mathrm{mg} \text { plus } 30 \mathrm{mg} \text { elemental iron weekly } \\ & \text { 2. Elemental iron: } 30 \mathrm{mg} \text { weekly } \\ & \text { Treatment strategy: randomized and treated all children }\end{aligned}$

Outcomes

1. Mean change in weight post-treatment

2. Mean change in height post-treatment

3. Mean change in haemoglobin post-treatment

4. Mean haemoglobin post-treatment

Not included in review: z-scores for height-for-age, weight-for-age, and weight-for-height (NCHS reference)

Notes

Location: Java, Indonesia

Community category: 2

Source of funding: Kimia Farma Indonesia.

\section{Risk of bias}

Bias

Authors' judgement

Support for judgement 
Palupi 1997 (Continued)

\begin{tabular}{|c|c|c|}
\hline $\begin{array}{l}\text { Random sequence generation (selection } \\
\text { bias) }\end{array}$ & Unclear risk & $\begin{array}{l}\text { "The children were randomly divided into } \\
\text { three, equal-sized treatment groups", no } \\
\text { further details reported }\end{array}$ \\
\hline Allocation concealment (selection bias) & Unclear risk & No details reported. \\
\hline $\begin{array}{l}\text { Blinding (performance bias and detection } \\
\text { bias) } \\
\text { All outcomes }\end{array}$ & Unclear risk & $\begin{array}{l}\text { Described as double blind, participants } \\
\text { were blinded, unclear whether provider and } \\
\text { assessor were }\end{array}$ \\
\hline $\begin{array}{l}\text { Incomplete outcome data (attrition bias) } \\
\text { All outcomes }\end{array}$ & Low risk & $\begin{array}{l}97 \%(289 / 299) \text { of enrolled participants } \\
\text { were evaluated. Inclusion of all random- } \\
\text { ized participants (number evaluable/num- } \\
\text { ber randomized): } 97 \%(289 / 299)\end{array}$ \\
\hline Selective reporting (reporting bias) & Low risk & Pre-specfied outcomes reported. \\
\hline Other bias & Low risk & No obvious other source of bias. \\
\hline
\end{tabular}

\section{Rousham 1994 (Cluster)}

\begin{tabular}{|c|c|}
\hline Methods & $\begin{array}{l}\text { Cluster-randomized controlled trial } \\
\text { Method to adjust for clustering: not adjusted } \\
\text { Cluster unit: village. } \\
\text { Average cluster size: } 114 . \\
\text { ICCs: not reported. } \\
\text { Length of follow up: } 18 \text { months }\end{array}$ \\
\hline Participants & $\begin{array}{l}\text { Number analysed for primary outcome: } 1402 \\
\text { Inclusion criteria: children ages } 2 \text { to } 6 \text { years from } 13 \text { villages surrounding a mother and } \\
\text { child health centre; subgroup living in } 8 \text { villages within waking distance of health centre } \\
\text { analysed for additional outcomes } \\
\text { Exclusion criteria: none stated }\end{array}$ \\
\hline Interventions & $\begin{array}{l}\text { Multiple doses versus placebo } \\
\text { 1. Mebendazole: } 500 \mathrm{mg} \text { (Janssen) every } 2 \text { months } \\
\text { 2. Placebo } \\
\text { 3. Pyrantel pamoate and mebendazole: initial dose of } 10 \mathrm{mg} / \mathrm{kg} \text { pyrantel pamoate (Com- } \\
\text { bantrin, Pfizer, UK) then mebendazole } 500 \mathrm{mg} \text { bimonthly for } 8 \text { months ( } 4 \text { doses) } \\
\text { Treatment strategy: randomized and treated all children }\end{array}$ \\
\hline Outcomes & $\begin{array}{l}\text { 1. ANOVAs for change in z-scores for z-scores for height-for-age, weight-for-age, and } \\
\text { weight-for-height (NCHS reference) } \\
\text { 2. Change in mid-upper arm circumference at } 6,12 \text {, and } 18 \text { months (no SD) } \\
\text { 3. Other outcomes measured but not reported: height; weight; stool examination for } \\
\text { prevalence and intensity in subgroup (eggs/g: modified sedimentation technique); sub- } \\
\text { group also analysed for intestinal permeability, albumin, alpha-1-antichymotrypsin, to- } \\
\text { tal protein every } 2 \text { months }\end{array}$ \\
\hline
\end{tabular}

Deworming drugs for soil-transmitted intestinal worms in children: effects on nutritional indicators, haemoglobin and school 
Rousham 1994 (Cluster) (Continued)

\begin{tabular}{ll}
\hline Notes & Location: Bangladesh \\
& Community category: 1 \\
& No adjustment made for cluster randomization \\
& Source of funding: the Overseas Development Administration and the University of \\
& Cambridge Maintenance Fund \\
\hline
\end{tabular}

Risk of bias

\begin{tabular}{|c|c|c|}
\hline Bias & Authors' judgement & Support for judgement \\
\hline $\begin{array}{l}\text { Random sequence generation (selection } \\
\text { bias) }\end{array}$ & Unclear risk & $\begin{array}{l}\text { The study was described as randomized, no } \\
\text { further details reported }\end{array}$ \\
\hline Allocation concealment (selection bias) & Unclear risk & No details reported \\
\hline $\begin{array}{l}\text { Blinding (performance bias and detection } \\
\text { bias) } \\
\text { All outcomes }\end{array}$ & Low risk & $\begin{array}{l}\text { Participants field } \\
\text { workers were blinded, unclear if assessment } \\
\text { was blinded. "The treatment and placebo } \\
\text { tablets were given in a double-blind man- } \\
\text { ner; neither the fieldworkers nor the par- } \\
\text { ents were aware of the group to which they } \\
\text { belonged" }\end{array}$ \\
\hline $\begin{array}{l}\text { Incomplete outcome data (attrition bias) } \\
\text { All outcomes }\end{array}$ & Low risk & $\begin{array}{l}94 \%(1402 / 1476) \text { of enrolled participants } \\
\text { were evaluated. Inclusion of all random- } \\
\text { ized participants (number evaluable/num- } \\
\text { ber randomized): } 94 \%(1402 / 1476)\end{array}$ \\
\hline Selective reporting (reporting bias) & Low risk & Not all pre-specified outcomes reported \\
\hline Other bias & Low risk & $\begin{array}{l}\text { Recruitment bias: unclear (Not known if } \\
\text { children shift clinics in the light of the in- } \\
\text { tervention) } \\
\text { Baseline imbalance: low (No differences ap- } \\
\text { parent) } \\
\text { Loss of clusters: low (none reported) } \\
\text { Incorrect analysis: not adjusted (high risk) } \\
\text { Comparability with RCTs randomizing in- } \\
\text { dividuals: unclear }\end{array}$ \\
\hline
\end{tabular}

Sarkar 2002

\begin{tabular}{ll}
\hline Methods & $\begin{array}{l}\text { Randomized controlled trial } \\
\text { Length of follow up: } 4 \text { months (16 weeks) }\end{array}$ \\
\hline Participants & $\begin{array}{l}\text { Number analysed for primary outcome: } 81 \\
\text { Inclusion criteria: children ages } 2 \text { to } 12 \text { living in Mirpur slum infected with Ascaris } \\
\text { Exclusion criteria: none stated }\end{array}$ \\
\hline
\end{tabular}

Deworming drugs for soil-transmitted intestinal worms in children: effects on nutritional indicators, haemoglobin and school 
Sarkar 2002 (Continued)

\begin{tabular}{|c|c|c|}
\hline Interventions & \multicolumn{2}{|c|}{$\begin{array}{l}\text { Single dose versus placebo } \\
\text { 1. Pyrantel pamoate: } 11 \mathrm{mg} / \mathrm{kg} \text { (Combantrin, Pfizer, Bangladesh) } \\
\text { 2. Placebo } \\
\text { Treatment strategy: screened children then randomized and treated infected children }\end{array}$} \\
\hline Outcomes & \multicolumn{2}{|c|}{$\begin{array}{l}\text { 1. Mean change in weight post-treatment } \\
\text { 2. Mean weight post-treatment } \\
\text { 3. Mean change in height post-treatment } \\
\text { 4. Mean height post-treatment } \\
\text { Not included in review: median \% weight-for-age, weight-for-height, and height-for- } \\
\text { age }\end{array}$} \\
\hline Notes & \multicolumn{2}{|c|}{$\begin{array}{l}\text { Location: Bangladesh } \\
\text { Community category: } 1 \\
\text { Source of funding: research grant from the World Bank and was funded by the Bangladesh } \\
\text { National Nutrition Council }\end{array}$} \\
\hline \multicolumn{3}{|l|}{ Risk of bias } \\
\hline Bias & Authors' judgement & Support for judgement \\
\hline $\begin{array}{l}\text { Random sequence generation (selection } \\
\text { bias) }\end{array}$ & Low risk & "Random table" \\
\hline Allocation concealment (selection bias) & Unclear risk & No details reported \\
\hline $\begin{array}{l}\text { Blinding (performance bias and detection } \\
\text { bias) } \\
\text { All outcomes }\end{array}$ & Low risk & $\begin{array}{l}\text { "Double-blind"; "The syrups were identi- } \\
\text { cal in appearance and flavor and were pack- } \\
\text { aged in identical containers. Randomized } \\
\text { patient numbers were labeled on the bot- } \\
\text { tles to maintain the double blind design" }\end{array}$ \\
\hline $\begin{array}{l}\text { Incomplete outcome data (attrition bias) } \\
\text { All outcomes }\end{array}$ & Low risk & $\begin{array}{l}94 \%(81 / 85) \text { of randomized participants } \\
\text { were evaluated. Inclusion of all random- } \\
\text { ized participants (number evaluable/num- } \\
\text { ber randomized): } 94 \%(81 / 85)\end{array}$ \\
\hline Selective reporting (reporting bias) & Low risk & Pre-specfied outcomes reported \\
\hline Other bias & Low risk & No obvious other source of bias \\
\hline
\end{tabular}

Deworming drugs for soil-transmitted intestinal worms in children: effects on nutritional indicators, haemoglobin and school 
Randomized controlled trial

Length of follow up: 6.5 months (26 weeks)

Participants

Number analysed for primary outcome: 392; age range 6 to 12 years

Inclusion criteria: children in grades 2 to 5 of 14 schools in Jamaica with intensities of Trichura $>1200 \mathrm{eggs} / \mathrm{g}$

Exclusion criteria: children with mental handicaps identified by their teachers

\begin{tabular}{ll} 
Interventions & $\begin{array}{l}\text { Multiple doses versus placebo } \\
\text { 1. Albendazole: } 800 \mathrm{mg}(400 \mathrm{mg} \text { in each of } 2 \text { days), repeated at } 3 \text { months and } 6 \mathrm{months} \\
\text { 2. Identical placebo } \\
\text { Treatment strategy: screened children then randomized and treated infected children }\end{array}$ \\
\hline Outcomes & $\begin{array}{l}\text { 1. Main study (264 children) } \\
\text { Wide range achievement test: reading, arithmetic, and spelling subtests; school atten- } \\
\text { dance from children with class registers pre- and post-intervention, height-for-age z- } \\
\text { score, body mass index pre- and post-intervention } \\
\text { 2. Subgroup } 1 \text { (189 infected children from original population) } \\
\text { Digit span; verbal fluency test; visual search; number choice; French vocabulary learning } \\
\text { 3. Subgroup } 2 \text { ( } 97 \text { children from grade 5) } \\
\text { French learning; digit spans (forward and backward); Corsi block span; verbal fluency; } \\
\text { picture search; silly sentences } \\
\text { Other outcomes measured but not reported: stool at baseline and at } 8 \text { weeks after sec- } \\
\text { ond treatment round (Kato): prevalence and intensity, weight, height, z-scores (NCHS } \\
\text { standard) }\end{array}$ \\
\hline
\end{tabular}

Notes

Location: Jamaica

Community category: 1

Source of funding: grant from the James S. McDonnell Foundation

\section{Risk of bias}

\begin{tabular}{|c|c|c|}
\hline Bias & Authors' judgement & Support for judgement \\
\hline $\begin{array}{l}\text { Random sequence generation (selection } \\
\text { bias) }\end{array}$ & Low risk & Random-numbers table \\
\hline Allocation concealment (selection bias) & Unclear risk & No details reported \\
\hline $\begin{array}{l}\text { Blinding (performance bias and detection } \\
\text { bias) } \\
\text { All outcomes }\end{array}$ & Unclear risk & $\begin{array}{l}\text { Paricipants blinded; unclear whether asses- } \\
\text { sors were }\end{array}$ \\
\hline $\begin{array}{l}\text { Incomplete outcome data (attrition bias) } \\
\text { All outcomes }\end{array}$ & Low risk & $\begin{array}{l}96 \%(392 / 407) \text { of randomized participants } \\
\text { were evaluated. Inclusion of all random- } \\
\text { ized participants (number evaluable/num- } \\
\text { ber randomized): } 96 \%(392 / 407)\end{array}$ \\
\hline Selective reporting (reporting bias) & Low risk & All stated outcomes reported \\
\hline
\end{tabular}


Simeon 1995 (Continued)

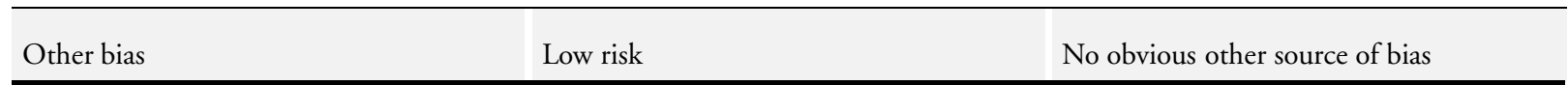

Solon 2003

\begin{tabular}{|c|c|}
\hline Methods & $\begin{array}{l}\text { Randomized controlled trial } \\
\text { Length of follow up: } 16 \text { weeks }\end{array}$ \\
\hline Participants & $\begin{array}{l}\text { Number analysed for primary outcome: } 808 / 851 \\
\text { Inclusion criteria: Children in grades } 1-6 \\
\text { Exclusion criteria: Children with Haemoglobin }<8 \mathrm{~g} / \mathrm{dL}\end{array}$ \\
\hline Interventions & $\begin{array}{l}\text { Single dose versus placebo } \\
\text { 1. Fortified beverage (multivitamin and iron) twice per day for } 16 \text { weeks with an- } \\
\text { thelmintic therapy (Albendazole } 400 \mathrm{mg} \text { ) } \\
\text { 2. Fortified beverage with placebo anthelmintic therapy } \\
\text { 3. Non-fortified beverage with anthelmintic therapy ( } 400 \mathrm{mg} \text { ) } \\
\text { 4. Non-fortified beverage with placebo anthelmintic therapy }\end{array}$ \\
\hline Outcomes & $\begin{array}{l}\text { No useable data. } \\
\text { Not included in review: Urine iodine, stool egg count } \\
\text { Measured but not reported: Weight, height, haemoglobin, physical fitness (Harvard step } \\
\text { test), heart rate, cognitive ability measured by the Primary Mental Abilities Test for } \\
\text { Filipino Children. The test measures verbal, non verbal and quantitative skills }\end{array}$ \\
\hline Notes & $\begin{array}{l}\text { Location: Philippines } \\
\text { Community category: } 2 \\
\text { Narrative results: } \\
\text { No significant difference in change in weight. Deworming improved the iron status of a } \\
\text { subgroup of moderately to severely subjects. Deworming had either no effect or a negative } \\
\text { effect on fitness scores, and the effect on heart rate was inconclusive. Deworming had } \\
\text { either no effect or a negative effect on mental ability scores } \\
\text { Sources of support: The Nutrition Center of the Philippines, The Procter \& Gamble Co }\end{array}$ \\
\hline
\end{tabular}

Risk of bias

\begin{tabular}{|c|c|c|}
\hline Bias & Authors' judgement & Support for judgement \\
\hline $\begin{array}{l}\text { Random sequence generation (selection } \\
\text { bias) }\end{array}$ & Unclear risk & $\begin{array}{l}\text { Randomization at individual level, no fur- } \\
\text { ther details. }\end{array}$ \\
\hline Allocation concealment (selection bias) & Unclear risk & No details reported. \\
\hline $\begin{array}{l}\text { Blinding (performance bias and detection } \\
\text { bias) } \\
\text { All outcomes }\end{array}$ & Low risk & $\begin{array}{l}\text { Double-blind study. "Both the researchers } \\
\text { and the study participants were blinded to } \\
\text { the treatment assignment of each child" } \\
\text { "Placebo bever- } \\
\text { age and placebo anthelmintic pills were in- }\end{array}$ \\
\hline
\end{tabular}

Deworming drugs for soil-transmitted intestinal worms in children: effects on nutritional indicators, haemoglobin and school 


\begin{tabular}{|c|c|c|}
\hline & & $\begin{array}{l}\text { distinguishable from their counterparts in } \\
\text { appearance, smell and taste" }\end{array}$ \\
\hline $\begin{array}{l}\text { Incomplete outcome data (attrition bias) } \\
\text { All outcomes }\end{array}$ & Low risk & $\begin{array}{l}808 / 851(95 \%) \text { enrolled participants were } \\
\text { evaluated, no reasons for withdrawal re- } \\
\text { ported. Inclusion of all randomized partici- } \\
\text { pants (number evaluable/number random- } \\
\text { ized): } 95 \%(808 / 851)\end{array}$ \\
\hline Selective reporting (reporting bias) & High risk & $\begin{array}{l}\text { Nutritional and haemoglobin outcomes } \\
\text { not fully reported. }\end{array}$ \\
\hline Other bias & Low risk & No obvious other source of bias. \\
\hline
\end{tabular}

Stephenson 1989

\begin{tabular}{|c|c|}
\hline Methods & $\begin{array}{l}\text { Randomized controlled trial } \\
\text { Length of follow up: } 6 \text { months }\end{array}$ \\
\hline Participants & $\begin{array}{l}\text { Number analysed for primary outcome: } 150 \\
\text { Inclusion criteria: all available children in lower grades (standards } 1 \text { and } 2 \text { ) in Mvindeni } \\
\text { Primary School, Kwale district (unscreened); subgroup of } 36 \text { boys chosen; haemoglobin } \\
>8 \mathrm{~g} / \mathrm{dL} \text {; willing to co-operate in physical tests; pre-pubertal } \\
\text { Exclusion criteria: haemoglobin }<8 \mathrm{~g} / \mathrm{dL} \text {. }\end{array}$ \\
\hline Interventions & $\begin{array}{l}\text { Single dose versus placebo } \\
\text { 1. Albendazole: } 2 \text { × } 200 \mathrm{mg} \text { (SmithKline and French) } \\
\text { 2. Placebo: identical } \\
\text { Treatment strategy: randomized and treated all children }\end{array}$ \\
\hline Outcomes & $\begin{array}{l}\text { 1. Mean weight post-treatment } \\
\text { 2. Mean change in weight post-treatment } \\
\text { 3. Mean height post-treatment } \\
\text { 4. Mean change in height post-treatment } \\
\text { 5. Mean mid-upper arm circumference } \\
\text { 6. Mean change in mid-upper arm circumference } \\
\text { 7. Mean triceps skinfold thickness } \\
\text { 8. Mean change in triceps skinfold thickness } \\
\text { 9. Mean subscapular skinfold thickness } \\
\text { 10. Mean change in subscapular skinfold thickness } \\
\text { Not included in review: all above converted to \% median for sex and age; prevalence and } \\
\text { mean egg counts (arithmetic and geometric means); Harvard Step Test heart rates and } \\
\text { score for subgroup }\end{array}$ \\
\hline Notes & $\begin{array}{l}\text { Location: Kenya } \\
\text { Community category: } 1 \\
\text { Source of funding: Smith Kline \& French Laboratories, Ltd., and the Edna McConnell } \\
\text { Clark Foundation, grant 284-0120 }\end{array}$ \\
\hline
\end{tabular}


Stephenson 1989 (Continued)

\section{Risk of bias}

\begin{tabular}{|c|c|c|}
\hline Bias & Authors' judgement & Support for judgement \\
\hline $\begin{array}{l}\text { Random sequence generation (selection } \\
\text { bias) }\end{array}$ & Unclear risk & $\begin{array}{l}\text { "allocated at random within sex", no fur- } \\
\text { ther details reported }\end{array}$ \\
\hline Allocation concealment (selection bias) & Unclear risk & No details reported \\
\hline $\begin{array}{l}\text { Blinding (performance bias and detection } \\
\text { bias) } \\
\text { All outcomes }\end{array}$ & Low risk & $\begin{array}{l}\text { Participants blinded, tablets identical for } \\
\text { treatment and placebo; "Both examina- } \\
\text { tions were carried out with the same team of } \\
\text { workers, each doing the same procedures, } \\
\text { and were done in a blind fashion" }\end{array}$ \\
\hline $\begin{array}{l}\text { Incomplete outcome data (attrition bias) } \\
\text { All outcomes }\end{array}$ & Low risk & $\begin{array}{l}88 \%(150 / 171) \text { of randomized participants } \\
\text { were evaluated, reasons for losses to follow } \\
\text { up not reported. Inclusion of all random- } \\
\text { ized participants (number evaluable/num- } \\
\text { ber randomized): } 88 \%(150 / 171)\end{array}$ \\
\hline Selective reporting (reporting bias) & Low risk & Pre-specified outcomes reported \\
\hline Other bias & Low risk & No obvious other source of bias \\
\hline
\end{tabular}

\section{Stephenson 1993}

Methods

Participants
Randomized controlled trial

Length of follow up: 3.6 months (subgroup) and 8.2 months (main study)

Number analysed for primary outcome: 284

Inclusion criteria: all school children (unscreened) in grades 1 to 5 in Mvindeni Primary School

Subgroup (53 analysed) of 60 boys chosen because haemoglobin $>80 \mathrm{~g} / \mathrm{L}$, willing to cooperate in physical tests and appetite tests, pre-pubertal, infected with at least 1 of helminths (screened), hookworm < 20,000 eggs/g; hookworm or Trichuris count $>1000$ eggs/g or Ascaris $>4000$ eggs/g

Exclusion criteria: Severe anaemia (haemoglobin $<75 \mathrm{~g} / \mathrm{L}$ )

Interventions

Multiple doses versus placebo

1. Albendazole (single dose) plus placebo: $600 \mathrm{mg}(3 \times 200 \mathrm{mg})$ SmithKline Beecham at outset, identical placebo at 3.6 months

2. Albendazole (multiple doses): single dose $600 \mathrm{mg}$ repeated at 3.6 months

3. Placebo: identical placebo

Treatment strategy: randomized and treated all children (but infected children for appetite/activity outcomes) 
Stephenson 1993 (Continued)

\begin{tabular}{|c|c|}
\hline Outcomes & $\begin{array}{l}\text { 1. Mean weight post-treatment } \\
\text { 2. Mean change in weight post-treatment } \\
\text { 3. Mean height post-treatment } \\
\text { 4. Mean change in height post-treatment } \\
\text { 5. Mean mid-upper arm circumference } \\
\text { 6. Mean change in mid-upper arm circumference } \\
\text { 7. Mean triceps skinfold thickness } \\
\text { 8. Mean change in triceps skinfold thickness } \\
\text { 9. Mean subscapular skinfold thickness } \\
\text { 10. Mean change in subscapular skinfold thickness } \\
\text { 11. Mean haemoglobin post-treatment } \\
\text { 12. Mean change in haemoglobin post treatment } \\
\text { Not included in review: prevalence, eggs/g: geometric and arithmetic mean; converted } \\
\text { to percentage of median for age and sex using NCHS references; \% weight-for-age, \% } \\
\text { height for age; \% weight-for-height; \% arm circumference for age; \% triceps for age; \% } \\
\text { subscapular for age; Harvard Step Test; appetite (self-rating and snack consumed intake } \\
\text { in kilojoules) }\end{array}$ \\
\hline Notes & $\begin{array}{l}\text { Location: Kwale, Kenya } \\
\text { Community category: } 1 \\
\text { Source of funding: supported in part by Thrasher Research Fund and SmithKline } \\
\text { Beecham, Ltd. }\end{array}$ \\
\hline
\end{tabular}

Risk of bias

\begin{tabular}{|c|c|c|}
\hline Bias & Authors' judgement & Support for judgement \\
\hline $\begin{array}{l}\text { Random sequence generation (selection } \\
\text { bias) }\end{array}$ & Unclear risk & $\begin{array}{l}\text { "at random within sex by descending hook- } \\
\text { worm egg count". }\end{array}$ \\
\hline Allocation concealment (selection bias) & Unclear risk & No details reported \\
\hline $\begin{array}{l}\text { Blinding (performance bias and detection } \\
\text { bias) } \\
\text { All outcomes }\end{array}$ & Low risk & $\begin{array}{l}\text { Participants blinded, tablets identical for } \\
\text { treatment and placebo; "Both examina- } \\
\text { tions were conducted by the same team, } \\
\text { each doing the same procedures, and were } \\
\text { done in a blind fashion" }\end{array}$ \\
\hline $\begin{array}{l}\text { Incomplete outcome data (attrition bias) } \\
\text { All outcomes }\end{array}$ & Low risk & $\begin{array}{l}86 \%(284 / 328) \text { of randomized participants } \\
\text { were evaluated, reasons for losses to follow } \\
\text { up not reported. Inclusion of all random- } \\
\text { ized participants (number evaluable/num- } \\
\text { ber randomized): } 86 \%(284 / 328)\end{array}$ \\
\hline Selective reporting (reporting bias) & Low risk & Pre-specified outcomes reported \\
\hline Other bias & Low risk & No obvious other source of bias \\
\hline
\end{tabular}

Deworming drugs for soil-transmitted intestinal worms in children: effects on nutritional indicators, haemoglobin and school 
Stoltzfus 1997 (Cluster)

\begin{tabular}{|c|c|}
\hline Methods & $\begin{array}{l}\text { Cluster-randomized controlled trial } \\
\text { Method to adjust for clustering: generalised estimating equations } \\
\text { Cluster unit: school. } \\
\text { Average cluster size: } 255 \text {. } \\
\text { ICCs: not reported. } \\
\text { Length of follow up: } 12 \text { months }\end{array}$ \\
\hline Participants & $\begin{array}{l}\text { Number analysed for primary outcome: } 3063 \text {; mean age } 10.5 \text { years } \\
\text { Inclusion criteria: children in grades } 1 \text { to } 5 \text { from } 12 \text { randomly selected schools on Pemba } \\
\text { island; only grades } 1 \text { to } 4 \text { included in evaluation of nutritional effect } \\
\text { Exclusion criteria: none stated }\end{array}$ \\
\hline Interventions & $\begin{array}{l}\text { Multiple doses versus placebo } \\
\text { 1. Mebendazole: } 500 \mathrm{mg} \text { twice yearly } \\
\text { 2. Mebendazole: } 500 \mathrm{mg} 3 \text { times a year } \\
\text { 3. Placebo } \\
\text { Treatment strategy: randomized and treated all children }\end{array}$ \\
\hline Outcomes & $\begin{array}{l}\text { 1. Weight gain } \\
\text { 2. Height gain } \\
\text { 3. Change in haemoglobin at } 12 \text { months } \\
\text { Estimates are provided from multiple regression models taking into account various } \\
\text { baseline differences for } 2 \text { subgroups above and below } 10 \text { years old. Unadjusted outcomes } \\
\text { not presented. (These } 2 \text { groups were combined in the Dickson } 2000 \text { a Cochrane Review. } \\
\text { Other outcomes measured but not reported: micronutrient status (blood) for protopor- } \\
\text { phyrin and serum ferritin; stool egg count (Kato-Katz); z-scores for height-for-age and } \\
\text { weight-for-height; body mass index }\end{array}$ \\
\hline Notes & $\begin{array}{l}\text { Location: Zanzibar, Tanzania } \\
\text { Community category: } 1 \\
\text { Appropriate adjustment made for cluster randomization using general estimating equa- } \\
\text { tion } \\
\text { Source of funding: Funded through cooperative agreement DAN-5116-1-00-8051-00 } \\
\text { between The Johns Hopkins University and the Office of Health and Nutrition, United } \\
\text { States Agency for International Development }\end{array}$ \\
\hline
\end{tabular}

Risk of bias

\begin{tabular}{|c|c|c|}
\hline Bias & Authors' judgement & Support for judgement \\
\hline $\begin{array}{l}\text { Random sequence generation (selection } \\
\text { bias) }\end{array}$ & Unclear risk & $\begin{array}{l}3 \text { schools randomly selected from each of } \\
\text { the } 4 \text { districts, and then allocated }\end{array}$ \\
\hline Allocation concealment (selection bias) & Unclear risk & No details reported \\
\hline $\begin{array}{l}\text { Blinding (performance bias and detection } \\
\text { bias) } \\
\text { All outcomes }\end{array}$ & Unclear risk & No details reported \\
\hline
\end{tabular}

Deworming drugs for soil-transmitted intestinal worms in children: effects on nutritional indicators, haemoglobin and school 
Stoltzfus 1997 (Cluster) (Continued)

\begin{tabular}{l|l|l}
\hline $\begin{array}{l}\text { Incomplete outcome data (attrition bias) } \\
\text { All outcomes }\end{array}$ & Low risk & $\begin{array}{l}84 \%(3063 / 3605) \text { of randomized partici- } \\
\text { pants were evaluated, reasons for losses to } \\
\text { follow up not reported. Inclusion of all ran- } \\
\text { domized participants (number evaluable/ } \\
\text { number randomized): 84\% (3063/3605) }\end{array}$ \\
\hline Selective reporting (reporting bias) & High risk & $\begin{array}{l}\text { Not all pre-specified outcomes reported ad- } \\
\text { equately. }\end{array}$ \\
\hline Other bias & Low risk & $\begin{array}{l}\text { Recruitment bias: low (Unlikely to change } \\
\text { schools) } \\
\text { Baseline imbalance: low (no differences ap- } \\
\text { parent) } \\
\text { Loss of clusters: low (none reported) } \\
\text { Incorrect analysis: cluster adjusted (low } \\
\text { risk). } \\
\text { Comparability with RCTs randomising in- } \\
\text { dividuals: unclear }\end{array}$ \\
\hline
\end{tabular}

Stoltzfus 2001

Methods

Participants
Randomized control trial (factorial design)

Length of follow up: 12 months

\begin{tabular}{ll} 
Participants & $\begin{array}{l}\text { Number analysed for primary outcome: } 359 \text { in mebendazole arm aged } 6 \text { to } 59 \text { months } \\
\text { Inclusion criteria: all children in Kengeja village, with age reported as } 3 \text { to } 56 \text { months } \\
\text { by parents; } 3 \text { months before planned start of trial (pre-school children) } \\
\text { Exclusion criteria: severe anaemia }(<70 \mathrm{~g} / \mathrm{L})\end{array}$ \\
\hline Interventions & $\begin{array}{l}\text { Multiple doses versus placebo } \\
1 . \text { Mebendazole: } 500 \mathrm{mg} \text { given every } 3 \text { months at home visits } \\
\text { 2. Placebo: identical } \\
\text { Treatment strategy: randomized and treated all children } \\
\text { Both groups also received: } 0.5 \mathrm{~mL} \text { ferrous sulfate }(20 \mathrm{mg} / \mathrm{mL}) ; 10 \mathrm{mg} \text { iron daily for } 1 \\
\text { year or placebo as per factorial design }\end{array}$ \\
\hline
\end{tabular}

Outcomes
1. Cognitive outcomes: motor and language development by parents reporting gross motor and language milestones using scoring system developed specifically for the trial 2. Anthropometric measures presented in a stratified manner: $(<30$ months, $>30$ months), and presented as proportion of children with small arm circumference, mild wasting, and stunting

3. Proportion of children with poor appetite, and proportion with severe anaemia are presented for the whole group

4. Iron indices (not disaggregated, independent of the iron randomization)

Not included in review: prevalence and egg counts (no SD/SEM); motor and language scores (results of multiple regression and correlations; raw data not reported) haemoglobin (results not reported by randomized comparisons)

Others measured but not reported: stool (Kato-Katz); weight; height; malaria film; fer- 
Stoltzfus 2001 (Continued)

ritin; appetite as reported by mothers

\begin{tabular}{ll}
\hline Notes & Location: Zanzibar, Tanzania \\
Community category: 2 & Factorial design, with households randomized to iron, random allocation of mebenda- \\
zole by child, stratified by iron allocation and age grouped households. An iron with \\
mebendazole treatment term was tested in all regression models, but it did not reach \\
significance \\
Source of funding: Thrasher Research Fund between The Johns Hopkins University and \\
the United States Agency for International Development, AL Pharma, Baltimore, MD, \\
and Pharmamed, Malta \\
\hline
\end{tabular}

Risk of bias

\begin{tabular}{|c|c|c|}
\hline Bias & Authors' judgement & Support for judgement \\
\hline $\begin{array}{l}\text { Random sequence generation (selection } \\
\text { bias) }\end{array}$ & Unclear risk & $\begin{array}{l}\text { Randomized by "blocks of } 4 \text { ", no further } \\
\text { details reported }\end{array}$ \\
\hline Allocation concealment (selection bias) & Low risk & $\begin{array}{l}\text { Pills in bottles with unique treatment } \\
\text { codes, assigned by } 1 \text { investigator, codes kept } \\
\text { in sealed envelopes }\end{array}$ \\
\hline $\begin{array}{l}\text { Blinding (performance bias and detection } \\
\text { bias) } \\
\text { All outcomes }\end{array}$ & Unclear risk & $\begin{array}{l}\text { Participants and provider were blinded; un- } \\
\text { clear whether assessor was blinded }\end{array}$ \\
\hline $\begin{array}{l}\text { Incomplete outcome data (attrition bias) } \\
\text { All outcomes }\end{array}$ & High risk & $\begin{array}{l}52 \%(359 / 684) \text { enrolled participants were } \\
\text { evaluated. Inclusion of all randomized par- } \\
\text { ticipants (number evaluable/number ran- } \\
\text { domized): } 52 \%(359 / 684=52 \%)\end{array}$ \\
\hline Selective reporting (reporting bias) & Low risk & All prespecified outcomes reported \\
\hline Other bias & High risk & No obvious other source of bias \\
\hline
\end{tabular}

Sur 2005

\begin{tabular}{l|l} 
Methods & $\begin{array}{l}\text { Randomized controlled trial } \\
\text { Length of follow up: } 12 \text { months }\end{array}$ \\
\hline Participants & $\begin{array}{l}\text { Number analysed for primary outcome: } 683 \\
\text { Inclusion criteria: all children aged } 2 \text { to } 5 \text { in slum area of Tiljala identified and enrol } \\
\text { Exclusion criteria: major illnesses; birth defects; and unwillingness to participate }\end{array}$ \\
\hline Interventions & $\begin{array}{l}\text { Multiple doses versus placebo } \\
\text { 1. Albendazole: } 400 \text { mg in a vitamin B complex base liquid; repeated at } 6 \text { months } \\
\text { 2. Placebo: vitamin B complex base }\end{array}$ \\
\hline
\end{tabular}

Deworming drugs for soil-transmitted intestinal worms in children: effects on nutritional indicators, haemoglobin and school 
Treatment strategy: randomized and treated all children

\begin{tabular}{|c|c|c|}
\hline Outcomes & \multicolumn{2}{|c|}{$\begin{array}{l}\text { 1. Mean weight post-treatment (presented graphically) } \\
\text { Other outcomes measured but not reported: stool samples from random sample of } 30 \% \\
\text { (formalin concentration technique) for prevalence of Ascaris; weight-for-age; diarrhoeal } \\
\text { episodes }\end{array}$} \\
\hline Notes & \multicolumn{2}{|c|}{$\begin{array}{l}\text { Location: India } \\
\text { Community category: } 2 \\
\text { Source of funding: the Indian Council of Medical Research, New Delhi, India }\end{array}$} \\
\hline \multicolumn{3}{|l|}{ Risk of bias } \\
\hline Bias & Authors' judgement & Support for judgement \\
\hline $\begin{array}{l}\text { Random sequence generation (selection } \\
\text { bias) }\end{array}$ & Low risk & $\begin{array}{l}\text { Computer-generated random numbers se- } \\
\text { quence }\end{array}$ \\
\hline Allocation concealment (selection bias) & Low risk & Identical coded bottles \\
\hline $\begin{array}{l}\text { Blinding (performance bias and detection } \\
\text { bias) } \\
\text { All outcomes }\end{array}$ & Low risk & $\begin{array}{l}\text { Participants and key personnel were } \\
\text { blinded }\end{array}$ \\
\hline $\begin{array}{l}\text { Incomplete outcome data (attrition bias) } \\
\text { All outcomes }\end{array}$ & Low risk & $\begin{array}{l}97 \%(683 / 702) \text { of enrolled participants } \\
\text { were evaluated. Inclusion of all random- } \\
\text { ized participants (number evaluable/num- } \\
\text { ber randomized): } 97 \%(683 / 702)\end{array}$ \\
\hline Selective reporting (reporting bias) & High risk & $\begin{array}{l}\text { Incomplete reporting of some outcomes } \\
\text { (prevalence of } \text { Ascaris in stools; weight-for- } \\
\text { age; diarrhoeal episodes). }\end{array}$ \\
\hline Other bias & Low risk & No obvious other source of bias \\
\hline
\end{tabular}

\section{Watkins 1996}

Methods

Participants
Randomized controlled trial

Length of follow up: 6 months

Number analysed for primary outcome: 226 for nutritional outcomes, reduced for cognitive outcomes; age 7 to 12 years

Inclusion criteria: children attending grades 1 to 4 in primary schools in the Guatemala highlands

Exclusion criteria: > 12 years; deworming medicine in last year 
Watkins 1996 (Continued)

\begin{tabular}{|c|c|}
\hline Interventions & $\begin{array}{l}\text { Multiple doses versus placebo } \\
\text { 1. Albendazole: } 2 \times 200 \mathrm{mg} \text { at baseline and } 12 \text { weeks } \\
\text { 2. Placebo: identical at baseline and } 12 \text { weeks } \\
\text { Treatment strategy: randomized and treated all children }\end{array}$ \\
\hline Outcomes & $\begin{array}{l}\text { 1. Mean weight post-treatment } \\
\text { 2. Mean change in weight post-treatment } \\
\text { 3. Mean height post-treatment } \\
\text { 4. Mean change in height post-treatment } \\
\text { 5. School performance: attendance rates of children actively attending school measured } \\
\text { using attendance books, dropout rates } \\
\text { 6. Mean mid-upper arm circumference } \\
\text { 7. Mean change in mid-upper arm circumference } \\
\text { 8. Cognitive tests: Interamerican vocabulary test, Interamerican reading test, Peabody } \\
\text { picture vocabulary test } \\
\text { Not included in review: egg counts (Kato-Katz: arithmetic and geometric mean); z-scores } \\
\text { (NCHS-CDC-WHO reference) for weight-for-age, change in weight-for-age, height, } \\
\text { change in height, height-for-age, change in height-for-age, weight-for-height, and change } \\
\text { in height-for-age }\end{array}$ \\
\hline Notes & $\begin{array}{l}\text { Location: Guatemala } \\
\text { Community category: } 1 \\
\text { Source of funding: Pew Charitable Trusts, the US Agency for International Develop- } \\
\text { ment University Development and Linkage Program, the Children's Miracle Network } \\
\text { Telethon, and the ARCS Foundation }\end{array}$ \\
\hline
\end{tabular}

Risk of bias

\begin{tabular}{l|ll}
\hline Bias & Authors' judgement & Support for judgement \\
\hline $\begin{array}{l}\text { Random sequence generation (selection } \\
\text { bias) }\end{array}$ & Unclear risk & $\begin{array}{l}\text { "stratified by gender and age and then ran- } \\
\text { domly assigned" }\end{array}$ \\
\hline $\begin{array}{l}\text { Allocation concealment (selection bias) } \\
\text { Blinding (performance bias and detection } \\
\text { bias) } \\
\text { All outcomes }\end{array}$ & Low risk & No details reported \\
\hline $\begin{array}{l}\text { Incomplete outcome data (attrition bias) } \\
\text { All outcomes }\end{array}$ & Low risk & $\begin{array}{l}\text { "The children and field workers were un- } \\
\text { aware of treatment group assignment" }\end{array}$ \\
\hline
\end{tabular}

Deworming drugs for soil-transmitted intestinal worms in children: effects on nutritional indicators, haemoglobin and school 
Watkins 1996 (Continued)

ber evaluable/number randomized): $90 \%$ (226/250)

\begin{tabular}{lll}
\hline Selective reporting (reporting bias) & Low risk & Pre-specified outcomes reported \\
\hline Other bias & Low risk & No other obvious source of bias. \\
\hline
\end{tabular}

\section{Willett 1979}

\begin{tabular}{|c|c|}
\hline Methods & $\begin{array}{l}\text { Randomized controlled trial } \\
\text { Length of follow up: } 12 \text { months }\end{array}$ \\
\hline Participants & $\begin{array}{l}\text { Number analysed for primary outcome: 268; age range } 6 \text { to } 91 \text { months } \\
\text { Inclusion criteria: pre-school children from Ubiri village who attended clinic and pro- } \\
\text { duced a stool sample } \\
\text { Exclusion criteria: none stated }\end{array}$ \\
\hline Interventions & $\begin{array}{l}\text { Multiple doses } \\
\text { 1. Levamisole syrup: } 2.5 \mathrm{mg} / \mathrm{kg} \text { every } 3 \text { months } \\
\text { 2. Flavoured sucrose syrup: every } 3 \text { months } \\
\text { Treatment strategy: randomized and treated all children }\end{array}$ \\
\hline Outcomes & $\begin{array}{l}\text { 1. Growth rates in both groups, and subgroup of those infected; these have been corrected } \\
\text { for various factors using analysis of covariance (unadjusted data are not reported and the } \\
\text { growth rates are not presented with any measure of variance) } \\
\text { Measured but not reported: height; length; stool egg count in subgroup (Kato method) } \\
\text {; growth rates using least square method }\end{array}$ \\
\hline Notes & $\begin{array}{l}\text { Location: Tanzania } \\
\text { Community category: } 3 \\
\text { Source of funding: Research and Publications Committee, University of Dar es Salaam. } \\
\text { Analysis was supported by a training grant (HL 05998-04) from the National Heart, } \\
\text { Lung and Blood Institute, NIH, DHEW Bethesda, MD }\end{array}$ \\
\hline
\end{tabular}

\section{Risk of bias}

\begin{tabular}{|c|c|c|}
\hline Bias & Authors' judgement & Support for judgement \\
\hline $\begin{array}{l}\text { Random sequence generation (selection } \\
\text { bias) }\end{array}$ & Low risk & Random-numbers table \\
\hline Allocation concealment (selection bias) & Unclear risk & No details reported \\
\hline $\begin{array}{l}\text { Blinding (performance bias and detection } \\
\text { bias) } \\
\text { All outcomes }\end{array}$ & Low risk & $\begin{array}{l}\text { "children were weighed and measured as } \\
\text { before by a person unaware of their treat- } \\
\text { ment status"; placebo and treatment given } \\
\text { as a flavoured syrup }\end{array}$ \\
\hline
\end{tabular}




\begin{tabular}{l|l|l}
\hline $\begin{array}{l}\text { Incomplete outcome data (attrition bias) } \\
\text { All outcomes }\end{array}$ & High risk & $\begin{array}{l}78 \%(268 / 341) \text { of randomized participants } \\
\text { were evaluated. Inclusion of all random- } \\
\text { ized participants (number evaluable/num- } \\
\text { ber randomized): 78\% (268/341) }\end{array}$ \\
\hline Selective reporting (reporting bias) & High risk & Not all pre-specified outcomes reported \\
\hline Other bias & Low risk & No obvious other source of bias \\
\hline
\end{tabular}

CI: confidence interval; Community category: a measure of the prevalence and intensity of infection (see Table 1); NCHS: National Center for Health Statistics: SD: standard deviation; SEM: standard error of the mean.

Characteristics of excluded studies [ordered by study ID]

\begin{tabular}{|c|c|}
\hline Study & Reason for exclusion \\
\hline Araujo 1987 & Not a randomized controlled trial. \\
\hline Beasley 1999 & $\begin{array}{l}\text { Treatment regimen comprised of albendazole for geohelminths and praziquantel against schistosomiasis versus } \\
\text { placebo }\end{array}$ \\
\hline Bhargava 2003 & $\begin{array}{l}\text { Treatment regimen comprised of albendazole for geohelminths and praziquantel against schistosomiasis versus } \\
\text { placebo }\end{array}$ \\
\hline Bhutta 2009 & $\begin{array}{l}\text { Population with significant comorbidity - 6-24 month old children with severe anaemia }(<70 \mathrm{~g} / \mathrm{L}) \text {. In popu- } \\
\text { lation with severe anaemia }\end{array}$ \\
\hline Boivin 1993 & $\begin{array}{l}\text { Factorial-designed randomized controlled trial with children allocated to deworming and iron supplementa- } \\
\text { tion, and in which the analysis compares the results for the levamisole and iron group against all the other } \\
\text { groups combined. Thus the analysis is confounded by the iron co-intervention (Included in the Dickson } \\
2000 \text { a Cochrane Review). }\end{array}$ \\
\hline Cooper 2006 & Study of allergy with no outcomes of interest. \\
\hline Cowden 2000 & Not a randomized controlled trial. \\
\hline Diouf 2002 & $\begin{array}{l}\text { Intervention comprised mebendazole, vitamin A, and iron supplementation and metronidazole as a combined } \\
\text { intervention versus placebo }\end{array}$ \\
\hline Evans 1986 & $\begin{array}{l}\text { Treatments randomized, but some placebo groups accessed treatment. Analysis was by the treatment received, } \\
\text { and randomization was ignored. (Included in the Dickson 2000a Cochrane Review). }\end{array}$ \\
\hline
\end{tabular}

Deworming drugs for soil-transmitted intestinal worms in children: effects on nutritional indicators, haemoglobin and school 
(Continued)

Fernando 1983 villages allocated to treatment or no treatment on the basis of a coin toss. Essentially a cluster-randomized trial
with 2 large clusters (Included in the Dickson 2000a Cochrane Review, which reported that no conclusions
could be drawn from the results due to selective reporting)

Forrester 1998 Treatment regimen comprised of 3 days of albendazole versus 1 day of albendazole and 2 days of placebo versus 1 day of pyrantel and 2 days of placebo

Friis $2003 \quad$ Combined treatment regimen albendazole for geohelminths and praziquantel for Schistosoma mansoni versus placebo.

Gilgen $2001 \quad$ Population consists of adults.

Gupta 1982 Only two units of allocation for relevant comparison. Children randomly divided into 4 groups, "taking care that age distribution was similar in each group". The 4 groups were then allocated 1 of 4 different single treatment regimens; no details given

Hadidjaja 1998 Cluster-randomized controlled trial with 2 units of allocation to mebendazole and placebo. Authors stated that there were differences in environmental sanitary conditions in the clusters (Included in the Dickson 2000a Cochrane Review, but it was noted that the groups were not comparable and there was high loss to follow up)

Hathirat 1992 Treatment regimen comprised of albendazole for geohelminths and iron versus placebo

\begin{tabular}{ll}
\hline Jalal 1998 & No relevant outcomes. \\
\hline Jinabhai 2001a & $\begin{array}{l}\text { Treatment regimen comprised of albendazole for geohelminths and praziquantel against schistosomiasis versus } \\
\text { placebo }\end{array}$
\end{tabular}

Jinabhai 2001b Treatment regimen comprised of albendazole for geohelminths and praziquantel against schistosomiasis versus placebo

Karyadi $1996 \quad$ Not a randomized controlled trial.

Krubwa $1974 \quad$ Not a randomized controlled trial.

Kvalsvig 1991b The researchers were unable to collect outcome data after treatment due to major floods in the area

Latham $1990 \quad$ Population with schistosomiasis treated with praziquantel.

Marinho $1991 \quad$ Treatment regimen comprised of mebendazole and metronidazole versus placebo

Mwaniki $2002 \quad$ Treatment regimen albendazole for geohelminths and praziquantel for schistosomiasis versus placebo

Pollitt $1991 \quad$ Not described as randomized; conference proceedings.

Rohner $2010 \quad$ Treatment regimen albendazole for geohelminths and praziquantel for schistosomiasis versus placebo

Steinmann $2008 \quad$ No relevant outcomes.

Deworming drugs for soil-transmitted intestinal worms in children: effects on nutritional indicators, haemoglobin and school 
(Continued)

\begin{tabular}{ll}
\hline Stephenson 1980 & Treatment consisted of levamisole with no untreated controls \\
\hline Stephenson 1985 & Treatment regimen metrifonate used to treat Schistosoma haematobium versus placebo \\
\hline Tanumihardjo 1996 & No relevant outcomes. \\
\hline Tanumihardjo 2004 & The only randomisation is the timing of the deworming medicine \\
\hline Taylor 2001 & Treatment regimen albendazole for geohelminths and praziquantel for Schistosoma haematobium versus placebo. \\
\hline Thein-Hlaing 1991 & $\begin{array}{l}\text { 3/21 intervention villages were not randomly allocated, and unclear how intervention and control villages } \\
\text { were allocated as there was a large imbalance (8 intervention and } 13 \text { non-intervention villages) }\end{array}$ \\
\hline Uscátegui 2009 & Study in population with malaria. \\
\hline Wright 2009 & No relevant outcomes. \\
\hline Yang 2003 & Did not consider nutritional or cognitive outcome measures. \\
\hline
\end{tabular}

Characteristics of ongoing studies [ordered by study ID]

\section{Alam 2006}

\begin{tabular}{ll} 
Trial name or title & "Relative efficacy of two regimens of ante-helminthic treatment" \\
\hline Methods & Clinical trial \\
\hline Participants & $\begin{array}{l}\text { Total enrolment: } 200 \\
\text { Inclusion criteria: age } 2 \text { to } 5 \text { years; not suffering from serious chronic illness; stool test positive for soil- } \\
\text { transmitted helminths; not taken any anthelminthic drug in previous } 6 \text { months; parents/guardian agree their } \\
\text { child's participation } \\
\text { Exclusion criteria: age }<2 \text { years and }>5 \text { years; stool test negative for any intestinal helminth; suffering from } \\
\text { serious chronic illness; parents/guardian not willing to give consent for their child's participation; if he/she } \\
\text { receives any anthelminthic drug after survey but before the study interventions }\end{array}$ \\
\hline Interventions & $\begin{array}{l}\text { 1. Conventional treatment of } 400 \text { mg of albendazole in a single dose at } 6 \text {-month interval } \\
\text { 2. Intervention group: } 400 \text { mg of albendazole in a single-dose treatment at 3-month interval }\end{array}$ \\
\hline Outcomes & $\begin{array}{l}\text { Primary } \\
\text { 1. To determine the relative efficacy of de-worming at every } 3 \text { months versus every } 6 \text { month single dose of } \\
\text { albendazole treatment } \\
\text { Secondary } \\
\text { 2. To compare additional morbidity information such as diarrhoeal diseases, respiratory tract infections, } \\
\text { nutritional status and } E \text {. histolytica associated morbidity between } 2 \text { groups }\end{array}$
\end{tabular}

Starting date Not yet recruiting

Deworming drugs for soil-transmitted intestinal worms in children: effects on nutritional indicators, haemoglobin and school 


\section{Alam 2006 (Continued)}

\begin{tabular}{ll} 
Contact information & $\begin{array}{l}\text { Mohammad M Alam MBBS, Principal Investigator, ICDDR,B: Centre for Health and Population Research, } \\
\text { masud_icddrb@yahoo.com }\end{array}$ \\
\hline Notes & $\begin{array}{l}\text { ClinicalTrials.gov identifier: NCT00367627 } \\
\text { Sources of support: International Centre for Diarrhoeal Disease Research, Bangladesh (sponsor) }\end{array}$
\end{tabular}

Elliot 2007

\begin{tabular}{|c|c|}
\hline Trial name or title & $\begin{array}{l}\text { The impact of helminths on the response to immunization and on the incidence of infection and disease in } \\
\text { childhood in Uganda: design of a randomized, double-blind, placebo-controlled, factorial trial of deworming } \\
\text { interventions delivered in pregnancy and early childhood [ISRCTN32849447] }\end{array}$ \\
\hline Methods & $\begin{array}{l}\text { The trial has three randomized, double-blind, placebo-controlled interventions at two times, in two people: a } \\
\text { pregnant woman and her child. Pregnant women are randomized to albendazole or placebo and praziquantel } \\
\text { or placebo. At age } 15 \text { months their children are randomized to three-monthly albendazole or placebo, to } \\
\text { continue to age five years. The proposed designation for this sequence of interventions is a } 2 \text { X } 2 \text { (x } 2 \text { ) factorial } \\
\text { design }\end{array}$ \\
\hline Participants & A cohort of 2500 women has been recruited. \\
\hline Interventions & $\begin{array}{l}\text { 1. Praziquantel + albendazole } \\
\text { 2. Praziquantel + placebo matching albendazole } \\
\text { 3. Placebo matching praziquantel + albendazole } \\
\text { 4. Placebo matching praziquantel + placebo matching albendazole }\end{array}$ \\
\hline Outcomes & $\begin{array}{l}\text { The principal outcomes are: } \\
\text { - Immunological responses to BCG and tetanus immunization } \\
\text { - Incidence of infection in childhood with malaria and Mycobacterium tuberculosis. } \\
\text { - Incidence of infectious and atopic disease events in childhood (pneumonia, diarrhoea, malaria,measles, } \\
\text { tuberculosis and vertical HIV transmission; atopic eczema, urticaria, allergic rhinitis and conjunctivitis, } \\
\text { wheeze). } \\
\text { Secondary outcomes are anaemia, growth and development. }\end{array}$ \\
\hline Starting date & $01 / 04 / 2003$ \\
\hline Contact information & Dr Alison Elliott, Uganda Virus Research Institute, Entebbe, Uganda \\
\hline Notes & $\begin{array}{l}\text { Added as of } 21 / 03 / 2012 \text { : } \\
\text { Funding has been awarded to allow follow-up to } 2016 \text {, this will allow the assessment of outcomes between } \\
\text { ages } 5 \text { and } 12 \text { years. Additional outcome measures have been added for this age group }\end{array}$ \\
\hline
\end{tabular}


DATA AND ANALYSES

Comparison 1. Screened for infection - Single dose

\begin{tabular}{|c|c|c|c|c|}
\hline Outcome or subgroup title & $\begin{array}{l}\text { No. of } \\
\text { studies }\end{array}$ & $\begin{array}{c}\text { No. of } \\
\text { participants }\end{array}$ & Statistical method & Effect size \\
\hline 1 Weight (kg) & 3 & 149 & Mean Difference (IV, Fixed, 95\% CI) & $0.58[0.40,0.76]$ \\
\hline 2 Height $(\mathrm{cm})$ & 2 & 136 & Mean Difference (IV, Fixed, 95\% CI) & $0.10[-0.15,0.35]$ \\
\hline $\begin{array}{l}3 \text { Mid-upper arm circumference } \\
(\mathrm{cm})\end{array}$ & 3 & 112 & Mean Difference (IV, Fixed, 95\% CI) & $0.28[0.12,0.44]$ \\
\hline 4 Triceps skin fold thickness $(\mathrm{mm})$ & 2 & 68 & Mean Difference (IV, Fixed, 95\% CI) & $0.77[0.46,1.08]$ \\
\hline $\begin{array}{l}5 \text { Subscapular skin fold thickness } \\
(\mathrm{mm})\end{array}$ & 1 & & Mean Difference (IV, Fixed, 95\% CI) & Totals not selected \\
\hline 6 Body mass index & 1 & & Mean Difference (IV, Fixed, 95\% CI) & Subtotals only \\
\hline 7 Haemoglobin $(\mathrm{g} / \mathrm{dL})$ & 2 & 108 & Mean Difference (IV, Fixed, 95\% CI) & $0.37[0.10,0.64]$ \\
\hline
\end{tabular}

\section{Comparison 2. Screened for infection - Multiple dose, outcomes in the first year}

\begin{tabular}{|c|c|c|c|c|}
\hline Outcome or subgroup title & $\begin{array}{l}\text { No. of } \\
\text { studies }\end{array}$ & $\begin{array}{c}\text { No. of } \\
\text { participants }\end{array}$ & Statistical method & Effect size \\
\hline 1 Body mass index & 1 & & Mean Difference (IV, Fixed, 95\% CI) & Totals not selected \\
\hline $\begin{array}{l}2 \text { School attendance (days present } \\
\text { at school) }\end{array}$ & 1 & & Mean Difference (IV, Fixed, 95\% CI) & Subtotals only \\
\hline
\end{tabular}

Comparison 3. Target population treated - Single dose

\begin{tabular}{|c|c|c|c|c|}
\hline Outcome or subgroup title & $\begin{array}{l}\text { No. of } \\
\text { studies }\end{array}$ & $\begin{array}{c}\text { No. of } \\
\text { participants }\end{array}$ & Statistical method & Effect size \\
\hline 1 Weight $(\mathrm{kg})$ & 9 & & Mean Difference (IV, Random, 95\% CI) & Subtotals only \\
\hline 1.1 High prevalence & 4 & 629 & Mean Difference (IV, Random, 95\% CI) & $0.73[-0.12,1.57]$ \\
\hline 1.2 Moderate prevalence & 2 & 873 & Mean Difference (IV, Random, 95\% CI) & $0.11[-0.16,0.38]$ \\
\hline 1.3 Low prevalence & 3 & 1556 & Mean Difference (IV, Random, 95\% CI) & $-0.09[-0.22,0.03]$ \\
\hline 2 Height $(\mathrm{cm})$ & 7 & & Mean Difference (IV, Random, 95\% CI) & Subtotals only \\
\hline 2.1 High prevalence & 3 & 566 & Mean Difference (IV, Random, 95\% CI) & $0.25[-0.10,0.60]$ \\
\hline 2.2 Moderate prevalence & 1 & 191 & Mean Difference (IV, Random, 95\% CI) & $-0.20[-0.47,0.07]$ \\
\hline 2.3 Low prevalence & 3 & 1556 & Mean Difference (IV, Random, 95\% CI) & $-0.26[-0.74,0.21]$ \\
\hline $\begin{array}{l}3 \text { Mid-upper arm circumference } \\
\quad(\mathrm{cm})\end{array}$ & 5 & & Mean Difference (IV, Random, 95\% CI) & Subtotals only \\
\hline 3.1 High prevalence & 3 & 546 & Mean Difference (IV, Random, 95\% CI) & $0.36[0.08,0.64]$ \\
\hline 3.2 Moderate prevalence & 1 & 482 & Mean Difference (IV, Random, 95\% CI) & $0.19[-0.01,0.40]$ \\
\hline 3.3 Low prevalence & 1 & 222 & Mean Difference (IV, Random, 95\% CI) & $-0.3[-0.52,-0.08]$ \\
\hline 4 Triceps skin fold thickness (mm) & 2 & & Mean Difference (IV, Random, 95\% CI) & Subtotals only \\
\hline
\end{tabular}

Deworming drugs for soil-transmitted intestinal worms in children: effects on nutritional indicators, haemoglobin and school 


\begin{tabular}{|c|c|c|c|c|}
\hline 4.1 High prevalence & 2 & 339 & Mean Difference (IV, Random, 95\% CI) & $1.50[0.91,2.08]$ \\
\hline $\begin{array}{l}5 \text { Subscapular skin fold thickness } \\
(\mathrm{mm})\end{array}$ & 2 & & Mean Difference (IV, Fixed, 95\% CI) & Subtotals only \\
\hline 5.1 High prevalence & 2 & 339 & Mean Difference (IV, Fixed, 95\% CI) & $1.29[1.13,1.44]$ \\
\hline 6 Haemoglobin $(\mathrm{g} / \mathrm{dL})$ & 3 & 1005 & Mean Difference (IV, Fixed, 95\% CI) & $0.06[-0.05,0.17]$ \\
\hline 6.1 Moderate prevalence & 2 & 658 & Mean Difference (IV, Fixed, 95\% CI) & $0.06[-0.06,0.17]$ \\
\hline 6.2 Low prevalence & 1 & 347 & Mean Difference (IV, Fixed, 95\% CI) & $0.06[-0.24,0.36]$ \\
\hline $\begin{array}{l}7 \text { Harvard Step Test (measure of } \\
\text { physical well being) }\end{array}$ & 2 & & Mean Difference (IV, Fixed, 95\% CI) & Subtotals only \\
\hline 7.1 High prevalence & 2 & 86 & Mean Difference (IV, Fixed, 95\% CI) & $6.0[4.31,7.69]$ \\
\hline
\end{tabular}

Comparison 4. Target population treated - Multiple dose, outcomes in the first year

\begin{tabular}{|c|c|c|c|c|}
\hline Outcome or subgroup title & $\begin{array}{l}\text { No. of } \\
\text { studies }\end{array}$ & $\begin{array}{c}\text { No. of } \\
\text { participants }\end{array}$ & Statistical method & Effect size \\
\hline 1 Weight $(\mathrm{kg})$ & 7 & 2460 & Mean Difference (IV, Random, 95\% CI) & $0.06[-0.17,0.30]$ \\
\hline 1.1 High prevalence & 2 & 414 & Mean Difference (IV, Random, 95\% CI) & $0.50[-0.25,1.25]$ \\
\hline 1.2 Moderate prevalence & 2 & 811 & Mean Difference (IV, Random, 95\% CI) & $0.03[-0.20,0.26]$ \\
\hline 1.3 Low prevalence & 3 & 1235 & Mean Difference (IV, Random, 95\% CI) & $-0.23[-0.60,0.14]$ \\
\hline 2 Height $(\mathrm{cm})$ & 6 & 1779 & Mean Difference (IV, Random, 95\% CI) & $-0.02[-0.17,0.12]$ \\
\hline 2.1 High prevalence & 2 & 415 & Mean Difference (IV, Random, 95\% CI) & $0.02[-0.15,0.18]$ \\
\hline 2.2 Moderate prevalence & 1 & 129 & Mean Difference (IV, Random, 95\% CI) & $0.10[-0.46,0.66]$ \\
\hline 2.3 Low prevalence & 3 & 1235 & Mean Difference (IV, Random, 95\% CI) & $-0.17[-0.59,0.25]$ \\
\hline $\begin{array}{l}3 \text { Mid-upper arm circumference } \\
\quad(\mathrm{cm})\end{array}$ & 4 & & Mean Difference (IV, Random, 95\% CI) & Subtotals only \\
\hline 3.1 High prevalence & 2 & 395 & Mean Difference (IV, Random, 95\% CI) & $0.24[-0.07,0.55]$ \\
\hline 3.2 Moderate prevalence & 1 & 129 & Mean Difference (IV, Random, 95\% CI) & $0.06[-0.22,0.33]$ \\
\hline 3.3 Low prevalence & 1 & 198 & Mean Difference (IV, Random, 95\% CI) & $-0.35[-0.65,-0.05]$ \\
\hline 4 Triceps skin fold thickness (mm) & 2 & & Mean Difference (IV, Random, 95\% CI) & Subtotals only \\
\hline 4.1 High prevalence & 1 & 188 & Mean Difference (IV, Random, 95\% CI) & $1.80[1.52,2.08]$ \\
\hline 4.2 Moderate prevalence & 1 & 130 & Mean Difference (IV, Random, 95\% CI) & $-0.30[-1.28,0.68]$ \\
\hline $\begin{array}{l}5 \text { Subscapular skin fold thickness } \\
(\mathrm{mm})\end{array}$ & 1 & & Mean Difference (IV, Fixed, 95\% CI) & Totals not selected \\
\hline 5.1 High prevalence & 1 & & Mean Difference (IV, Fixed, 95\% CI) & $0.0[0.0,0.0]$ \\
\hline 6 Haemoglobin $(\mathrm{g} / \mathrm{dL})$ & 4 & 807 & Mean Difference (IV, Fixed, 95\% CI) & $-0.01[-0.14,0.13]$ \\
\hline 6.1 Moderate prevalence & 2 & 464 & Mean Difference (IV, Fixed, 95\% CI) & $0.02[-0.15,0.19]$ \\
\hline 6.2 Low prevalence & 2 & 343 & Mean Difference (IV, Fixed, 95\% CI) & $-0.06[-0.28,0.17]$ \\
\hline $\begin{array}{l}7 \text { School attendance (days present } \\
\text { at school) }\end{array}$ & 2 & & Mean Difference (Random, 95\% CI) & Subtotals only \\
\hline $\begin{array}{l}\text { 7.1 High prevalence (Miguel } \\
1998 \text { comparison) }\end{array}$ & 2 & & Mean Difference (Random, 95\% CI) & $0.04[-0.06,0.14]$ \\
\hline $\begin{array}{l}7.2 \text { High prevalence (Miguel } \\
1999 \text { comparison) }\end{array}$ & 2 & & Mean Difference (Random, 95\% CI) & $0.02[-0.04,0.08]$ \\
\hline
\end{tabular}

Deworming drugs for soil-transmitted intestinal worms in children: effects on nutritional indicators, haemoglobin and school 


\begin{tabular}{|c|c|c|c|c|}
\hline Outcome or subgroup title & $\begin{array}{l}\text { No. of } \\
\text { studies }\end{array}$ & $\begin{array}{c}\text { No. of } \\
\text { participants }\end{array}$ & Statistical method & Effect size \\
\hline 1 Weight $(\mathrm{kg})$ & 5 & & Mean Difference (Random, 95\% CI) & Subtotals only \\
\hline 1.1 High prevalence & 1 & & Mean Difference (Random, 95\% CI) & $0.0[-0.14,0.14]$ \\
\hline 1.2 Moderate prevalence & 1 & & Mean Difference (Random, 95\% CI) & $0.15[-0.02,0.33]$ \\
\hline 1.3 Low prevalence & 3 & & Mean Difference (Random, 95\% CI) & $0.37[-0.40,1.15]$ \\
\hline 2 Height $(\mathrm{cm})$ & 3 & & Mean Difference (IV, Fixed, 95\% CI) & Subtotals only \\
\hline 2.1 Low prevalence & 3 & 1219 & Mean Difference (IV, Fixed, 95\% CI) & $-0.26[-0.84,0.31]$ \\
\hline 3 Haemoglobin $(\mathrm{g} / \mathrm{dL})$ & 2 & & Mean Difference (IV, Fixed, 95\% CI) & Subtotals only \\
\hline 3.1 Low prevalence & 2 & 1365 & Mean Difference (IV, Fixed, 95\% CI) & $6.52[-0.08,0.08]$ \\
\hline $\begin{array}{l}4 \text { School attendance (days present } \\
\text { at school) }\end{array}$ & 1 & & Mean Difference (Fixed, 95\% CI) & Totals not selected \\
\hline 4.1 High prevalence & 1 & & Mean Difference (Fixed, 95\% CI) & $0.0[0.0,0.0]$ \\
\hline
\end{tabular}

Comparison 6. Target population treated - Single dose (low risk of bias for allocation concealment)

\begin{tabular}{|c|c|c|c|c|}
\hline Outcome or subgroup title & $\begin{array}{l}\text { No. of } \\
\text { studies }\end{array}$ & $\begin{array}{c}\text { No. of } \\
\text { participants }\end{array}$ & Statistical method & Effect size \\
\hline 1 Weight $(\mathrm{kg})$ & 2 & 1029 & Mean Difference (IV, Fixed, 95\% CI) & $0.04[-0.11,0.19]$ \\
\hline 1.1 Moderate prevalence & 1 & 682 & Mean Difference (IV, Fixed, 95\% CI) & $0.5[-0.28,1.28]$ \\
\hline 1.2 Low prevalence & 1 & 347 & Mean Difference (IV, Fixed, 95\% CI) & $0.02[-0.13,0.17]$ \\
\hline 2 Height $(\mathrm{cm})$ & 1 & & Mean Difference (IV, Fixed, 95\% CI) & Subtotals only \\
\hline 2.3 Low prevalence & 1 & 347 & Mean Difference (IV, Fixed, 95\% CI) & $0.08[-0.21,0.37]$ \\
\hline $\begin{array}{l}3 \text { Mid-upper arm circumference } \\
(\mathrm{cm})\end{array}$ & 1 & & Mean Difference (IV, Fixed, 95\% CI) & Subtotals only \\
\hline 3.1 Moderate prevalence & 1 & 482 & Mean Difference (IV, Fixed, 95\% CI) & $0.19[-0.01,0.40]$ \\
\hline 4 Haemoglobin $(\mathrm{g} / \mathrm{dL})$ & 2 & 814 & Mean Difference (IV, Fixed, 95\% CI) & $0.05[-0.07,0.17]$ \\
\hline 4.1 Moderate prevalence & 1 & 467 & Mean Difference (IV, Fixed, 95\% CI) & $0.05[-0.08,0.17]$ \\
\hline 4.2 Low prevalence & 1 & 347 & Mean Difference (IV, Fixed, 95\% CI) & $0.06[-0.24,0.36]$ \\
\hline
\end{tabular}

Comparison 7. Target population treated - Multiple dose, outcomes in the first year (low risk of bias for allocation concealment)

\begin{tabular}{lcccc} 
Outcome or subgroup title & $\begin{array}{c}\text { No. of } \\
\text { studies }\end{array}$ & $\begin{array}{c}\text { No. of } \\
\text { participants }\end{array}$ & Statistical method & Effect size \\
\hline 1 Weight $(\mathrm{kg})$ & 1 & & Mean Difference (IV, Fixed, 95\% CI) & Totals not selected \\
1.1 Moderate prevalence & 1 & & Mean Difference (IV, Fixed, 95\% CI) & $0.0[0.0,0.0]$ \\
2 Haemoglobin $(\mathrm{g} / \mathrm{dL})$ & 1 & & Mean Difference (IV, Fixed, 95\% CI) & Subtotals only \\
2.1 Moderate prevalence & 1 & 326 & Mean Difference (IV, Fixed, 95\% CI) & $-0.02[-0.21,0.16]$ \\
\hline
\end{tabular}

Deworming drugs for soil-transmitted intestinal worms in children: effects on nutritional indicators, haemoglobin and school 
Comparison 8. Target population treated - Multiple dose, outcomes after the first year (low risk of bias for allocation concealment)

Outcome or subgroup title

$$
\begin{array}{cc}
\text { No. of } & \text { No. of } \\
\text { studies } & \text { participants }
\end{array}
$$

Statistical method

Mean Difference (Fixed, 95\% CI)

Mean Difference (Fixed, 95\% CI)

Mean Difference (IV, Fixed, 95\% CI)

Mean Difference (IV, Fixed, 95\% CI)
Effect size

Totals not selected $0.0[0.0,0.0]$

Totals not selected $0.0[0.0,0.0]$

\section{Analysis I.I. Comparison I Screened for infection - Single dose, Outcome I Weight (kg).}

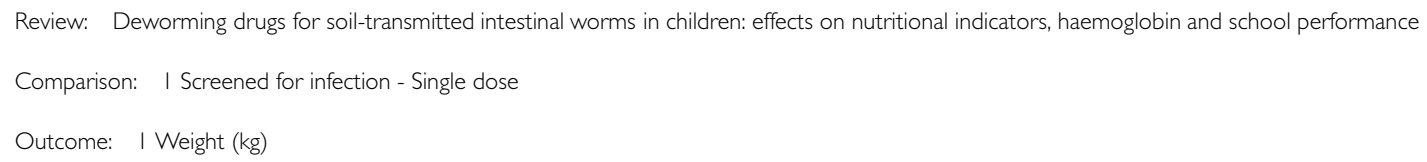

\begin{tabular}{|c|c|c|c|c|c|c|c|c|}
\hline \multirow[t]{2}{*}{ Study or subgroup } & \multirow{2}{*}{$\begin{array}{r}\text { Deworming } \\
\mathrm{N}\end{array}$} & \multicolumn{3}{|c|}{ Control } & \multicolumn{2}{|c|}{$\begin{array}{r}\text { Mean } \\
\text { Difference }\end{array}$} & \multirow[t]{2}{*}{ Weight } & \multirow{2}{*}{$\begin{array}{r}\text { Mean } \\
\text { Difference } \\
\text { |V,Fixed,95\% Cl }\end{array}$} \\
\hline & & Mean(SD) & N & Mean(SD) & & $\mathrm{d}, 95 \% \mathrm{Cl}$ & & \\
\hline Adams 1994 & 28 & I $(0.32)$ & 27 & $0.3(0.51)$ & & +1 & $62.7 \%$ & $0.70[0.47,0.93]$ \\
\hline Freij 1979a (I) & 6 & $12.3(2.9 \mid)$ & 7 & $12.1(2.29)$ & & & $0.4 \%$ & $0.20[-2.68,3.08]$ \\
\hline Sarkar 2002 & 40 & $0.92(0.84)$ & 41 & $0.54(0.45)$ & & $\longrightarrow$ & $36.9 \%$ & $0.38[0.09,0.67]$ \\
\hline Total $(95 \% \mathrm{CI})$ & 74 & & 75 & & & 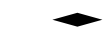 & $100.0 \%$ & $0.58[0.40,0.76]$ \\
\hline \multicolumn{9}{|c|}{ Heterogeneity: $\mathrm{Chi}^{2}=2.92, \mathrm{df}=2(\mathrm{P}=0.23) ; \mathrm{I}^{2}=32 \%$} \\
\hline \multicolumn{9}{|c|}{ Test for overall effect: $Z=6.35(P<0.0000 I)$} \\
\hline \multicolumn{9}{|c|}{ Test for subgroup differences: Not applicable } \\
\hline
\end{tabular}

(I) End value data 


\section{Analysis I.2. Comparison I Screened for infection - Single dose, Outcome 2 Height (cm).}

Review: Deworming drugs for soil-transmitted intestinal worms in children: effects on nutritional indicators, haemoglobin and school performance

Comparison: I Screened for infection - Single dose

Outcome: 2 Height $(\mathrm{cm})$

\begin{tabular}{|c|c|c|c|c|c|c|c|}
\hline \multirow[t]{2}{*}{ Study or subgroup } & Deworming & \multicolumn{3}{|c|}{ Control } & \multirow{2}{*}{$\begin{array}{c}\text { Mean } \\
\text { Difference } \\
\text { IV,Fixed,95\% Cl }\end{array}$} & \multirow[t]{2}{*}{ Weight } & \multirow{2}{*}{$\begin{array}{r}\text { Mean } \\
\text { Difference } \\
\text { IV,Fixed,95\% Cl }\end{array}$} \\
\hline & $N$ & Mean(SD) & $\mathrm{N}$ & Mean(SD) & & & \\
\hline Adams 1994 & 28 & $0.9(0.53)$ & 27 & $0.8(0.57)$ & 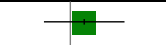 & $75.6 \%$ & $0.10[-0.19,0.39]$ \\
\hline Sarkar 2002 & 40 & $1.2(1.5)$ & 41 & I.I (0.7) & & $24.4 \%$ & $0.10[-0.41,0.61]$ \\
\hline
\end{tabular}

Total (95\% CI) 68

68

$100.0 \% \quad 0.10[-0.15,0.35]$

Heterogeneity: $\mathrm{Chi}^{2}=0.00, \mathrm{df}=\mathrm{I}(\mathrm{P}=1.00) ; \mathrm{I}^{2}=0.0 \%$

Test for overall effect: $Z=0.77(P=0.44)$

Test for subgroup differences: Not applicable

$\begin{array}{ccccc}-1 & -0.5 & 0 & 0.5 & 1 \\ \text { Favours control } & & \text { Favours deworming }\end{array}$

Analysis I.3. Comparison I Screened for infection - Single dose, Outcome 3 Mid-upper arm circumference (cm).

Review: Deworming drugs for soil-transmitted intestinal worms in children: effects on nutritional indicators, haemoglobin and school performance

Comparison: I Screened for infection - Single dose

Outcome: 3 Mid-upper arm circumference $(\mathrm{cm})$

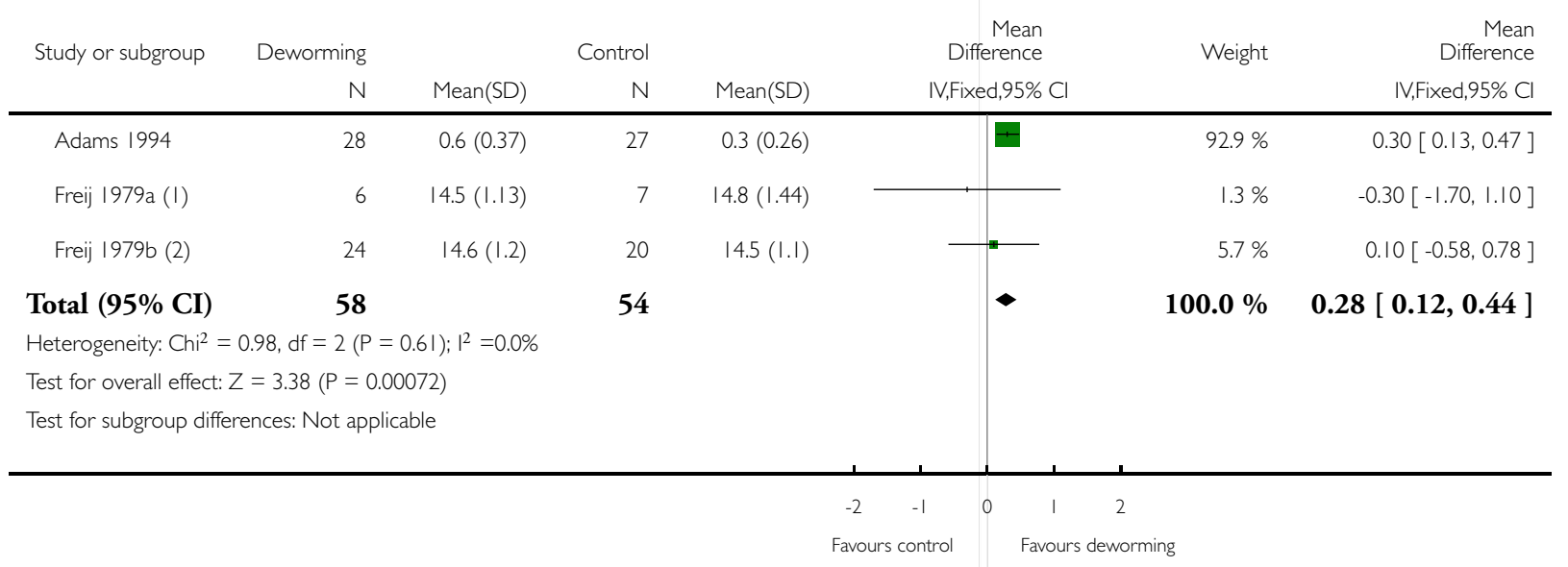

Deworming drugs for soil-transmitted intestinal worms in children: effects on nutritional indicators, haemoglobin and school 
(I) End value data

(2) End value data

\section{Analysis I.4. Comparison I Screened for infection - Single dose, Outcome 4 Triceps skin fold thickness} (mm).

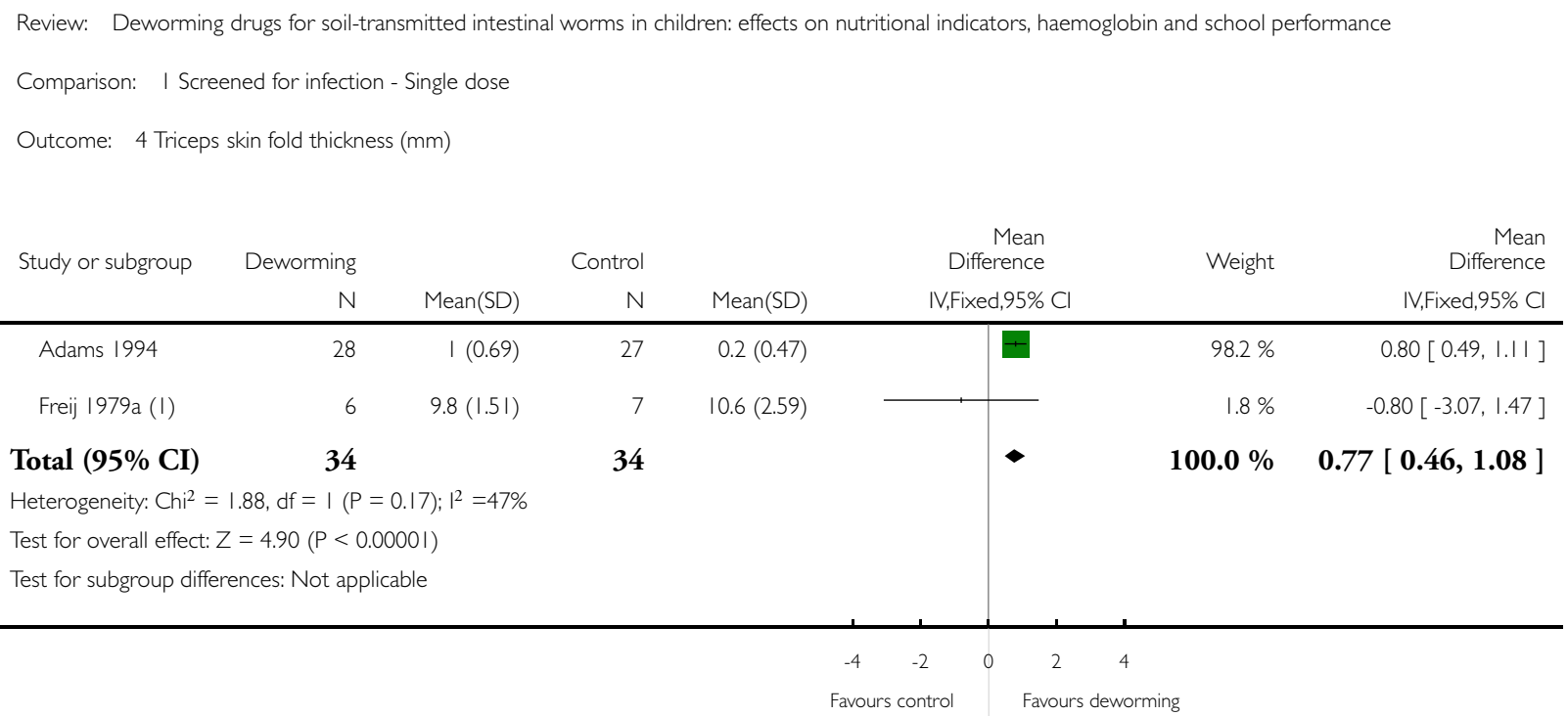

( I) End value data 
Analysis I.5. Comparison I Screened for infection - Single dose, Outcome 5 Subscapular skin fold thickness (mm).

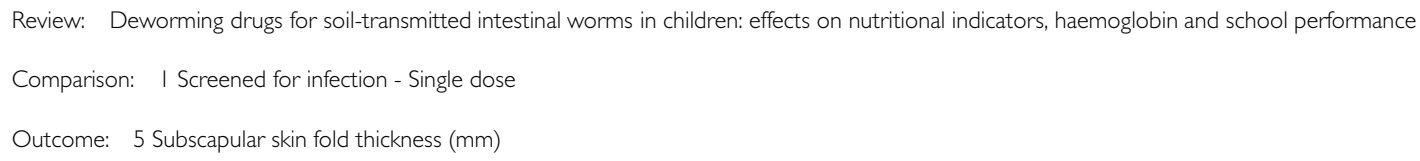

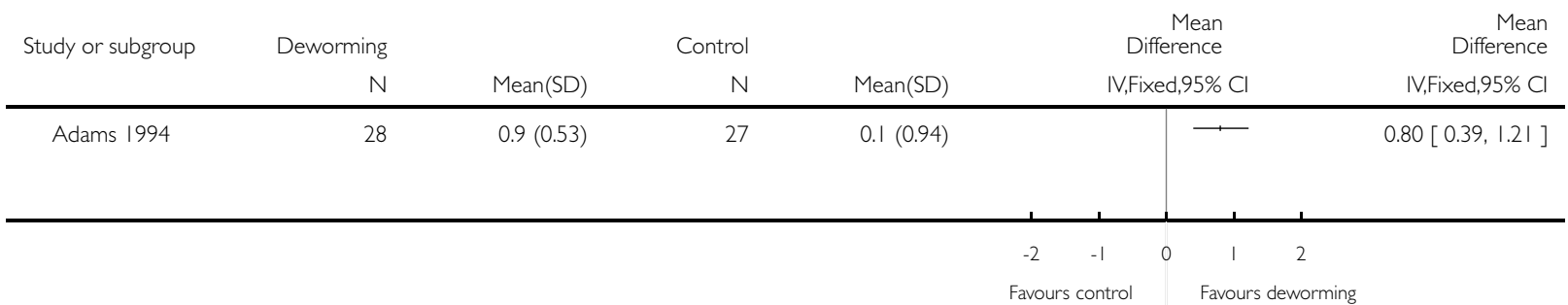

\section{Analysis I.6. Comparison I Screened for infection - Single dose, Outcome 6 Body mass index.}

Review: Deworming drugs for soil-transmitted intestinal worms in children: effects on nutritional indicators, haemoglobin and school performance

Comparison: I Screened for infection - Single dose

Outcome: 6 Body mass index

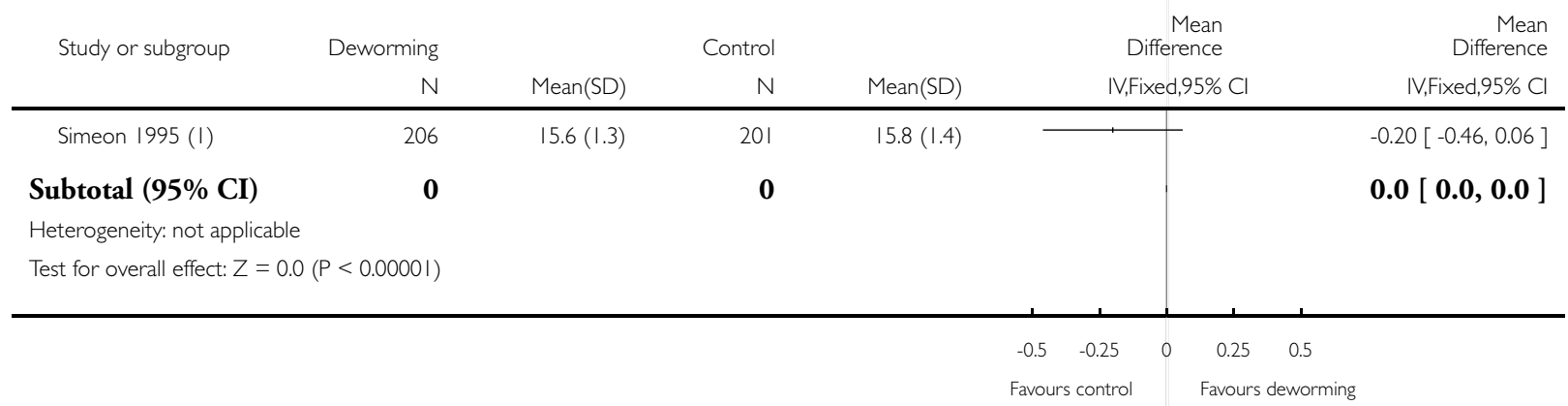

( I) End value data 


\section{Analysis I.7. Comparison I Screened for infection - Single dose, Outcome 7 Haemoglobin (g/dL).}

Review: Deworming drugs for soil-transmitted intestinal worms in children: effects on nutritional indicators, haemoglobin and school performance

Comparison: I Screened for infection - Single dose

Outcome: 7 Haemoglobin $(\mathrm{g} / \mathrm{dL})$

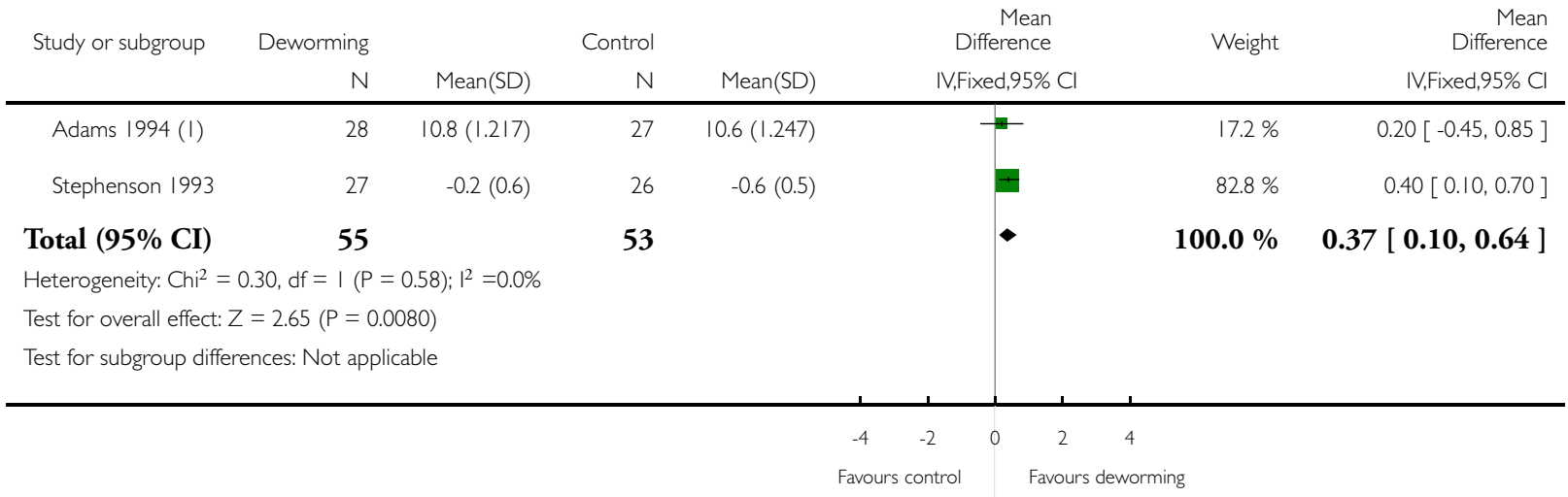

( I) End value data

Analysis 2.I. Comparison 2 Screened for infection - Multiple dose, outcomes in the first year, Outcome I Body mass index.

Review: Deworming drugs for soil-transmitted intestinal worms in children: effects on nutritional indicators, haemoglobin and school performance

Comparison: 2 Screened for infection - Multiple dose, outcomes in the first year

Outcome: I Body mass index

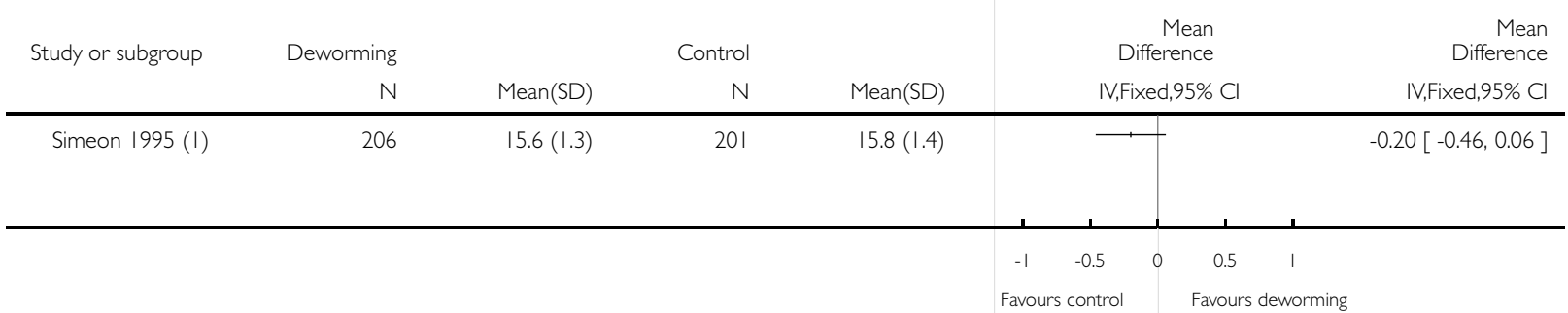

( 1$)$ end value 
Analysis 2.2. Comparison 2 Screened for infection - Multiple dose, outcomes in the first year, Outcome 2 School attendance (days present at school).

Review: Deworming drugs for soil-transmitted intestinal worms in children: effects on nutritional indicators, haemoglobin and school performance

Comparison: 2 Screened for infection - Multiple dose, outcomes in the first year

Outcome: 2 School attendance (days present at school)

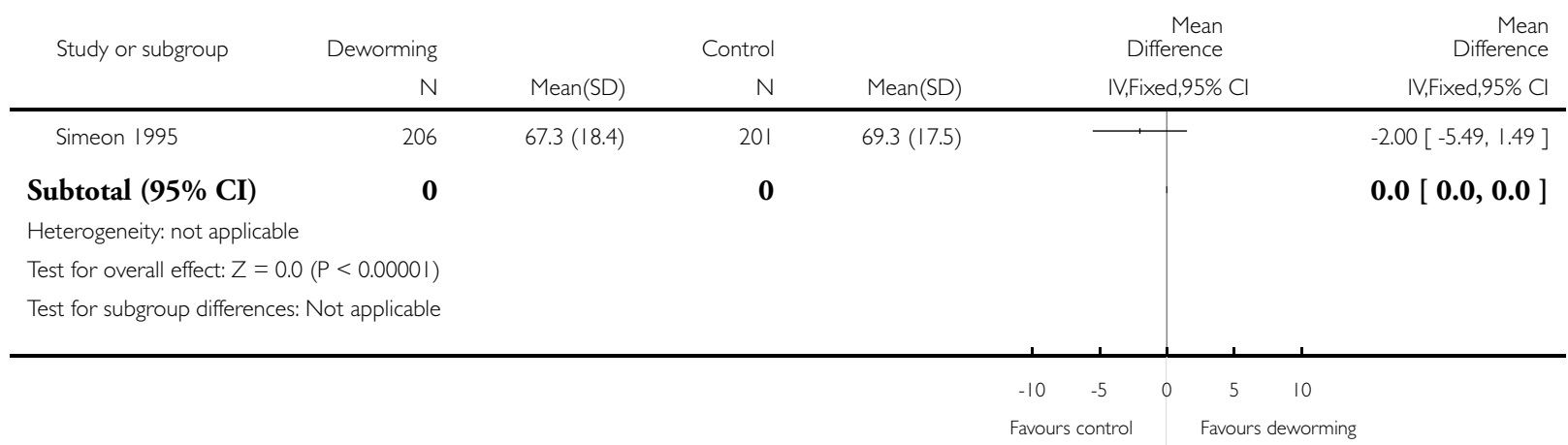

Deworming drugs for soil-transmitted intestinal worms in children: effects on nutritional indicators, haemoglobin and school 


\section{Analysis 3.I. Comparison 3 Target population treated - Single dose, Outcome I Weight (kg).}

Review: Deworming drugs for soil-transmitted intestinal worms in children: effects on nutritional indicators, haemoglobin and school performance

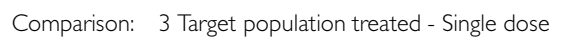

$30 \quad 19.9(2.2)$

Stephenson 1993

$78 \quad 2.1(0.79)$
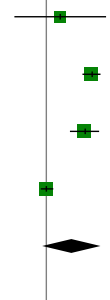

$16.7 \%$

$28.0 \%$

$26.8 \%$

$28.4 \%$

$100.0 \%$

$88.6 \%$

$11.4 \%$

$100.0 \%$

$34.7 \%$

$28.1 \%$

$37.3 \%$

$100.0 \%$
$0.06[-0.13,0.25]$

$0.50[-0.28,1.28]$

$0.11[-0.16,0.38]$

$-0.17[-0.33,-0.01]$

$-0.15[-0.34,0.04]$

$0.02[-0.13,0.17]$ IV,Random,95\% Cl

\section{$0.40[-0.93,1.73]$}

$1.30[1.04,1.56]$

$1.10[0.68,1.52]$

$0.01[-0.16,0.18]$

$0.73[-0.12,1.57]$

,

$-0.09[-0.22,0.03]$

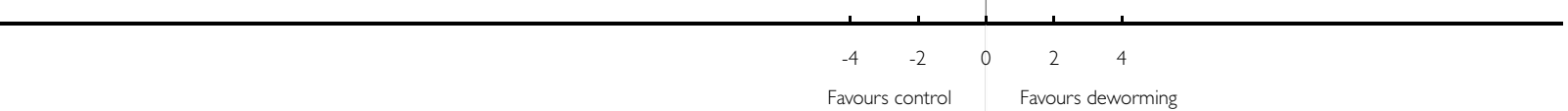

(I) End value data

(2) End value data 


\section{Analysis 3.2. Comparison 3 Target population treated - Single dose, Outcome 2 Height $(\mathrm{cm})$.}

Review: Deworming drugs for soil-transmitted intestinal worms in children: effects on nutritional indicators, haemoglobin and school performance

Comparison: 3 Target population treated - Single dose

Outcome: 2 Height $(\mathrm{cm})$

Study or subgroup Deworming

N

I High prevalence

Stephenson 1989

Stephenson 1993

Watkins 1996

Subtotal (95\% CI)

$\begin{array}{llll}78 & 2.8(0.79) & 72 & 2.2(0.85)\end{array}$

$96 \quad 3.8(1.18)$

93

$116 \quad 1.44(0.54)$

III

276

Heterogeneity: $\mathrm{Tau}^{2}=0.08 ; \mathrm{Chi}^{2}=12.82, \mathrm{df}=2(\mathrm{P}=0.002) ; \mathrm{I}^{2}=84 \%$

Test for overall effect: $Z=1.40(P=0.16)$

2 Moderate prevalence

$$
\text { Palupi } 1997
$$$$
95
$$$$
1.2(0.9)
$$

96

95

96

Subtotal (95\% CI)

Heterogeneity: not applicable

Test for overall effect: $Z=1.45(P=0.15)$

3 Low prevalence

$\begin{array}{llll}\text { Awasthi } 2000 & 592 & 4.19(5.08) & 395 \\ \text { Donnen 1998 } & 112 & 1.96(1.99) \\ \text { Garg 2002 } & 166 & 4.25(1.42)\end{array}$

Subtotal (95\% CI)

870

686

Heterogeneity: Tau $^{2}=0.12 ; \mathrm{Chi}^{2}=5.89, \mathrm{df}=2(\mathrm{P}=0.05) ; \mathrm{I}^{2}=66 \%$

Test for overall effect: $Z=1.08(P=0.28)$

Test for subgroup differences: $\mathrm{Chi}^{2}=4.72, \mathrm{df}=2(\mathrm{P}=0.09), \mathrm{I}^{2}=58 \%$
$3.7(1.16)$

$1.38(0.53)$

$\begin{array}{rr}\text { Mean } & \begin{array}{r}\text { Mean } \\ \text { Difference }\end{array}\end{array}$

Mean(SD) IV,Random,95\% Cl

IV,Random,95\% Cl

|

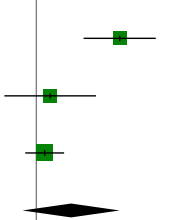

$32.8 \%$

$0.60[0.34,0.86]$

$29.4 \%$

$0.10[-0.23,0.43]$

$37.8 \%$

$0.06[-0.08,0.20]$

$100.0 \%$

$0.25[-0.10,0.60]$

$100.0 \%$

$-0.20[-0.47,0.07]$

$100.0 \%$

$-0.20[-0.47,0.07]$

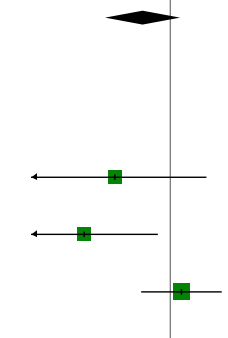

$25.8 \%$

$-0.40[-1.06,0.26]$

$31.3 \%$

$-0.62[-1.15,-0.09]$

$42.9 \%$

$0.08[-0.21,0.37]$

$100.0 \% \quad-0.26[-0.74,0.21]$ 


\section{Analysis 3.3. Comparison 3 Target population treated - Single dose, Outcome 3 Mid-upper arm circumference $(\mathbf{c m})$.}

Review: Deworming drugs for soil-transmitted intestinal worms in children: effects on nutritional indicators, haemoglobin and school performance

Comparison: 3 Target population treated - Single dose

Outcome: 3 Mid-upper arm circumference $(\mathrm{cm})$

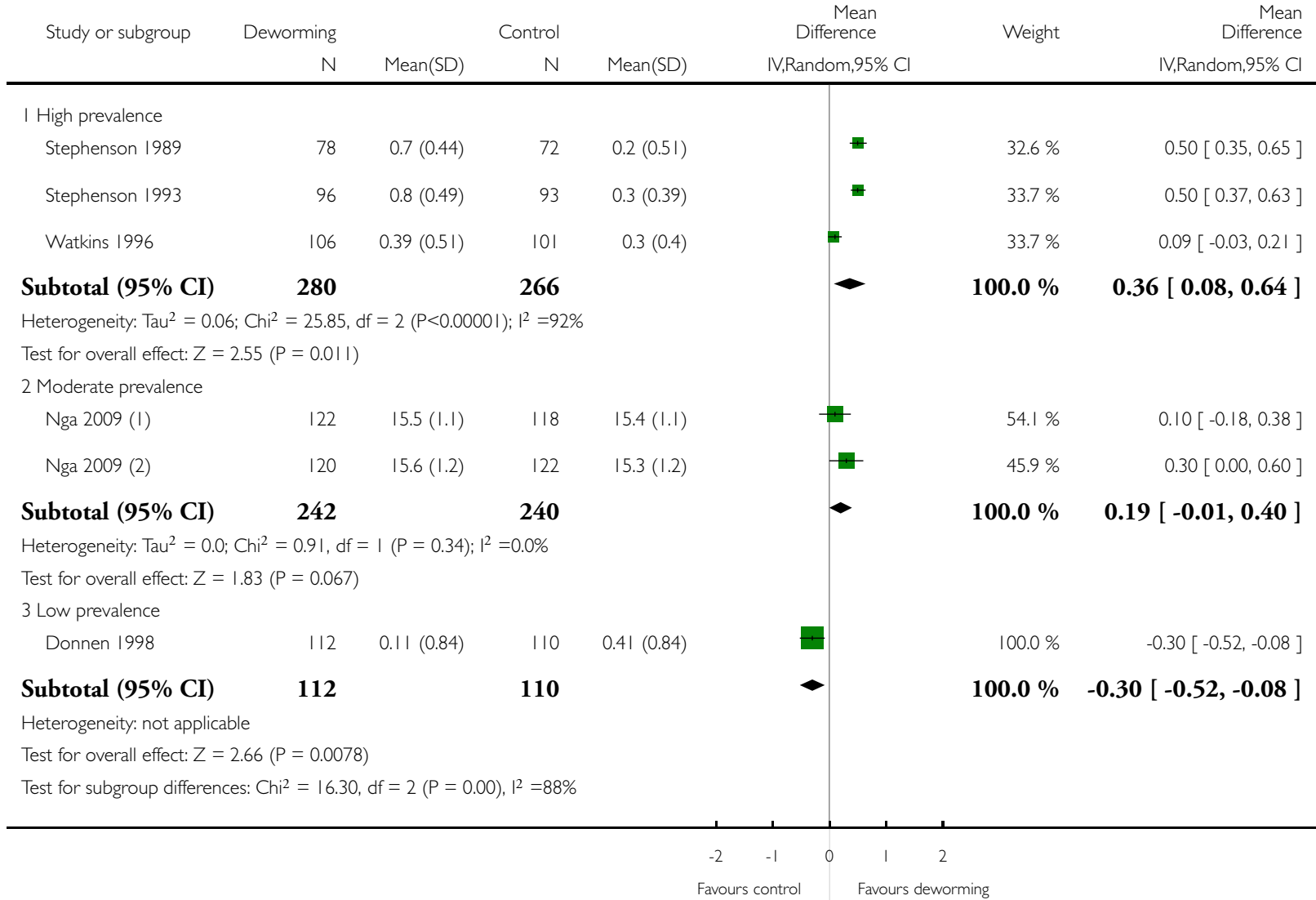

( I) End value data

(2) End value data 


\section{Analysis 3.4. Comparison 3 Target population treated - Single dose, Outcome 4 Triceps skin fold thickness} $(\mathrm{mm})$.

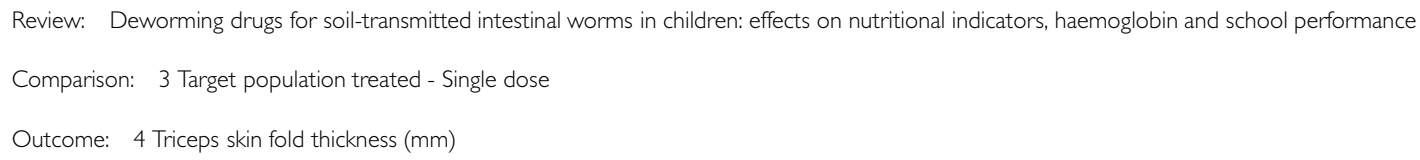

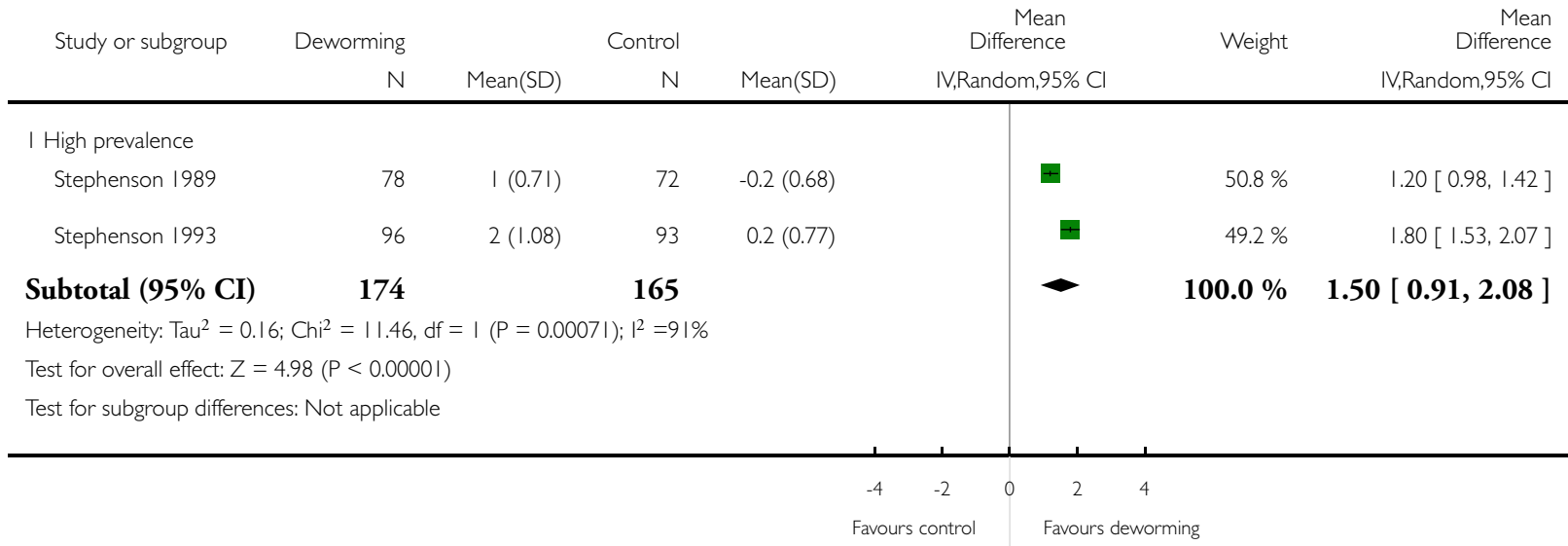


Analysis 3.5. Comparison 3 Target population treated - Single dose, Outcome 5 Subscapular skin fold thickness $(\mathrm{mm})$.

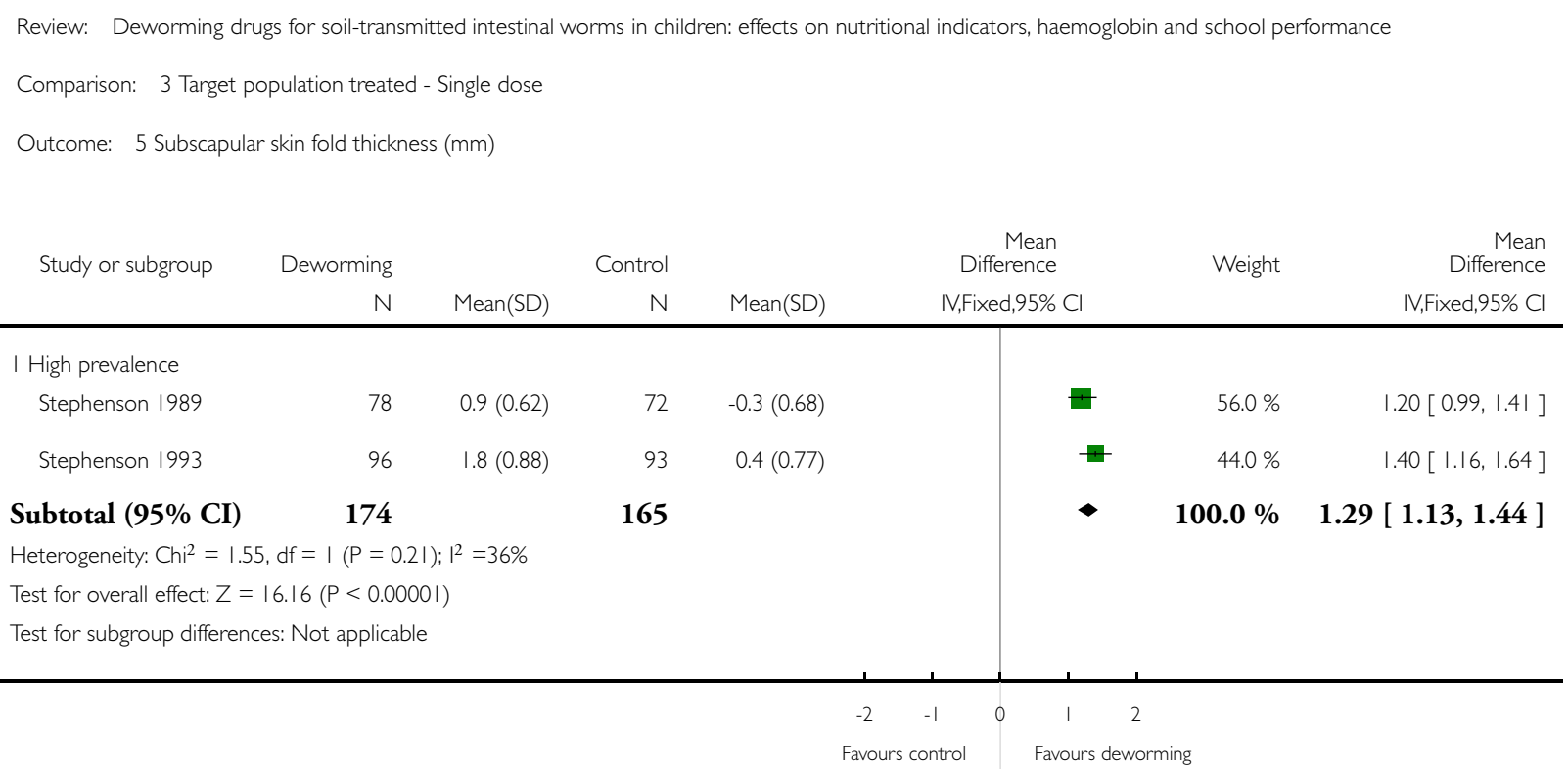




\section{Analysis 3.6. Comparison 3 Target population treated - Single dose, Outcome 6 Haemoglobin (g/dL).}

Review: Deworming drugs for soil-transmitted intestinal worms in children: effects on nutritional indicators, haemoglobin and school performance

Comparison: 3 Target population treated - Single dose

Outcome: 6 Haemoglobin $(\mathrm{g} / \mathrm{dL})$

Mean Mean Meight

N Mean(SD) N $\quad$ Mean(SD) IV,Fixed,95\% Cl IV,Fixed,95\% Cl

I Moderate prevalence

Nga 2009 ( I)

$\begin{array}{llll}118 & 12.22(0.62) \quad 114 & 12.12(0.73)\end{array}$

Nga 2009 (2)

$117 \quad 11.99(0.7)$

118

$12.01(0.8)$

Palupi 1997

$95 \quad 0.75(0.88)$

$96 \quad 0.64(1.06)$

330

328

Subtotal (95\% CI)

$(P=0.61) ; I^{2}=0.0 \%$

Test for overall effect: $Z=0.96(P=0.34)$

2 Low prevalence

$$
\text { Garg } 2002
$$$$
166 \quad 0.54(1.42)
$$

$|8|$

$0.48(1.47)$

166

181

Subtotal (95\% CI)

Heterogeneity: not applicable

Test for overall effect: $Z=0.39(P=0.70)$

Total (95\% CI)

496

509

Heterogeneity: $\mathrm{Chi}^{2}=0.99, \mathrm{df}=3(\mathrm{P}=0.80) ; \mathrm{I}^{2}=0.0 \%$

Test for overall effect: $Z=1.03(P=0.30)$

Test for subgroup differences: $\mathrm{Chi}^{2}=0.00, \mathrm{df}=\mathrm{I}(\mathrm{P}=0.99), \mathrm{I}^{2}=0.0 \%$
$39.2 \%$
$0.10[-0.07,0.27]$
$32.3 \%$
$-0.02[-0.21,0.17]$
$15.6 \%$
$0.11[-0.17,0.39]$

$87.1 \% \quad 0.06[-0.06,0.17]$

$12.9 \% \quad 0.06[-0.24,0.36]$

$12.9 \% \quad 0.06[-0.24,0.36]$

$100.0 \%$

$0.06[-0.05,0.17]$

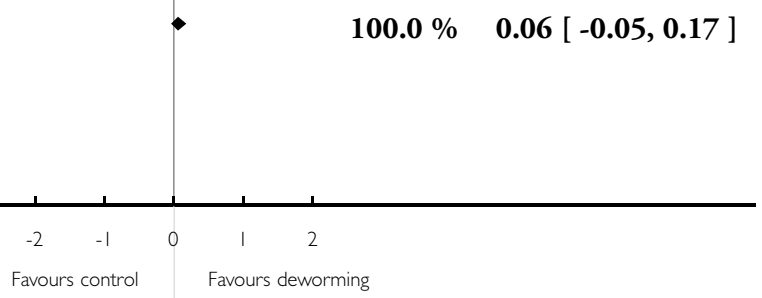

( I) End value data

(2) End value data 


\section{Analysis 3.7. Comparison 3 Target population treated - Single dose, Outcome 7 Harvard Step Test}

(measure of physical well being).

Review: Deworming drugs for soil-transmitted intestinal worms in children: effects on nutritional indicators, haemoglobin and school performance

Comparison: 3 Target population treated - Single dose

Outcome: 7 Harvard Step Test (measure of physical well being)

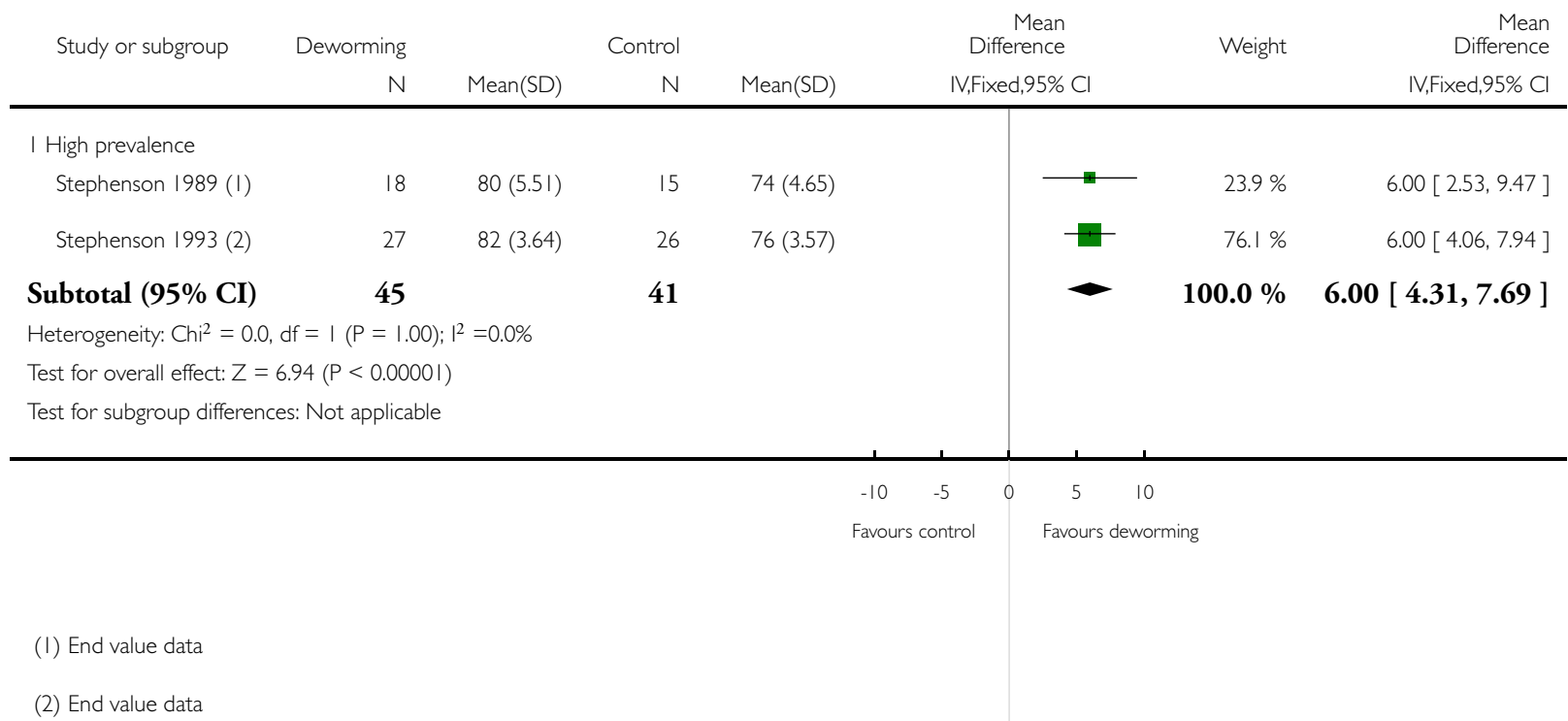

Deworming drugs for soil-transmitted intestinal worms in children: effects on nutritional indicators, haemoglobin and school 


\section{Analysis 4.I. Comparison 4 Target population treated - Multiple dose, outcomes in the first year, Outcome} I Weight (kg).

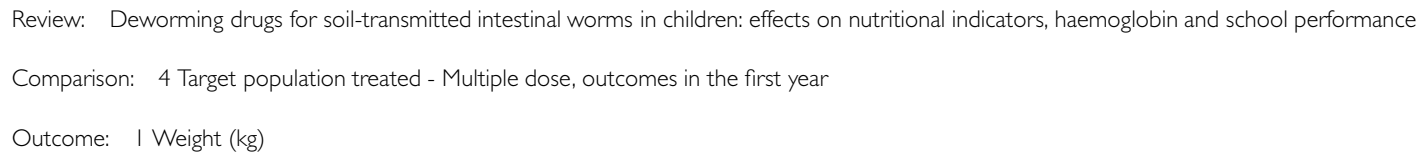

$\begin{array}{rrrrrrr}\text { Study or subgroup } & \text { Deworming } & & \text { Control } & \text { Difference } & \text { Weight } \\ & \mathrm{N} & \text { Mean(SD) } & \mathrm{N} & \text { Mean(SD) } & \text { IV,Random,95\% Cl } & \text { IV,Random,95\% Cl }\end{array}$

$95 \quad 3.1(1.36) \quad 93 \quad 2.2(1.16)$

$\begin{array}{lllll}\text { Watkins } 1996 & 116 & 1.82(0.86) & 110 & 1.69(0.73)\end{array}$

Subtotal (95\% CI) $211 \quad 203$

Heterogeneity: $\mathrm{Tau}^{2}=0.27 ; \mathrm{Chi}^{2}=13.13, \mathrm{df}=\mathrm{I}(\mathrm{P}=0.00029) ; \mathrm{I}^{2}=92 \%$

Test for overall effect: $Z=1.30(P=0.19)$

2 Moderate prevalence

$\begin{array}{lrrrr}\text { Dossa 200I } & 31 & 1.2(0.6) & 33 & 1.2(0.5) \\ \text { Dossa 200I } & 37 & 1.2(1) & 28 & 1.2(1.1) \\ \text { Sur 2005 (I) } & 342 & 12.9(7.4) & 340 & 12.4(4.61) \\ \text { Subtotal (95\% CI) } & \mathbf{4 1 0} & & \mathbf{4 0 1} & \end{array}$

Heterogeneity: $\mathrm{Tau}^{2}=0.0 ; \mathrm{Chi}^{2}=1.05, \mathrm{df}=2(\mathrm{P}=0.59) ; \mathrm{I}^{2}=0.0 \%$

Test for overall effect: $Z=0.27(P=0.79)$

3 Low prevalence

$\begin{array}{lcccc}\text { Awasthi } 2000 & 576 & 0.99(0.62) & 387 & 0.95(0.85) \\ \text { Donnen 1998 } & 100 & 1.64(1.12) & 98 & 2.09(1.19) \\ \text { Kruger 1996 } & 37 & 2.32(0.64) & 37 & 2.7(1.22)\end{array}$

$12.7 \%$ $0.90[0.54,1.26]$

$16.0 \%$

$0.13[-0.08,0.34]$

$28.7 \% 0.50[-0.25,1.25]$

Subtotal (95\% CI)

713

522

Heterogeneity: $\mathrm{Tau}^{2}=0.09 ; \mathrm{Chi}^{2}=10.80, \mathrm{df}=2(\mathrm{P}=0.005) ; \mathrm{I}^{2}=81 \%$

Test for overall effect: $Z=1.20(P=0.23)$

Total (95\% CI)

1334

1126

Heterogeneity: $\mathrm{Tau}^{2}=0.08 ; \mathrm{Chi}^{2}=35.84, \mathrm{df}=7(\mathrm{P}<0.0000 \mathrm{I}) ; \mathrm{I}^{2}=80 \%$

Test for overall effect: $Z=0.53(P=0.60)$

Test for subgroup differences: $C h i^{2}=3.20, d f=2(P=0.20), \mathrm{I}^{2}=38 \%$
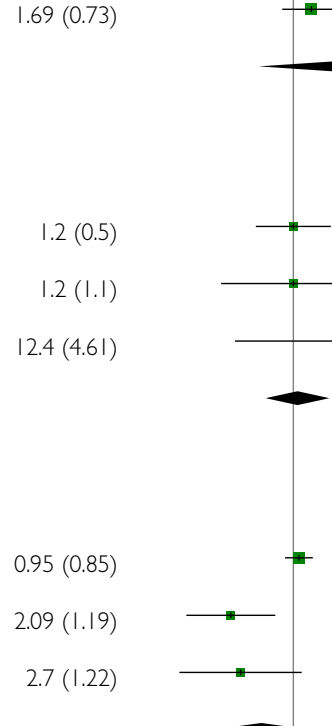
$14.7 \% \quad 0.0[-0.27,0.27]$
$9.6 \%$
$0.0[-0.52,0.52]$
$4.7 \%$
$0.50[-0.42,1.42]$

$28.9 \%$

0.03 [ - 0.20, 0.26 ]

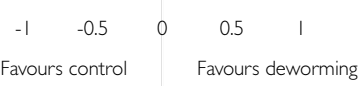

(I) End value data 


\section{Analysis 4.2. Comparison 4 Target population treated - Multiple dose, outcomes in the first year, Outcome} 2 Height (cm).

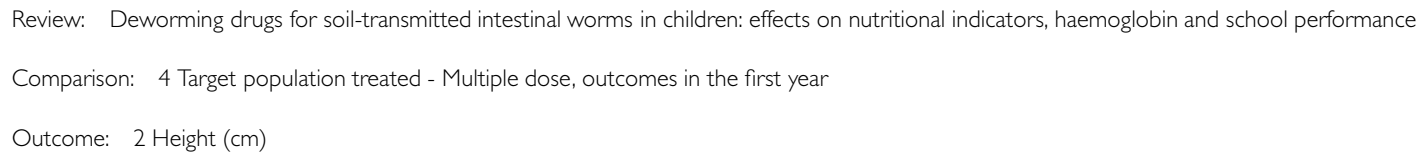

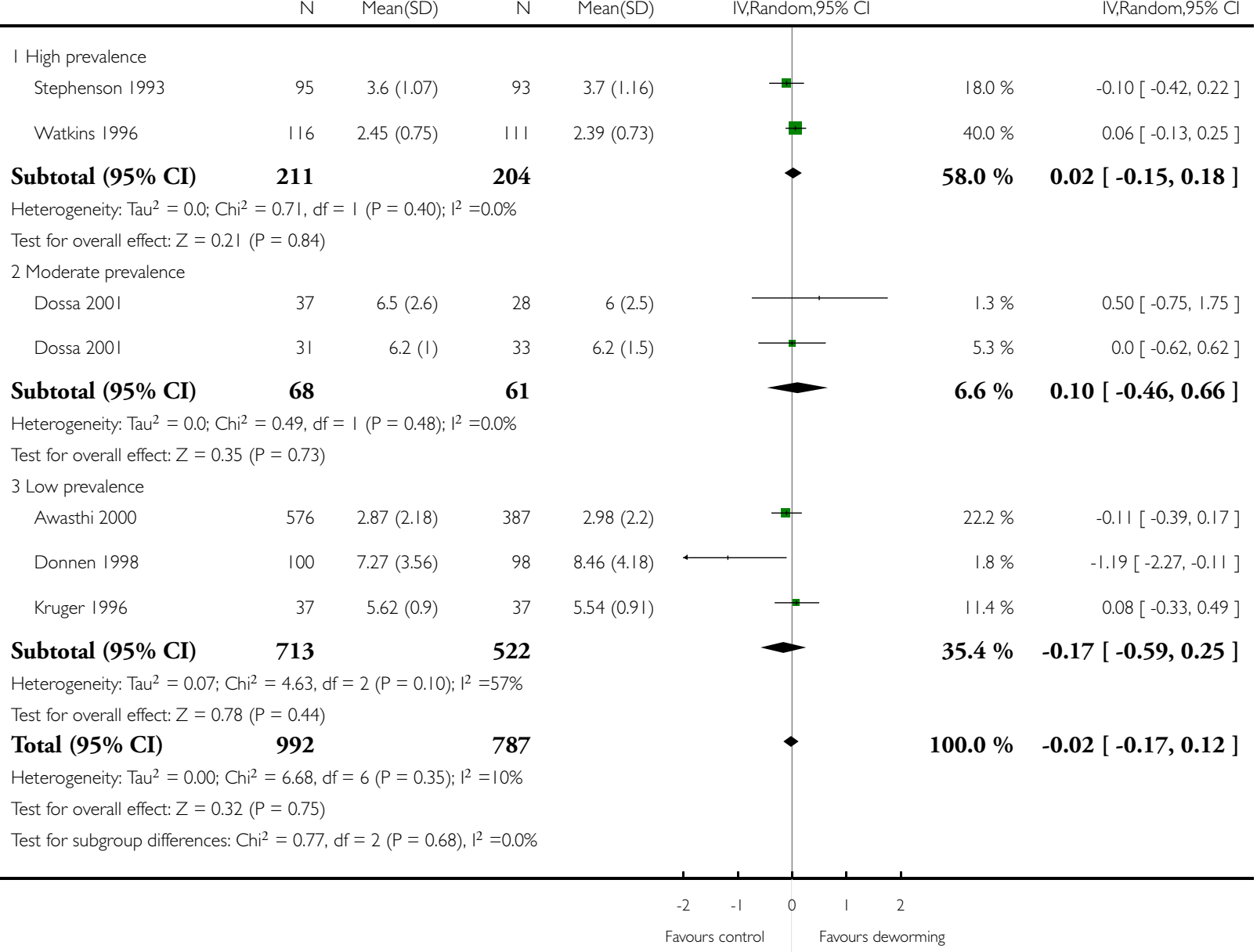




\section{Analysis 4.3. Comparison 4 Target population treated - Multiple dose, outcomes in the first year, Outcome 3 Mid-upper arm circumference $(\mathrm{cm})$.}

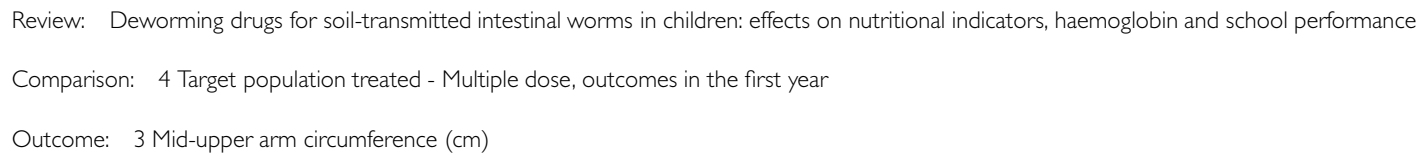

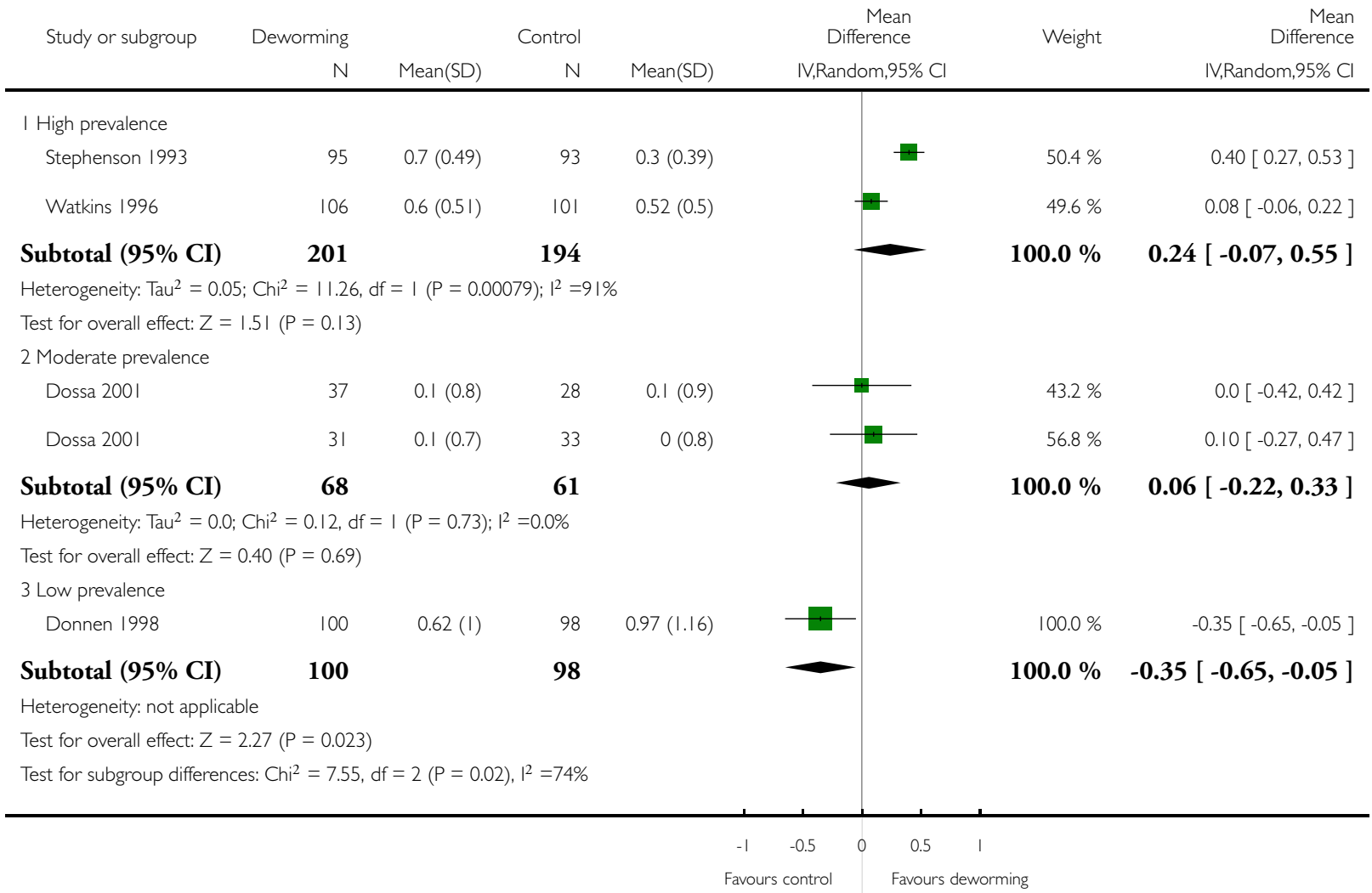


Analysis 4.4. Comparison 4 Target population treated - Multiple dose, outcomes in the first year, Outcome 4 Triceps skin fold thickness $(\mathrm{mm})$.

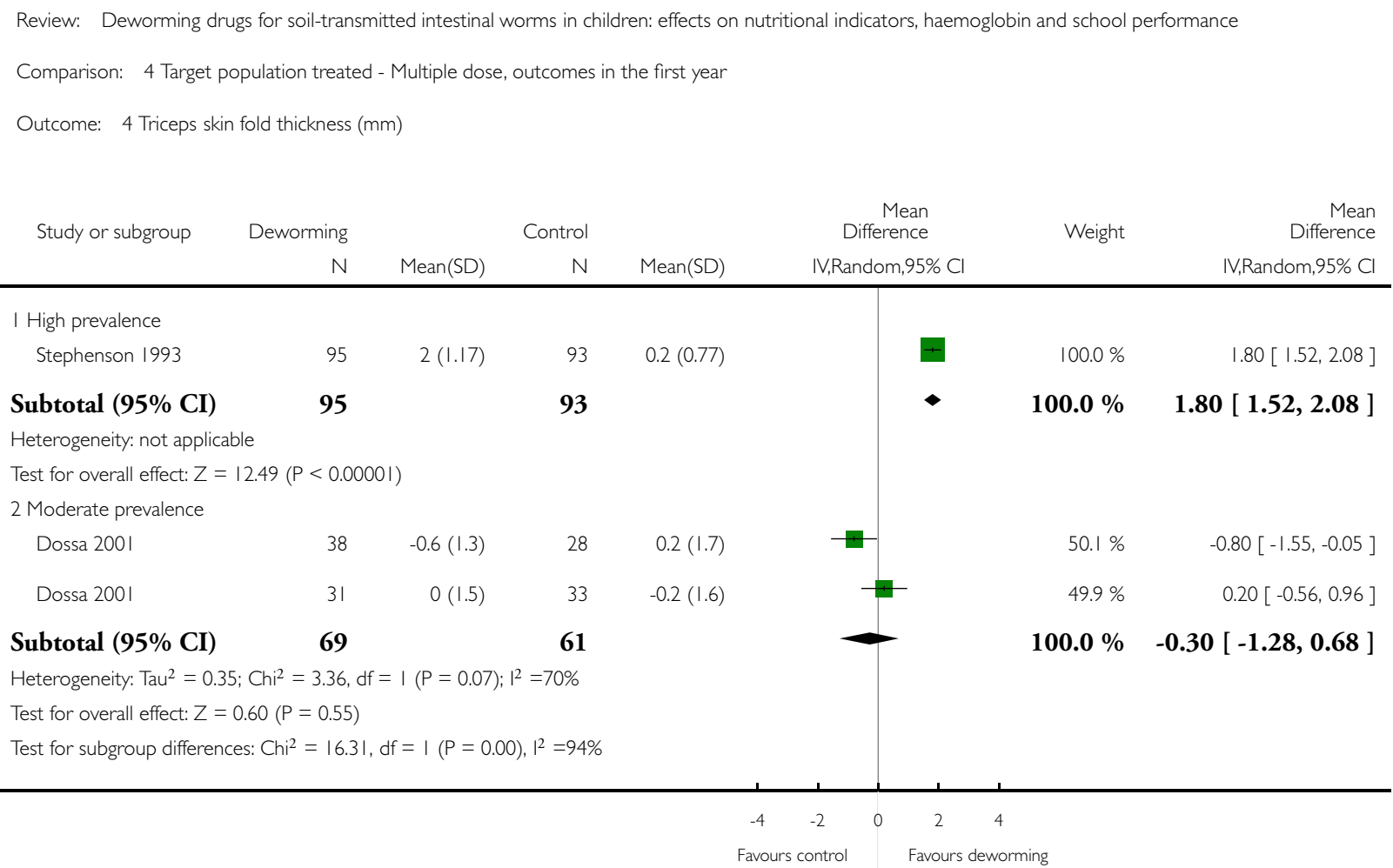


Analysis 4.5. Comparison 4 Target population treated - Multiple dose, outcomes in the first year, Outcome 5 Subscapular skin fold thickness $(\mathrm{mm})$.

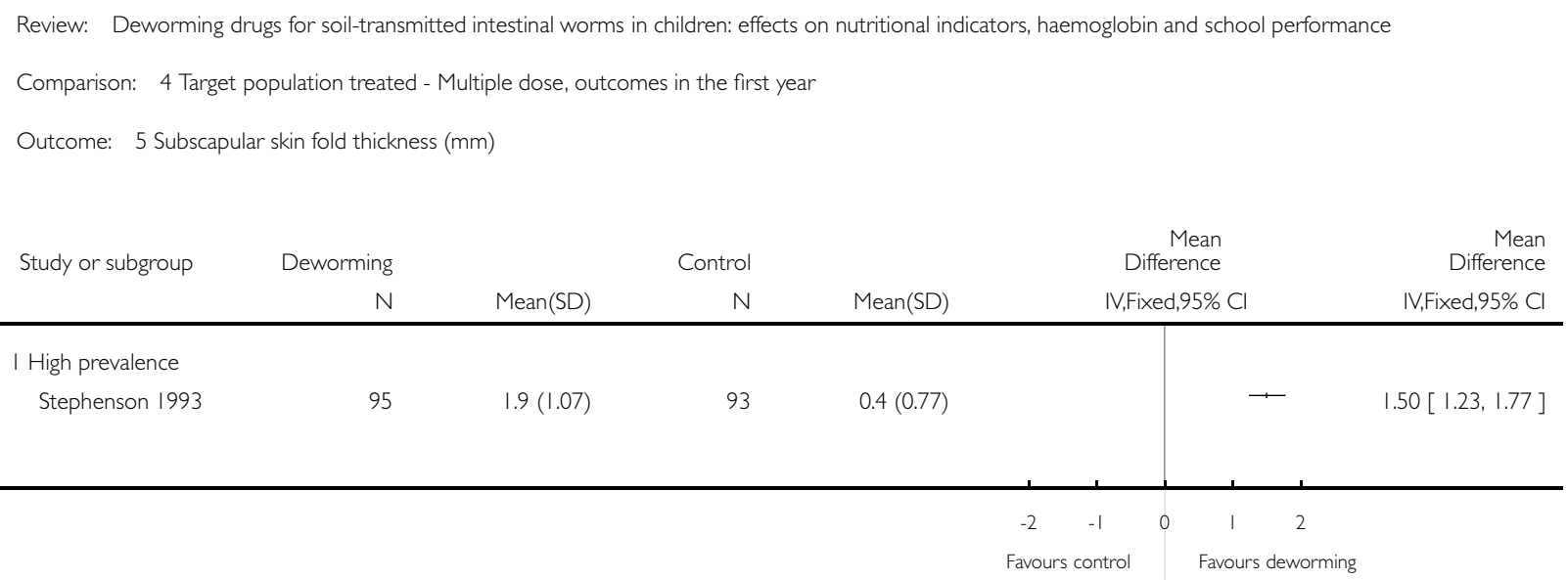


Analysis 4.6. Comparison 4 Target population treated - Multiple dose, outcomes in the first year, Outcome 6 Haemoglobin $(g / d L)$.

\begin{tabular}{|c|c|c|c|c|c|c|c|}
\hline \multicolumn{8}{|c|}{ Comparison: 4 Target population treated - Multiple dose, outcomes in the first year } \\
\hline Outcome: 6 Haemoglo & n $(g / d L)$ & & & & \multirow{3}{*}{$\begin{array}{c}\text { Mean } \\
\text { Difference } \\
\text { IV,Fixed,95\% Cl }\end{array}$} & & \\
\hline \multirow[t]{2}{*}{ Study or subgroup } & \multirow{2}{*}{$\begin{array}{r}\text { Deworming } \\
\mathrm{N}\end{array}$} & \multicolumn{3}{|c|}{ Control } & & \multirow[t]{2}{*}{ Weight } & \multirow{2}{*}{$\begin{array}{r}\text { Mean } \\
\text { Difference } \\
\text { IV,Fixed,95\% Cl }\end{array}$} \\
\hline & & Mean(SD) & $\mathrm{N}$ & Mean(SD) & & & \\
\hline \multicolumn{8}{|l|}{ I Moderate prevalence } \\
\hline Dossa 2001 & 34 & $1.3(1.5)$ & 34 & $1.1(1.2)$ & & $4.3 \%$ & $0.20[-0.45,0.85]$ \\
\hline Dossa 2001 & 38 & $0.8(1.3)$ & 32 & $0.5(1.2)$ & & $5.3 \%$ & $0.30[-0.29,0.89]$ \\
\hline Le Huong 2007 & 86 & $1.78(0.9)$ & 79 & $1.75(0.755)$ & $\longrightarrow$ & $28.4 \%$ & $0.03[-0.22,0.28]$ \\
\hline Le Huong 2007 & 79 & $1.46(0.888)$ & 82 & $1.54(0.833)$ & $\mp$ & $25.6 \%$ & $-0.08[-0.35,0.19]$ \\
\hline Subtotal $(95 \% \mathrm{CI})$ & 237 & & 227 & & - & $63.6 \%$ & $0.02[-0.15,0.19]$ \\
\hline \multicolumn{8}{|c|}{ Heterogeneity: Chi $^{2}=1.72, d f=3(P=0.63) ; 1^{2}=0.0 \%$} \\
\hline \multicolumn{8}{|c|}{ Test for overall effect: $Z=0.23(P=0.82)$} \\
\hline \multicolumn{8}{|c|}{2 Low prevalence } \\
\hline Goto 2009 (I) & 134 & $9.59(1.39)$ & 135 & $9.69(1.38)$ & $\longrightarrow$ & $16.5 \%$ & $-0.10[-0.43,0.23]$ \\
\hline Kruger 1996 & 37 & $0.24(0.6)$ & 37 & $0.26(0.72)$ & 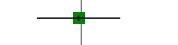 & $19.9 \%$ & $-0.02[-0.32,0.28]$ \\
\hline Subtotal $(95 \% \mathrm{CI})$ & 171 & & 172 & & - & $36.4 \%$ & $-0.06[-0.28,0.17]$ \\
\hline \multicolumn{8}{|c|}{ Heterogeneity: Chi $^{2}=0.12, d f=I(P=0.73) ; 1^{2}=0.0 \%$} \\
\hline \multicolumn{8}{|c|}{ Test for overall effect: $Z=0.49(P=0.62)$} \\
\hline Total $(95 \% \mathrm{CI})$ & 408 & & 399 & & - & $100.0 \%$ & $-0.01[-0.14,0.13]$ \\
\hline \multicolumn{8}{|c|}{ Heterogeneity: $\mathrm{Chi}^{2}=2.13, \mathrm{df}=5(\mathrm{P}=0.83) ; \mathrm{I}^{2}=0.0 \%$} \\
\hline \multicolumn{8}{|c|}{ Test for overall effect: $Z=0.12(P=0.91)$} \\
\hline \multicolumn{8}{|c|}{ Test for subgroup differences: $\mathrm{Chi}^{2}=0.28, \mathrm{df}=\mathrm{I}(\mathrm{P}=0.59), \mathrm{I}^{2}=0.0 \%$} \\
\hline
\end{tabular}

(I) End value data 


\section{Analysis 4.7. Comparison 4 Target population treated - Multiple dose, outcomes in the first year, Outcome} 7 School attendance (days present at school).

Review: Deworming drugs for soil-transmitted intestinal worms in children: effects on nutritional indicators, haemoglobin and school performance

Comparison: 4 Target population treated - Multiple dose, outcomes in the first year

Outcome: 7 School attendance (days present at school)

Study or subgroup Mean Difference (SE) Mean Meight Mean

IV,Random,95\% Cl IV,Random,95\% Cl

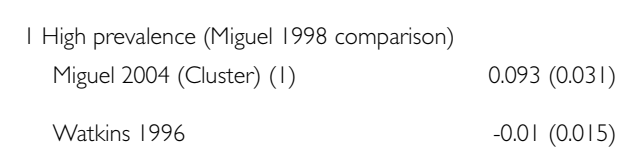

Subtotal $(95 \%$ CI)

Heterogeneity: $\mathrm{Tau}^{2}=0.00 ; \mathrm{Chi}^{2}=8.95, \mathrm{df}=\mathrm{I}(\mathrm{P}=0.003) ; \mathrm{I}^{2}=89 \%$

Test for overall effect: $Z=0.74(P=0.46)$

2 High prevalence (Miguel 1999 comparison)

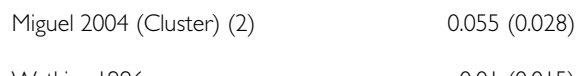

Watkins $1996 \quad-0.01(0.015)$

Subtotal (95\% CI)

Heterogeneity: $\mathrm{Tau}^{2}=0.00 ; \mathrm{Chi}^{2}=4.19, \mathrm{df}=\mathrm{I}(\mathrm{P}=0.04) ; \mathrm{I}^{2}=76 \%$

Test for overall effect: $Z=0.56(P=0.57)$

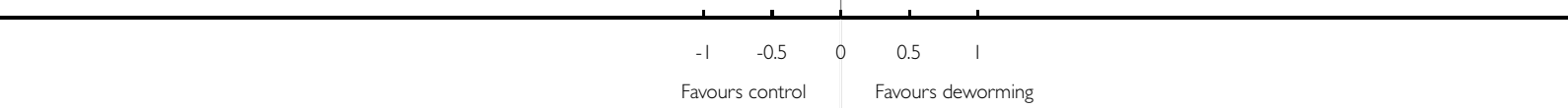

(I) Miguel 1998: group I vs. 2 and 3

(2) Miguel 1999: group 2 versus 3 
Analysis 5.I. Comparison 5 Target population treated - Multiple dose, outcomes after the first year, Outcome I Weight (kg).

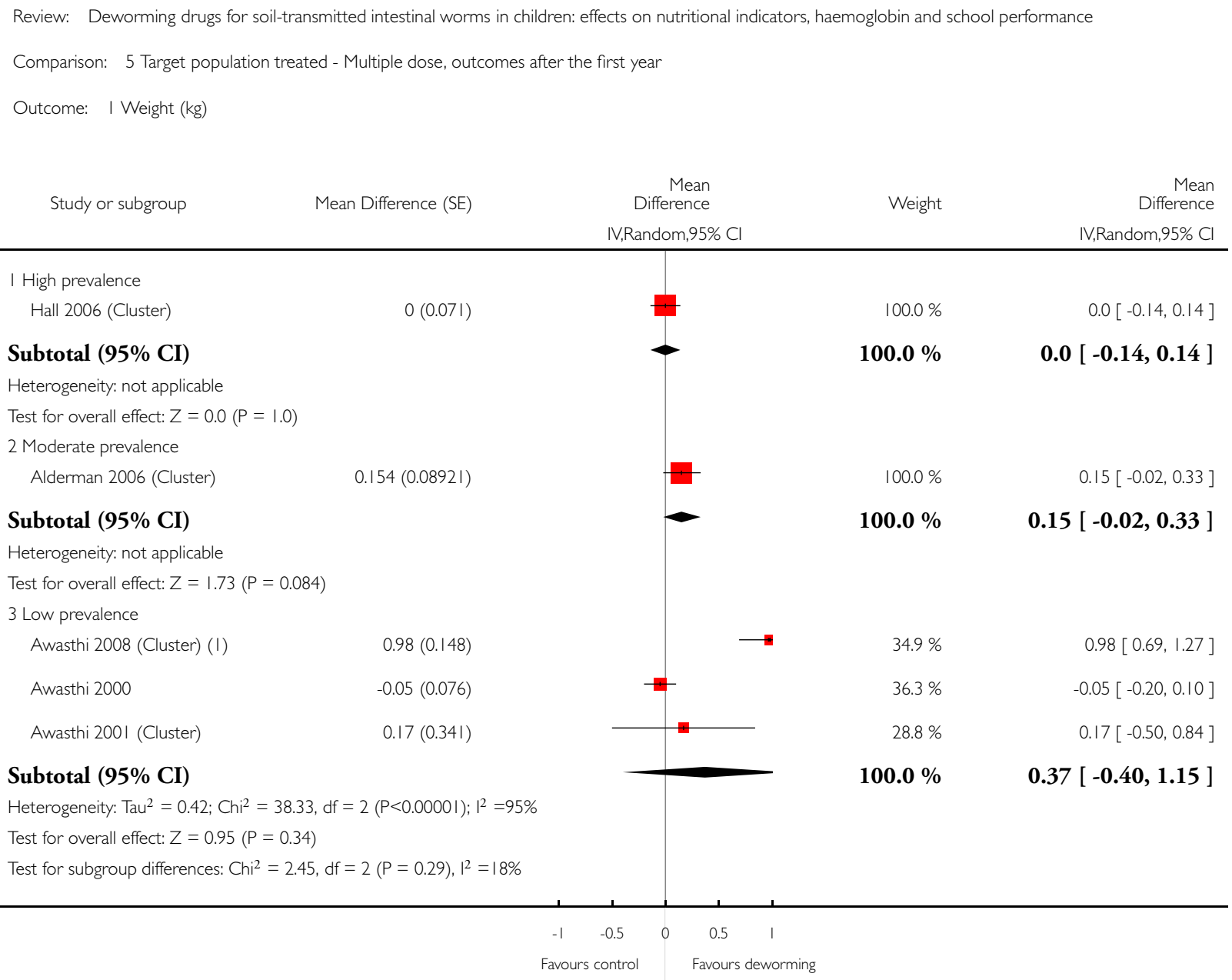

( I) Trial carried out in 1995 
Analysis 5.2. Comparison 5 Target population treated - Multiple dose, outcomes after the first year, Outcome 2 Height $(\mathrm{cm})$.

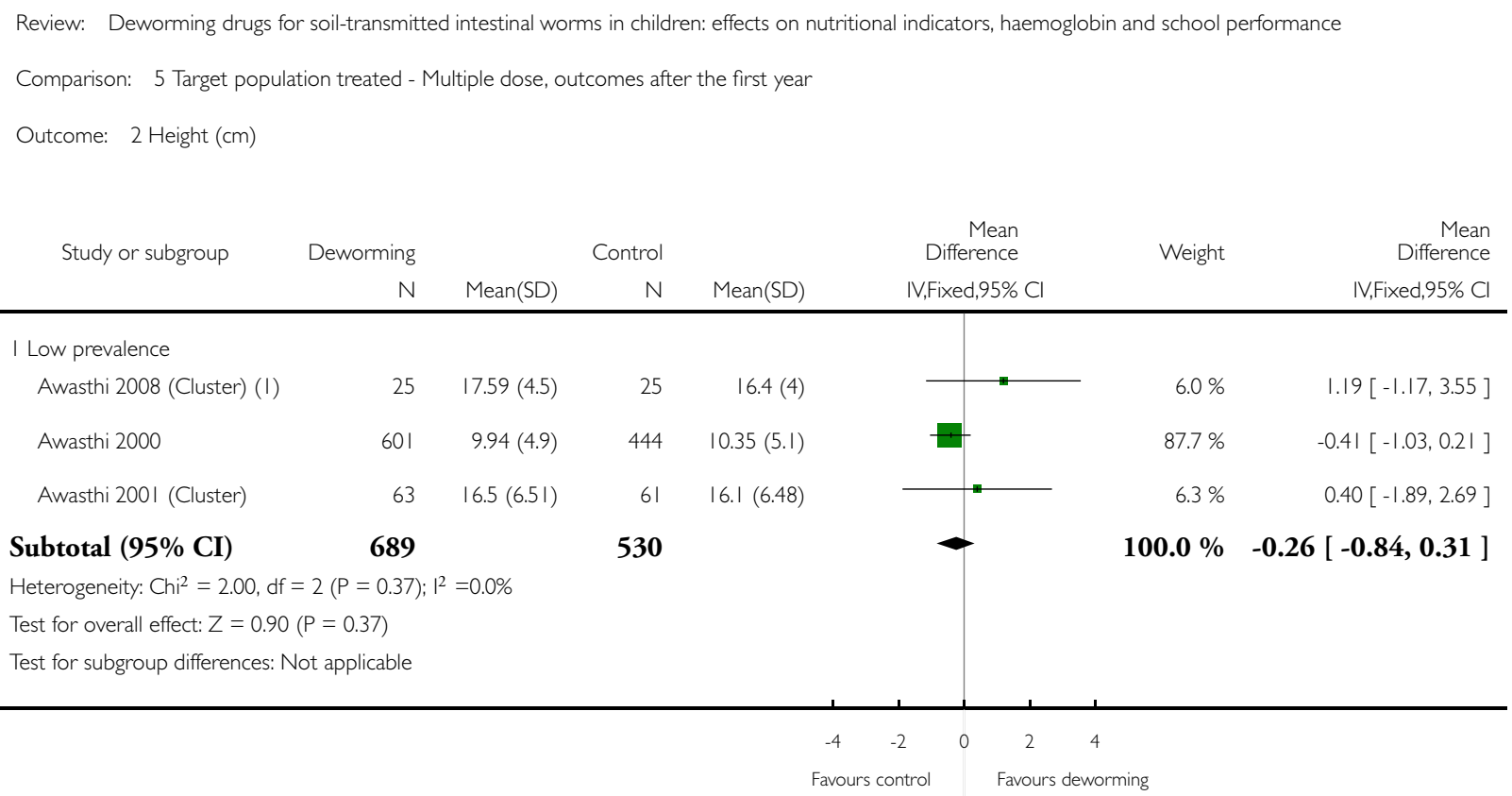

(1) Trial carried out in 1995 
Analysis 5.3. Comparison 5 Target population treated - Multiple dose, outcomes after the first year, Outcome 3 Haemoglobin (g/dL).

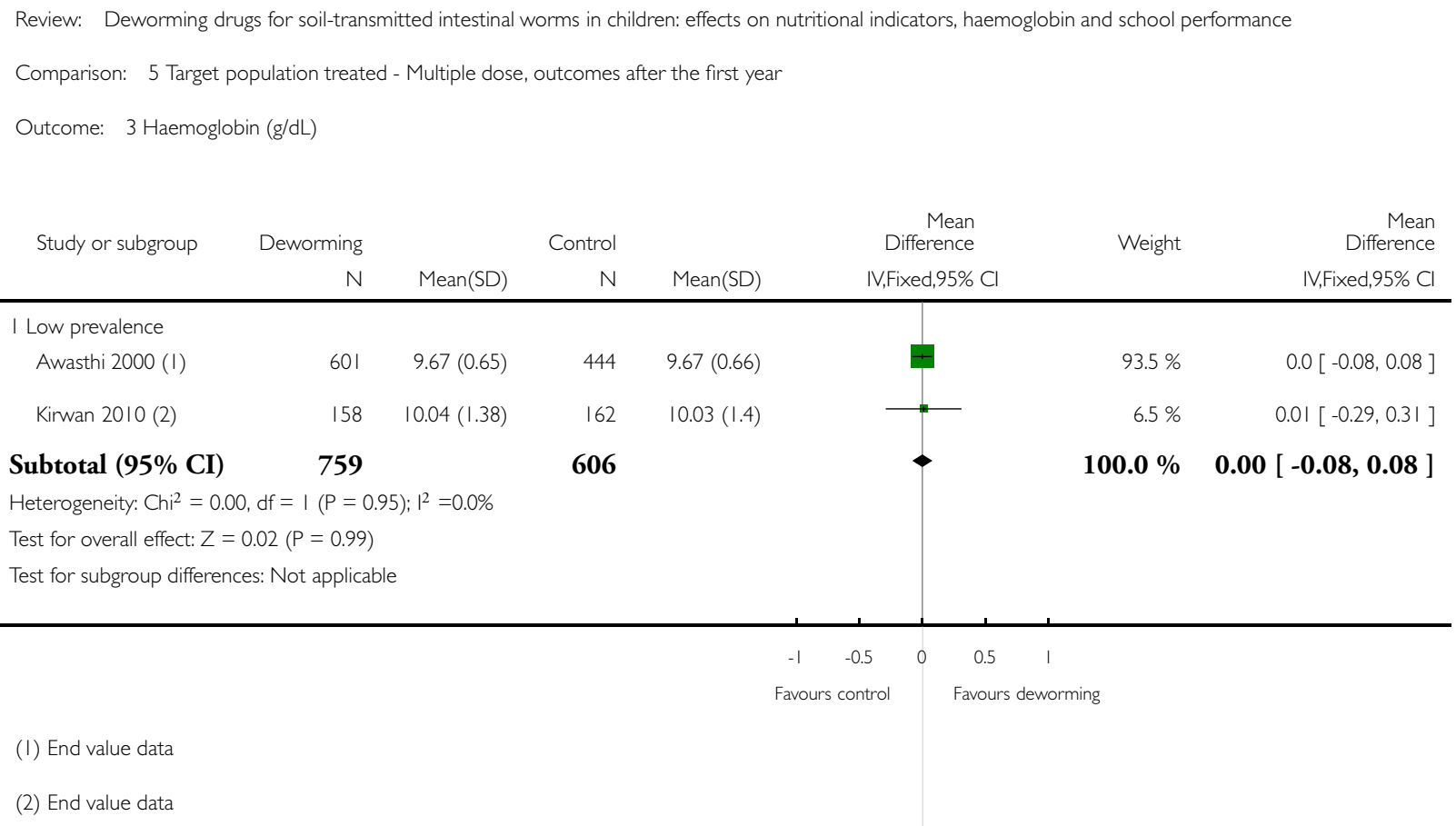

Analysis 5.4. Comparison 5 Target population treated - Multiple dose, outcomes after the first year, Outcome 4 School attendance (days present at school).

Review: Deworming drugs for soil-transmitted intestinal worms in children: effects on nutritional indicators, haemoglobin and school performance

Comparison: 5 Target population treated - Multiple dose, outcomes after the first year

Outcome: 4 School attendance (days present at school)

Study or subgroup Mean Difference (SE) Mean Mifference Meren

IV,Fixed,95\% Cl Fixed,95\% Cl

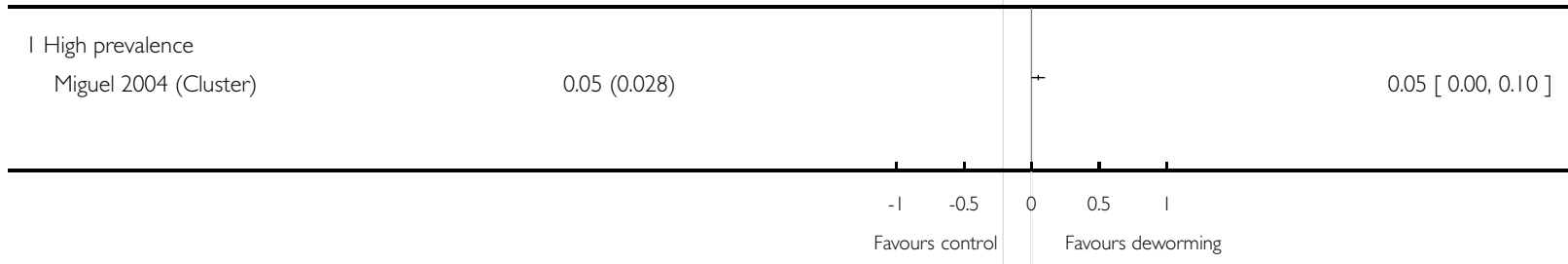

Deworming drugs for soil-transmitted intestinal worms in children: effects on nutritional indicators, haemoglobin and school 


\section{Analysis 6.I. Comparison 6 Target population treated - Single dose (low risk of bias for allocation concealment), Outcome I Weight (kg).}

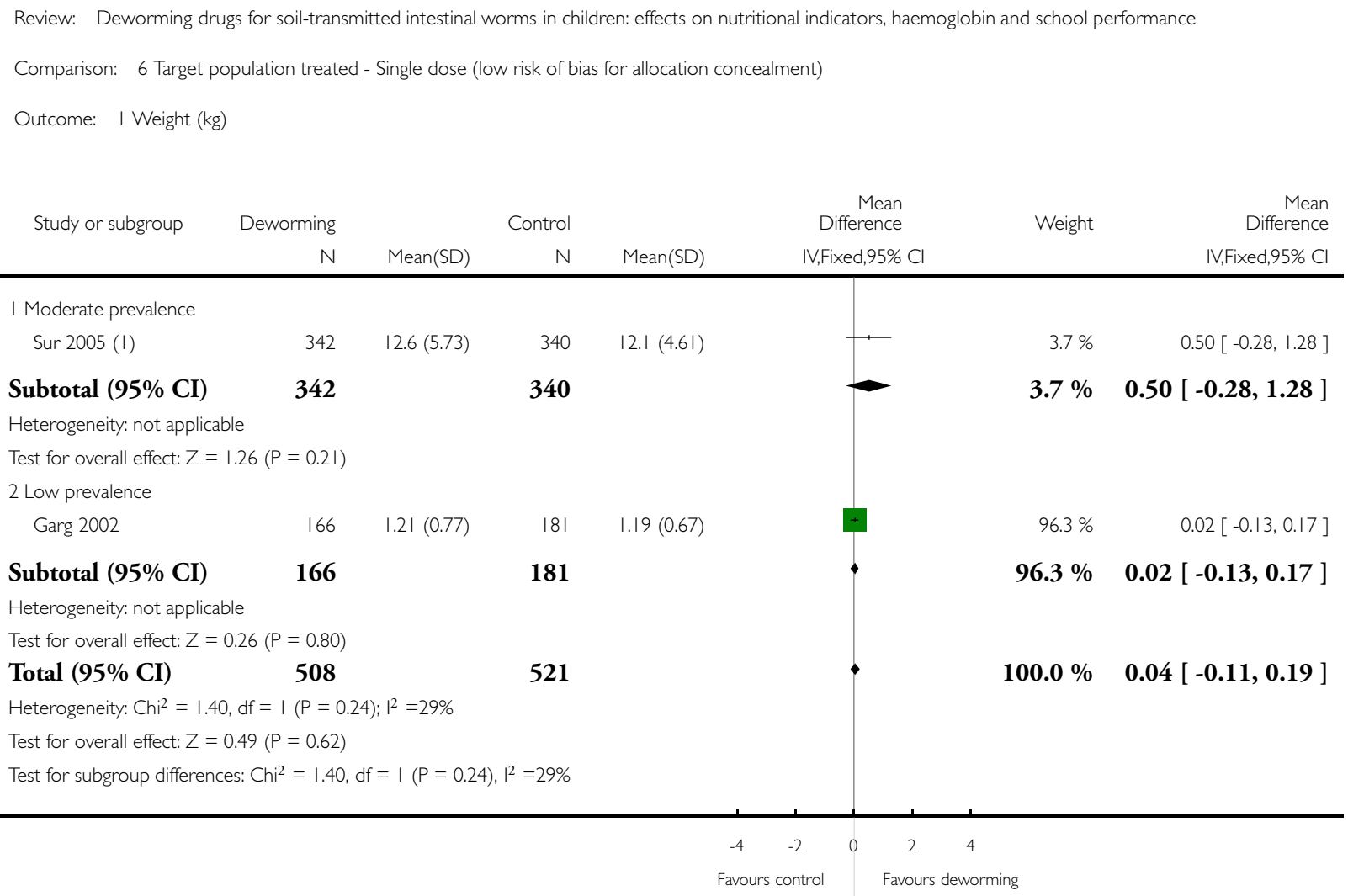

( I) End value data 


\section{Analysis 6.2. Comparison 6 Target population treated - Single dose (low risk of bias for allocation concealment), Outcome 2 Height $(\mathrm{cm})$.}

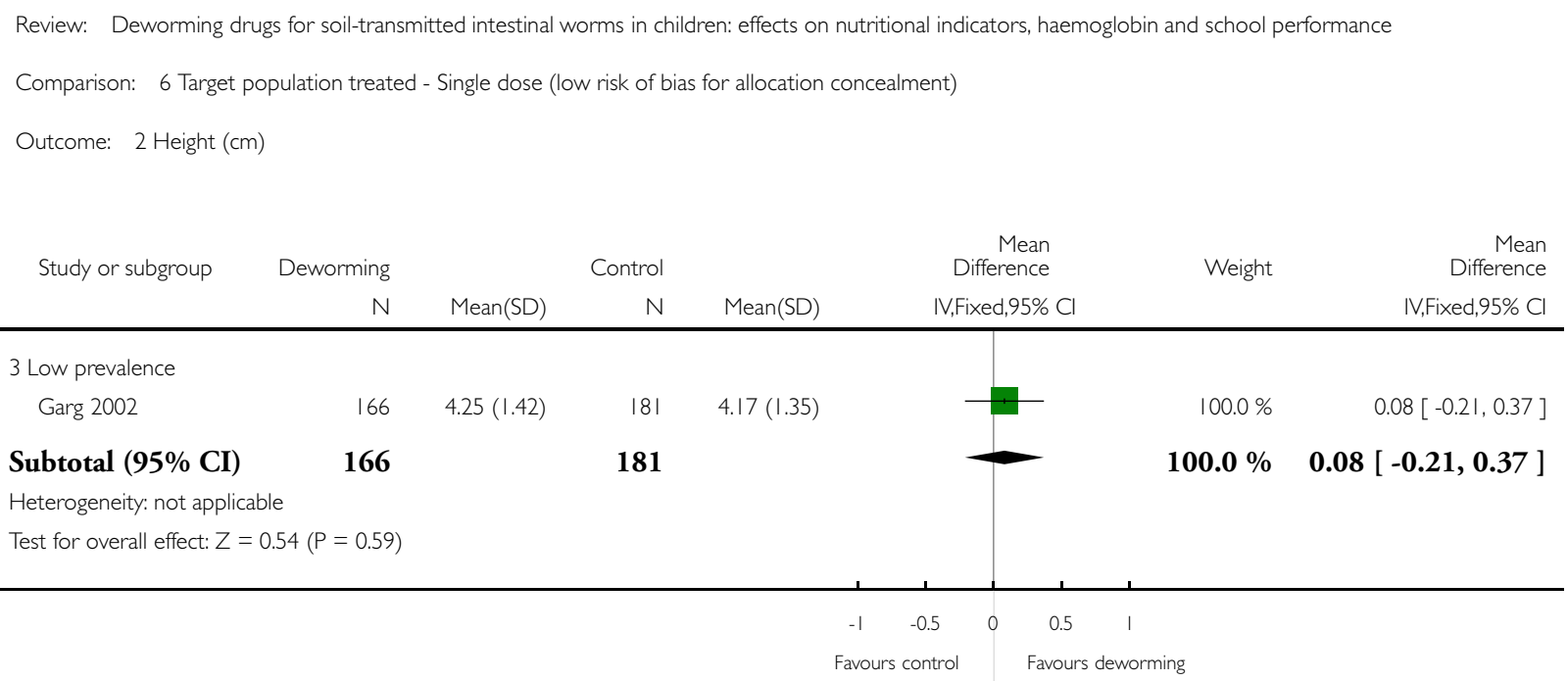

\section{Analysis 6.3. Comparison 6 Target population treated - Single dose (low risk of bias for allocation concealment), Outcome 3 Mid-upper arm circumference $(\mathrm{cm})$.}

Review: Deworming drugs for soil-transmitted intestinal worms in children: effects on nutritional indicators, haemoglobin and school performance

Comparison: 6 Target population treated - Single dose (low risk of bias for allocation concealment)

Outcome: 3 Mid-upper arm circumference $(\mathrm{cm})$

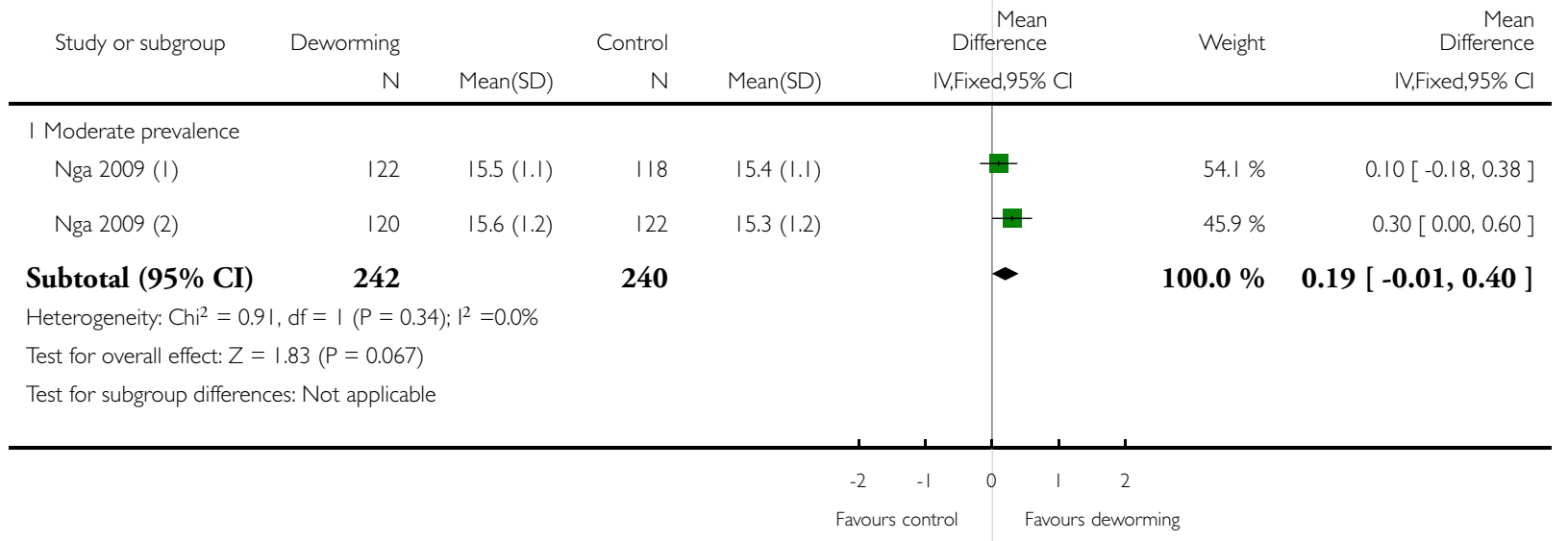

Deworming drugs for soil-transmitted intestinal worms in children: effects on nutritional indicators, haemoglobin and school 
(I) End value data
(2) End value data

\section{Analysis 6.4. Comparison 6 Target population treated - Single dose (low risk of bias for allocation} concealment), Outcome 4 Haemoglobin (g/dL).

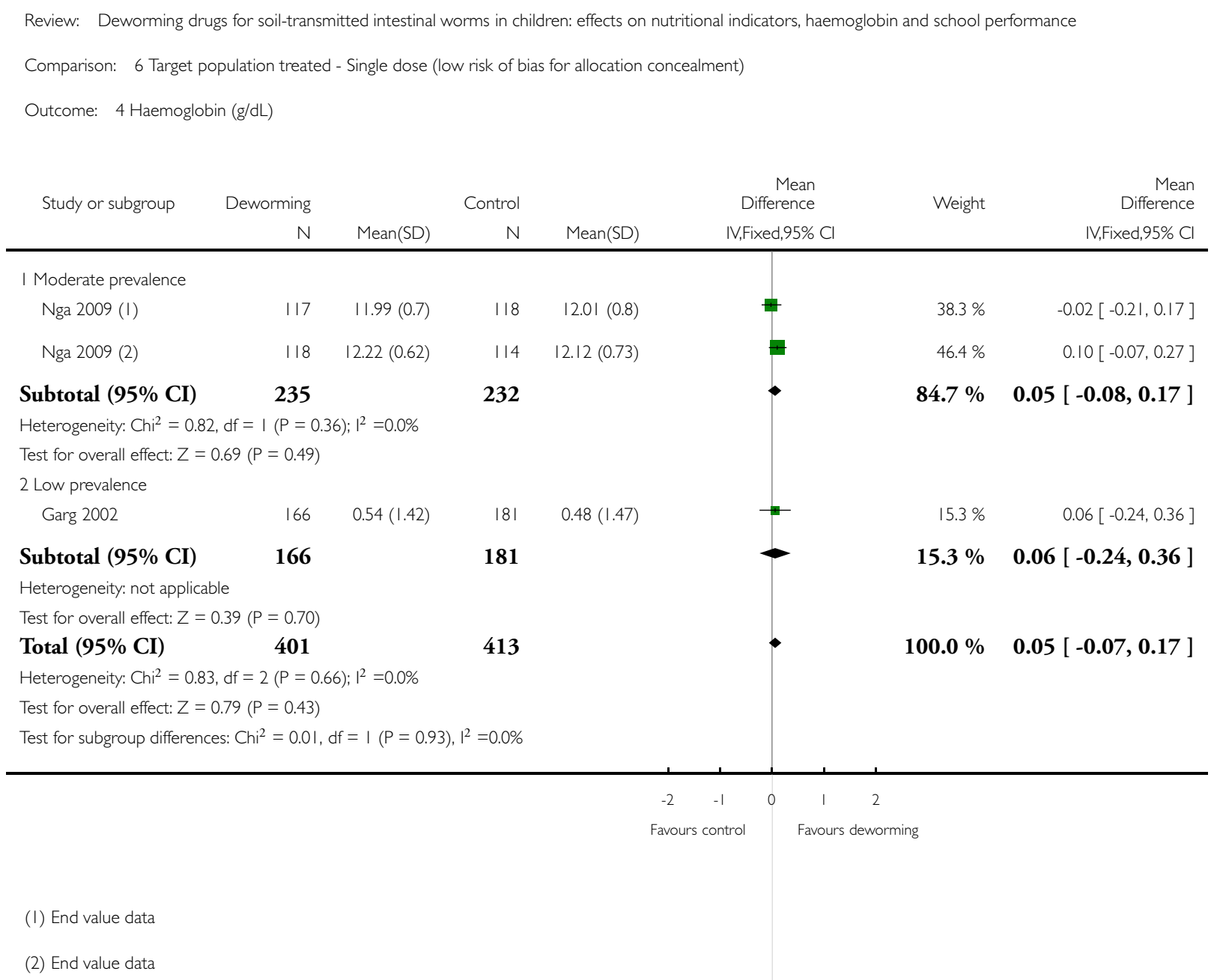

Deworming drugs for soil-transmitted intestinal worms in children: effects on nutritional indicators, haemoglobin and school 
Analysis 7.I. Comparison 7 Target population treated - Multiple dose, outcomes in the first year (low risk of bias for allocation concealment), Outcome I Weight (kg).

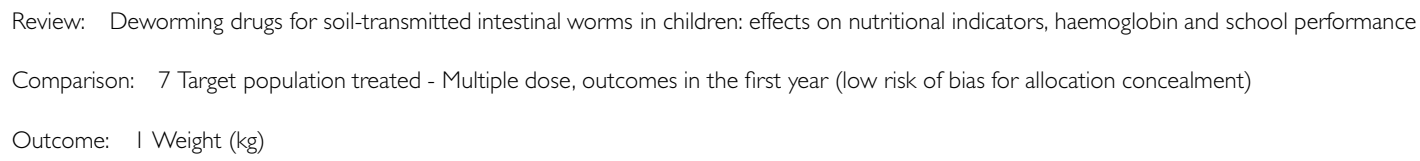

( I) End value data

Analysis 7.2. Comparison 7 Target population treated - Multiple dose, outcomes in the first year (low risk of bias for allocation concealment), Outcome 2 Haemoglobin (g/dL).

Review: Deworming drugs for soil-transmitted intestinal worms in children: effects on nutritional indicators, haemoglobin and school performance

Comparison: 7 Target population treated - Multiple dose, outcomes in the first year (low risk of bias for allocation concealment)

Outcome: 2 Haemoglobin $(\mathrm{g} / \mathrm{dL})$

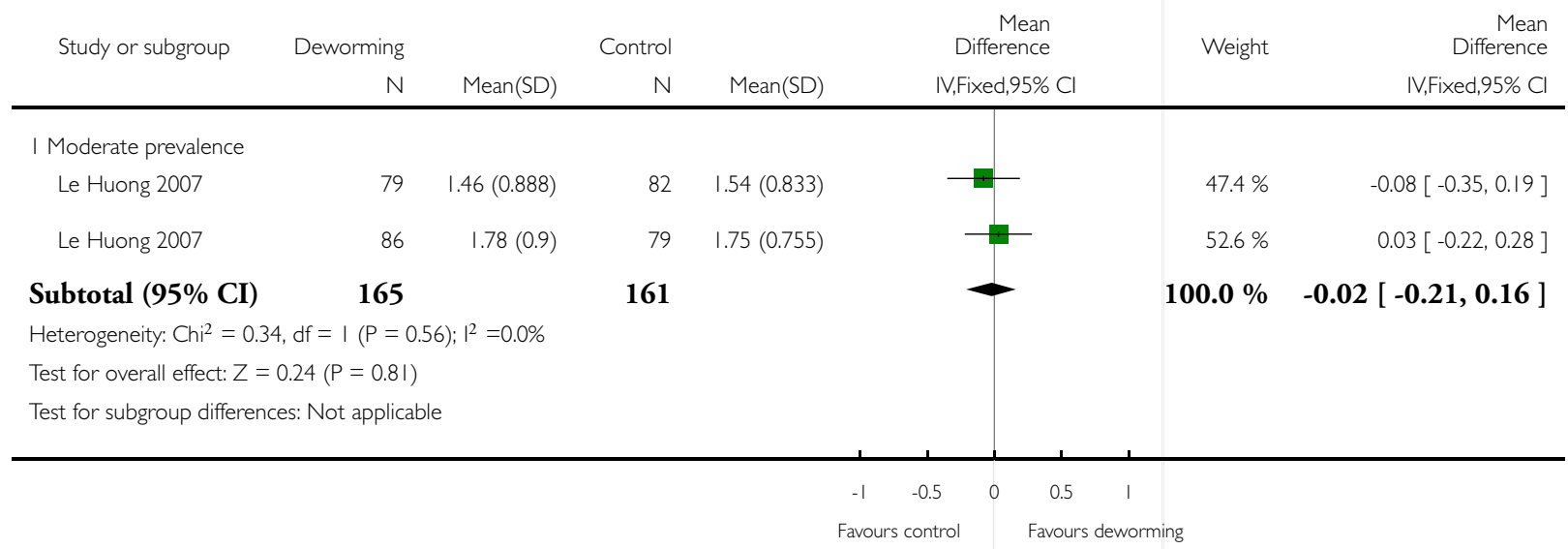


Analysis 8.I. Comparison 8 Target population treated - Multiple dose, outcomes after the first year (low risk of bias for allocation concealment), Outcome I Weight (kg).

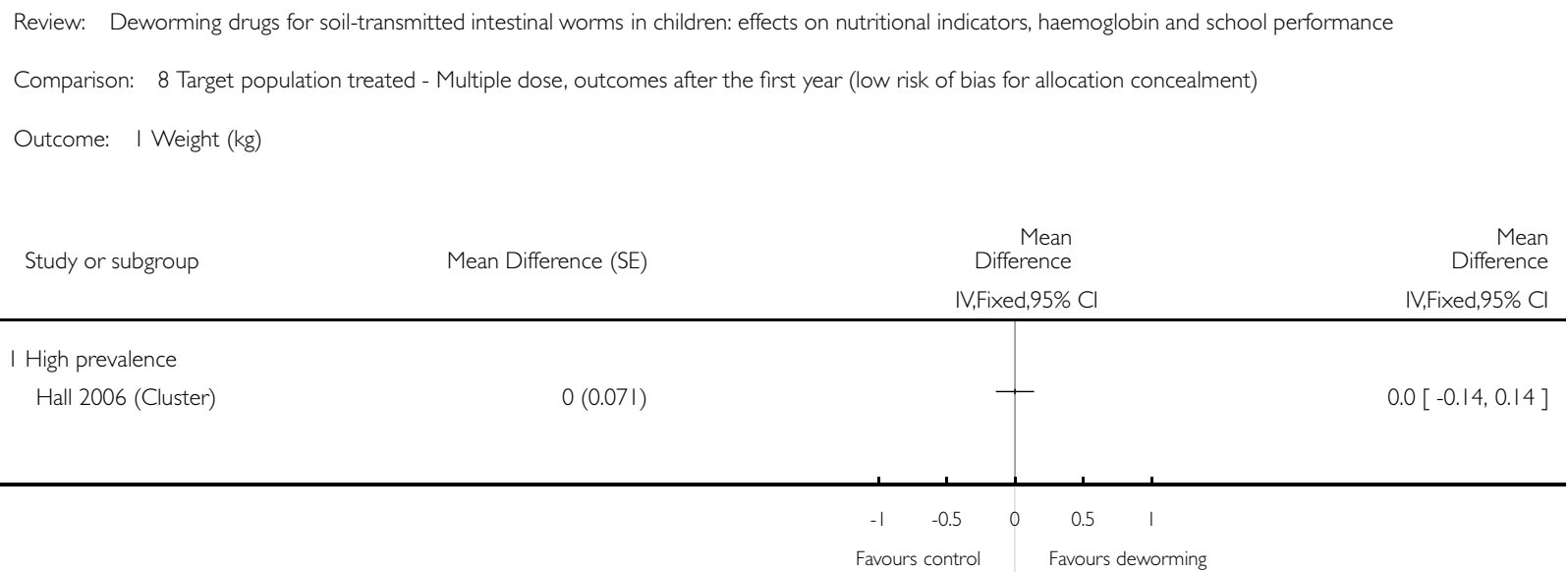

Analysis 8.2. Comparison 8 Target population treated - Multiple dose, outcomes after the first year (low risk of bias for allocation concealment), Outcome 2 Height (cm).

Review: Deworming drugs for soil-transmitted intestinal worms in children: effects on nutritional indicators, haemoglobin and school performance

Comparison: 8 Target population treated - Multiple dose, outcomes after the first year (low risk of bias for allocation concealment)

Outcome: 2 Height $(\mathrm{cm})$

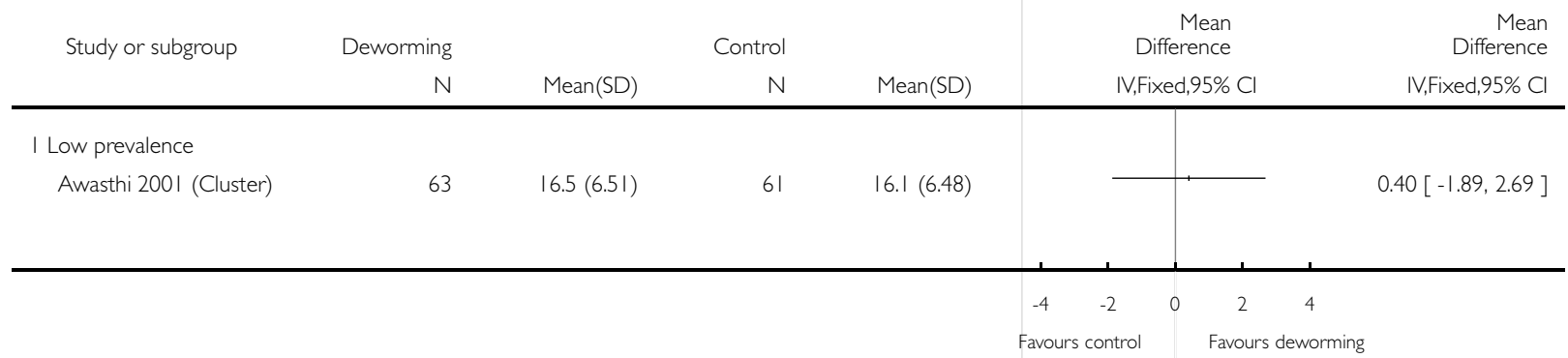

Deworming drugs for soil-transmitted intestinal worms in children: effects on nutritional indicators, haemoglobin and school 
ADDITIONAL TABLES

Table 1. Detailed search strategies

\begin{tabular}{|c|c|c|c|c|c|}
\hline Search set & CIDG $\mathbf{S R}^{a}$ & CENTRAL & MEDLINE $^{b}$ & EMBASE $^{b}$ & LILACS $^{b}$ \\
\hline 1 & helmint* & helmint* & helmint* & helmint\$ & helmint* \\
\hline 2 & $\begin{array}{l}\text { Ancylostoma duode- } \\
\text { nale }\end{array}$ & $\begin{array}{l}\text { Ancylostoma duode- } \\
\text { nale }\end{array}$ & $\begin{array}{l}\text { Ancylostoma duode- } \\
\text { nale }\end{array}$ & $\begin{array}{l}\text { Ancylostoma duode- } \\
\text { nale }\end{array}$ & $\begin{array}{l}\text { Ancylostoma duode- } \\
\text { nale }\end{array}$ \\
\hline 3 & Necator americanus & Necator americanus & Necator americanus & Necator americanus & Necator americanus \\
\hline 4 & Ascaris & Ascaris & Ascaris & Ascaris & Ascaris \\
\hline 5 & $\begin{array}{l}\text { Enterobius vermicu- } \\
\text { laris }\end{array}$ & $\begin{array}{l}\text { Enterobius vermicu- } \\
\text { laris }\end{array}$ & $\begin{array}{l}\text { Enterobius vermicu- } \\
\text { laris }\end{array}$ & $\begin{array}{l}\text { Enterobius vermicu- } \\
\text { laris }\end{array}$ & $\begin{array}{l}\text { Enterobius vermicu- } \\
\text { laris }\end{array}$ \\
\hline 6 & trichuris & trichuris & trichuris & trichuris & trichuris \\
\hline 7 & Strongyloid* & Strongyloid* & Strongyloid* & Strongyloid* & Strongyloid* \\
\hline 8 & albendazole & hookworm* & hookworm* & hookworm\$ & $1-7 / \mathrm{OR}$ \\
\hline 9 & mebendazole & roundworm* & roundworm* & roundworm\$ & albendazole \\
\hline 10 & piperazine & pinworm* & pinworm* & pinworm\$ & mebendazole \\
\hline 11 & levamisole & whipworm* & whipworm* & whipworm\$ & piperazine \\
\hline 12 & pyrantel & $1-11 / \mathrm{OR}$ & $1-11 / \mathrm{OR}$ & $1-11 / \mathrm{OR}$ & levamisole \\
\hline 13 & tiabendazole & albendazole & albendazole & albendazole & pyrantel \\
\hline 14 & - & mebendazole & mebendazole & mebendazole & tiabendazole \\
\hline 15 & - & piperazine & piperazine & piperazine & $9-14 / \mathrm{OR}$ \\
\hline 16 & - & levamisole & levamisole & levamisole & 8 and 15 \\
\hline 17 & - & pyrantel & pyrantel & pyrantel & Limit 16 to human \\
\hline 18 & - & tiabendazole & tiabendazole & tiabendazole & - \\
\hline 19 & - & $\begin{array}{l}13 \text { or } 14 \text { or } 15 \text { or } 16 \\
\text { or } 17 \text { or } 18\end{array}$ & $\begin{array}{l}13 \text { or } 14 \text { or } 15 \text { or } 16 \\
\text { or } 17 \text { or } 18\end{array}$ & $\begin{array}{l}13 \text { or } 14 \text { or } 15 \text { or } 16 \\
\text { or } 17 \text { or } 18\end{array}$ & - \\
\hline 20 & - & 12 and 19 & 12 and 19 & 12 and 19 & - \\
\hline 21 & - & - & Limit 20 to human & Limit 20 to human & - \\
\hline
\end{tabular}

${ }^{a}$ Cochrane Infectious Diseases Group Specialized Register.

Deworming drugs for soil-transmitted intestinal worms in children: effects on nutritional indicators, haemoglobin and school 
${ }^{b}$ Search terms used in combination with the search strategy for retrieving trials developed by The Cochrane Collaboration (Lefebvre 2011).

\section{Table 2. Haemoglobin search strategy}

\begin{tabular}{|c|c|}
\hline 1 & helmint* \\
\hline 2 & Ancylostoma duodenale \\
\hline 3 & Necator americanus \\
\hline 4 & Ascaris \\
\hline 5 & Enterobius vermicularis \\
\hline 6 & trichuris \\
\hline 7 & Strongyloid* \\
\hline 8 & hookworm* \\
\hline 9 & roundworm* \\
\hline 10 & pinworm* \\
\hline 11 & whipworm* \\
\hline 12 & $1-11 / \mathrm{OR}$ \\
\hline 13 & albendazole \\
\hline 14 & mebendazole \\
\hline 15 & piperazine \\
\hline 16 & levamisole \\
\hline 17 & pyrantel \\
\hline 18 & tiabendazole \\
\hline 19 & 13 or 14 or 15 or 16 or 17 or 18 \\
\hline 20 & haemoglobin \\
\hline 21 & hemoglobin \\
\hline 22 & anemia \\
\hline 23 & anaemia \\
\hline
\end{tabular}


$24 \mathrm{HB}$

2520 or 21 or 22 or 23 or 24

$26 \quad 12$ and 19 and 25

27 Limit 26 to human

Search terms used in electronic databases in combination with the search strategy for retrieving trials developed by The Cochrane

Collaboration (Lefebvre 2011);

Table 3. Community diagnosis categories and recommended treatment strategies

\begin{tabular}{|c|c|c|c|}
\hline $\begin{array}{l}\text { Community category (WHO } \\
\text { 2002) }\end{array}$ & Prevalence $^{a}$ & Proportion $^{b}$ & School intervention \\
\hline $\begin{array}{l}\text { 1. High prevalence or high in- } \\
\text { tensity }\end{array}$ & $>70 \%$ & $>10 \%$ & Targeted treatment of school-age children 2 to 3 times per year \\
\hline $\begin{array}{l}\text { 2. Moderate prevalence and low } \\
\text { intensity }\end{array}$ & $>50 \%$ but $<70 \%$ & $<10 \%$ & Targeted treatment of school-age children once per year \\
\hline $\begin{array}{l}\text { 3. Low prevalence and low in- } \\
\text { tensity }\end{array}$ & $<50 \%$ & $<10 \%$ & Selective treatment \\
\hline Category (WHO 2006b) & Prevalence $^{a}$ & & Action to be taken \\
\hline High risk community & $>50 \%$ & & $\begin{array}{l}\text { Targeted treatment of pre-school and school-age children } 2 \text { or } \\
3 \text { times per year }\end{array}$ \\
\hline Low risk community & $>20 \%$ but $<50 \%$ & & $\begin{array}{l}\text { Targeted treatment of pre-school and school-age children once } \\
\text { per year }\end{array}$ \\
\hline
\end{tabular}

${ }^{a}$ Of any worm infection.

${ }^{b}$ Of moderate to heavy infections.

Table 4. Data not included in meta-analysis

Screened for infection - single dose (outcomes measured $<1$ year)

Nokes 1992

Albendazole
Growth measured but not reported: 9 weeks cited as too short a follow-up period to demonstrate a change

Screened for infection - multiple dose (outcome measured $<1$ year) 
Table 4. Data not included in meta-analysis (Continued)

Simeon 1995

Albendazole
No significant difference in any reported outcome for whole group.

Height-for-age z-score at baseline in treatment group -0.48 (0.95) and in placebo group $-0.39(0.90)$. At follow up in treatment group -0.48 (0.97) and in placebo group -0.41 (0.89).

Body mass index $\left(\mathrm{kg} / \mathrm{m}^{2}\right)$ at baseline in treatment group $15.3(1.3)$ and in placebo group 15.5 (1.3). At follow up in treatment group 15.6 (1.3) and in placebo group 15.8 (1.4)

Whole target population treated - single dose (outcome measured $<1$ year)

Beach 1999

Albendazole

A nutritional benefit of treatment was not detectable after 4 months for the entire study population (853 participants, no figures provided).

Stratification by infection demonstrated small positive effects in the treatment group for some anthropometric outcomes. In $A s-$ caris-infected children (51), height gain was $0.62 \mathrm{~cm}$ greater than placebo in the combination treatment group $(\mathrm{P}=0.01)$ at 4 months. In Trichuris-infected children (158), weight gain was 0. $56 \mathrm{~kg}$ greater than placebo in the combination treatment group $(\mathrm{P}=0.01)$ at 4 months

Fox 2005

Albendazole

No results provided for whole study population.

Results for height and weight only presented in the narrative for subgroups infected with hookworm and Ascaris: no significant anthropometric changes detected (no figures quoted). In those infected with Trichuris, weight gain was greater in the albendazole group (difference compared to placebo $0.28 \mathrm{~kg}, \mathrm{P}=0.038$ ). Adverse events: no serious adverse events (albendazole 0/46 versus placebo 0/43). Myalgia and cough were reported significantly more frequently in the placebo group compared to albendazole

Greenberg 1981

Piperazine citrate

Treatment group tended to show worse nutrition than placebo.

Comparison showed no significant difference for all measured anthropometric variables for the total group and for subgroups defined by severity of infection (no figures provided)

Kloetzel 1982

Mebendazole
No significant difference was found between the groups.

Results reported as the proportion of treatment or control group that improved, deteriorated, or experienced no change. Unclear which anthropological measures were used in this categorization process. Proportions in each category were not significantly different between trial arms (improved: $51 \%$ in mebendazole group versus $49 \%$ in control; deteriorated: $35 \%$ in mebendazole group versus $33 \%$ in control; no change: $14 \%$ in mebendazole group versus $18 \%$ in control; no significance test results quoted) 
Table 4. Data not included in meta-analysis (Continued)

Koroma 1996

Albendazole

Significant increases in weight-for-height, weight-for-age, and height-for-age $z$-scores recorded in rural and urban treatment groups at 6 months.

Mean increase in rural treatment group compared to placebo: weight-for-height z-score 0.28 (SE 0.17) $\mathrm{P}<0.05$; weight-for-age z-score 1.04 (SE 0.03) P < 0.05; and height-for-age $z$-score 0.83 (SE 0.03) $\mathrm{P}<0.001$.

Mean increase in urban treatment group compared to placebo: weight-for-height z-score 1.04 (SE 0.07) $\mathrm{P}<0.05$; weight-for-age z-score 1.02 (SE 0.09) $\mathrm{P}<0.001$; and height-for-age $\mathrm{z}$-score 1.01 (SE 0.02) $\mathrm{P}<0.05$

Michaelsen 1985

Tetra-chlorethylene

No significant difference in change in mean for haemoglobin. (tetrachloroethylene $0.22 \mathrm{~g} / 100 \mathrm{~mL}$ versus placebo $0.09 \mathrm{~g} /$ $100 \mathrm{~mL}$; quoted as non-significant) or weight for height at 5 months (tetrachloroethylene $-1.3 \%$ of WHO reference mean versus placebo $-0.4 \%$; quoted as non-significant)

Adverse events: $17 \%$ (19/119: results not given for separate trial arms) of the children suffered adverse effects (nausea and ataxia) that began one and a half hours after treatment. All symptoms disappeared within four hours. Tetrachlorethylene is not in current use as a deworming drug

Nga 2009

Albendazole
No significant differences in weight-for-height, weight-forage, and height-for-age $z$-scores and skin fold thickness at 4 months.

There was no statistically significant effect of deworming on weight, height, HAZ scores, WAZ scores, or WHZ scores. There were no statistically significant differences in skin fold thickness after four months of intervention

Whole target population treated - multiple dose (outcome measured $<1$ year)

Goto 2009

Albendazole plus secnidazole
No significant differences in mean $z$-scores or prevalence of stunting, underweight or wasting between the intervention groups were found, and the changes between intervals (eg between weeks 0 to 12,0 to 24,0 to 36,12 to 24 , etc.) did not differ significantly between groups.

Height-for-age z-score: at baseline in treatment group -1.08 (1.02) and in control group -1.21 (1.0). At follow up in treatment group $-1.59(0.93)$ and in control group -1.70 (0.93).

Weight-for-age z-score: at baseline in treatment group -1.91 (1.15) and in control group -1.85 (1.14). At follow up in treatment group $-2.62(1.17)$ and in control group -2.59 (1.17).

Weight-for-height z-score: at baseline in treatment group -1.25 (1. 18 ) and in control group - 0.96 (1.17). At follow up in treatment group -1.55 (1.07) and in control group -1.83 (1.06) 
Hadju 1997

Pyrantel pamoate

Albendazole

No significant differences detected between treatment groups on basis of multivariate analyses controlling for age, sex, and 'times'.

Change in weight-for-age z-score: placebo 0.02 ; pyrantel $1 \mathrm{x}$ treatment 0.03 ; pyrantel $2 \mathrm{x}$ treatments 0.08 ; albendazole $1 \mathrm{x}$ treatment -0.10 ; albendazole $2 \mathrm{x}$ treatments 0.01 .

Change in height-for-age z-score: placebo 0.01 ; pyrantel $1 \mathrm{x}$ treatment 0.00 ; pyrantel $2 \mathrm{x}$ treatments 0.04 ; albendazole $1 \mathrm{x}$ treatment -0.07 ; albendazole $2 \mathrm{x}$ treatments 0.01 .

Change in weight-for-heightz-score: placebo 0.02 ; pyrantel $1 \mathrm{x}$ treatment 0.08 ; pyrantel $2 \mathrm{x}$ treatments 0.05 ; albendazole $1 \mathrm{x}$ treatment -0.07 ; albendazole $2 \mathrm{x}$ treatments 0.03 .

Change mid-arm circumference $z$-score: placebo -0.09; pyrantel 1 $\mathrm{x}$ treatment -0.11 ; pyrantel $2 \mathrm{x}$ treatments -0.11 ; albendazole $1 \mathrm{x}$ treatment -0.07 ; albendazole $2 \mathrm{x}$ treatments -0.01

Le Huong 2007

No obvious trend in nutrition variable.

Anthropometric indices were calculated using WHO/NCHS reference data. Being wasted, stunted and underweight was defined by z-scores,$<-2$ SD for weight-for-height, height-for-age and weight-for-age, respectively.

Percentage underweight: At baseline Fe 41.9, Fe + MEB 51.9, MEB 50.6, Placebo 45 1 ; after treatment Fe 33.7, Fe + MEB 46.8, MEB 38, Placebo $35 \cdot 4$.

Percentage stunted: At baseline $\mathrm{Fe} 30 \cdot 2, \mathrm{Fe}+\mathrm{MEB}$ 31.6, MEB 41.8, Placebo 31·7; after treatment Fe 29.1, Fe + MEB 27·8, MEB 29.1, Placebo 29.3.

Percentage wasted: At baseline Fe 9·3, Fe + MEB 16.5, MEB 13.9, Placebo 12.2; after treatment Fe 5·8, Fe + MEB 17·7, MEB 13.9, Placebo $13 \cdot 4$

\footnotetext{
Miguel 2004 (Cluster)
}

\section{No effect on nutrition or haemoglobin demonstrated}

Data from published paper including praziquantel treated clusters (25 treatment schools versus 25 control schools in 1998 comparison):

It is unclear how many children were followed up for nutritional outcomes. For haemoglobin a sample of around 4\% (778/20,000) of the quasi-randomized comparison of group 1 versus group 2 in 1998 was analysed. It is unclear how this group was selected Difference in weight-for age $\mathrm{Z}$ score (treatment - control): 0.00 (SE 0.04)

Difference in height-for-age $\mathrm{Z}$ score end value (treatment - control): 0.09 (SE 0.05).

Difference in haemoglobin (g/L) (treatment - control): 1.6 (SE 1. 4) lence of mild wasting malnutrition in a subgroup of children aged $<30$ months only 
Willett 1979

Levamisole adjusted odds ratio for mebendazole 0.38 (95\% CI 0.16 to 0 . 90) for weight-for-height $z$-score $<-1$. Mebendazole is reported as significantly reducing the prevalence of poor appetite across the whole group (adjusted odds ratio for mebendazole 0.52 (95\% CI 0.30 to 0.89 ) for weight-for-height $z$-score $<-1$ ). Mebendazole had no impact on iron indices. Adjusted effect on motor scores had a tendency to favour mebendazole, but this was not significant

No statistical difference in nutrition in terms of height and weight differences between the 2 groups.

Growth rates presented are adjusted for a number of variables. Weight gain (kg/year) in levamisole group 2.08 versus 1.92 in placebo group $(\mathrm{P}=0.06)$. Height gain $(\mathrm{cm} /$ year) in levamisole group 7.58 versus 7.73 in placebo group (no significance quoted)

Stoltzfus 1997 (Cluster)

Mebendazole
Weight gain: in a subgroup of under 10 year olds, the twiceyearly treated group experienced significantly greater weight gain (kg) compared to control (2.38 (SE 0.08) versus 2.11 (SE 0.08), $P<0.05)$.

In the thrice yearly treatment group the difference was not significant (2.31 (SE 0.08) versus 2.11 (SE 0.08), no P value stated).

Height gain: in under 10 year olds the thrice-yearly treated group experienced significantly greater height gain $(\mathrm{cm})$ compared to control (4.59 (SE 0.07) versus 4.29 (SE 0.07), P < 0.01). In the twice-yearly treatment group the difference in height gain was not significant (4.42 (SE 0.07) versus 4.29 (SE 0.07), no P value stated). There were no significant differences found in the subgroup of children aged over 10 years.

Haemoglobin change: deworming had no effect on haemoglobin change in an adjusted analysis presented for the whole study group (g/L): control 11.3 (SE 1.7); twice-yearly treatment group 10.3 (SE 1.7); and thrice-yearly group 12.7 (SE 1.7)

Whole target population treated - multiple dose (outcome measured $>1$ year)

Awasthi 2008 (Cluster)

Mebendazole plus pyrantel
During the study there were 23 deaths, 13 were in the usual care arm and 10 were in the treatment arm.

These data were not adjusted for cluster randomization.

No difference in height or weight between treatment and control group at the end of 2-year follow up. Standard deviations not provided. Results stratified for males and females:

Females: change in height in treatment arm $12.2 \mathrm{~cm}$ versus change in height in placebo arm $12.4 \mathrm{~cm}$; change in weight in treatment arm $5.6 \mathrm{~kg}$ versus change in weight in placebo arm $5.6 \mathrm{~kg}$.

Males: change in height in treatment arm $11.8 \mathrm{~cm}$ versus change in height in placebo arm $11.4 \mathrm{~cm}$; change in weight in treatment arm $5.7 \mathrm{~kg}$ versus change in weight in placebo arm $4.7 \mathrm{~kg}$ 
Table 4. Data not included in meta-analysis (Continued)

\begin{tabular}{l|l}
$\begin{array}{l}\text { Hall } 2006 \text { (Cluster) } \\
\text { Albendazole }\end{array}$ & $\begin{array}{l}\text { Trial authors reported no difference in final and change in } \\
\text { height. } \\
\text { Mid-upper arm circumference and subscapular skinfold thickness } \\
\text { improved significantly in the control group compared to the al- } \\
\text { bendazole group }(7.87 \text { versus } 7.61, \mathrm{P}=0.005 \text { and } 1.22 \text { versus } 1 .\end{array}$ \\
$05, \mathrm{P}=0.005$ respectively). These results do not appear to have \\
been adjusted for cluster randomization. The results that show no \\
effect, however, will not remain non-significant even after appro- \\
priate adjustment, though the CIs may change
\end{tabular}

Rousham 1994 (Cluster)

Mebendazole
ANOVAS of the change in z-scores revealed no significant improvement with treatment.

Change in weight-for-age and weight-for-height z-scores were significantly worse in the treatment group. Height-for-age z-score (mebendazole 0.25 v 0.17 in placebo group, P 'non-significant'), weight-for-age $\mathrm{z}$-score (mebendazole 0.03 versus 0.12 in placebo group, $\mathrm{P}<0.05$ ), weight-for-height $\mathrm{z}$-score (mebendazole -0.25 versus -0.05 in placebo group, $\mathrm{P}<0.001$ ), and mid-upper arm circumference were presented (mebendazole 0.33 versus 0.23 in placebo group, P 'non-significant')

Table 5. Trials evaluating psychometric tests of cognition

\begin{tabular}{|c|c|c|}
\hline Trial details & Outcome measures & Results \\
\hline \multicolumn{3}{|c|}{ Screened for infection - single dose (outcomes measured $<1$ year) } \\
\hline $\begin{array}{l}\text { Kvalsvig 1991a } \\
\text { Mebendazole versus placebo, } 1 \text { month }\end{array}$ & $\begin{array}{l}\text { Card sorting task; cancellation task (num- } \\
\text { ber of letter 's' in text deleted in a time pe- } \\
\text { riod) }\end{array}$ & $\begin{array}{l}\text { Changes in cognitive scores are not clearly } \\
\text { reported since "the dose of mebendazole } \\
\text { was inadequate to free children from infec- } \\
\text { tion" }\end{array}$ \\
\hline $\begin{array}{l}\text { Nokes } 1992 \\
\text { Albendazole versus placebo } \\
2.25 \text { months }\end{array}$ & $\begin{array}{l}\text { Digit span (forward and backward); arith- } \\
\text { metic and coding from Wechsler Intelli- } \\
\text { gence Scale for Children; fluency; listening } \\
\text { comprehension from the Clinical Evalua- } \\
\text { tion of Language functions; matching fa- } \\
\text { miliar figures test }\end{array}$ & $\begin{array}{l}\text { Mean test scores pre-and post-intervention } \\
\text { presented with CIs } \\
\text { No comment made on significance of un- } \\
\text { adjusted data. } \\
\text { Results of multiple regression suggest a } \\
\text { greater improvement in treated children } \\
\text { in } 3 / 10 \text { tests (fluency, digit span forwards, } \\
\text { digit span backwards) }\end{array}$ \\
\hline
\end{tabular}

Screened for infection - multiple dose (outcome measured $<1$ year)

$\begin{array}{lll}\text { Simeon } 1995 & \text { 1. Main study }(264 \text { children }) & \text { 1. Main study: no difference in any re- } \\ \text { Albendazole versus placebo } & \text { Wide range achievement test: reading, } & \text { ported outcome measure } \\ 6.5 \text { months } & \text { arithmetic, and spelling sub tests; } & \text { 2. Subgroup 1: no significant effect on any } \\ & \text { 2. Subgroup } 1 \text { (189 children } 189 \text { infected } & \text { of the outcome measures }\end{array}$


Table 5. Trials evaluating psychometric tests of cognition (Continued)

children from original population)

Digit span; verbal fluency test; visual search; number choice; French vocabulary learning

3. Subgroup 2 (97 children from grade 5)

French learning; digit spans (forward and backward); Corsi block span; verbal fluency; picture search; silly sentences
3. Subgroup 2: no significant improvement with treatment in any of the tests was found in multiple regression modelling

Whole target population treated - single dose (outcome measured $<1$ year)

Nga 2009

Albendazole
Cognitive performance was measured using Raven's Colored Matrices and also a series of cognitive tests from Wechsler's Intelligence Scale for Children III: digit span backward and forward, block design and coding
Solon 2003

Albendazole versus placebo

16 weeks
Cognitive ability was measured using a standardized written mental-abilities test called the Primary Mental Abilities Test for Filipino Children (PMAT-FC). The test covers general knowledge and comprehension, verbal relationships, fundamental mathematical comprehension and skills, numerical sequencing, and ability to perceive and apply relationships based on meaningless stimuli
Deworming had no significant effect on any of the cognitive tests

Deworming had either no effect or a negative effect on mental ability scores. Data was not reported

Whole target population treated - multiple dose (outcome measured $<1$ year)

Miguel 2004 (Cluster)

Deworming package including albendazole versus placebo

1 year
1. Exam score performance (measured by Internationaal Christelijk Steunfonds Africa (ICS) administered English, Mathematics and Science-Agriculture exams) in pupils in grades 3 to 8

2. Cognitive tests including picture search, Raven matrix, verbal fluency, digit span, Spanish learning, and a dynamic test using syllogisms measured for all three school groups in 2000
1. The authors did not provide outcomes by the quasi-randomized comparison eligible for this review (1998 Group 1 versus Group $2 \&$ 3; 1999 Group 1\&2 versus group 3). Regression modelling, adjusting for participation and treatment year presented 2. Outcome data not reported for cognitive tests, though authors state: "Deworming treatment effects are not significantly different than zero for any component of the cognitive exam (results available on request)"
Stoltzfus 2001

Mebendazole versus placebo, 1 year
Motor and language development by par- Unadjusted data not reported. ents reporting gross motor and language Treatment had no significant effect on momilestones using scoring system developed tor or language development specifically for the trial 
Table 5. Trials evaluating psychometric tests of cognition (Continued)

Watkins 1996

Albendazole versus placebo, 6 months
Interamerican vocabulary test; Interamerican reading test; Peabody picture vocabulary test
All outcome measures reported as unadjusted scores.

No difference in any of the tests found between treatment groups

\section{Whole target population treated - multiple dose (outcome measured $>1$ year)}

Awasthi 2000

Albendazole versus placebo, 2 years

Developmental status (Denver Questionnaire).
No difference in development between treatment groups in terms of proportion with "normal" development
Hall 2006 (Cluster)

Albendazole versus placebo, 2 years
Mathematics test score, Vietnamese test score.
No statistically significant differences in test results at start or end of study. These results have not been adjusted for cluster randomization. They will remain non-significant, however, even after appropriate adjustment, though the CIs may change

Table 6. Trials evaluating school attendance (days present at school).

Trial details

Outcome measures

Results

Screened for infection - multiple dose (outcome measured $<1$ year)

Simeon 1995

Albendazole versus placebo

6.5 months
Main study (264 children).

School attendance from children with class registers pre- and post-intervention
There was no significant difference between the treatment and placebo groups at either baseline or post-test

The mean percentage of school attendance went from 62.6 (SD 20.4) at baseline to 67.3 (SD 18.4) post-test in the treatment group, and from 66.3 (SD 20.8) to 69.3 (SD 17.5) in the placebo group

Whole target population treated - multiple dose (outcome measured $<1$ year)

Miguel 2004 (Cluster)
1. School participation rate was computed among all pupils enrolled in 1998 (group 1 versus groups 2 and 3, 1998 comparison) 2. School participation rate was computed among all pupils enrolled in 1998 (group 2 versus group 3, 1999 comparison) Pupils present on the day of an unannounced NGO visit were considered participant. Pupils had 3.8 observations on average per year. This was then calculated as a weighted average by school
In 1998, in the intervention group, school participation in girls $<13$ and boys was 84 . $1 \%$, and in group 2 it was $73.1 \%$, and in group 3 it was $76.7 \%$ giving a difference of 9.3\% (SE 3.1\%) between intervention and comparison (groups 2 and 3)

In 1999, in the intervention group 2, school participation in girls $<13$ and boys was $71.7 \%$, and in the comparison group 3 (groups 3) it was $66.3 \%$, giving a difference of $5.5 \%$ (SE $2.8 \%$ )

However, there are no comparable baseline 
Table 6. Trials evaluating school attendance (days present at school). (Continued)

values to know whether baseline attendance happens to be higher in group 1 schools

Watkins 1996

Albendazole versus placebo, 6 months
Attendance rates of children actively attending school.
There was no difference in attendance between the albendazole and placebo groups before or after treatment

Treatment group: before treatment: $\mathrm{n}=108$, mean $=0.92$, SEM $=0.01$; after treatment $\mathrm{n}=123$ mean $=0.88 \mathrm{SEM}=0.01$

Placebo group: before treatment $\mathrm{n}=105$ mean $=0.90$, SEM $=0.01$ and after treatment $\mathrm{n}=120$, mean $=0.89, \mathrm{SEM}=0.01$

Whole target population treated - multiple dose (outcome measured $>1$ year)

Miguel 2004 (Cluster)
1. School participation rate was computed among all pupils enrolled in 1998 (Group 1 versus Group 3, 1999 comparison) Pupils present on the day of an unannounced NGO visit were considered participant. Pupils had 3.8 observations on average per year. This was then calculated as a weighted average by school
In the intervention group, school participations in girls $<13$ and boys was $71.3 \%$, and in the comparison group (group3) it was $66.3 \%$, giving a difference of $5 \%$ (SE $2.8 \%)$

However, there are no comparable baseline values to know whether baseline attendance happens to be higher in Group 1 schools

Table 7. Summary of findings A: In children screened for infection, what is the effect of a single dose of deworming drugs?

In children screened for infection, what is the effect of a a single dose of deworming drugs?

Patient or population: children known to be infected with soil-transmitted intestinal worms

Settings: areas endemic for intestinal helminths

Intervention: Single dose deworming drugs

\begin{tabular}{|c|c|c|c|c|c|c|}
\hline \multirow[t]{3}{*}{ Outcomes } & \multicolumn{2}{|c|}{$\begin{array}{l}\text { Illustrative comparative risks* } \\
(95 \% \mathrm{CI})\end{array}$} & \multirow[t]{3}{*}{$\begin{array}{l}\text { Relative effect } \\
(95 \% \mathrm{CI})\end{array}$} & \multirow{3}{*}{$\begin{array}{l}\text { No of Partici- } \\
\text { pants } \\
\text { (studies) }\end{array}$} & \multirow{3}{*}{$\begin{array}{l}\text { Quality of the } \\
\text { evidence } \\
\text { (GRADE) }\end{array}$} & \multirow[t]{3}{*}{ Comments } \\
\hline & Assumed risk & $\begin{array}{l}\text { Corresponding } \\
\text { risk }\end{array}$ & & & & \\
\hline & Control & $\begin{array}{l}\text { Single dose de- } \\
\text { worming drugs }\end{array}$ & & & & \\
\hline $\begin{array}{l}\text { Weight (kg) } \\
\text { Follow-up: } 4 \text { to } \\
16 \text { weeks }\end{array}$ & $\begin{array}{l}\text { The mean gain } \\
\text { in weight in the } \\
\text { control groups } \\
\text { ranged from } 0 . \\
30 \text { to } 0.54 \mathrm{~kg}\end{array}$ & $\begin{array}{l}\text { The mean } \\
\text { gain in weight in } \\
\text { the intervention } \\
\text { groups was } \\
\mathbf{0 . 5 8} \mathbf{~ k g ~ h i g h e r} \\
(0.4 \text { to } 0.76\end{array}$ & & $\begin{array}{l}149 \\
\text { (3 studies) }\end{array}$ & $\begin{array}{l}\oplus \oplus \bigcirc \bigcirc \\
\text { low }^{1,2}\end{array}$ & \\
\hline
\end{tabular}


Table 7. Summary of findings A: In children screened for infection, what is the effect of a single dose of deworming drugs? (Continued)

\begin{tabular}{|c|c|c|c|c|c|}
\hline & & higher) & & & \\
\hline $\begin{array}{l}\text { Haemoglobin } \\
\text { (g/dL) } \\
\text { Follow- } \\
\text { up: } 9 \text { weeks to } 4 \\
\text { months }\end{array}$ & $\begin{array}{l}\text { The } \\
\text { mean haemoglo- } \\
\text { bin in the con- } \\
\text { trol groups was } \\
10.60 \mathrm{~g} / \mathrm{dl}\end{array}$ & $\begin{array}{l}\text { The mean hae- } \\
\text { moglobin in the } \\
\text { intervention } \\
\text { groups was } \\
\mathbf{0 . 3 7} \text { g/dL } \\
\text { higher } \\
(0.1 \text { to } 0.64 \\
\text { higher) }\end{array}$ & $\begin{array}{l}108 \\
\text { (2 studies) }\end{array}$ & $\begin{array}{l}\oplus \oplus \bigcirc \bigcirc \\
\text { low }^{1,2}\end{array}$ & \\
\hline $\begin{array}{l}\text { Formal tests of } \\
\text { cognition }\end{array}$ & - & - & $\begin{array}{l}103 \\
\text { (2 studies) }\end{array}$ & $\begin{array}{l}\oplus \bigcirc \bigcirc \bigcirc \\
\text { very low } \\
3,4,5\end{array}$ & $\begin{array}{l}\text { One trial did not } \\
\text { report the } \\
\text { results, and the } \\
\text { other suggested } \\
\text { improvement in } \\
3 \text { out of } 10 \text { tests } \\
\text { after multiple re- } \\
\text { gression analysis }\end{array}$ \\
\hline
\end{tabular}

*The basis for the assumed risk (eg the median control group risk across studies) is provided in footnotes. The corresponding risk (and its $95 \% \mathrm{CI}$ ) is based on the assumed risk in the comparison group and the relative effect of the intervention (and its 95\% CI). CI: Confidence interval;

GRADE Working Group grades of evidence

High quality: Further research is very unlikely to change our confidence in the estimate of effect.

Moderate quality: Further research is likely to have an important impact on our confidence in the estimate of effect and may change the estimate.

Low quality: Further research is very likely to have an important impact on our confidence in the estimate of effect and is likely to change the estimate.

Very low quality: We are very uncertain about the estimate.

${ }^{1}$ Downgraded by 1 for risk of bias: none of the studies adequately described allocation concealment to be considered "low risk of bias"

${ }^{2}$ Downgraded by 1 for imprecision: the trials are too few and too small to have full confidence in the observed effects

${ }^{3}$ Downgraded by 2 for risk of bias: both studies have deficiencies in randomization, concealment and blinding; in addition, one study did not report on the results, suggesting selective reporting

${ }^{4}$ Downgraded by 1 on imprecision: results were not clearly presented and did not include estimates of effect size.

5 Two studies measured cognitive functioning: i) Kvalsvig 1991a, with a follow-up of one month, did not clearly report the changes in cognitive scores since "the dose of mebendazole was inadequate to free children from infection"; and ii) Nokes 1992, with a followup of nine weeks, reported that results of a multiple regression suggest a greater improvement in treated children in 3/10 tests (fluency, digit span forwards, digit span backwards). 
Table 8. Summary of findings B: In children living in communities where intestinal helminths are endemic, what is the effect of a single dose of deworming drugs?

In children living in communities where intestinal helminths are endemic, what is the effect of a single dose of deworming drugs?

Patient or population: children

Settings: areas endemic for intestinal helminths

Intervention: Single dose deworming drugs

\begin{tabular}{|c|c|c|c|c|c|c|}
\hline \multirow[t]{3}{*}{ Outcomes } & \multicolumn{2}{|c|}{$\begin{array}{l}\text { Illustrative comparative risks* } \\
(95 \% \text { CI })\end{array}$} & \multirow[t]{3}{*}{$\begin{array}{l}\text { Relative effect } \\
(95 \% \text { CI })\end{array}$} & \multirow{3}{*}{$\begin{array}{l}\text { No of Partici- } \\
\text { pants } \\
\text { (studies) }\end{array}$} & \multirow{3}{*}{$\begin{array}{l}\text { Quality of the } \\
\text { evidence } \\
\text { (GRADE) }\end{array}$} & \multirow[t]{3}{*}{ Comments } \\
\hline & Assumed risk & $\begin{array}{l}\text { Corresponding } \\
\text { risk }\end{array}$ & & & & \\
\hline & Control & $\begin{array}{l}\text { Single dose de- } \\
\text { worming drugs }\end{array}$ & & & & \\
\hline $\begin{array}{l}\text { Weight (kg) } \\
\text { Follow-up: } 7 \\
\text { weeks to } 1 \text { year }\end{array}$ & - & - & & $\begin{array}{l}3058 \\
\text { (9 studies) }\end{array}$ & $\begin{array}{l}\oplus \bigcirc \bigcirc \bigcirc \\
\text { very low }\end{array}$ & $\begin{array}{l}\text { A positive ef- } \\
\text { fect was demon- } \\
\text { strated in } 2 \text { trials } \\
\text { from a single lo- } \\
\text { cation but not re- } \\
\text { peated elsewhere }\end{array}$ \\
\hline $\begin{array}{l}\text { Haemoglobin } \\
\text { (g/dL) } \\
\text { Follow- } \\
\text { up: } 9 \text { weeks to } 6 \\
\text { months }\end{array}$ & $\begin{array}{l}\text { The mean hae- } \\
\text { moglobin in the } \\
\text { control groups } \\
\text { ranged from } 12 \text {. } \\
01 \text { to } 12.12 \mathrm{~g} / \mathrm{dl}\end{array}$ & $\begin{array}{l}\text { The mean hae- } \\
\text { moglobin in the } \\
\text { intervention } \\
\text { groups was } \\
\mathbf{0 . 0 6} \quad \mathbf{g} / \mathbf{d L} \\
\text { higher } \\
(0.05 \text { lower to } 0 \text {. } \\
17 \text { higher) }\end{array}$ & & $\begin{array}{l}1005 \\
\text { (3 studies) }\end{array}$ & $\begin{array}{l}\oplus \oplus \oplus \bigcirc \\
\text { moderate }^{1}\end{array}$ & \\
\hline $\begin{array}{l}\text { Formal tests of } \\
\text { cognition }\end{array}$ & - & - & & $\begin{array}{l}1361 \\
\text { ( } 2 \text { studies) }\end{array}$ & $\begin{array}{l}\oplus \oplus \bigcirc \bigcirc \\
\text { low }^{1,4}\end{array}$ & $\begin{array}{l}\text { One trial } \\
\text { reported that de- } \\
\text { worming had no } \\
\text { effect, and the } \\
\text { other that de- } \\
\text { worm- } \\
\text { ing reduces cog- } \\
\text { nitive scores }\end{array}$ \\
\hline $\begin{array}{ll}\text { Physical well } \\
\text { being } & \\
\text { Harvard } & \text { Step } \\
\text { Test } & \end{array}$ & $\begin{array}{l}\text { The mean score } \\
\text { in the control } \\
\text { groups ranged } \\
\text { from } 74 \text { to } 76 \%\end{array}$ & $\begin{array}{l}\text { The mean score } \\
\text { in the interven- } \\
\text { tion groups was } \\
\mathbf{6 \%} \text { higher } \\
\text { ( } 4.31 \text { to } 7.69 \\
\text { higher) }\end{array}$ & & $\begin{array}{l}86 \\
\text { ( } 2 \text { studies })\end{array}$ & $\begin{array}{l}\oplus \oplus \bigcirc \bigcirc \\
\mathbf{l o w}^{1,3,5}\end{array}$ & \\
\hline
\end{tabular}

Deworming drugs for soil-transmitted intestinal worms in children: effects on nutritional indicators, haemoglobin and school 
Table 8. Summary of findings B: In children living in communities where intestinal helminths are endemic, what is the effect of a single dose of deworming drugs? (Continued)

*The basis for the assumed risk (eg the median control group risk across studies) is provided in footnotes. The corresponding risk (and its 95\% CI) is based on the assumed risk in the comparison group and the relative effect of the intervention (and its $95 \% \mathrm{CI}$ ).

CI: Confidence interval;

GRADE Working Group grades of evidence

High quality: Further research is very unlikely to change our confidence in the estimate of effect.

Moderate quality: Further research is likely to have an important impact on our confidence in the estimate of effect and may change the estimate.

Low quality: Further research is very likely to have an important impact on our confidence in the estimate of effect and is likely to change the estimate.

Very low quality: We are very uncertain about the estimate.

${ }^{1}$ Downgraded by 1 for risk of bias: all studies have 1 or more methodological deficiencies

2 Downgraded by 1 for inconsistency: In two trials from Kenya carried out 15 years ago, the average increase in weight was $1.1 \mathrm{~kg}$ and $1.3 \mathrm{~kg}$ more in the intervention group. For the other trials, from high (two trials), moderate (two trials) and low (three trials) prevalence areas, no effect was demonstrated

${ }^{3}$ Downgraded by 1 for indirectness: The two studies demonstrating a benefit were conducted in the same primary school in Kenya, in a population where virtually all of the children had hookworm and Trichuris infection, and about half were also infected with Ascaris. This result may not be easily generalized to elsewhere.

${ }^{4}$ Downgraded by 1 for indirectness: Only two studies have assessed these outcomes. In the Philippines Solon 2003 reports deworming either has no effect or a negative effect on cognitive test scores, and in Vietnam Nga 2009 reports no difference detected. Data could not be combined

${ }^{5}$ The Harvard Step Test is scored out of 100, and Stephenson 1989 and Stephenson 1993 have both 6\% higher value in treated groups.

Table 9. Summary of findings C: Multiple dose deworming drugs for soil-transmitted intestinal worms in children: effects on nutritional indicators, haemoglobin and school performance (outcomes measured at less than 1 year)

Multiple dose deworming drugs for soil-transmitted intestinal worms in children: effects on nutritional indicators, haemoglobin and school performance (outcomes measured at less than 1 year)

Patient or population: children

Settings: areas endemic for intestinal helminths

Intervention: Multiple dose deworming drugs

\begin{tabular}{|c|c|c|c|c|c|c|}
\hline \multirow[t]{3}{*}{ Outcomes } & \multicolumn{2}{|c|}{$\begin{array}{l}\text { Illustrative comparative risks* } \\
(95 \% \mathrm{CI})\end{array}$} & \multirow[t]{3}{*}{$\begin{array}{l}\text { Relative effect } \\
(95 \% \mathrm{CI})\end{array}$} & \multirow{3}{*}{$\begin{array}{l}\text { No of Partici- } \\
\text { pants } \\
\text { (studies) }\end{array}$} & \multirow{3}{*}{$\begin{array}{l}\text { Quality of the } \\
\text { evidence } \\
\text { (GRADE) }\end{array}$} & \multirow[t]{3}{*}{ Comments } \\
\hline & Assumed risk & $\begin{array}{l}\text { Corresponding } \\
\text { risk }\end{array}$ & & & & \\
\hline & Control & $\begin{array}{l}\text { Mul- } \\
\text { tiple dose de- } \\
\text { worming drugs }\end{array}$ & & & & \\
\hline
\end{tabular}

Deworming drugs for soil-transmitted intestinal worms in children: effects on nutritional indicators, haemoglobin and school 
Table 9. Summary of findings C: Multiple dose deworming drugs for soil-transmitted intestinal worms in children: effects on nutritional indicators, haemoglobin and school performance (outcomes measured at less than 1 year) (Continued)

\begin{tabular}{|c|c|c|c|c|c|c|}
\hline $\begin{array}{l}\text { Weight (kg) } \\
\text { Follow-up: } 6 \text { to } \\
12 \text { months }\end{array}$ & $\begin{array}{l}\text { The mean gain } \\
\text { in weight in the } \\
\text { control groups } \\
\text { ranged from } 0 . \\
95 \text { to } 2.70 \mathrm{~kg}\end{array}$ & $\begin{array}{l}\text { The mean } \\
\text { gain in weight in } \\
\text { the intervention } \\
\text { groups was } \\
\mathbf{0 . 0 6} \text { kg higher } \\
(0.17 \text { lower to } 0 . \\
3 \text { higher) }\end{array}$ & & $\begin{array}{l}2460 \\
\text { (7 studies) }\end{array}$ & $\begin{array}{l}\oplus \oplus \bigcirc \bigcirc \\
\text { low }^{1,2}\end{array}$ & \\
\hline $\begin{array}{l}\text { Haemoglobin } \\
\text { (g/dL) } \\
\text { Follow-up: } 6 \text { to } \\
11 \text { months }\end{array}$ & $\begin{array}{l}\text { The mean } \\
\text { change in hae- } \\
\text { moglobin in the } \\
\text { control groups } \\
\text { ranged from } 0 . \\
26 \text { to } 1.75 \mathrm{~g} / \mathrm{dL}\end{array}$ & $\begin{array}{l}\text { LThe } \\
\text { mean change in } \\
\text { haemoglobin in } \\
\text { the intervention } \\
\text { groups was } \\
\mathbf{0 . 0 1} \text { g/dL } \\
\text { higher } \\
(0.14 \text { lower to } 0 . \\
13 \text { higher) }\end{array}$ & & $\begin{array}{l}807 \\
\text { (4 studies) }\end{array}$ & $\begin{array}{l}\oplus \oplus \bigcirc \bigcirc \\
\mathbf{l o w}^{3,4}\end{array}$ & \\
\hline $\begin{array}{l}\text { Formal tests of } \\
\text { cognition }\end{array}$ & - & - & Not estimable & $\begin{array}{l}30,571 \\
\left(3 \text { studies }^{5}\right)\end{array}$ & $\begin{array}{l}\oplus \oplus \bigcirc \bigcirc \\
\text { low }^{1,6,7}\end{array}$ & $\begin{array}{l}\text { None of the trials } \\
\text { reported a bene- } \\
\text { fit of deworming }\end{array}$ \\
\hline $\begin{array}{l}\text { School } \\
\text { attendance (\%) } \\
\text { Follow-up: } 6 \text { to } \\
12 \text { months }\end{array}$ & $\begin{array}{l}\text { The mean school } \\
\text { attendance in the } \\
\text { control group } \\
\text { was } 66.3 \%\end{array}$ & $\begin{array}{l}\text { The mean school } \\
\text { attendance in the } \\
\text { intervention } \\
\text { groups was } \\
\mathbf{4} \% \text { higher } \\
\text { (6 lower to } 14 \\
\text { higher) }\end{array}$ & & $\begin{array}{l}30,243 \\
\left(2 \text { studies }^{8}\right)\end{array}$ & $\begin{array}{l}\oplus \oplus \bigcirc \bigcirc \\
\text { low }^{1,9}\end{array}$ & \\
\hline
\end{tabular}

*The basis for the assumed risk (eg the median control group risk across studies) is provided in footnotes. The corresponding risk (and its 95\% CI) is based on the assumed risk in the comparison group and the relative effect of the intervention (and its 95\% CI). CI: Confidence interval;

GRADE Working Group grades of evidence

High quality: Further research is very unlikely to change our confidence in the estimate of effect.

Moderate quality: Further research is likely to have an important impact on our confidence in the estimate of effect and may change the estimate.

Low quality: Further research is very likely to have an important impact on our confidence in the estimate of effect and is likely to change the estimate.

Very low quality: We are very uncertain about the estimate.

${ }^{1}$ Downgraded by 1 for risk of bias: most studies had one or more methodological deficiencies

${ }^{2}$ Downgraded by 1 for inconsistency: One study from a very high prevalence setting found a significant benefit $(0.9 \mathrm{~kg})$, but other studies from high prevalence (one trial), moderate prevalence (two trials) and low prevalence settings (three trials) have not found a difference.

${ }^{3}$ Downgraded by 1 for risk of bias: Dossa 2001 and Kruger 1996 have a high risk of bias for incomplete outcome data.

${ }^{4}$ Downgraded by 1 for indirectness: none of the studies are from high prevalence settings

575 clusters with approximately 30,000 participants and 571 individually randomized participants (varies with outcome measured).

Deworming drugs for soil-transmitted intestinal worms in children: effects on nutritional indicators, haemoglobin and school 
${ }^{6}$ Downgraded by 1 on imprecision: none of the trials found a benefit on cognitive tests, but the data were not presented in a way to assess combined effects

7 Three studies measured intellectual development: Miguel 2004 (Cluster) measured a range of cognitive tests, but no deworming effect was demonstrated. Stoltzfus 2001, with a follow-up of 12 months, found that treatment had no significant effect on motor or language development; ii) Watkins 1996, with a follow-up of six months, found no difference on any of the tests between treatment groups.

875 clusters with approximately 30,000 participants and 243 individually randomized participants

${ }^{9}$ Downgraded by 1 for indirectness: Most of the data is from a single high prevalence setting in Kenya and the result may not be easily generalised to elsewhere.

\section{A P P E N DICES}

\section{Appendix I. Authors' judgment on risk of bias}

\section{Potential bias}

Random sequence generation (selection bias)

Allocation concealment (selection bias)

Blinding (performance bias and detection bias)

Incomplete outcome data (attrition bias)

Selective reporting (reporting bias)

\section{Authors' judgement}

High - not randomized or quasi-randomized

Unclear - States "randomized", but does not report method

Low - describes method of randomization

High - not concealed, open label trial for individually randomized, method of concealment not adequate

Unclear - details of method not reported or insufficient details

Low - central allocation, sequentially numbered opaque sealed envelopes

High - personnel, participants or outcome assessors not blinded

Unclear - no details reported, insufficient details reported

Low - personnel, participants and outcome assessors blinded

High - losses to follow-up not evenly distributed across intervention and control group, high attrition rate ( $20 \%$ or more for the main outcome)

Unclear - no details reported, insufficient details reported

Low - no losses to follow-up, losses below $20 \%$ and evenly distributed across groups, intention-to-treat analysis used

Note: for cluster RCTs, the loss relates to the clusters

High - did not fully report measured or relevant outcomes

Unclear - not enough information reported to judge

Low - all stated outcomes reported
Low - no obvious other source of bias of concern to reviewers High - major source of bias such as unexplained differences in baseline characteristics 


\section{WHAT'S NEW}

Last assessed as up-to-date: 31 May 2012.

\begin{tabular}{|c|c|c|}
\hline Date & Event & Description \\
\hline 10 October 2012 & $\begin{array}{l}\text { New citation required but conclusions have not } \\
\text { changed }\end{array}$ & $\begin{array}{l}\text { Updated Summary of Findings, updated abstract, and } \\
\text { minor corrections }\end{array}$ \\
\hline 10 October 2012 & New search has been performed & $\begin{array}{l}\text { In September 2012, we identified a minor data entry } \\
\text { error with a haemoglobin value, which we corrected } \\
\text { We also received feedback on the GRADE assessments. } \\
\text { This led to changes in the assessment of the quality of } \\
\text { the evidence for several outcomes. Most changes were } \\
\text { towards higher quality evidence. We refined the table } \\
\text { by adding additional footnotes to to clarify the classifi- } \\
\text { cation. The specific changes were: } \\
\text { For single dose weight, screened, GRADE moved from } \\
\text { moderate to low } \\
\text { For single dose HB, haemoglobin GRADE moved from } \\
\text { low to moderate, after data entry corrected; and for } \\
\text { formal tests, GRADE moved from very low to low } \\
\text { For multiple dose (<1 year), formal tests and schooling } \\
\text { moved from very low to low, following upgrading of } \\
\text { study quality } \\
\text { For multiple doses ( }>1 \text { year), weight and haemoglobin } \\
\text { moved from very low to low, following upgrading of } \\
\text { study quality; and cognition moved from very low to } \\
\text { low } \\
\text { We adjusted the wording in the abstract to take these } \\
\text { changes into account }\end{array}$ \\
\hline
\end{tabular}

\section{H I S T O R Y}

Protocol first published: Issue 3, 1997

Review first published: Issue 2, 1998

\begin{tabular}{l|l|l}
\hline Date & Event & Description \\
\hline 31 May 2012 & New search has been performed & $\begin{array}{l}\text { Substantive update: } \\
1 . \text { We added a logic framework to the background. } \\
2 . \text { We replaced Awasthi 1995 (unpublished data) } \\
\text { with the published data (Awasthi 2008 (Cluster)). We } \\
\text { received clarification on methods and results from } \\
\text { Miguel and Kremer and included this study in the } \\
\text { review (Miguel 2004 (Cluster)). Also, we tried to }\end{array}$ \\
\hline
\end{tabular}

Deworming drugs for soil-transmitted intestinal worms in children: effects on nutritional indicators, haemoglobin and school 


\begin{tabular}{|c|c|c|}
\hline & & $\begin{array}{l}\text { include the DEVTA (unpublished) completed in } 2006 \\
\text { but were unable to as it remains unpublished as of May } \\
2012 \text {. } \\
\text { 3. We added haemoglobin as a primary outcome } \\
\text { and we added all trials measuring haemoglobin. We } \\
\text { merged end values and change values to simplify the } \\
\text { review. We reanalysed the school attendance data. In } \\
\text { addition, we brought the sensitivity analysis in line } \\
\text { with current best practice (by only including trials with } \\
\text { evidence of allocation concealment). } \\
\text { 4. We added Summary of Findings tables. We } \\
\text { adjusted the wording in line with our policy of using } \\
\text { standard words to correspond to quality of the } \\
\text { evidence. } \\
\text { 5. In the light of these changes, we rewrote the } \\
\text { review entirely. }\end{array}$ \\
\hline 31 May 2012 & New citation required but conclusions have not changed & Review updated, new studies added. \\
\hline 7 May 2008 & Amended & $\begin{array}{l}\text { There are two alterations to the review: } \\
1 \text {. We have corrected an error in the discussion. The } \\
\text { sentence that read "There was a weight gain of } 2.413 \mathrm{~kg} \\
\text { in the treatment parishes and } 2.474 \mathrm{~kg} \text { in the control } \\
\text { parishes at an unspecified follow-up point." now reads } \\
\text { "There was a weight gain of } 2.413 \mathrm{~kg} \text { in the treatment } \\
\text { parishes and } 2.259 \mathrm{~kg} \text { in the control parishes at an un- } \\
\text { specified follow-up point." } \\
\text { 2. We have detailed our correspondence to date with } \\
\text { Michael Kremer and Edward Miguel in the discussion }\end{array}$ \\
\hline 12 August 2007 & New citation required and conclusions have changed & $\begin{array}{l}\text { 2007, Issue } 4 \text { (substantive update): author team } \\
\text { changed; review title modified from the original title of } \\
\text { "Anthelmintic drugs for treating worms in children: ef- } \\
\text { fects on growth and cognitive performance"; updated } \\
\text { methods, reapplied the inclusion criteria, repeated data } \\
\text { extraction, added new trials, and included additional } \\
\text { analyses as recommended by policy specialists }\end{array}$ \\
\hline 31 March 2000 & New citation required and conclusions have changed & $\begin{array}{l}\text { 2000, Issue } 2 \text { (substantive update): new trials added and } \\
\text { review updated }\end{array}$ \\
\hline
\end{tabular}




\section{CONTRIBUTIONSOFAUTHORS}

DTR wrote the protocol, applied inclusion criteria, assessed quality, extracted data, conducted data analysis, and wrote the first draft of the review. KS-W and NM applied inclusion criteria, assessed quality, extracted data, conducted data analysis, and drafted the results of the update. SD assessed risk of bias and extracted data for a subset of the trials; and contributed to the analysis and the writing of the review. PGr provided advice at all stages of the review production, applied inclusion criteria, assessed quality, quality assured data extraction, helped construct the comparisons, and helped write the review.

\section{DECLARATIONSOF INTEREST}

DTR is supported by an MRC Population Health Scientist Fellowship (G0802448). The funders had no role in study design, data collection and analysis, decision to publish, or preparation of the manuscript.

This review is supported by a Department for International Development (DFID) grant aimed at ensuring the best possible systematic reviews, particularly Cochrane Reviews, are completed on topics relevant to the poor, particularly women, in low- and middle-income countries. DFID does not participate in the selection of topics, in the conduct of the review, or in the interpretation of findings. The grant provides partial salary support for PG, SD, and the funds for the contract with Enhance Reviews Ltd.

\section{SOURCES OF SUPPORT}

\section{Internal sources}

- Liverpool School of Tropical Medicine, UK.

\section{External sources}

- Department for International Development, UK.

\section{DIFFERENCES BETWEEN PROTOCOLANDREVIEW}

Not applicable.

\section{NOTES}

Not applicable.

\section{INDEX TERMS}

\section{Medical Subject Headings (MeSH)}

Anthelmintics [* pharmacology; therapeutic use]; Child Development [drug effects]; Cognition [*drug effects]; Growth [drug effects]; Helminthiasis [complications; ${ }^{*}$ drug therapy]; Intestinal Diseases, Parasitic [complications; ${ }^{*}$ drug therapy]; Nutritional Status [*drug effects]; Randomized Controlled Trials as Topic; Soil [* parasitology]; Weight Gain [drug effects] 


\section{MeSH check words}

Adolescent; Child; Child, Preschool; Humans

Deworming drugs for soil-transmitted intestinal worms in children: effects on nutritional indicators, haemoglobin and school performance (Review)

Copyright $\odot 2012$ The Cochrane Collaboration. Published by John Wiley \& Sons, Ltd. 